\title{
Energy metabolism in relation to diet and physical activity
}

Citation for published version (APA):

Wulan, S. N. (2015). Energy metabolism in relation to diet and physical activity: a comparison between Asians and Caucasians. [Doctoral Thesis, Maastricht University]. Maastricht University. https://doi.org/10.26481/dis.20151112sw

Document status and date:

Published: 01/01/2015

DOI:

10.26481/dis.20151112sw

Document Version:

Publisher's PDF, also known as Version of record

\section{Please check the document version of this publication:}

- A submitted manuscript is the version of the article upon submission and before peer-review. There can be important differences between the submitted version and the official published version of record.

People interested in the research are advised to contact the author for the final version of the publication, or visit the DOI to the publisher's website.

- The final author version and the galley proof are versions of the publication after peer review.

- The final published version features the final layout of the paper including the volume, issue and page numbers.

Link to publication

\footnotetext{
General rights rights.

- You may freely distribute the URL identifying the publication in the public portal. please follow below link for the End User Agreement:

www.umlib.nl/taverne-license

Take down policy

If you believe that this document breaches copyright please contact us at:

repository@maastrichtuniversity.nl

providing details and we will investigate your claim.
}

Copyright and moral rights for the publications made accessible in the public portal are retained by the authors and/or other copyright owners and it is a condition of accessing publications that users recognise and abide by the legal requirements associated with these

- Users may download and print one copy of any publication from the public portal for the purpose of private study or research.

- You may not further distribute the material or use it for any profit-making activity or commercial gain

If the publication is distributed under the terms of Article $25 \mathrm{fa}$ of the Dutch Copyright Act, indicated by the "Taverne" license above, 


\section{Energy metabolism in relation to diet and physical activity:}

A comparison between Asians and Caucasians 


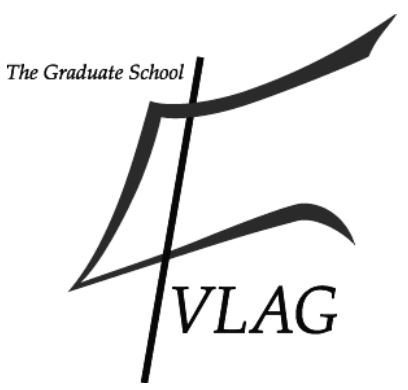

The studies presented in this thesis were performed at the School of Nutrition and Translational Research in Metabolism (NUTRIM), Maastricht University Medical Center (MUMC+) which participates in the Graduate School VLAG (Food Technology, Agrobiotechnology, Nutrition and Health Sciences), accredited by the Royal Netherlands Academy of Arts and Sciences (KNAW).
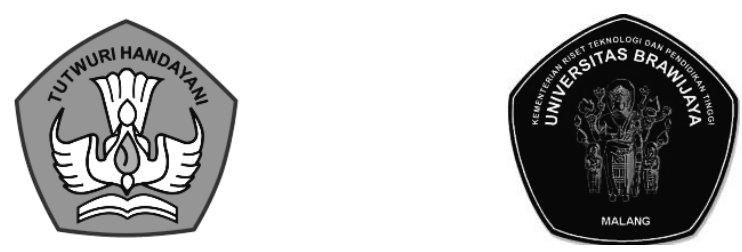

Financial support from the Directorate General of Higher Education, the Ministry of Education and Culture (former Ministry of Research, Technology and Higher Education) of the Republic of Indonesia and the University of Brawijaya for the studies is gratefully acknowledged.

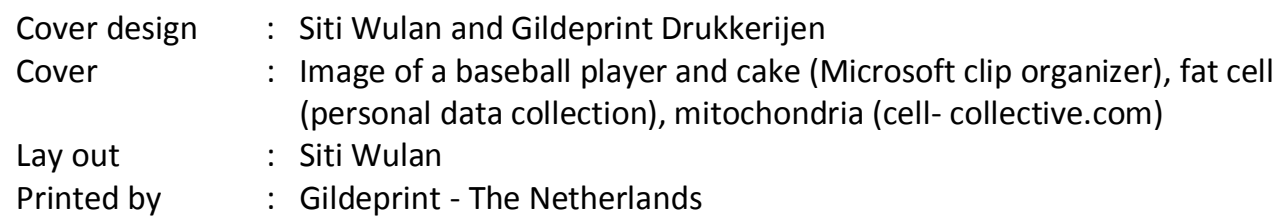

(C)copyright Siti Wulan, Maastricht 2015

ISBN 978-94-6233-133-4 


\title{
Energy metabolism in relation to diet and physical activity:
}

\author{
A comparison between Asians and Caucasians
}

\author{
PROEFSCHRIFT \\ ter verkrijging van de graad van doctor \\ aan de Universiteit Maastricht, \\ op gezag van de Rector Magnificius, \\ Prof.dr. L.L.G. Soete, \\ volgens het besluit van het College van Decanen, \\ in het openbaar te verdedigen \\ op donderdag 12 november 2015 om 16:00 uur
}

door

Siti Narsito Wulan

Geboren te Magelang, Midden Java, Indonesië

op 25 december 1973 
Promotor

Prof. dr. K.R. Westerterp

Co-promotor

Dr. G. Plasqui

\section{Board of the Examination Comittee}

Prof. dr. L.P.A.J. Schrauwen (chairman)

Prof. dr. C.J. Henry (National University of Singapore)

Prof. dr. ir. J. Keijer (Wageningen University)

Prof. dr. M.S. Westerterp-Plantenga

Prof. dr. J.E. Wildberger 


\section{Table of content}

Chapter 1 General introduction 7

Chapter 2 Ethnic differences in body composition and the associated 21

metabolic profile: a comparative study between Asians and Caucasians

Chapter $3 \quad$ Dietary and $24 \mathrm{~h}$ fat oxidation in Asians and whites who differ in 37 body composition

Chapter 4 Liver fat accumulation in response to overfeeding with a high fat diet: a comparison between South Asian and Caucasian men

Chapter 5 Metabolic profile before and after short-term overfeeding with a high fat diet: a comparison between South Asian and white men

Chapter $6 \quad$ Substrate utilization and metabolic profile in response to overfeeding with a high fat diet in South Asian and white men: a sedentary life style study

Chapter 7 Molecular adaptation in response to overfeeding with a high fat diet under sedentary conditions in South Asian and Caucasian men

Chapter 8 General discussion

Summary

Samenvatting

Ringkasan

Valorization

Dankwoord

Curriculum vitae

Publications 



\section{CHAPTER 1}

General introduction 


\section{CHAPTER 1}

\section{OBESITY AND METABOLIC SYNDROME: A SOUTH ASIAN PERSPECTIVE}

The prevalence of overweight and obesity is increasing globally, not only in western countries but also in developing countries that are progressing towards a more industrial way of living such as in Asia. In 1995, the WHO found a greater problem with overweight than underweight in developing countries (1). The world incidence of overweight and obesity was projected to be 1.3 billion and 573 million individuals respectively by 2030 , with $43 \%$ and $21 \%$ of that number respectively living in Asia (2). In addition, the world prevalence of diabetes among adults (20-79 years old) was estimated to increase from $6.4 \%$ in 2010 to $7.7 \%$ in 2030 affecting more than 400 million people (3). Considering the current trends, the increase was expected to be around 69\% in developing countries and $20 \%$ in developed countries (3). By 2030 , around $80 \%$ of people with diabetes will be living in developing countries of which India and China share the largest contribution (4). Unlike in western countries, diabetes in Asia has developed in a shorter time (3-5 fold increase within 30 years), in a younger age group (20-64 years old) and in people with a lower BMI (5). The much larger increase of overweight and obesity as well as obesity-related noncommunicable diseases in developing regions are triggered by growth in population size, population aging, urbanization and changes in lifestyle including increases in energy intake and reductions in physical activity $(2,6)$.

Among Asians, people of South Asian descent (Indian sub-continent) were reported to have the highest prevalence of obesity and obesity-associated diseases $(5,7)$. The increasing number of adults with type 2 diabetes is extremely high, reaching 1.8 million annually (3) and continues to raise both in native and migrant South Asians $(8,9)$. In their home countries, recent data showed the prevalence was increasing in urban, semi urban and rural areas and included especially people belonging to middle and low socioeconomic strata (10). About one-third of the urban population in large cities in India was reported to have metabolic syndrome (11). Diabetes is not the only non-communicable disease that South Asians are prone to, they also have earlier onset, more severe and 
more prevalent cardiovascular disease (CVD) than other ethnicities (12). Several studies have revealed that the higher risk of CVD in South Asians is associated with an unfavorable lipid profile or dyslipidemia (9) such as an elevated fasting plasma triglyceride and LDL $(13,14)$, a lower HDL cholesterol $(14,15)$ and a lower HDL to total cholesterol ratio $(16)$.

While India already has the highest number of patients with type 2 diabetes globally, a rapid increase in childhood obesity is the prime reason for increasing insulin resistance, dyslipidemia and metabolic syndrome (17). Children from South Asian ancestry manifest adiposity, insulin resistance and metabolic perturbations earlier in live compared to other ethnic groups (17-19). South Asian adolescents were found to be more insulin resistant with more body fat and exhibit a higher risk of cardiovascular disease with a higher blood pressure and fasting triglycerides (20) compared to white British adolescents. A strong gene-environment interaction was suggested to be the cause of the rapid increase of diabetes and metabolic syndrome in South Asians (4). This condition is worsened by lower disease awareness and health-seeking behavior, delayed diagnosis due to uncommon presentation and language barrier, and socio-cultural as well as religious factors (21).

\section{THE FEATURES OF BODY COMPOSITION, BODY FAT DISTRIBUTION, ECTOPIC FAT ACCUMULATION AND LIPODISTROPHY IN SOUTH ASIANS}

The high prevalence of metabolic syndrome in South Asians may be partly explained by the unfavorable body composition, where Asians are reported to have a higher body fat percentage for the same BMI as compared to white Caucasians (22-28). The difference in body composition was observed in men as well as in women. For the same BMI as Caucasians, South Asian men have a 4-7\% higher body fat percentage (22-26) while women have an $8 \%$ higher body fat percentage $(27,28)$. Additionally, it has been reported consistently that Asians have a lower fat-free mass (lean body mass) and/or appendicular skeletal muscle mass compared to other ethnicities $(26,27,29)$, also after adjusting for height. The fat-free mass index (FFMI) was the lowest for Asians compared to other 


\section{CHAPTER 1}

ethnicities such as Caucasians, African-Americans and Hispanics (30). In South Asian men, lean body mass was $3.4 \mathrm{~kg}$ lower than in Aboriginals, $3.0 \mathrm{~kg}$ lower than in Chinese and 3.6 kg lower than in Caucasians (31). In South Asian women, the lean body mass was $2.0 \mathrm{~kg}$ lower than in Aboriginals, $2.2 \mathrm{~kg}$ lower than Chinese and $3.0 \mathrm{~kg}$ lower than Caucasians (31).

Interestingly, the unfavorable body composition is already present at young age. South Asian adolescents of 14-17 y old (32), 11-12 y old (33) and children of 5-7 y old (34) had a higher body fat percentage compared to their European counterparts in the UK. Percentage body fat was significantly higher in middle school South Asian children compared to children with Caucasian, East Asian, African-American and Hispanic backgrounds living in the US (35). A recent study (36) showed that in early infancy (6-12 weeks), South Asian infants had $0.34 \mathrm{~kg}$ less FFM, and an indication towards a higher FM than white European infants. This difference persisted after adjustment for the smaller body size of South Asians. The most interesting findings of the study were; that for a given infant weight, the balance of body composition of South Asians was shifted by $0.16 \mathrm{~kg}$ from FFM to FM. These differences in the amount of FFM were almost completely accounted for by ethnic differences in the rate of growth in utero and length of gestation (36). This finding confirmed the results of previous studies on neonatal anthropometry, comparing Indian babies born in India and white babies born in the UK, observing a lower weight, smaller waist and mid circumference but a higher subscapular skinfold thickness in Indian babies $(37,38)$. Truncal adiposity was larger at 4 y of age $(38)$, suggesting a thin-fat phenotype from young age onwards. A longitudinal study performed in a New Delhi cohort, India (39) showed that birth weight and BMI gain during infancy and early childhood predicted adult lean mass more strongly than adult adiposity, whereas larger $\mathrm{BMI}$ gain in late childhood and adolescence predicted adult adiposity. This suggests that postnatal environment may modify the development of an unfavorable body composition in South Asians. 
Estimation of body fat using BMI may not adequately reflect the amount of atherogenic adipose tissue i.e. visceral and ectopic fat (40). Fat distribution might be a more informative parameter. The sum of truncal skinfolds in South Asian men were found to be higher and was associated with lower glucose disposal rate (41) and increased incidence of diabetes in women but not in men (42). Simple anthropometric indices such as waist circumference (WC), hip circumference $(\mathrm{HC})$, waist to hip ratio (WHR) and skinfold thickness are useful measures to assess obesity related metabolic disease risk in large population studies focusing on South Asians, however those measures are a proxy of abdominal fat content (total abdominal fat: TAT, subcutaneous fat: SAT, visceral fat: VAT) and may differ in the accuracy when comparing ethnicities. Depending on the age and gender of the populations studied, some studies found differences in indices of abdominal adiposity (TAT, SAT and VAT) when South Asian and BMI matched Caucasians were compared, while others did not. Studies that compared a group of South Asian men and women matched for age, BMI and WC with Caucasian men and women found a higher abdominal adiposity in South Asians (22,43). Despite similar WC, part of that study (22) also showed South Asians displayed an unfavorable lipid profile (44). Visceral fat was found to mediate the effect of ethnicity on the risk factors of developing dyslipidemia and CVD, suggesting that the high risk for CVD in South Asians may be attributed to higher visceral fat (45), whereas another study found a stronger correlation between CVD risk and subcutaneous fat (46). One study in relatively older aged and BMI matched South Asian and Caucasian men did not find any difference in WHR and visceral fat area, despite a higher body fat percentage of the South Asians (23). Comparing young South Asian and BMI matched Caucasian men, body fat percentage, subcutaneous fat and adipocyte size were higher in South Asians, with no difference in intra-peritoneal fat (24). When the subcutaneous abdominal compartment was further divided into superficial and deep subcutaneous, South Asians had a higher deep subcutaneous fat than BMI-matched Europeans $(47,48)$. Interestingly, a recent study in young South Asian and white women, 


\section{CHAPTER 1}

showed no difference in any of the abdominal obesity measures and no metabolic disease observed (49). Besides subject characteristics, the way the compared ethnicity groups were matched and the number of subjects seemed to affect the differences in the findings of many studies. However, in large population studies $(22,45,47,48)$, differences were observed in the body fat distribution between South Asians and white Caucasians towards a more centrally fat depot in South Asians. A gene-environment interaction of obesityrelated traits was confirmed by a longitudinal genome-wide association study in a large cohort in South India, as indicated by an association between the rs9939609 variant in the FTO locus with measures of adiposity (BMI, WC, HC, WHR, skinfold thickness) and metabolic consequences (50).

The unfavorable body fat distribution towards a more centrally fat depot may not be the only feature responsible for the development of metabolic complications in South Asians. Adipose tissue does not function as energy stores only, but also as an endocrine organ producing adipokines for energy balance regulation. It was suggested that South Asians and Caucasians differ in adipokine production, where a lowered adiponectin and an elevated leptin in South Asians contributed to higher diabetes prevalence $(51,52)$. In addition, a higher ApoB/ApoA-I ratio in South Asians with central adiposity was suggested as a risk factor for developing CVD (53).

Last but not least, the susceptibility of South Asians to central adiposity and atherogenic dyslipidemia at a lower range of body fat than white Caucasians raised the hypothesis of adipose tissue expandability and lipid overflow (54). It was suggested that South Asians may have a smaller superficial subcutaneous adipose tissue compartment (present throughout the body) than Caucasians. When obesity develops, South Asians exceed the storage capacity of that compartment before Caucasians do, leading to lipid overflow to the deep subcutaneous adipose tissue compartment (present at upper body) and visceral adipose tissue, subsequently triggering dyslipidemia (54). The limited storage capacity of the superficial subcutaneous adipose tissue may be characterized by a larger 
adipocyte size in South Asians than Caucasians, accounting for ethnic differences in insulin, HDL-cholesterol, adiponectin and ectopic fat accumulation in the liver (55).

\section{ARE SOUTH ASIANS MORE SUSCEPTIBLE TO THE NEGATIVE EFFECT OF HIGH ENERGY DENSITY FOODS?}

Developing countries are undergoing a rapid nutritional transition concurrent with an increasing incidence of obesity and metabolic syndrome $(56,57)$. Dietary factors are likely to escalate the incidence of metabolic syndrome in South Asians, already predisposed to obesity. The South Asian dietary pattern is characterized by a high intake of carbohydrate (60-67\%), saturated fatty acids (SFA, from animal fat, coconut oil, palm oil and ghee butter), trans fatty acids (TFA), n-6 polyunsaturated fatty acids (PUFA, from sunflower, safflower, corn, soybean, sesame oil) and a low intake of n-3 PUFA (thus a lower ratio of n3/n-6 PUFA) and a low intake of dietary fiber $(56,58)$. Increased dietary n-6 PUFA and SFA intakes in South Asians were found to be associated with fasting hyperinsulinemia and sub-clinical inflammation, respectively (59).

Immigration to developed countries was shown to increase the risk for atherosclerosis in South Asians. The longer the time since immigrated, the higher the risk of atherosclerosis (60). Body composition of South Asians was altered towards a higher body fat with increasing residence time in the UK (61). It was suggested that dietary acculturation after migration to western countries may be involved in the development of metabolic syndrome in South Asians (61). The main dietary trend of South Asians after migration to Norway was a substantial increase in energy and fat intake, a reduction in carbohydrate intake in particular a switch from complex to refined carbohydrate, an increased consumption of meat and dairy products and a reduced vegetable intake (62). In the UK (63) and Canada (13), South Asians had a significantly higher carbohydrate intake as compared to Caucasians ( $50 \%$ or more), and this was associated with a lower $\mathrm{HDL}$ and $\mathrm{HDL} /$ total cholesterol ratio. In a 12 country study, the prevalence of low HDL was 


\section{CHAPTER 1}

the highest in South Asians (63\% in non-diabetic and $67 \%$ in diabetic) (15). With increasing length of residence in Canada, South Asians adopted a more positive dietary practice (higher consumption of fruits and vegetables and reduced consumption of fried foods), however there was also an increased consumption of convenience foods, sugarsweetened beverages, meat and dining out (64). There was no difference observed in the dietary pattern in multi-ethnic adolescents (including South Asians) in Canada suggesting a dietary acculturation in younger age group (65).

Nutrient imbalances in the indigenous dietary pattern of native South Asians as well as the dietary acculturation of migrant South Asians in Western countries may deteriorate the metabolic complications in the long term. For Caucasians, it has been shown that high carbohydrate intake (mono- and polysaccharides) is associated with elevated TAG, as result of increased TAG production (via increased de novo lipogenesis and VLDL secretion) or reduced TAG clearance (66). In South Asians, consuming a large amount of carbohydrates in their diet, HDL cholesterol was reduced as well (13). Additionally, SFA and TFA intake was associated with increased LDL-cholesterol (67). Thus, a combination of imbalanced nutrients in the South Asian diet may contribute to the excessive risk of CVD in this population.

\section{DOES SEDENTARISM HAVE A MORE ADVERSE EFFECT ON SOUTH ASIANS?}

Numerous epidemiological studies have been performed to assess the physical activity level of South Asians prone to obesity. Indeed, migrant South Asians in western countries were reported to have a lower physical activity level than Caucasians (68-71), this was also observed in adolescents (65). In South Asians, lower physical activity was associated with higher adiposity, whereas a higher physical activity level was associated with a lower waist circumference (68). South Asians with a higher visceral fat spent less time in moderate intensity physical activity, vigorous activity and moderate-to-vigorous activity as compared to Caucasians. However, after adjustment for physical activity levels, the 
visceral fat remained significantly higher (69). In addition, vigorous activity was a predictor for a lower liver fat accumulation, but moderate or moderate-to-vigorous activity may not be enough to prevent liver fat accumulation (72). Since South Asians exhibit an increased cardio-metabolic disease risk, the question remains whether the recommendation of participation in moderate intensity physical activity (MPA) of 150 min/week for Caucasians is appropriate for South Asians (73). It was shown that South Asians should undertake more moderate physical activity (MPA= $266 \mathrm{~min} /$ week) to elicit a similar cardio-metabolic risk profile as Caucasians (73).

Compared to Caucasians, South Asians were also shown to have a lower cardiorespiratory fitness and $\mathrm{VO}_{2} \max (71,74)$. Those studies however did not correct for a difference in fat-free mass between ethnicities. Lower cardiorespiratory fitness, lower physical activity and greater total adiposity together explained $83 \%$ of the ethnic difference in $\operatorname{HOMA}(\mathrm{IR})$, whereas $63 \%$ of the ethnic difference in fasting glucose was explained by cardiorespiratory fitness and total adiposity (71). Cardiorespiratory fitness is closely related to skeletal muscle lipid oxidative capacity. It was shown that South Asians oxidized less fat than Caucasians during sub-maximal exercise but not during rest (74). Interestingly, the lower oxidative capacity during sub-maximal exercise was not explained by a lower expression of oxidative and lipid metabolism genes in the skeletal muscle (instead, these genes were highly expressed), but it did relate to a lower expression of insulin-signaling proteins in the skeletal muscle (74). Mitochondria, as a primary organelle involved in fuel metabolism, had a higher capacity for oxidative phosphorylation (OXPHOS) in diabetic and non-diabetic South Asian Indians compared to BMI matched Caucasians(25). Thus, mitochondrial dysfunction and oxidative genes expression in the skeletal muscle may not be the explanation for the lower oxidative capacity during submaximal exercise, as previously thought to be the reason for the development of obesity and insulin resistance. It could be that increased gene expression may not be followed by an increase in proteins responsible for lipid metabolism. In addition, fatty acids oxidation 


\section{CHAPTER 1}

may provide only one part of the story, fatty acids mobilization and handling as well as their storage may also be important.

\section{OUTLINE OF THE THESIS}

Asians and Caucasians have differences in body composition that may be partly explained by genetic predisposition to adiposity and muscularity. The interaction with the environment both pre-natal and post-natal and during the life course may modify the effect of genes resulting in differences in obesity phenotype and traits between ethnicities. Chapter 2 reviewed the ethnic differences in body composition between Asians and Caucasians and the associated metabolic profiles. The underlying mechanism of the higher body fat accumulation in Asians despite having similar BMI as Caucasians was unknown. In Chapter 3, it was hypothesized that Asians may have a lower fat oxidation than Caucasians leading to a higher body fat accumulation; alternatively an unfavorable body composition may lead to a lower fat oxidation. Therefore dietary and 24-h fat oxidations were studied in the two ethnicities when they were fed in energy balance. Changes in lifestyle such as an increased consumption of high energy density high fat foods, were suggested to exaggerate the development of metabolic syndrome in South Asians more than Caucasians, and may be initiated by an increased liver fat accumulation, which is discussed in Chapter 4 leading to metabolic complications discussed in Chapter 5. The study described in Chapter 4 and Chapter 5 was performed under free-living conditions. Physical inactivity as shown by a sedentary lifestyle may have a more negative effect on obesity-predisposed individuals such as South Asians. Whether South Asians and Caucasians respond differently to overfeeding with a high fat diet under sedentary conditions (creating a massively positive energy balance) is investigated in Chapter 6. Furthermore, to gain more insight in the individual and ethnicity response to a massively positive energy balance, the molecular adaptation is discussed in Chapter 7. Of note, the words Caucasian and white are interchangeable in this thesis. 


\section{REFERENCES}

1. James WP (2008) WHO recognition of the global obesity epidemic. Int J Obes (Lond) 32 Suppl 7, S120-126.

2. Kelly T, Yang W, Chen CS, Reynolds K, He J (2008) Global burden of obesity in 2005 and projections to 2030. Int J Obes (Lond) 32, 1431-1437.

3. Shaw JE, Sicree RA, Zimmet PZ Global estimates of the prevalence of diabetes for 2010 and 2030. Diabetes Res Clin Pract 87, 4-14.

4. Ramachandran A, Ma RC, Snehalatha C (2010) Diabetes in Asia. Lancet 375, 408-418.

5. Yoon KH, Lee JH, Kim JW, Cho JH, Choi YH, Ko SH et al. (2006) Epidemic obesity and type 2 diabetes in Asia. Lancet 368, 1681-1688.

6. Misra A, Khurana L (2008) Obesity and the metabolic syndrome in developing countries. J Clin Endocrinol Metab 93, S9-30.

7. King H, Aubert RE, Herman WH (1998) Global burden of diabetes, 1995-2025: prevalence, numerical estimates, and projections. Diabetes Care 21, 1414-1431.

8. Gujral UP, Pradeepa R, Weber MB, Narayan KM, Mohan V (2013) Type 2 diabetes in South Asians: similarities and differences with white Caucasian and other populations. Ann N Y Acad Sci 1281, 51-63.

9. Garduno-Diaz SD, Khokhar S (2012) Prevalence, risk factors and complications associated with type 2 diabetes in migrant South Asians. Diabetes Metab Res Rev 28, 6-24.

10. Misra A, Ramchandran A, Jayawardena R, Shrivastava U, Snehalatha C (2014) Diabetes in South Asians. Diabet Med.

11. Pandit K, Goswami S, Ghosh S, Mukhopadhyay P, Chowdhury S (2012) Metabolic syndrome in South Asians. Indian journal of endocrinology and metabolism 16, 44-55.

12. Gadgil MD, Anderson CA, Kandula NR, Kanaya AM (2014) Dietary patterns in Asian Indians in the United States: an analysis of the metabolic syndrome and atherosclerosis in South Asians Living in America study. Journal of the Academy of Nutrition and Dietetics 114, 238-243.

13. Merchant AT, Anand SS, Kelemen LE, Vuksan V, Jacobs R, Davis B et al. (2007) Carbohydrate intake and HDL in a multiethnic population. Am J Clin Nutr 85, 225-230.

14. Basit A, Shera AS (2008) Prevalence of metabolic syndrome in Pakistan. Metab Syndr Relat Disord 6, 171-175.

15. Zhang L, Qiao Q, Tuomilehto J, Janus ED, Lam TH, Ramachandran A et al. Distinct ethnic differences in lipid profiles across glucose categories. J Clin Endocrinol Metab 95, 1793-1801.

16. Anand SS, Yusuf S (1997) Risk factors for cardiovascular disease in Canadians of South Asian and European origin: a pilot study of the Study of Heart Assessment and Risk in Ethnic Groups (SHARE). Clin Invest Med 20, 204-210.

17. Bhardwaj S, Misra A, Khurana L, Gulati S, Shah P, Vikram NK (2008) Childhood obesity in Asian Indians: a burgeoning cause of insulin resistance, diabetes and sub-clinical inflammation. Asia Pac J Clin Nutr 17 Suppl 1, 172-175.

18. Basit A, Hakeem R, Hydrie MZ, Ahmedani MY, Masood Q (2005) Relationship among fatness, blood lipids, and insulin resistance in Pakistani children. Journal of health, population, and nutrition 23, 34-43.

19. Misra A, Khurana L, Vikram NK, Goel A, Wasir JS (2007) Metabolic syndrome in children: current issues and South Asian perspective. Nutrition 23, 895-910.

20. Hemmings S, Conner A, Maffulli N, Morrissey D (2011) Cardiovascular disease risk factors in adolescent British South Asians and whites: a pilot study. Postgrad Med 123, 104-111.

21. Misra A, Khurana L (2011) Obesity-related non-communicable diseases: South Asians vs White Caucasians. Int J Obes (Lond) 35, 167-187.

22. Lear SA, Humphries KH, Kohli S, Birmingham CL (2007) The use of BMI and waist circumference as surrogates of body fat differs by ethnicity. Obesity (Silver Spring) 15, 2817-2824.

23. Forouhi NG, Jenkinson G, Thomas EL, Mullick S, Mierisova S, Bhonsle U et al. (1999) Relation of triglyceride stores in skeletal muscle cells to central obesity and insulin sensitivity in European and South Asian men. Diabetologia 42, 932-935. 


\section{CHAPTER 1}

24. Chandalia M, Lin P, Seenivasan T, Livingston EH, Snell PG, Grundy SM et al. (2007) Insulin resistance and body fat distribution in South Asian men compared to Caucasian men. PLoS One 2, e812.

25. Nair KS, Bigelow ML, Asmann YW, Chow LS, Coenen-Schimke JM, Klaus KA et al. (2008) Asian Indians have enhanced skeletal muscle mitochondrial capacity to produce ATP in association with severe insulin resistance. Diabetes 57, 1166-1175.

26. Rush EC, Freitas I, Plank LD (2009) Body size, body composition and fat distribution: comparative analysis of European, Maori, Pacific Island and Asian Indian adults. Br J Nutr 102, 632-641.

27. Rush EC, Goedecke JH, Jennings C, Micklesfield L, Dugas L, Lambert EV et al. (2007) BMI, fat and muscle differences in urban women of five ethnicities from two countries. Int J Obes (Lond) 31, 1232-1239.

28. Kamath SK, Hussain EA, Amin D, Mortillaro E, West B, Peterson CT et al. (1999) Cardiovascular disease risk factors in 2 distinct ethnic groups: Indian and Pakistani compared with American premenopausal women. Am J Clin Nutr 69, 621-631.

29. Wouters-Adriaens MP, Westerterp KR (2008) Low resting energy expenditure in Asians can be attributed to body composition. Obesity (Silver Spring) 16, 2212-2216.

30. Hull HR, Thornton J, Wang J, Pierson RN, Jr., Kaleem Z, Pi-Sunyer X et al. (2011) Fat-free mass index: changes and race/ethnic differences in adulthood. Int J Obes (Lond) 35, 121-127.

31. Lear SA, Kohli S, Bondy GP, Tchernof A, Sniderman AD (2009) Ethnic variation in fat and lean body mass and the association with insulin resistance. $J$ Clin Endocrinol Metab 94, 4696-4702.

32. Ehtisham S, Crabtree N, Clark P, Shaw N, Barrett T (2005) Ethnic differences in insulin resistance and body composition in United Kingdom adolescents. J Clin Endocrinol Metab 90, 3963-3969.

33. Stone MA, Williams L, Chatterjee S, Davies MJ, Khunti K (2008) Ethnic differences in body composition in adolescents. Primary care diabetes 2, 55-57.

34. Shaw NJ, Crabtree NJ, Kibirige MS, Fordham JN (2007) Ethnic and gender differences in body fat in British schoolchildren as measured by DXA. Arch Dis Child 92, 872-875.

35. Rosenbaum M, Fennoy I, Accacha S, Altshuler L, Carey DE, Holleran S et al. (2013) Racial/ethnic differences in clinical and biochemical type 2 diabetes mellitus risk factors in children. Obesity (Silver Spring) 21, 20812090.

36. Stanfield KM, Wells JC, Fewtrell MS, Frost C, Leon DA (2012) Differences in body composition between infants of South Asian and European ancestry: the London Mother and Baby Study. Int J Epidemiol 41, 14091418.

37. Yajnik CS, Fall CH, Coyaji KJ, Hirve SS, Rao S, Barker DJ et al. (2003) Neonatal anthropometry: the thin-fat Indian baby. The Pune Maternal Nutrition Study. Int J Obes Relat Metab Disord 27, 173-180.

38. Krishnaveni GV, Hill JC, Veena SR, Leary SD, Saperia J, Chachyamma KJ et al. (2005) Truncal adiposity is present at birth and in early childhood in South Indian children. Indian pediatrics 42, 527-538.

39. Sachdev HS, Fall CH, Osmond C, Lakshmy R, Dey Biswas SK, Leary SD et al. (2005) Anthropometric indicators of body composition in young adults: relation to size at birth and serial measurements of body mass index in childhood in the New Delhi birth cohort. Am J Clin Nutr 82, 456-466.

40. Arsenault BJ, Beaumont EP, Despres JP, Larose E Mapping body fat distribution: a key step towards the identification of the vulnerable patient? Ann Med 44, 758-772.

41. Chandalia M, Abate N, Garg A, Stray-Gundersen J, Grundy SM (1999) Relationship between generalized and upper body obesity to insulin resistance in Asian Indian men. J Clin Endocrinol Metab 84, 2329-2335.

42. Tillin T, Hughes AD, Godsland IF, Whincup P, Forouhi NG, Welsh P et al. (2013) Insulin resistance and truncal obesity as important determinants of the greater incidence of diabetes in Indian Asians and African Caribbeans compared with Europeans: the Southall And Brent REvisited (SABRE) cohort. Diabetes Care 36, 383-393.

43. Raji A, Seely EW, Arky RA, Simonson DC (2001) Body fat distribution and insulin resistance in healthy Asian Indians and Caucasians. J Clin Endocrinol Metab 86, 5366-5371.

44. Lear SA, Toma M, Birmingham CL, Frohlich JJ (2003) Modification of the relationship between simple anthropometric indices and risk factors by ethnic background. Metabolism 52, 1295-1301. 
45. Lear SA, Chockalingam A, Kohli S, Richardson CG, Humphries KH (2012) Elevation in cardiovascular disease risk in South Asians is mediated by differences in visceral adipose tissue. Obesity (Silver Spring) 20, 12931300.

46. Goel K, Misra A, Vikram NK, Poddar P, Gupta N (2010) Subcutaneous abdominal adipose tissue is associated with the metabolic syndrome in Asian Indians independent of intra-abdominal and total body fat. Heart 96, 579-583.

47. Kohli S, Sniderman AD, Tchernof A, Lear SA (2010) Ethnic-specific differences in abdominal subcutaneous adipose tissue compartments. Obesity (Silver Spring) 18, 2177-2183.

48. Kohli S, Lear SA (2013) Differences in subcutaneous abdominal adiposity regions in four ethnic groups. Obesity (Silver Spring) 21, 2288-2295.

49. Szuszkiewicz-Garcia M, Li R, Grundy SM, Abate N, Chandalia M (2012) Fat distribution and insulin resistance in young adult nonobese Asian Indian women. Metab Syndr Relat Disord 10, 326-330.

50. Vasan SK, Fall T, Neville MJ, Antonisamy B, Fall CH, Geethanjali FS et al. (2012) Associations of variants in FTO and near MC4R with obesity traits in South Asian Indians. Obesity (Silver Spring) 20, 2268-2277.

51. Abate N, Chandalia M, Snell PG, Grundy SM (2004) Adipose tissue metabolites and insulin resistance in nondiabetic Asian Indian men. J Clin Endocrinol Metab 89, 2750-2755.

52. Shah A, Hernandez A, Mathur D, Budoff MJ, Kanaya AM (2012) Adipokines and body fat composition in South Asians: results of the Metabolic Syndrome and Atherosclerosis in South Asians Living in America (MASALA) study. Int J Obes (Lond) 36, 810-816.

53. Smith J, Cianflone K, Al-Amri M, Sniderman A (2006) Body composition and the apoB/apoA-I ratio in migrant Asian Indians and white Caucasians in Canada. Clin Sci (Lond) 111, 201-207.

54. Sniderman AD, Bhopal R, Prabhakaran D, Sarrafzadegan N, Tchernof A (2007) Why might South Asians be so susceptible to central obesity and its atherogenic consequences? The adipose tissue overflow hypothesis. Int J Epidemiol 36, 220-225.

55. Anand SS, Tarnopolsky MA, Rashid S, Schulze KM, Desai D, Mente A et al. Adipocyte hypertrophy, fatty liver and metabolic risk factors in South Asians: the Molecular Study of Health and Risk in Ethnic Groups (molSHARE). PLoS One 6, e22112.

56. Misra A, Singhal N, Khurana L Obesity, the metabolic syndrome, and type 2 diabetes in developing countries: role of dietary fats and oils. J Am Coll Nutr 29, 289S-301S.

57. Popkin BM (2006) Global nutrition dynamics: the world is shifting rapidly toward a diet linked with noncommunicable diseases. Am J Clin Nutr 84, 289-298.

58. Misra A, Khurana L, Isharwal S, Bhardwaj S (2009) South Asian diets and insulin resistance. Br J Nutr 101, 465-473.

59. Isharwal S, Misra A, Wasir JS, Nigam P (2009) Diet \& insulin resistance: a review \& Asian Indian perspective. Indian J Med Res 129, 485-499.

60. Lear SA, Humphries KH, Hage-Moussa S, Chockalingam A, Mancini GB (2009) Immigration presents a potential increased risk for atherosclerosis. Atherosclerosis 205, 584-589.

61. Garduno-Diaz SD, Khokhar S (2013) South Asian dietary patterns and their association with risk factors for the metabolic syndrome. J Hum Nutr Diet 26, 145-155.

62. Holmboe-Ottesen G, Wandel M (2012) Changes in dietary habits after migration and consequences for health: a focus on South Asians in Europe. Food \& nutrition research 56.

63. Goff LM, Griffin BA, Lovegrove JA, Sanders TA, Jebb SA, Bluck LJ et al. (2013) Ethnic differences in beta-cell function, dietary intake and expression of the metabolic syndrome among UK adults of South Asian, black African-Caribbean and white-European origin at high risk of metabolic syndrome. Diabetes \& vascular disease research : official journal of the International Society of Diabetes and Vascular Disease 10, 315-323.

64. Lesser IA, Gasevic D, Lear SA (2014) The association between acculturation and dietary patterns of South Asian immigrants. PLoS One 9, e88495.

65. Vuksan V, Rogovik A, Jenkins A, Peeva V, Beljan-Zdravkovic U, Stavro M et al. (2012) Cardiovascular risk factors, diet and lifestyle among European, South Asian and Chinese adolescents in Canada. Paediatrics \& child health 17, e1-6. 


\section{CHAPTER 1}

66. Parks EJ, Hellerstein MK (2000) Carbohydrate-induced hypertriacylglycerolemia: historical perspective and review of biological mechanisms. Am J Clin Nutr 71, 412-433.

67. Grundy SM, Abate N, Chandalia M (2002) Diet composition and the metabolic syndrome: what is the optimal fat intake? Am J Med 113 Suppl 9B, 25S-29S.

68. Kolt GS, Schofield GM, Rush EC, Oliver M, Chadha NK (2007) Body fatness, physical activity, and nutritional behaviours in Asian Indian immigrants to New Zealand. Asia Pac J Clin Nutr 16, 663-670.

69. Lesser IA, Yew AC, Mackey DC, Lear SA (2012) A Cross-Sectional Analysis of the Association between Physical Activity and Visceral Adipose Tissue Accumulation in a Multiethnic Cohort. J Obes 2012, 703941.

70. Berntsen S, Richardsen KR, Morkrid K, Sletner L, Birkeland KI, Jenum AK (2014) Objectively recorded physical activity in early pregnancy: a multiethnic population-based study. Scand J Med Sci Sports 24, 594-601.

71. Ghouri N, Purves D, McConnachie A, Wilson J, Gill JM, Sattar N (2013) Lower cardiorespiratory fitness contributes to increased insulin resistance and fasting glycaemia in middle-aged South Asian compared with European men living in the UK. Diabetologia 56, 2238-2249.

72. Lesser IA, Dick T, Gasevic D, Mackey DC, Leipsic JA, Lear SA (2014) The association between physical activity and liver fat after five years of follow-up in a primary prevention multi-ethnic cohort. Prev Med.

73. Celis-Morales CA, Ghouri N, Bailey ME, Sattar N, Gill JM (2013) Should physical activity recommendations be ethnicity-specific? Evidence from a cross-sectional study of South Asian and European men. PLoS One 8 , e82568.

74. Hall LM, Moran CN, Milne GR, Wilson J, MacFarlane NG, Forouhi NG et al. (2010) Fat oxidation, fitness and skeletal muscle expression of oxidative/lipid metabolism genes in South Asians: implications for insulin resistance? PLoS One 5, e14197. 


\section{CHAPTER 2}

Ethnic differences in body composition and the associated metabolic profile: A comparative study between Asians and Caucasians

S.N. Wulan, K.R. Westerterp and G. Plasqui

Maturitas (2010), 65: 315-319 


\section{CHAPTER 2}

\section{ABSTRACT}

It is estimated that Asia will be the home of more than 100 million people with type 2 diabetes by the year of 2025 . This region combines a high proportion of the world's population with rapidly rising diabetes prevalence rates. The increase in diabetes in Asia differs from that reported in other parts of the world: it has developed in a shorter time, in a younger age group, and in people with lower body-mass index (BMI).

Studies reported that for the same BMI, Asians have a higher body fat percentage, a prominent abdominal obesity, a higher intramyocellular lipid and/or a higher liver fat content compared to Caucasians. These characteristics may contribute to a higher predisposition to insulin resistance at a lesser degree of obesity than Caucasians. The differences in body composition are more pronounced depending on the region. For the same BMI, among three major ethnic groups in Asia, Asian Indians have the highest body fat, followed by Malay and Chinese.

Lower insulin sensitivity is already observed in Asian Indian adolescents with a higher body fat and abdominal obesity compared to Caucasian adolescents. In general, Asian adolescents share the same feature of body composition such as higher body subcutaneous fat, lower appendicular skeletal muscle and lower gynoid fat compared to Caucasian adolescents. This unfavourable body composition may predispose to the development of insulin resistance at later age. Genetics may play a role and the interaction with environmental factors (changes in lifestyle) could increase the risk of developing the metabolic syndrome. 


\section{INTRODUCTION}

By the year 2025, 300 million people will have diabetes and among them more than 100 million people live in Asia (1). This region combines a high proportion of the world's population with rapidly rising diabetes prevalence rates (2) due to the pronounced demographic, epidemiologic and socioeconomic changes in recent decades (3). The increase of diabetes in Asia differs from that reported in other parts of the world: it has developed in a shorter time (3-5 fold increase within 30 years), in a younger age group (45-64 years old), and in people with a lower body-mass index (BMI) compared to that in Western countries (3).

$\mathrm{BMI}$ is significantly correlated with adiposity $(4,5)$ and can predict body fat percentage adequately as long as age and gender are taken into account (6). Excess adiposity (body fat) has been shown to be an independent risk factor for diabetes, cardiovascular disease, dyslipidaemia and hypertension (7). The phenomenon in Asians, is most likely due to a higher percentage of body fat accumulation at a given BMI level compared to Caucasians (8), as pointed out by a series of comparative studies from Deurenberg et al. (9-11). Hence, the relationship between body fat percentage and BMI is ethnic-specific (12). Increased body fat percentage may affect individuals differently due to differences in genetic make-up, intra-uterine (developmental) environment, or dietary and physical activity patterns (8) .

\section{COMPARATIVE STUDIES IN BODY COMPOSITION AND FAT DISTRIBUTION}

\section{Body composition}

Numerous comparative studies reported that for the same BMI, age and gender, Asians had a higher body fat percentage compared to Caucasians. The studies were performed among South Asian Indians and/or Pakistani (13-18), East Asian Hong Kong Chinese (19) , Japanese (20), Korean women (21) and Taiwanese (22) as well as Southeast 


\section{CHAPTER 2}

Asian Indonesian (23), Singaporean (11) and Philipino (24). Some studies reported no differences $(11,25,26)$.

For the same BMI as Caucasians, the body fat percentage in Asians would be $5-7 \%$ higher in Indian men $(13-15,17), 8 \%$ in Indian women (16-18), 1-4\% in Japanese women (20), 5\% and 7\% for Indonesian men and women from Malay ancestry respectively (23), and $1.3 \%$ and $1.7 \%$ for Indonesian Chinese men and women respectively (23). Interestingly, there was a tendency that the difference in body fat percentage became smaller with increasing BMI and age (20). In Asians, it was predicted that with increasing age, the body fat percentage increased to a lesser degree than in Caucasians $(17,21)$.

Among Asians, Indians have the highest body fat percentage followed by Malays and Chinese. The suggested BMI cut-off points for obesity are $26 \mathrm{~kg} / \mathrm{m}^{2}$ for Indians, $27 \mathrm{~kg} / \mathrm{m}^{2}$ for Malays and $27.5 \mathrm{~kg} / \mathrm{m}^{2}$ for Chinese, as compared to $30 \mathrm{~kg} / \mathrm{m}^{2}$ for Caucasians (27). Pongchaiyatkul et al. (28) also suggested for Thai, the obesity cut-off point should be lowered to $27 \mathrm{~kg} / \mathrm{m}^{2}$ and $25 \mathrm{~kg} / \mathrm{m}^{2}$ for men and women respectively.

It can be concluded that the difference in body fat percentage between Asians and Caucasians is dependent on the region/ethnicity. It is most pronounced in South (Indians), then Southeast (Malay) and then East Asian (Chinese/Japanese). Ethnic differences in the relationship between $\mathrm{BMI}$ and \% body fat may be explained by the difference in body build and frame size (9), in part by differences in muscularity and bone mineral content (16) as well as fat distribution and relative leg length (17).

\section{Body fat distribution}

Asians tend to have a higher abdominal fat mass compared to Caucasians as measured anthropometrically as waist circumference and waist to hip ratio or using computed tomography as subcutaneous abdominal and visceral fat content. This unfavourable fat distribution was found in Indians $(16,17,25)$, Pakistani (29), Japanese $(30,31)$, and Philipino (24). For the same waist circumference as Caucasian, Philipino women (24) and 
Japanese men (30) had a higher visceral fat and visceral/subcutaneous abdominal fat ratio. While, Park et al. (32) reported that among East Asians the difference in visceral adipose tissue was only found in women. In addition, Gallagher et al. (33) found that the visceral fat depot was not significantly different between East Asians and Caucasians at low levels of adiposity.

In contrast, Chandalia et al. (14) reported that the higher abdominal adipose tissue in young Asian Indian men was mostly found in subcutaneous abdominal, while for the intraperitoneal abdominal fat there was no difference with Caucasians. It is important to notice that for the same level of subcutaneous abdominal fat, adipocyte size was greater in Indians.

High levels of fatty acids along with the inability of adipose tissue to store more lipid, induces lipid overflow to other tissues such as skeletal muscle, liver etc. (ectopic fat depot) (34). One study showed that Asian Indian had a higher intramyocellular lipid content compared to European Caucasians (13), while another study reported no difference compared to American Caucasians (15). With increasing adiposity, East Asians tended to accumulate fat as visceral fat but not intramyocellular (33). Japanese men also developed a higher liver fat content compared to Caucasian men even with lower mean BMI (31).

In conclusion, Asians in general tend to have a higher abdominal fat compared to Caucasians. There was some inconsistency as to where exactly in the abdominal region the fat was stored. Young South Asians (Indian) stored more fat in the subcutaneous abdominal region, while East and Southeast Asians were found to store more fat viscerally.

\section{THE METABOLIC PROFILE ASSOCIATED WITH THE “UNFAVOURABLE” BODY COMPOSITION IN ASIANS}

The "unfavourable" body composition in Asians implicates some metabolic consequences. As Asians were found to have a higher risk to develop the metabolic 


\section{CHAPTER 2}

syndrome at a relatively lower BMI (3), they were identified as metabolically obese but normal body weight (MONW) (35). The existence of a subgroup of normal-weight individuals displaying an obesity-related phenotype was first proposed in 1981 by Ruderman et al. (36). These individuals might be characterized by hyperinsulinemia and/or insulin resistance, hypertriglyceridemia and high blood pressure despite having a normal BMI $\left(<25 \mathrm{~kg} / \mathrm{m}^{2}\right)$. When compared to control subjects, MONW subjects showed an altered insulin sensitivity, a higher abdominal and visceral adiposity, a more atherogenic lipid profile, a higher blood pressure and a lower physical activity energy expenditure. Additionally, they were at higher risk for developing diabetes and cardiovascular disease (35).

Among Asians, the metabolic consequences seemed to be more pronounced in Asian Indian as shown by the high prevalence of the metabolic syndrome, compared to other Asian countries $(1,3)$. Dhawan et al. (37) reported that Asian Indian who either lived in the UK or in India, had a higher total insulin, higher triglycerides and lower HDL than Caucasians, and that the waist to hip ratio (WHR) was the strongest independent predictor of the blood lipid profile. Forouhi et al. (13) and Misra et al. (38) confirmed that insulin sensitivity correlated with the WHR in South Asian men, but not with visceral fat, intramyocellular lipid, BMI and body fat. In contrast, Kamath et al. (18) reported an adverse blood lipid profile in Indian and Pakistani women compared to White Americans despite of no differences in WHR. In South Asian men, insulin resistance was observed to occur without a higher intraperitoneal fat depot, but was related to a large adipocyte size in subcutaneous abdominal fat. Hence, it appears to be related more to the excess truncal fat and dysfunctional adipose tissue than excess visceral fat (14).

After adjusting for BMI and waist circumference, Japanese were reported to have significantly higher blood levels of triglycerides, total-, HDL-, and LDL- cholesterol compared to Caucasians (39). The liver fat content was also higher despite a lower BMI and it correlated with triglyceride levels, insulin resistance and C-reactive protein (31). 
Egusa et al. (40) showed that among Japanese, the WHR of American-born Japanese was the highest followed by Japanese migrants and Japanese who lived in Japan. The adverse fat distribution was followed by higher fasting insulin, serum cholesterol level and triglyceride levels in the same order.

A higher abdominal adiposity in Thai people was also significantly correlated with insulin sensitivity $(41,42)$. While in Philipino women, the prevalence of diabetes was higher at every level of visceral adipose tissue compared to white. However, visceral adipose tissue did not explain their elevated diabetes risk (24).

\section{GENERAL DISCUSSION}

Evidence showed that the high prevalence of metabolic disease in Asia was partly explained by an unfavourable body composition. However, there is a lack of understanding of the ethnic-specific nature of the association between the various components of body composition and morbidity sequelae (17). For example, in contrast with Caucasians, the higher BMI, body fat percentage, visceral fat and intramyocellular lipid in Asian Indians did not correlate with insulin sensitivity (13), but waist to hip ratio did $(13,37,38)$. Increased abdominal adiposity and reduced apendicular skeletal muscle may be more important risk factors than total body fat in Asian Indians (17).

Body composition is determined by complex phenotypes for which multiple genetic and non-genetic factors are expected to be involved (43). Results from genetic correlation analysis revealed some evidence of common genetic pathways underlying certain aspects of growth and adult health outcomes, including body composition and blood pressure variables (44). Environmental factors are important, however they cannot account for all the characteristic of the epidemic in Asia $(3)$. Genetic $(3,8)$ and intra-uterine development (8) may also play an important role. This was supported by several studies in Asian children and adolescents, which found that the unfavourable body composition was present from young age onwards. Since body composition consists of two major 


\section{CHAPTER 2}

compartments, fat-free mass (lean body mass) and fat mass, the discussion below is focussed on these two major body compartments.

Asian Indian babies were reported as lighter and smaller compared to UK babies but the subscapular skinfold thickness was larger (45). The follow up study at four years of age, observed that the skinfold thickness of Asian Indian children was larger whereas all other anthropometric measurements were smaller (46), suggesting that the thin-fat phenotype is present from childhood onwards (46). South Asian adolescents had a higher percentage of body fat and waist to hip ratio compared to white European. In addition, they had lower insulin sensitivity even though the effect of ethnicity was no longer seen when body fat was included as a covariate (47).

East Asian girls and boys were reported to have a lower appendicular skeletal muscle mass (48) and lower gynoid fat (49) than Caucasian girls and boys respectively. The difference in body fat percentage of Asian and Caucasian girls varied by BMI for age, with excess body fatness of Asians evident only among relatively thin children (50). Sampei et al. (51) found no difference in body fat between Japanese and Caucasian boys, but Japanese boys had a statistically lower fat-free mass. Interestingly, the gain in fat freemass and the loss in body fat when attaining maturation were greater in Caucasian boys. Singaporean boys and girls were also shorter, lighter, had a lower BMI but a higher sum of skinfold thickness and predicted body fat percentage than Dutch Caucasians (52).

It can be concluded that in general Asian whether observed in South Asian adults (16, 17) or in East Asian adolescents $(48,51)$ had a lower lean body mass/skeletal muscle mass compared to Caucasian. Based on the interesting finding that the gain in fat free-mass when attaining maturation was greater in Caucasians (51), it is most likely that this was genetically determined. A genome wide scan study on the variation in lean body mass was first reported by Liu et al (53). The study, which was replicated in three independent populations, two US Caucasians and one Chinese, reported the association between a polymorphism in the thyrotropin-releasing hormone receptor (TRHR) gene and variations 
in lean body mass. This receptor is known to have physiological relevance to the hypothalamic-pituitary-thyroid axis (HPTA) and the growth hormone-insuline-like growth factor-I (GH-IGF I) axis, which are responsible for the development of vertebrae skeletal muscle and muscle protein balance respectively (53).

Several studies found a significant correlation between fetal programming, growing during infancy and childhood, and adult body composition. It was consistently reported that birth weight was positively correlated with height (54-56) and higher fat-free mass in later life, both in Caucasians $(54,56-58)$ and Asian Indians (59). The genetic variation in lean body mass and the high correlation between fat-free mass and birth weight suggest that the intra-uterine environment might modify the effect of genes acting on lean body mass development and therefore body composition in later life, since lean body mass accounts for $\sim 60 \%$ or more of body weight (60). The association between birth weight and later fatness was weaker both in Caucasians $(54,61)$ and Asian Indians (59). In addition, the association with fat distribution remains controversial and requires confirmation using more sophisticated methodology (61). Others suggest that infancy (58, 62) and early childhood (62) are critical periods, which have a large impact on body size and body composition in later life. Breast feeding during infancy (63) or dietary patterns and a sedentary life style during childhood might be the explanation but the causal effect still needs to be demonstrated (62). Campbell et al. (64) reported that the stability of body composition indicators from childhood into adulthood was moderately high but measures of adipose tissue distribution were somewhat lower. While, Peeters et al. (65) found that subcutaneous fat distribution during adolescence was predominantly explained by genetic factors.

Several candidate genes associated with adiposity and fat distribution have been found across populations, among them, the FTO (fat mass and obesity related) gene may be one of the worldwide obesity-risk genes (66). FTO gene variants were associated with adiposity both in Caucasian (67-71) and Asian populations (66, 72-74). Interestingly, the 


\section{CHAPTER 2}

action of this gene becomes evident only after 7 years of age (75), is strengthened during childhood and adolescence, peaked at age 20 and weakened during adulthood (76). Fatness induced by FTO polymorphisms in early childhood is sustained until early adulthood, where further weight gain may occur (77). Taken together all these findings suggest that the action of this gene is strongly influenced by environmental factors such as physical activity and dietary patterns. This was supported by several studies which reported that an increase in BMI across FTO genotypes was found in those who had a high fat diet (78) and low physical activity both in the Caucasian (79-81) and Chinese and Malay population (73). This might also explain the weaker association between birth weight and body fatness in later life due to the higher influence of postnatal exposure to the environment on the action of the FTO gene.

Different variants of this gene appeared to affect obesity and BMI in European and non-European populations (82). In addition, the way the FTO gene works may also influence the susceptibility to diabetes in European and other populations (74). The action of the FTO gene is possibly related to how it affects fat cell lipolysis (83). Since there is heterogeneity in regional lipolysis in humans (84), it may lead to differences in fat deposition. This might be one of the possible explanations for the difference in fat distribution towards the central fat depot in Asians $(13,14,17,20,30,31)$. It was also supported by the fact that FTO gene variants were significantly associated with subcutaneous fat and a trend for liver fat content, non-visceral adipose tissue and visceral fat in Caucasians (69) and with waist circumference in Chinese and Malay (73).

In South Asian Indian however, FTO gene variants predisposed to diabetes but did not entirely do so through their influence on BMI, general and central adiposity (74). Since Chandalia et al (14) reported that insulin sensitivity in Indian correlated with a higher subcutaneous abdominal fat depot due to lipodistrophy (large adipocyte size). Another gene affecting lypolitic capacity such as the hormone-sensitive lipase gene may also play a role. HSL was reported to have a significant correlation with fat cell size (85) and reduced 
activity of HSL in the abdominal subcutaneous fat depot led to a greater fat accumulation due to a lower fat mobilization (86). However, polymorphisms in the HSL gene were reported to result in different adiposity phenotypes dependent on the race, gender and insulin level (86). In addition, a polygenic approach found that diabetes susceptibility can be modulated by genetic variation in insulin action or insulin secretion depending on obesity status (87). Thus, gene-gene interaction might play a role in the susceptibility to diabetes. This suggests a different possible mechanism, mediated by body composition and fat distribution, in the development of diabetes, in European and South Asian or other Asian populations that needs to be further investigated.

\section{CONCLUSION}

The difference in body fat percentage between Asians and Caucasians is dependent on the region/ethnicity. It is most pronounced in South (Indians), followed by Southeast (Malay) and then East Asian (Chinese/Japanese). In general, Asians tend to store more fat in abdominal regions.

Genetic variation in lean body mass and fat mass may predispose individuals in different ethnicities to a different muscularity and adiposity. The interaction with other genes or the environment, both prenatal and postnatal, as well as during the life course may modify the effect of genes on body composition, fat distribution and the associated metabolic profiles.

\section{CONTRIBUTIONS}

As the first author, Siti Wulan is responsible for most of the writing of the manuscript. Klaas Westerterp and Guy Plasqui, as supervisors of Ms. Siti Wulan, have contributed by discussing the content of the paper, as well as reviewing and correcting the manuscript.

\section{COMPETING INTEREST}

The authors have no conflict of interest 


\title{
CHAPTER 2
}

\section{PROVENANCE AND PEER REVIEW}

\author{
Commissioned and externally peer reviewed
}

\section{ACKNOWLEDGEMENT}

This work was supported by The Ministry of Education and Culture of The Republic of Indonesia

\section{REFERENCES}

1. King H, Aubert RE, Herman WH. Global burden of diabetes, 1995-2025: prevalence, numerical estimates, and projections. Diabetes Care 1998; 21: 1414-1431.

2. Cockram CS. Diabetes mellitus: perspective from the Asia-Pacific region. Diabetes Res Clin Pract 2000; 50 Suppl 2: S3-7.

3. Yoon KH, Lee JH, Kim JW, Cho JH, Choi YH, Ko SH, et al. Epidemic obesity and type 2 diabetes in Asia. Lancet 2006; 368: 1681-1688.

4. Lear SA, Humphries $\mathrm{KH}$, Kohli S, Birmingham CL. The use of BMI and waist circumference as surrogates of body fat differs by ethnicity. Obesity (Silver Spring) 2007; 15: 2817-2824.

5. Romero-Corral A, Somers VK, Sierra-Johnson J, Thomas RJ, Collazo-Clavell ML, Korinek J, et al. Accuracy of body mass index in diagnosing obesity in the adult general population. Int J Obes (Lond) 2008; 32: 959-966.

6. Deurenberg-Yap M, Deurenberg P. Validity of deuterium oxide dilution for the measurement of body fat among Singaporeans. Food Nutr Bull 2002; 23: 34-37.

7. Asia Pacific Cohort Studies Collaboration. The burden of overweight and obesity in the Asia-Pacific region. Obes Rev 2007; 8: 191-196.

8. Pan WH, Yeh WT, Weng LC. Epidemiology of metabolic syndrome in Asia. Asia Pac J Clin Nutr 2008; 17 Suppl 1: 37-42.

9. Deurenberg P, Deurenberg Yap M, Wang J, Lin FP, Schmidt G. The impact of body build on the relationship between body mass index and percent body fat. Int J Obes Relat Metab Disord 1999; 23: 537-542.

10. Deurenberg $P$, Deurenberg-Yap $M$. Differences in body-composition assumptions across ethnic groups: practical consequences. Curr Opin Clin Nutr Metab Care 2001; 4: 377-383.

11. Deurenberg P, Deurenberg-Yap M, Foo LF, Schmidt G, Wang J. Differences in body composition between Singapore Chinese, Beijing Chinese and Dutch children. Eur J Clin Nutr 2003; 57: 405-409.

12. Deurenberg P, Deurenberg-Yap M, Guricci S. Asians are different from Caucasians and from each other in their body mass index/body fat per cent relationship. Obes Rev 2002; 3: 141-146.

13. Forouhi NG, Jenkinson G, Thomas EL, Mullick S, Mierisova S, Bhonsle U, et al. Relation of triglyceride stores in skeletal muscle cells to central obesity and insulin sensitivity in European and South Asian men. Diabetologia 1999; 42: 932-935.

14. Chandalia M, Lin P, Seenivasan T, Livingston EH, Snell PG, Grundy SM, et al. Insulin resistance and body fat distribution in South Asian men compared to Caucasian men. PLoS One 2007; 2: e812.

15. Nair KS, Bigelow ML, Asmann YW, Chow LS, Coenen-Schimke JM, Klaus KA, et al. Asian Indians have enhanced skeletal muscle mitochondrial capacity to produce ATP in association with severe insulin resistance. Diabetes 2008; 57: 1166-1175.

16. Rush EC, Goedecke JH, Jennings C, Micklesfield L, Dugas L, Lambert EV, et al. BMI, fat and muscle differences in urban women of five ethnicities from two countries. Int J Obes (Lond) 2007; 31: 1232-1239.

17. Rush EC, Freitas I, Plank LD. Body size, body composition and fat distribution: comparative analysis of European, Maori, Pacific Island and Asian Indian adults. Br J Nutr 2009; 102: 632-641. 
18. Kamath SK, Hussain EA, Amin D, Mortillaro E, West B, Peterson CT, et al. Cardiovascular disease risk factors in 2 distinct ethnic groups: Indian and Pakistani compared with American premenopausal women. Am J Clin Nutr 1999; 69: 621-631.

19. Ko GT, Tang J, Chan JC, Sung R, Wu MM, Wai HP, et al. Lower BMI cut-off value to define obesity in Hong Kong Chinese: an analysis based on body fat assessment by bioelectrical impedance. Br J Nutr 2001; 85: 239242.

20. Gallagher D, Heymsfield SB, Heo M, Jebb SA, Murgatroyd PR, Sakamoto Y. Healthy percentage body fat ranges: an approach for developing guidelines based on body mass index. Am J Clin Nutr 2000; 72: 694-701.

21. Chung S, Song MY, Shin HD, Kim DY, He Q, Heshka S, et al. Korean and Caucasian overweight premenopausal women have different relationship of body mass index to percent body fat with age. J Appl Physiol 2005; 99: 103-107.

22. Chang CJ, Wu CH, Chang CS, Yao WJ, Yang YC, Wu JS, et al. Low body mass index but high percent body fat in Taiwanese subjects: implications of obesity cutoffs. Int J Obes Relat Metab Disord 2003; 27: 253-259.

23. Gurrici S, Hartriyanti Y, Hautvast JG, Deurenberg P. Differences in the relationship between body fat and body mass index between two different Indonesian ethnic groups: the effect of body build. Eur J Clin Nutr 1999; 53: 468-472.

24. Araneta MR, Barrett-Connor E. Ethnic differences in visceral adipose tissue and type 2 diabetes: Filipino, African-American, and white women. Obes Res 2005; 13: 1458-1465.

25. Cruz ML, Evans K, Frayn KN. Postprandial lipid metabolism and insulin sensitivity in young Northern Europeans, South Asians and Latin Americans in the UK. Atherosclerosis 2001; 159: 441-449.

26. Kagawa M, Kerr D, Uchida H, Binns CW. Differences in the relationship between BMI and percentage body fat between Japanese and Australian-Caucasian young men. BrJ Nutr 2006; 95: 1002-1007.

27. Deurenberg-Yap M, Schmidt G, van Staveren WA, Hautvast JG, Deurenberg P. Body fat measurement among Singaporean Chinese, Malays and Indians: a comparative study using a four-compartment model and different two-compartment models. Br J Nutr 2001; 85: 491-498.

28. Pongchaiyakul C, Nguyen TV, Kosulwat V, Rojroongwasinkul N, Charoenkiatkul S, Pongchaiyakul C, et al. Defining obesity by body mass index in the Thai population: an epidemiologic study. Asia Pac J Clin Nutr 2006; 15: 293-299.

29. Pollard TM, Unwin N, Fischbacher C, Chamley JK. Differences in body composition and cardiovascular and type 2 diabetes risk factors between migrant and British-born British Pakistani women. Am J Hum Biol 2008; 20: 545-549.

30. Kadowaki T, Sekikawa A, Murata K, Maegawa H, Takamiya T, Okamura T, et al. Japanese men have larger areas of visceral adipose tissue than Caucasian men in the same levels of waist circumference in a population-based study. Int J Obes (Lond) 2006; 30: 1163-1165.

31. Azuma K, Kadowaki T, Cetinel C, Kadota A, El-Saed A, Kadowaki S, et al. Higher liver fat content among Japanese in Japan compared with non-Hispanic whites in the United States. Metabolism 2009; 58: 12001207.

32. Park YW, Allison DB, Heymsfield SB, Gallagher D. Larger amounts of visceral adipose tissue in Asian Americans. Obes Res 2001; 9: 381-387.

33. Gallagher D, Kuznia P, Heshka S, Albu J, Heymsfield SB, Goodpaster B, et al. Adipose tissue in muscle: a novel depot similar in size to visceral adipose tissue. Am J Clin Nutr 2005; 81: 903-910.

34. Montani JP, Carroll JF, Dwyer TM, Antic V, Yang Z, Dulloo AG. Ectopic fat storage in heart, blood vessels and kidneys in the pathogenesis of cardiovascular diseases. Int J Obes Relat Metab Disord 2004; 28 Suppl 4: S5865.

35. Conus F, Rabasa-Lhoret R, Peronnet F. Characteristics of metabolically obese normal-weight (MONW) subjects. Appl Physiol Nutr Metab 2007; 32: 4-12.

36. Ruderman NB, Schneider SH, Berchtold P. The "metabolically-obese," normal-weight individual. Am J Clin Nutr 1981; 34: 1617-1621.

37. Dhawan J, Bray CL, Warburton R, Ghambhir DS, Morris J. Insulin resistance, high prevalence of diabetes, and cardiovascular risk in immigrant Asians. Genetic or environmental effect? Br Heart J 1994; 72: 413-421. 


\section{CHAPTER 2}

38. Misra A, Sinha S, Kumar M, Jagannathan NR, Pandey RM. Proton magnetic resonance spectroscopy study of soleus muscle in non-obese healthy and Type 2 diabetic Asian Northern Indian males: high intramyocellular lipid content correlates with excess body fat and abdominal obesity. Diabet Med 2003; 20: 361-367.

39. Iwao N, Iwao S, Muller DC, Koda M, Ando F, Shimokata H, et al. Differences in the relationship between lipid CHD risk factors and body composition in Caucasians and Japanese. Int J Obes (Lond) 2005; 29: 228-235.

40. Egusa G, Watanabe H, Ohshita K, Fujikawa R, Yamane K, Okubo M, et al. Influence of the extent of westernization of lifestyle on the progression of preclinical atherosclerosis in Japanese subjects. J Atheroscler Thromb 2002; 9: 299-304.

41. Rattarasarn C, Leelawattana R, Soonthornpun S, Setasuban W, Thamprasit A. Gender differences of regional abdominal fat distribution and their relationships with insulin sensitivity in healthy and glucose-intolerant Thais. J Clin Endocrinol Metab 2004; 89: 6266-6270.

42. Stolk RP, Suriyawongpaisal P, Aekplakorn W, Woodward M, Neal B. Fat distribution is strongly associated with plasma glucose levels and diabetes in Thai adults-the InterASIA study. Diabetologia 2005; 48: 657-660.

43. Chagnon YC, Rice T, Perusse L, Borecki IB, Ho-Kim MA, Lacaille M, et al. Genomic scan for genes affecting body composition before and after training in Caucasians from HERITAGE. J Appl Physiol 2001; 90: 17771787.

44. Czerwinski SA, Lee M, Choh AC, Wurzbacher K, Demerath EW, Towne B, et al. Genetic factors in physical growth and development and their relationship to subsequent health outcomes. Am J Hum Biol 2007; 19: 684-691.

45. Yajnik CS, Fall CH, Coyaji KJ, Hirve SS, Rao S, Barker DJ, et al. Neonatal anthropometry: the thin-fat Indian baby. The Pune Maternal Nutrition Study. Int J Obes Relat Metab Disord 2003; 27: 173-180.

46. Krishnaveni GV, Hill JC, Veena SR, Leary SD, Saperia J, Chachyamma KJ, et al. Truncal adiposity is present at birth and in early childhood in South Indian children. Indian Pediatr 2005; 42: 527-538.

47. Ehtisham S, Crabtree N, Clark P, Shaw N, Barrett T. Ethnic differences in insulin resistance and body composition in United Kingdom adolescents. J Clin Endocrinol Metab 2005; 90: 3963-3969.

48. Song MY, Kim J, Horlick M, Wang J, Pierson RN, Jr., Heo M, et al. Prepubertal Asians have less limb skeletal muscle. J Appl Physiol 2002; 92: 2285-2291.

49. He Q, Horlick M, Thornton J, Wang J, Pierson RN, Jr., Heshka S, et al. Sex-specific fat distribution is not linear across pubertal groups in a multiethnic study. Obes Res 2004; 12: 725-733

50. Freedman DS, Wang J, Thornton JC, Mei Z, Pierson RN, Jr., Dietz WH, et al. Racial/ethnic differences in body fatness among children and adolescents. Obesity (Silver Spring) 2008; 16: 1105-1111.

51. Sampei MA, Novo NF, Juliano Y, Sigulem DM. Anthropometry and body composition in ethnic Japanese and Caucasian adolescent boys. Pediatr Int 2008; 50: 679-686.

52. Deurenberg P, Bhaskaran K, Lian PL. Singaporean Chinese adolescents have more subcutaneous adipose tissue than Dutch Caucasians of the same age and body mass index. Asia Pac J Clin Nutr 2003; 12: 261-265.

53. Liu XG, Tan L, Lei SF, Liu YJ, Shen H, Wang L, et al. Genome-wide association and replication studies identified TRHR as an important gene for lean body mass. Am J Hum Genet 2009; 84: 418-423.

54. Chomtho S, Wells JC, Williams JE, Lucas A, Fewtrell MS. Associations between birth weight and later body composition: evidence from the 4-component model. Am J Clin Nutr 2008; 88: 1040-1048.

55. Elia $M$, Betts $P$, Jackson DM, Mulligan J. Fetal programming of body dimensions and percentage body fat measured in prepubertal children with a 4-component model of body composition, dual-energy X-ray absorptiometry, deuterium dilution, densitometry, and skinfold thicknesses. Am J Clin Nutr 2007;6: 618-624

56. Weyer C, Pratley RE, Lindsay RS, Tataranni PA. Relationship between birth weight and body composition, energy metabolism, and sympathetic nervous system activity later in life. Obes Res 2000; 8: 559-565.

57. Singhal A, Wells J, Cole TJ, Fewtrell M, Lucas A. Programming of lean body mass: a link between birth weight, obesity, and cardiovascular disease? Am J Clin Nutr 2003; 77: 726-730.

58. Eriksson M, Tynelius $P$, Rasmussen F. Associations of birthweight and infant growth with body composition at age 15--the COMPASS study. Paediatr Perinat Epidemiol 2008; 22: 379-388. 
59. Sachdev HS, Fall CH, Osmond C, Lakshmy R, Dey Biswas SK, Leary SD, et al. Anthropometric indicators of body composition in young adults: relation to size at birth and serial measurements of body mass index in childhood in the New Delhi birth cohort. Am J Clin Nutr 2005; 82: 456-466.

60. Liu X, Zhao LJ, Liu YJ, Xiong DH, Recker RR, Deng HW. The MTHFR gene polymorphism is associated with lean body mass but not fat body mass. Hum Genet 2008; 123: 189-196.

61. Wells JC, Chomtho S, Fewtrell MS. Programming of body composition by early growth and nutrition. Proc Nutr Soc 2007; 66: 423-434.

62. Ekelund U, Ong K, Linne Y, Neovius M, Brage S, Dunger DB, et al. Upward weight percentile crossing in infancy and early childhood independently predicts fat mass in young adults: the Stockholm Weight Development Study (SWEDES). Am J Clin Nutr 2006; 83: 324-330.

63. Karaolis-Danckert N, Gunther AL, Kroke A, Hornberg C, Buyken AE. How early dietary factors modify the effect of rapid weight gain in infancy on subsequent body-composition development in term children whose birth weight was appropriate for gestational age. Am J Clin Nutr 2007; 86: 1700-1708.

64. Campbell PT, Katzmarzyk PT, Malina RM, Rao DC, Perusse L, Bouchard C. Stability of adiposity phenotypes from childhood and adolescence into young adulthood with contribution of parental measures. Obes Res 2001; 9: 394-400.

65. Peeters MW, Beunen GP, Maes HH, Loos RJ, Claessens AL, Vlietinck R, et al. Genetic and environmental determination of tracking in subcutaneous fat distribution during adolescence. Am J Clin Nutr 2007; 86: 652660.

66. Cha SW, Choi SM, Kim KS, Park BL, Kim JR, Kim JY, et al. Replication of genetic effects of FTO polymorphisms on BMI in a Korean population. Obesity (Silver Spring) 2008; 16: 2187-2189.

67. Cecil JE, Tavendale R, Watt P, Hetherington MM, Palmer CN. An obesity-associated FTO gene variant and increased energy intake in children. N Engl J Med 2008; 359: 2558-2566.

68. Franks PW, Jablonski KA, Delahanty LM, McAteer JB, Kahn SE, Knowler WC, et al. Assessing gene-treatment interactions at the FTO and INSIG2 loci on obesity-related traits in the Diabetes Prevention Program. Diabetologia 2008; 51: 2214-2223.

69. Haupt A, Thamer C, Machann J, Kirchhoff K, Stefan N, Tschritter O, et al. Impact of variation in the FTO gene on whole body fat distribution, ectopic fat, and weight loss. Obesity (Silver Spring) 2008; 16: 1969-1972.

70. Kring SI, Holst C, Zimmermann E, Jess T, Berentzen T, Toubro S, et al. FTO gene associated fatness in relation to body fat distribution and metabolic traits throughout a broad range of fatness. PLoS One 2008; 3: e2958.

71. Lappalainen TJ, Tolppanen AM, Kolehmainen M, Schwab U, Lindstrom J, Tuomilehto J, et al. The common variant in the FTO gene did not modify the effect of lifestyle changes on body weight: the Finnish Diabetes Prevention Study. Obesity (Silver Spring) 2009; 17: 832-836.

72. Chang YC, Liu PH, Lee WJ, Chang TJ, Jiang YD, Li HY, et al. Common variation in the fat mass and obesityassociated (FTO) gene confers risk of obesity and modulates BMI in the Chinese population. Diabetes 2008; 57: $2245-2252$.

73. Tan JT, Dorajoo R, Seielstad M, Sim XL, Ong RT, Chia KS, et al. FTO variants are associated with obesity in the Chinese and Malay populations in Singapore. Diabetes 2008; 57: 2851-2857.

74. Yajnik CS, Janipalli CS, Bhaskar S, Kulkarni SR, Freathy RM, Prakash S, et al. FTO gene variants are strongly associated with type 2 diabetes in South Asian Indians. Diabetologia 2009; 52: 247-252.

75. Hakanen M, Raitakari OT, Lehtimaki T, Peltonen N, Pahkala K, Sillanmaki L, et al. FTO genotype is associated with body mass index after the age of seven years but not with energy intake or leisure-time physical activity. J Clin Endocrinol Metab 2009; 94: 1281-1287.

76. Hardy R, Wills AK, Wong A, Elks CE, Wareham NJ, Loos RJ, et al. Life course variations in the associations between FTO and MC4R gene variants and body size. Hum Mol Genet 2010;19: 545-552

77. Jess T, Zimmermann E, Kring SI, Berentzen T, Holst C, Toubro S, et al. Impact on weight dynamics and general growth of the common FTO rs9939609: a longitudinal Danish cohort study. Int J Obes (Lond) 2008; 32: 13881394. 


\section{CHAPTER 2}

78. Sonestedt E, Roos C, Gullberg B, Ericson U, Wirfalt E, Orho-Melander M. Fat and carbohydrate intake modify the association between genetic variation in the FTO genotype and obesity. Am J Clin Nutr 2009; 90: 14181425.

79. Andreasen CH, Stender-Petersen KL, Mogensen MS, Torekov SS, Wegner L, Andersen G, et al. Low physical activity accentuates the effect of the FTO rs9939609 polymorphism on body fat accumulation. Diabetes 2008; 57: 95-101.

80. Cauchi S, Stutzmann F, Cavalcanti-Proenca C, Durand E, Pouta A, Hartikainen AL, et al. Combined effects of MC4R and FTO common genetic variants on obesity in European general populations. J Mol Med 2009; 87: 537-546.

81. Vimaleswaran KS, Li S, Zhao JH, Luan J, Bingham SA, Khaw KT, et al. Physical activity attenuates the body mass index-increasing influence of genetic variation in the FTO gene. Am J Clin Nutr 2009; 90: 425-428.

82. Grant SF, Li M, Bradfield JP, Kim CE, Annaiah K, Santa E, et al. Association analysis of the FTO gene with obesity in children of Caucasian and African ancestry reveals a common tagging SNP. PLoS One 2008; 3: e1746.

83. Wahlen K, Sjolin E, Hoffstedt J. The common rs9939609 gene variant of the fat mass-and obesity-associated gene FTO is related to fat cell lipolysis. J Lipid Res 2008; 49: 607-611.

84. Jensen MD. Lipolysis: contribution from regional fat. Annu Rev Nutr 1997; 17: 127-139.

85. Reynisdottir S, Dauzats M, Thorne A, Langin D. Comparison of hormone-sensitive lipase activity in visceral and subcutaneous human adipose tissue. J Clin Endocrinol Metab 1997; 82: 4162-4166.

86. Garenc C, Perusse L, Chagnon YC, Rankinen T, Gagnon J, Borecki IB, et al. The hormone-sensitive lipase gene and body composition: the HERITAGE Family Study. Int J Obes Relat Metab Disord 2002; 26: 220-227.

87. Cauchi S, Nead KT, Choquet H, Horber F, Potoczna N, Balkau B, et al. The genetic susceptibility to type 2 diabetes may be modulated by obesity status: implications for association studies. BMC Med Genet 2008; 9: 45 . 


\section{BIAPTER 3}

Dietary and 24-h fat oxidation in Asians and whites who differ in body composition

Siti N. Wulan, Klaas R. Westerterp and Guy Plasqui Am J Clin Nutr (2012), 95: 1335-1341 


\section{CHAPTER 3}

\section{ABSTRACT}

Background: With the same body mass index, age and sex, Asians were reported to have a higher body fat percentage than whites.

Objective: This study aimed to determine the difference in body composition and its effect on dietary and $24 \mathrm{~h}$-fat oxidation between Asians and whites, when fed a diet that contained $30 \%$ of energy as fat.

Methods: Seventeen Asians (8 men) were matched with 17 whites ( 8 men) for BMI, age and sex. Physical activity was measured for $7 \mathrm{~d}$ with an accelerometer. During the last $3 \mathrm{~d}$ of the activity measurement, subjects were given a diet to maintain energy balances. Energy expenditure and substrate use were measured for $24 \mathrm{~h}$ in a respiration chamber. Dietary fat oxidation was determined from the percentage recovery of deuterium in the urine after a breakfast meal that contained deuterated palmitic acid. Body composition was calculated with a 3-compartment model from body mass, body volume (hydrodensitometry) and total body water (deuterium dilution).

Results: Asians had a $5 \%$ higher body fat than whites $(28.1 \pm 7.3 \%$ compared with $23.0 \pm$ $6.9 \%$, respectively; $P=0.03)$. The fat-free mass-index tended to be lower in Asians than in whites $\left(16.3 \pm 1.6\right.$ compared with $17.0 \pm 1.7 \mathrm{~kg} / \mathrm{m}^{2}$, respectively; $\left.\mathrm{P}=0.07\right)$. Dietary fat oxidation as a percentage of fat consumed was $11.7 \pm 3.6$ compared with $10.8 \pm 4.5 \%(P=$ $0.50)$ for Asians and whites, respectively. In Asians and whites, the 24-h fat oxidation as a percentage of total energy expenditure was $17.7 \pm 6.9 \%$ compared with $19.2 \pm 5.1 \%$ ( $P=$ 0.63 ), respectively; carbohydrate oxidation was $68.0 \pm 6.8 \%$ compared with $66.1 \pm 5.1 \%$ ( $P$ $=0.51)$, respectively; and protein oxidation was $14.3 \pm 2.2 \%$ compared with $14.7 \pm 1.6 \%$ ( $P$ $=0.61$ ), respectively.

Conclusion: Dietary and 24-h fat oxidation were not different between Asians and whites despite differences in body composition. 


\section{INTRODUCTION}

Several studies reported that Asians compared with whites with the same BMI, age and sexes were shown to have a higher body fat percentage (1-5) and a lower fat-free mass (6-8). These characteristics may partly explain the increasing prevalence of type 2 diabetes and metabolic syndrome in Asia $(9,10)$. In different Asian populations, in both adults $(4,11,12)$ and children $(13,14)$, there were also differences in the BMI - body fat relation depending on the ethnic background (e.g. Chinese, Malay or South Asian Indian). This unfavorable body composition may be a consequence of a lower rate of energy metabolism and a higher respiratory quotient (RQ), which indicate a lower proportion of fat to carbohydrate oxidation. This effect has been reported in other ethnic groups such as in African Americans (15) or Pima Indians (16). Alternatively, a low rate of energy metabolism may be partly due to the unfavorable body composition.

The relationship between body composition and energy metabolism has been studied extensively in health and disease. Studies have established fat-free mass as the major determinant of resting energy expenditure (REE) (17), which is the largest component of daily total energy expenditure (TEE). Asians were reported to have a lower REE compared to Caucasians due to the lower FFM; the difference in REE disappeared when adjusted for body composition (18).

Energy expenditure equals energy intake when in energy balance. Under conditions of a perfect energy and nutrient balance, the food quotient (FQ) equals the $R Q(19)$. In the long term, an RQ higher than the FQ implicates a conversion of carbohydrate and protein to body fat, and an RQ lower than the FQ implicates a mobilization of energy from body fat (19). In a follow up study, a higher RQ has been associated with weight gain in obesityprone Pima Indians (16), although another study reported no evidence of a low metabolic rate and impaired $24 \mathrm{~h}$ - fat oxidation in Pima Indians (20). However, one should acknowledge that the rise in endogenous fat storage that accompanies a prolonged increase in fat intake, progressively leads to an enhanced fat oxidation in the dynamic 


\section{CHAPTER 3}

phase of weight gain up to a re-equilibrium in fat balance (21). In South Asian Indians, Hall et al. (22) reported that during sub-maximal exercise, they oxidized less fat than did Europeans, whereas at rest there was no difference in fat oxidation. To our knowledge, there has been no study that compared the 24-h energy metabolism of Asians and Caucasians measured in a respiration chamber. In addition, because humans spend the majority of $24 \mathrm{~h}$ in a fed (postprandial) state, fatty acids from dietary sources also play a major metabolic role (23). The objective of the current study was to determine the effect of differences in body composition between Asians and Caucasians on 24h fat oxidation and dietary fat oxidation.

\section{SUBJECTS AND METHODS}

\section{Subjects}

Subjects were 17 healthy adult Asians ( 8 men) and 17 whites ( 8 men). Subjects were matched for BMI (in $\mathrm{kg} / \mathrm{m}^{2}$ ), age and sex. Subject characteristics are presented in Table 3.1. Asian subjects had 4 grandparents from Asia, whereas white subjects were nonHispanic Europeans. Subjects were selected on the basis of the following inclusion criteria: healthy, not using medication (except oral contraceptive), aged between 20 and $40 \mathrm{y}$, had a BMI between 20 and 27, had a stable body weight for the past 3 mo, were not on a diet and were not athletes. All subjects received verbal and written information before giving their consent. The study was approved by Medical Ethics Committee of Maastricht University Medical Centre (10-3-013) and was registered in the public trial registry at www.ccmo.nl as NL31217.068.10

\section{Experimental design}

This study had a cross-sectional study. Daily physical activity was measured for 7 consecutive days; during the last $3 \mathrm{~d}$ of activity measurement, subjects were given a diet to maintain energy balance. On the evening of day 3 of the balance diet, subjects came to 
the university to have dinner and started their 36-h stay in the respiration chamber (the test day). In the morning after the 36-h stay in the respiration chamber, body composition was measured.

\section{Daily physical activity level}

The daily physical activity level (PAL) was measured with a tri-axial accelerometer (Tracmor, Philips Research) for movement registration. The accelerometer was attached to the lower back by means of an elastic belt. The accelerometer registered accelerations minute by minute, in the mediolateral (x-axis), longitudinal ( $y$-axis) and anterioposterior (z-axis) of the trunk as described elsewhere (24). Subjects were instructed to wear the accelerometer for 7 consecutive days, during waking hours except during water activities. Subjects were advised to maintain their habitual PAL and not to perform any strenuous physical activity the day before the test day. Accelerometer output was defined as activity counts/day ( $A C D)$, as the sum of all 3 axes over $7 \mathrm{~d}$ divided by 7 . Daily PAL was calculated on the basis of the ACD by using the following formula,

$$
\mathrm{PAL}=1.267+\left(1.437 \times 10^{-6} \times \text { counts } / \mathrm{d}\right)
$$

$\left(R^{2}=0.59\right)(24)$. Daily total energy expenditure was calculated with the formula of Plasqui et al. (24) as follows:

TEE accelerometer $=-7.98+2.58 \times \mathrm{SMR}+8.57 \times 10^{-3} \times$ kcounts $\left(R^{2}=0.95\right)$ by including $A C D$ (from the accelerometer) and sleeping metabolic rate (SMR; from the respiration chamber measurement).

\section{Energy intake}

The energy balance diet to be consumed at home for $3 \mathrm{~d}$ before the test day was calculated on the basis of the average daily energy requirements with a moderate PAL of 


\section{CHAPTER 3}

1.75. The daily energy requirement was estimated as 1.75 times basal metabolic rate (BMR) (25). BMR was calculated on the basis of the Harris-Bennedict formula (26). A written instruction was given to prepare the diet at home. Subjects were provided with the diet in an amount in excess of the average daily energy requirement of 1.75 times the BMR. Subjects were allowed to eat more or less from the diet prescribed, according to what they needed (ad libitum). Any additional amount from those prescribed foods was recorded. All unfinished foods were collected and returned to the university, to calculate actual energy intake.

The energy requirement in the respiration chamber was estimated as 1.35 times the BMR. Percentage of energy from the diet was divided as follows: $20 \%$ from breakfast, $40 \%$ from lunch, 35\% from dinner and 5\% from evening snacks. Breakfast was served at 08:30, lunch was served at 12:00, dinner was served at 18:00 and evening snacks were served at 20:00. The macronutrients distribution of the diet before and during the chamber stay was $55 \%$ carbohydrate, $15 \%$ protein and $30 \%$ fat.

The diet was a combination of typical Western and Asian diets. Breakfast was a typical Western diet with bread and spreads, which is becoming more common in Asia as well. Lunch was a sandwich with a chicken burger or fish filet. Dinner was a typical Asian diet of rice and other dishes and a Mediterranean diet of pasta, which is also commonly eaten in Asia as noodles. Foods were selected by reviewing ingredient contents to avoid an effect of certain ingredients on fat oxidation (such as spices). During the chamber stay, subjects were also provided with decaffeinated coffee and fruit-tea, because caffeine has also been reported to increase fat oxidation.

The diet was given $3 \mathrm{~d}$ before and during the stay in the respiration chamber. In total, the diet was given for $4 \mathrm{~d}$. To simulate the variety of foods as on a day-to-day basis, the diet was arranged as follows: day $1=$ day 3 , and day $2=$ day 4 . This arrangement also allowed subjects to become accustomed to the diet in the respiration chamber because they already had the diet before the chamber stay. 


\section{Energy expenditure}

Subjects stayed in the respiration chamber from 20:00 in the evening of the third day of their balance diet (day 3) until 08:00 in the morning of day $5(36 \mathrm{~h})$. The respiration chamber was a $14-\mathrm{m}^{3}$ room furnished with a full-sized foldaway bed, a bureau with a builtin sink, a folding chair, a television, a DVD player, an alarm clock, a telephone, an automated intercom, and a computer-network connection. The chamber gave the impression of a normal room, with windows positioned in the door for contact with researchers, in the wall (outside view), and between the chambers for visual contact between subjects. A more detailed description of the chamber has been provided elsewhere (27).

During the 36-h stay in the respiration chamber, oxygen consumption and carbon dioxide production were measured continuously. Subjects were allowed to move freely, sit, lie down, study, use the telephone, listen to the radio, watch television, and use the computer from $07: 00$ to $23: 00$, but were not allowed to do strenuous physical activity (exercise) or sleep. The TEE over $24 \mathrm{~h}$ and $24-\mathrm{h}$ RQ were calculated from 08:00 on the first morning until 08:00 on the second morning in the respiration chamber. A radar system based on the Doppler principle was used to measure the spontaneous physical activity of subjects in the chamber. The TEE was calculated by using the following equation of Carpenter, as published by Brouwer (28):

$\operatorname{TEE}(\mathrm{kJ} / \mathrm{d})=16 \times \mathrm{O}_{2}(\mathrm{~L} / \mathrm{d})+5 \mathrm{CO}_{2}(\mathrm{~L} / \mathrm{d})-0.95 \times P$

where $P$ is oxidized protein in grams per day.

The SMR was calculated by assessing the lowest mean activity of subjects during 3 consecutive hours between 00:00 and 07:00 during the second night of their stay in the respiration chamber. The SMR was also corrected for body composition (FFM) on the basis of the previous study (18). 


\section{CHAPTER 3}

\section{Substrate oxidation}

Substrate oxidation was calculated from 24-h urinary nitrogen, oxygen consumption, and carbon dioxide production. Urine samples $(24 \mathrm{~h})$ were collected from the second voiding on day 4 until the first voiding on day 5 . To prevent nitrogen loss through evaporation, 24-h urine was collected in containers with $10 \mathrm{~mL} \mathrm{HCl}$, whereas the total volume was measured afterwards. Nitrogen concentrations were measured with a nitrogen analyzer (CHN-O-Rapid; Heraeus). Protein oxidation $(\mathrm{g} / \mathrm{d})$ was calculated by multiplying $24-\mathrm{h}$ urinary nitrogen $(\mathrm{g} / \mathrm{d})$ by 6.25 . Carbohydrate $(\mathrm{g} / \mathrm{d})$ and fat oxidation $(\mathrm{g} / \mathrm{d})$ were calculated by using the following equations of Carpenter as published by Brouwer (28):

$$
\begin{aligned}
& \text { Carbohydrate oxidation }=-2.97 \times \mathrm{O}_{2}(\mathrm{~L} / \mathrm{d})+4.17 \times \mathrm{CO}_{2}(\mathrm{~L} / \mathrm{d})-0.39 \times \mathrm{P} \\
& \text { Fat oxidation }=1.72 \times \mathrm{O}_{2}(\mathrm{~L} / \mathrm{d})-1.72 \times \mathrm{CO}_{2}(\mathrm{~L} / \mathrm{d})-0.32 \times \mathrm{P}
\end{aligned}
$$

\section{Dietary fat oxidation}

Deuterated palmitic acid (d31-palmitic acid, 98 atom\%; Cambridge Isotope) at a dose of $20 \mathrm{mg} / \mathrm{kg}$ body weight was added to $200 \mathrm{~mL}$ hot chocolate milk, which was previously heated up to $65^{\circ} \mathrm{C}$ and consumed simultaneously with breakfast while subjects were fed in

energy balance in the respiration chamber (29). Deuterium $\left({ }^{2} \mathrm{H}\right)$ was measured in a baseline urine sample collected before dosing, and samples were collected $12 \mathrm{~h}$ and $14 \mathrm{~h}$ after dosing. Urine samples were analyzed for deuterium content with an isotope ratio mass spectrometer (Optima, VG) after preparation by using the platinum-equilibration methodology (30). Urine samples of $300 \mu \mathrm{L}$ were placed in the bottom of 3-mL glass containers with $4 \mathrm{mg}$ catalyst (5\% platinum-on alumina, 325 mesh; Aldrich Chemical Company Ltd) in an insert, filled with hydrogen from a cylinder to $60 \mathrm{kPa}$ above atmospheric pressure, and left for $3 \mathrm{~d}$ at room temperature before analysis. The recovery of deuterium from palmitic acid oxidation was calculated as excess ${ }^{2} \mathrm{H}$ multiplied by the dilution space divided by the dose of ${ }^{2} \mathrm{H}$ administered as described by Vortubra et al. (31) 


\section{Body composition}

Body composition was determined according to a 3-compartment model on the basis of body weight, body volume and total body water. Body weight and body volume were determined in the morning, in a fasting state after the overnight stay in the respiration chamber. Body volume was determined by using hydro-densitometry with simultaneous measurement of residual lung capacity by using the helium-dilution technique. Total body water was determined by using deuterium dilution according to the Maastricht protocol (32). Body composition was calculated from body density and total body water using the equation of Siri (33).

\section{Statistical analysis}

Data are presented as means and SDs and were analyzed with 2-factor ANOVA (ethnicity and sex). The main effect of ethnicity, sex and the interaction between ethnicity and sex were assessed. To assess the contribution of several independent variables to the variability of the dependent variables, multiple regression analysis was applied. The SPSS program (version 16; SPSS) was used for statistical analysis, and the statistical significance was set as $P<0.05$.

\section{RESULTS}

\section{Subject characteristics}

Asian subjects were South Asian Indian ( $n=4 ; 3$ men) and Pakistani ( $n=3 ; 2$ men), Southeast Asian Indonesian ( $n=5 ; 2$ men) and Thai ( $n=1$ woman) and East Asian Chinese ( $n=4 ; 1$ man). Thirteen of these subjects were measured within $1 \mathrm{y}$ of their stay in the Netherlands, 3 subjects were measured within 2-3 y of their stay in the Netherlands, and 1 subject had been in Europe for 5 y. White subjects were Western European Dutch ( $n=7$; 4 men) and Germans ( $n=3$; women), as well as Eastern Europeans ( $n=7 ; 4$ men). Eastern 


\section{CHAPTER 3}

Europeans were measured within 1 y $(n=4)$ and 3 y $(n=3)$ of their stay in the Netherlands. Subject characteristics are presented in Table 3.1.

Asian subjects had a $5 \%$ higher body fat percentage $(P=0.03)$. Because whites were significantly taller than Asians, the absolute FFM of whites was significantly higher than that of Asians ( $P=0.001)$. To adjust the difference in fat-free mass for height, we used fat-free mass index [FFMI; FFM divided by the square of height $\left(\mathrm{kg} / \mathrm{m}^{2}\right)$ ]. With this index, Asians tended to have a lower FFM per square $m$ of height compared with that of whites $(P=0.07)$ (Table 3. 1).

\section{Body composition}

As expected, there was a sex difference in body composition in both ethnicities (Table 3.1). The body fat percentage was higher in women than men $(P=0.01)$, whereas the FFMI was higher in men than in women $(P=0.001)$. As shown in Table 3.1, the ANOVA analysis revealed that there was an ethnic difference $(P=0.03)$ and a sex difference $(P=$ 0.01), but there was no interaction between ethnicity and sex in relation to percentage body fat.

In general, Asians had a slightly lower FFMI than that of whites, but the difference was not significant. Compared with their white counterparts, Asian women had a $0.3-\mathrm{kg}$ lower FFM per square meter, whereas Asian men had a $1 \mathrm{~kg}$ lower FFM per square meter.

\section{Energy balance before the test-day}

There was no difference in ACD and, hence, no difference in the daily PAL between ethnicities (Table 3.2). The TEE was significantly higher in whites. The energy balance before the test day was not significantly different between ethnicities $(P=0.22)$ (Table 3.2). 


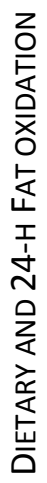

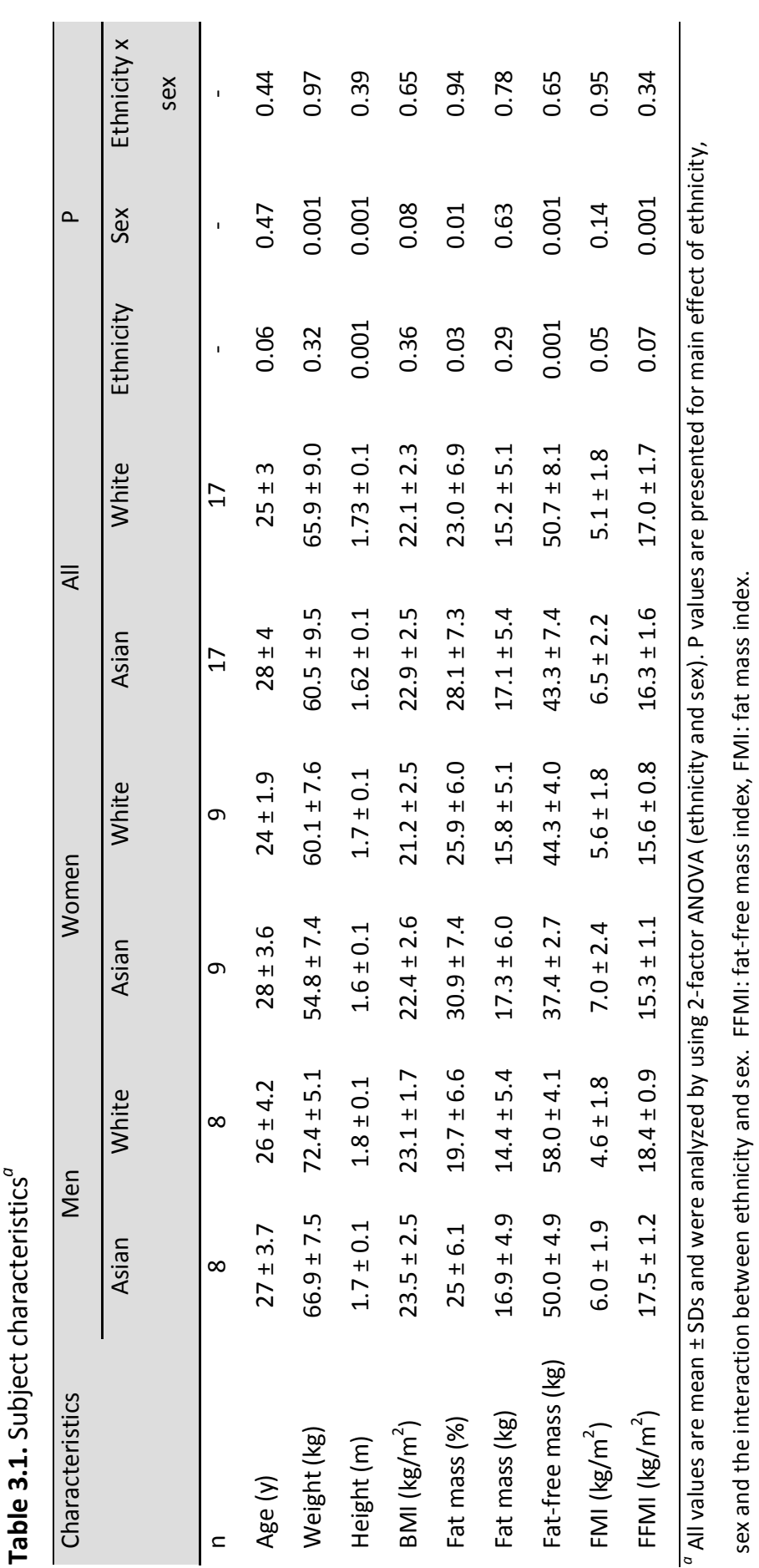




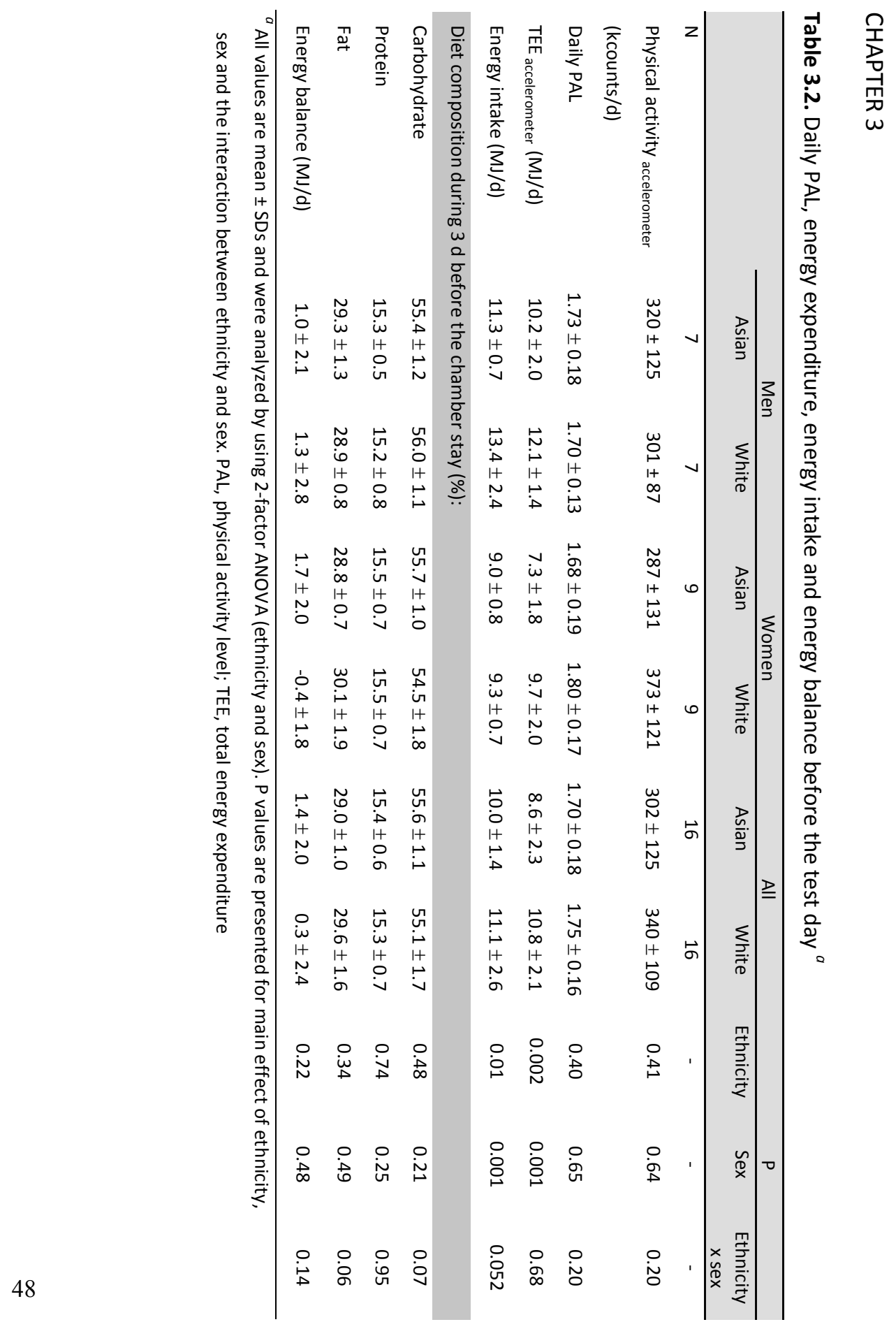




\section{Energy metabolism and substrate oxidation in the respiration chamber}

The TEE was higher in whites than in Asians ( $P=0.02)$, and was mostly contributed by a higher SMR ( $P=0.001)$. The difference in SMR was no longer seen when adjusted for FFM (Table 3.3). Asians were slightly more active in the respiration chamber than were whites [i.e. the lower SMR was compensated with a higher PAL (1.36 compared with 1.30, respectively, $P=0.03)$ ]. The radar output was not different between Asians and whites (1883 compared with 1620 counts/d, respectively, $P=0.14$ ).

Both ethnicities were in a slightly positive energy balance in the respiration chamber, but there was no difference between ethnicities, sex, and ethnicity by sex $(P=0.98, P=0.96$, and $P=0.95$, respectively). There was no difference in the $24 \mathrm{~h}-\mathrm{RQ}$ between Asians and whites (both groups had an RQ of 0.9).

There was no difference in the 24-h substrate oxidation between ethnicities (Figure3.1). Carbohydrate, protein and fat oxidation as a percentage of TEE were not different between Asians and whites. For Asians and whites, the 24-h fat oxidation as a percentage of TEE was $17.7 \pm 6.9 \%$ compared with $19.2 \pm 5.1 \%(P=0.63)$, respectively; carbohydrate oxidation was $68.0 \pm 6.9$ compared with $66.1 \pm 5.1 \%(P=0.51)$, respectively; and protein oxidation was $14.3 \pm 2.2$ compared with $14.7 \pm 1.6 \%(P=0.61)$, respectively. In addition, dietary fat oxidation as a percentage of fat eaten was not different between Asians and whites $(P=0.50)$ (Table 3.3).

\section{Determinants of $24 \mathrm{~h}$ fat oxidation and dietary fat oxidation}

A multiple regression analysis was performed to determine predictors of 24- $h$ fat oxidation. In a model with 24-h fat oxidation as the dependent variable, ethnicity, percentage of fat mass, energy balance in the respiration chamber and daily physical activity (accelerometer $A C D$ ) were included as the independent variables. These variables were chosen on the basis of previous studies. The energy balance in the respiration 


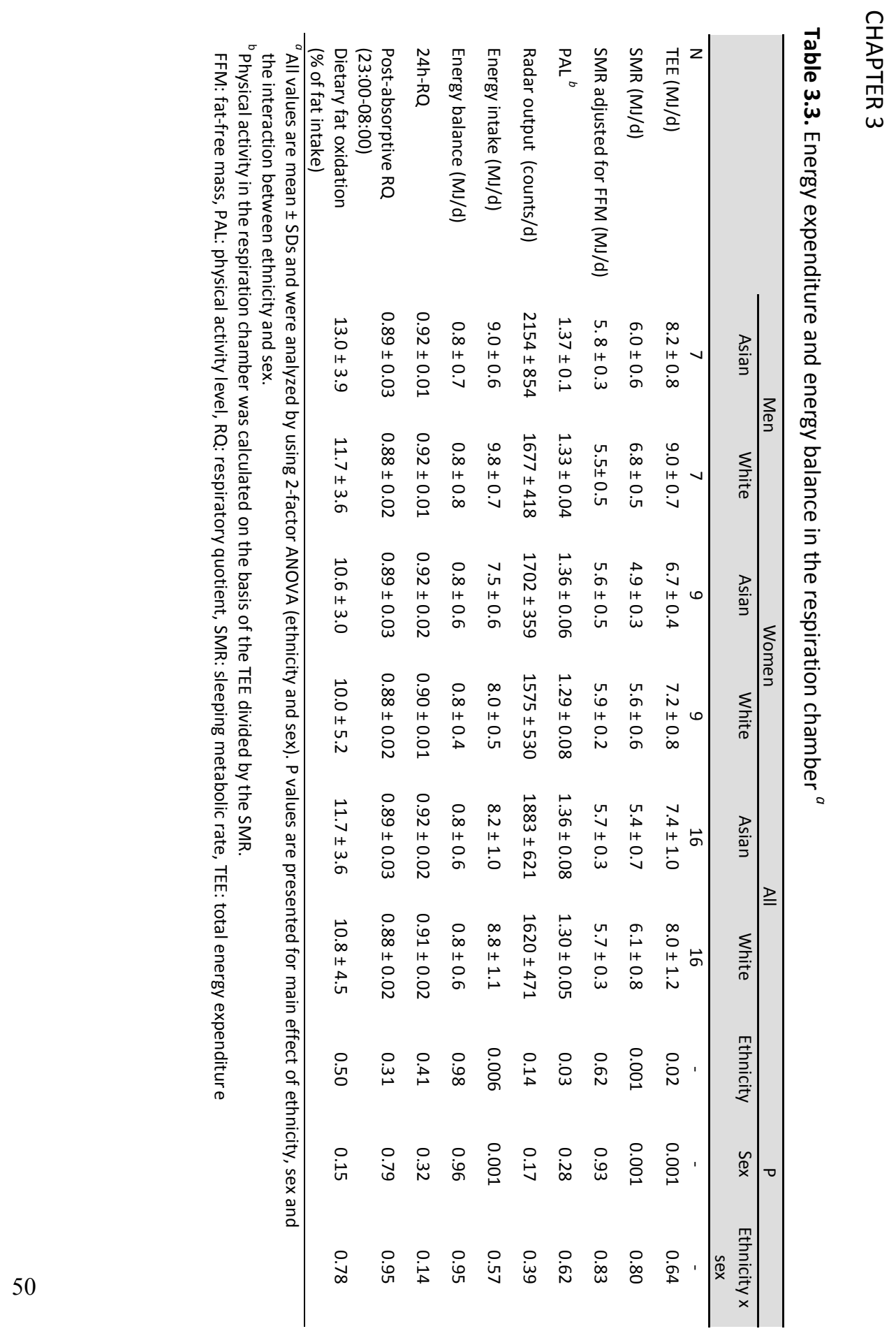




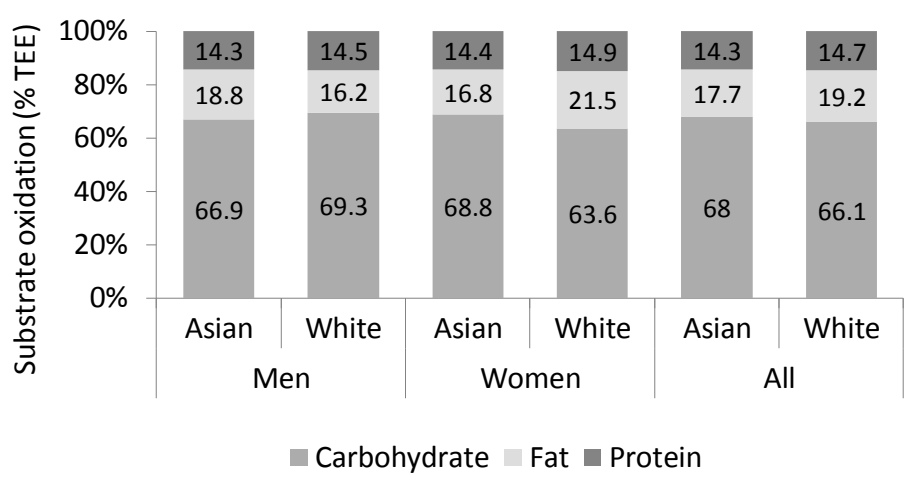

Figure 3.1. Substrate oxidation as a percentage of total energy expenditure in Asians (7 men, 9 women) and whites (7 men; 9 women) [ 2 -factor ANOVA (ethnicity $x$ sex)]. There was no difference between ethnicities or sexes and no interaction between ethnicity and sex in the substrate oxidations (carbohydrate: P-ethnicity $=0.51$, P-sex $=0.37$, P-ethnicity $x$ sex $=0.08$; fat: P-ethnicity $=0.63$, P-sex $=0.43$, P-ethnicity $x$ sex $=0.09$; protein: P-ethnicity $=0.61$, P-sex $=0.74$, P-ethnicity $x$ sex $=0.89$ ). TEE, total energy expenditure

chamber $(P=0.04)$ and daily physical activity counts $(P=0.04)$ together explained $32 \%$ of the variation in $24-\mathrm{h}$ fat oxidation.

In a model with dietary fat oxidation as the dependent variable, ethnicity, percentage fat mass, energy balance in the respiration chamber and radar output, which represented spontaneous physical activity in the chamber, were included as independent variables. Only energy balance $(P=0.077)$ and radar output $(P=0.089)$ tended to predict the dietary fat oxidation. 


\section{CHAPTER 3}

\section{DISCUSSION}

This study confirmed the findings from previous studies that there were differences in body composition between Asians and whites matched for sex, BMI and age (1-8). Asians had a $5 \%$ higher body fat percentage, a lower FFM and a tendency towards a lower FFMI. Despite differences in body composition, dietary and 24-h fat oxidation were not different between ethnicities.

Asian subjects in this study were South Asian Indian and Pakistani, Indonesian Malay and East Asian Chinese, which represented 3 major ethnic groups in Asia. A previous study found similar results with Asian subjects who were predominantly Indonesians (18). Deurenberg-Yap et al. (11) reported that South Asian Indian had the most pronounced difference in body fat percentage compared with Whites, followed by Malay and Chinese subjects. The FFMI tended to be lower in Asians compared to whites. This is in agreement with that of a large population study by Hull et al. (34) that showed that Asians had the lowest FFMI compared to other ethnicities such as whites, African-Americans and Hispanic

The 24-h fat oxidation did not differ between Asians and whites. In a respiration chamber study, Weyer et al. (18) reported there was no evidence for a lower metabolic rate or impaired 24-h fat oxidation in obesity-prone Pima Indians who also had a higher body fat percentage compared with that of whites. These results could be explained by the phenomenon that the high proportion of total fat oxidation in obese subjects was due to the increased supply of fat substrates from an enlarged fat mass $(21,35)$. We included normal- and overweight subjects with $\mathrm{BMI} \leq 27$, to avoid the complexity of metabolic changes because of obesity. However, the effect of an enlarged fat mass on fat oxidation could have occurred in Asians who, in absolute amounts, had $1.5 \mathrm{~kg}$ more fat mass per square meter of height than did whites (Table 3.1). In a prospective study, Schutz et al. (36) predicted that, for each 10-kg increase in fat mass, there is an expected increase in fat oxidation that averages $\sim 20 \mathrm{~g} / \mathrm{d}$, or a $12 \%$ increase in fat oxidation when expressed as a percentage of REE. 
In the current study, dietary fat oxidation (exogenous fat oxidation) was not different between Asians and whites. Most exogenous fat is stored in adipose tissue during the postprandial period, whereas a limited fraction ( 10\%) is directly oxidized (37). The range of dietary fat oxidation, (i.e. 3-20\%), was within previously reported ranges (31). Dietary fat oxidation was shown to be negatively correlated with the percentage body fat (i.e. the lowest in obese and the highest in lean subjects) $(38,39)$. In comparison with these studies $(38,39)$, our subjects were within a narrow range of $\mathrm{BMI}$, and there was not a huge difference in body composition (i.e. between lean and obese subjects). Other authors who used ${ }^{13} \mathrm{C}$ as a tracer and showed an increase in dietary fat oxidation with increasing body fat, suggested that these results may reflect a mechanism to protect other tissues from fat exposure (40) or to prevent an additional increase in fat mass (37).

Hall et al. (22) reported that during sub-maximal exercise, Asian Indians oxidized less fat than did Europeans, whereas at rest, there was no difference in fat oxidation, which pointed out the role of skeletal muscle in fat oxidation. In the current study, fat oxidation was measured in a respiration chamber with limited physical activity. In agreement with previous studies, Asians had a lower absolute FFM than that of whites $(6,7)$, which is the major determinant of REE. However, FFM is not an energetically homogeneous compartment but varies systematically in heat-producing components as a function of body mass and FFM (i.e. high metabolic tissues/organs and low metabolic tissues) (41). In adults, $70-80 \%$ of the REE is derived from organs that constitute only $5 \%$ of body weight (42). In contrast, skeletal muscle constitutes $40-50 \%$ of total body weight and accounts for only $20-30 \%$ of REE (43). Therefore, in the resting or sedentary condition, whole body fat oxidation was less determined by skeletal muscle (22) of which whites had significantly more than did Asians. This may also explain the similar contribution of fat oxidation to 24$\mathrm{h}$ TEE in Asians and whites when physical activity was limited in the respiration chamber.

We observed variability in the spontaneous PAL (PAL equals TEE divided by SMR) of subjects in the respiration chamber that ranged from 1.21-1.51. Ravussin et al. (44) also 


\section{CHAPTER 3}

reported the variability in PAL even within the confines of a respiration chamber. The spontaneous physical activity per se was reported not to correlate with the 24-h RQ. Instead, the 24-h RQ was associated with and sensitive to the 24-h energy balance (16). It seems that whites benefited from the more favorable body composition (higher FFM and thus, SMR) in reaching a significantly higher TEE, whereas Asians compensated a lower SMR with a slightly higher PAL (Table 3.3), which resulted in no difference in energy balance. In a multiple regression analysis, the energy balance in the respiration chamber was the significant predictor of 24-h fat oxidation. Although the energy balance was not different between groups, subjects were in a slightly positive energy balance. In a perfect energy and nutrient balance, RQ equals FQ (19). In a slightly positive energy balance both ethnicities had an RQ of 0.91-0.92, which indicated a greater reliance on carbohydrate oxidation. The glycogen stores of the body are so small that regulatory mechanisms are capable of efficiently adjusting carbohydrate oxidation to carbohydrate intake, whereas fat oxidation is regulated primarily by events that pertain to the carbohydrate economy of the body, rather than by fat intake (45). Thus, in a condition of a positive energy balance when glycogen stores are ensured, the proportion of carbohydrate from the diet that are oxidized is larger than it is in a condition of perfect or negative energy balance. Even though variation in both $24-\mathrm{h}$ fat oxidation and dietary fat oxidation was predicted by variation in energy balance, energy balance was the same between ethnicities.

Daily activity counts as a measure of the daily PAL also predicted 24-h fat oxidation, whereas 24-h fat oxidation was not related with ethnicity and body composition. On average, the PAL was 1.7 in Asians and 1.75 in whites, and ranged from 1.5-2.1, which, thus, was within the range of "sustainable lifestyles"(46). Eckel et al. (47) reported that subjects with a high daily PAL were able to maintain a positive carbohydrate balance during a period of inactivity in the respiration chamber, which meant that they relied to a greater extent on fat oxidation than did subjects who were more sedentary in daily life. Also, even within the range of normal daily life activities, the mitochondrial oxidative 
capacity was positively associated with the PAL (48). Thus, an active life style leads to an increased capacity of these vital organelles involved in the oxidative degradation of macronutrients to maintain the cellular ATP level (48).

In conclusion, we observed no differences in dietary and 24-h fat oxidation despite differences in body composition in young moderately active Asians and whites. The energy balance in the respiration chamber significantly predicted the 24-h fat oxidation and tended to predict the dietary fat oxidation. The daily PAL (ACD) significantly predicted the 24-h fat oxidation, whereas spontaneous physical activity as radar output tended to predict dietary fat oxidation.

It could be interesting to address the metabolic responses of Asians and whites when they are challenged to a high fat diet, which may better mimic the current changes in life style in Asia.

\section{ACKNOWLEDGEMENTS}

We gratefully thank Paul Schoffelen, Loek Wouters, Laurens Ronden, Wendy Sluijsmans and Gabby Hul for technical assistance and help with the analysis. Also, we deeply appreciate and thank all subjects who participated in the study.

The present study was funded by a scholarship from the Directorate General of Higher Education (DGHE), the Ministry of Education and Culture of The Republic of Indonesia to S.N.W. The Ministry of Education and Culture of the Republic of Indonesia had no role in the design and analysis of the study and in writing of this article.

The authors' responsibilities were as follows_ SNW: conducted the research, performed the data analysis and wrote the manuscript; and KRW and GP: designed the study, interpreted the data, and reviewed the manuscript.

None of the authors had a conflict of interest 


\section{CHAPTER 3}

\section{REFERENCES}

1. Forouhi NG, Jenkinson G, Thomas EL, et al. Relation of triglyceride stores in skeletal muscle cells to central obesity and insulin sensitivity in European and South Asian men. Diabetologia 1999;42:932-5.

2. Deurenberg $P$, Deurenberg-Yap $M$. Differences in body-composition assumptions across ethnic groups: practical consequences. Curr Opin Clin Nutr Metab Care 2001;4:377-83.

3. Deurenberg P, Deurenberg-Yap M. Validity of body composition methods across ethnic population groups. Forum Nutr 2003;56:299-301.

4. Deurenberg P, Deurenberg-Yap M, Guricci S. Asians are different from Caucasians and from each other in their body mass index/body fat per cent relationship. Obes Rev 2002;3:141-6.

5. Chang $\mathrm{CJ}, \mathrm{Wu} \mathrm{CH}$, Chang CS, et al. Low body mass index but high percent body fat in Taiwanese subjects: implications of obesity cutoffs. Int J Obes Relat Metab Disord 2003;27:253-9.

6. Rush EC, Goedecke JH, Jennings C, et al. BMI, fat and muscle differences in urban women of five ethnicities from two countries. Int J Obes (Lond) 2007;31(8):1232-9.

7. Rush EC, Freitas I, Plank LD. Body size, body composition and fat distribution: comparative analysis of European, Maori, Pacific Island and Asian Indian adults. Br J Nutr 2009;102:632-41.

8. Sampei MA, Novo NF, Juliano Y, Sigulem DM. Anthropometry and body composition in ethnic Japanese and Caucasian adolescent boys. Pediatr Int 2008;50:679-86.

9. King H, Aubert RE, Herman WH. Global burden of diabetes, 1995-2025: prevalence, numerical estimates, and projections. Diabetes Care 1998;21:1414-31.

10. Yoon KH, Lee JH, Kim JW, et al. Epidemic obesity and type 2 diabetes in Asia. Lancet 2006;368:1681-8.

11. Deurenberg-Yap M, Schmidt G, van Staveren WA, Hautvast JG, Deurenberg P. Body fat measurement among Singaporean Chinese, Malays and Indians: a comparative study using a four-compartment model and different two-compartment models. Br J Nutr 2001;85:491-8.

12. Gurrici S, Hartriyanti Y, Hautvast JG, Deurenberg P. Differences in the relationship between body fat and body mass index between two different Indonesian ethnic groups: the effect of body build. Eur J Clin Nutr 1999;53:468-72.

13. Liu A, Byrne NM, Kagawa M, et al. Ethnic differences in the relationship between body mass index and percentage body fat among Asian children from different backgrounds. Br J Nutr: 2011;106:1390-7.

14. Deurenberg P, Deurenberg-Yap M, Foo LF, Schmidt G, Wang J. Differences in body composition between Singapore Chinese, Beijing Chinese and Dutch children. Eur J Clin Nutr 2003;57:405-9.

15. Weyer C, Snitker S, Bogardus C, Ravussin E. Energy metabolism in African Americans: potential risk factors for obesity. Am J Clin Nutr 1999;70:13-20.

16. Zurlo F, Lillioja S, Esposito-Del Puente A, et al. Low ratio of fat to carbohydrate oxidation as predictor of weight gain: study of 24-h RQ. Am J Physiol 1990;259:E650-7.

17. Muller MJ, Bosy-Westphal A, Later W, Haas V, Heller M. Functional body composition: insights into the regulation of energy metabolism and some clinical applications. Eur J Clin Nutr 2009;63:1045-56.

18. Wouters-Adriaens MP, Westerterp KR. Low resting energy expenditure in Asians can be attributed to body composition. Obesity (Silver Spring) 2008;16:2212-6.

19. Westerterp KR. Food quotient, respiratory quotient, and energy balance. Am J Clin Nutr 1993 May;57(5 Suppl):759S-764S; discussion 764S-765S.

20. Weyer C, Snitker S, Rising R, Bogardus C, Ravussin E. Determinants of energy expenditure and fuel utilization in man: effects of body composition, age, sex, ethnicity and glucose tolerance in 916 subjects. Int J Obes Relat Metab Disord 1999;23:715-22.

21. Schutz Y. Dietary fat, lipogenesis and energy balance. Physiol Behav 2004;83:557-64.

22. Hall LM, Moran CN, Milne GR, et al. Fat oxidation, fitness and skeletal muscle expression of oxidative/lipid metabolism genes in South Asians: implications for insulin resistance? PLoS One 2010;5:e14197.

23. Ruge $T$, Hodson L, Cheeseman J, et al. Fasted to fed trafficking of Fatty acids in human adipose tissue reveals a novel regulatory step for enhanced fat storage. J Clin Endocrinol Metab 2009;94:1781-8. 
24. Plasqui G, Joosen AM, Kester AD, Goris AH, Westerterp KR. Measuring free-living energy expenditure and physical activity with triaxial accelerometry. Obes Res 2005;13:1363-9.

25. Hochstenbach-Waelen A, Veldhorst MA, Nieuwenhuizen AG, Westerterp-Plantenga MS, Westerterp KR. Comparison of 2 diets with either $25 \%$ or $10 \%$ of energy as casein on energy expenditure, substrate balance, and appetite profile. Am J Clin Nutr 2009;89:831-8.

26. Harris JA, Benedict FG. A Biometric Study of Human Basal Metabolism. Proc Natl Acad Sci U S A 1918;4:3703.

27. Schoffelen PF, Westerterp KR, Saris WH, Ten Hoor F. A dual-respiration chamber system with automated calibration. J Appl Physiol 1997;83:2064-72.

28. Brouwer E. On simple formulae for calculating the heat expenditure and the quantities of carbohydrate and fat oxidized in metabolism of men and animals, from gaseous exchange (Oxygen intake and carbonic acid output) and urine-N. Acta Physiol Pharmacol Neerl 1957;6:795-802.

29. Smeets AJ, Westerterp-Plantenga MS. Acute effects on metabolism and appetite profile of one meal difference in the lower range of meal frequency. Br J Nutr 2008;99:1316-21.

30. Scrimgeour CM, Rollo MM, Mudambo SM, Handley LL, Prosser SJ. A simplified method for deuterium/hydrogen isotope ratio measurements on water samples of biological origin. Biol Mass Spectrom 1993;22:383-7.

31. Votruba SB, Zeddun SM, Schoeller DA. Validation of deuterium labeled fatty acids for the measurement of dietary fat oxidation: a method for measuring fat-oxidation in free-living subjects. Int J Obes Relat Metab Disord 2001;25:1240-5.

32. Westerterp KR, Wouters L, van Marken Lichtenbelt WD. The Maastricht protocol for the measurement of body composition and energy expenditure with labeled water. Obes Res. 1995 Mar;3 Suppl 1:49-57

33. Siri WE. Body composition from fluid spaces and density: analysis of methods. 1961. Nutrition. 1993;9:48091

34. Hull HR, Thornton J, Wang J, et al. Fat-free mass index: changes and race/ethnic differences in adulthood. Int J Obes (Lond). 2011;35:121-7

35. Astrup A. The relevance of increased fat oxidation for body-weight management: metabolic inflexibility in the predisposition to weight gain. Obes Rev. 2011;12:859-65.

36. Schutz Y, Tremblay A, Weinsier RL, Nelson KM. Role of fat oxidation in the long-term stabilization of body weight in obese women. Am J Clin Nutr 1992;55:670-4.

37. Maffeis C, Armellini F, Tato L, Schutz Y. Fat oxidation and adiposity in prepubertal children: exogenous versus endogenous fat utilization. J Clin Endocrinol Metab 1999;84:654-8.

38. Westerterp KR, Smeets A, Lejeune MP, Wouters-Adriaens MP, Westerterp-Plantenga MS. Dietary fat oxidation as a function of body fat. Am J Clin Nutr 2008;87:132-5.

39. Buemann B, Toubro S, Astrup A. Substrate oxidation and thyroid hormone response to the introduction of a high fat diet in formerly obese women. Int J Obes Relat Metab Disord 1998;22:869-77.

40. Hodson L, McQuaid SE, Humphreys SM, et al. Greater dietary fat oxidation in obese compared with lean men: an adaptive mechanism to prevent liver fat accumulation? Am J Physiol Endocrinol Metab 2010;299:E584-92.

41. Heymsfield SB, Gallagher D, Kotler DP, Wang Z, Allison DB, Heshka S. Body-size dependence of resting energy expenditure can be attributed to nonenergetic homogeneity of fat-free mass. Am J Physiol Endocrinol Metab 2002;282:E132-8.

42. Muller MJ, Bosy-Westphal A, Kutzner D, Heller M. Metabolically active components of fat-free mass and resting energy expenditure in humans: recent lessons from imaging technologies. Obes Rev 2002;3:113-22.

43. Dulloo AG, Jacquet J, Solinas G, Montani JP, Schutz Y. Body composition phenotypes in pathways to obesity and the metabolic syndrome. Int J Obes (Lond). 2010;34:S4-17.

44. Ravussin E, Lillioja S, Anderson TE, Christin L, Bogardus C. Determinants of 24-hour energy expenditure in man. Methods and results using a respiratory chamber. J Clin Invest 1986;78:1568-78.

45. Flatt JP. Use and storage of carbohydrate and fat. Am J Clin Nutr 1995;61:952S-959S. 


\section{CHAPTER 3}

46. Westerterp KR, Plasqui G. Physical activity and human energy expenditure. Curr Opin Clin Nutr Metab Care 2004;7:607-13.

47. Eckel RH, Hernandez TL, Bell ML, et al. Carbohydrate balance predicts weight and fat gain in adults. Am J Clin Nutr 2006;83:803-8.

48. den Hoed M, Hesselink MK, van Kranenburg GP, Westerterp KR. Habitual physical activity in daily life correlates positively with markers for mitochondrial capacity. J Appl Physiol 2008;105:561-8. 


\section{GHAPTER 4}

Liver fat accumulation in response to overfeeding with a high fat diet: a comparison between South Asian and Caucasian men

SN Wulan, VB Schrauwen-Hinderling, KR Westerterp and G Plasqui Nutrition \& Metabolism (2015), 12:18 


\section{CHAPTER 4}

\section{ABSTRACT}

Background: South Asians were reported to have a higher liver fat content as compared to BMI-matched Caucasians. This study compared the increase in liver fat content in response to overfeeding with a high-fat diet in South Asian and Caucasian men when matched for body fat percentage.

Methods: Ten South Asian men (BMI $\left.18-29 \mathrm{~kg} / \mathrm{m}^{2}\right)$ and 10 Caucasian men $\left(22-33 \mathrm{~kg} / \mathrm{m}^{2}\right)$, aged 20-40 y, matched for body fat percentage, were included. A weight maintenance diet was given for 3 days based on the individual energy requirement. Individual energy requirement of the subjects was calculated based on their body composition (measured by hydro densitometry and deuterium dilution) and activity counts (accelerometer). Liver fat content was measured before and after 4 days of overfeeding (50\% excess energy need) with a high fat diet (60\% energy from fat). Fat distribution was measured by anthropometry and an MRI scan of the abdomen while liver fat content using $1 \mathrm{H}-\mathrm{MRS}$.

Results: While having a similar body fat\% $(P=0.58)$, South Asians had a lower BMI $(P=0.04)$ than Caucasians. Liver fat content at baseline did not differ between ethnicities $(P=0.48)$ and was associated with visceral fat area $\left(P=0.002, R^{2}=0.56\right)$ but not with ethnicity $(P=0.13)$. Overfeeding with a high fat diet significantly increased liver fat $(P=0.01)$ but the increase did not differ between ethnicities $(P=0.47)$. There was no difference in the total abdominal fat area $(P=0.37)$, subcutaneous abdominal fat area $(P=0.18)$ and visceral fat area (VAT, $\mathrm{P}=0.32$ ). However, as a percentage of the total abdominal fat area, VAT was higher in South Asians ( $P=0.003)$.

Conclusion: Despite a relatively higher percentage of visceral fat area, liver fat increased similarly in South Asian and Caucasian men in response to overfeeding with a high fat diet. 


\section{INTRODUCTION}

The epidemic of overweight and obesity is one of the major public health problems not only in western countries but also in a number of Asian countries(1,2). Globally, adult obesity is more common than under-nutrition affecting around 475 million adults who are obese, with over twice that number overweight. When Asian-specific cut-off points for the definition of obesity (body mass index $>28 \mathrm{~kg} / \mathrm{m}^{2}$ ) are taken into account, the number of adults considered obese globally is over 600 million (3).

Differences in body composition between Asians and Caucasians matched for sex, BMI and age have been reported in several comparative studies. We (4) and others (5-9) found that Asians have a higher body fat percentage and a lower fat-free mass/appendicular skeletal muscle mass (10-12) compared to that of Caucasians. In addition, when the fatfree mass was corrected for body height, Asians were shown to have the lowest fat-free mass index (FFMI, in $\mathrm{kg} / \mathrm{m} 2$ ) of ethnicities such as Hispanics, African-Americans and Caucasians (13).

Among Asians, South Asians (people from Indian sub-continent) have the most pronounced difference in body fat (14) and an increased ectopic fat deposition in the liver (15) and muscle (5) compared to those in BMI-matched European Caucasians. It is hypothesized that South Asians have a lower capacity to store fat in subcutaneous adipocytes than Caucasians (16). Excess fat may therefore overflow to the ectopic compartments, such as in the liver (15). Thus, South Asians may be more susceptible to the negative effects of a high-fat diet. Ectopic fat accumulation in the liver has been shown to be associated with insulin resistance in Caucasians $(17,18)$ and South Asians $(15)$.

It is well known that genetics may play a role and the interaction with environmental factors such as changes in lifestyle could increase the risk of developing the metabolic syndrome (19). In Asia, the consumption of fat and added sugar in the diet have increased in recent decades (20). The effect of a high-fat diet on ectopic fat accumulation in the liver in Caucasian populations has been documented in some studies (21-23), whereas 


\section{CHAPTER 4}

intramyocellular (IMCL) content increased in some studies (24) but not in others (21). Van Herpen et al.(21) conducted a 3- week period of high fat isocaloric diet study with $60 \%$ energy from fat and reported that the increase in liver fat was observed after 1 week with no further increase in the following weeks. In the present study, we induced liver fat accumulation with a high fat diet (60 \% energy from fat) in a shorter time by overfeeding with $50 \%$ excess energy than the requirement. Whether a high-fat diet affects liver fat accumulation in South Asians and Caucasians similarly is unknown. A previous crosssectional study (15) reported a higher liver fat content in South Asians compared to Caucasians after correcting for BMI, sex and age. As there is an ethnic-specific BMI-body fat percentage relationship (8), in the present study South Asian and Caucasian men were matched for body fat percentage instead of BMI.

The objectives of the present study were to compare liver fat content at baseline between South Asian and Caucasian men matched for body fat percentage and to compare the increase in fat accumulation in the liver in response to short-term overfeeding with a high fat diet.

\section{METHODS}

\section{Study subjects}

Subjects were 10 healthy adult non-diabetic South Asian men and 10 Caucasian men, matched for body fat percentage. The number of subjects was determined based on previous studies showing an increased in liver fat content after short-term high fat feeding in Caucasian subjects (21,23). Subject characteristics are presented in Table 4.1. Asian subjects had 4 grandparents from South Asia, while Caucasian subjects were non-Hispanic Europeans. South Asian subjects were students who temporarily living in Europe, and were not recruited from the European population. Subjects were selected based on the following inclusion criteria: healthy, not having metabolic diseases (diabetes or cardiovascular diseases), not using medication, aged between 20 and 40 years old with a 
body mass index between $18-29 \mathrm{~kg} / \mathrm{m}^{2}$ for South Asians and $22-33 \mathrm{~kg} / \mathrm{m} 2$ for Caucasians, having a stable body weight for the last three months, having no- low- or moderate alcohol intake, not being on a diet and no athletes. All subjects received verbal and written information before giving their consent to participate in the study. The study was approved by Medical Ethics Committee of Maastricht University Medical Centre, MEC No. 10-3-013 and registered in the public trial registry (www.ccmo.nl No. NL31217.068.10)

\section{Study design}

This study was a diet-intervention study in free-living conditions. Body composition was measured at baseline to have a matched body fat percentage between two ethnic groups. Cardio-respiratory fitness was measured prior to the diet intervention. Daily physical activity was measured for 7 consecutive days with an accelerometer. A diet to maintain energy balance for 3 days was prepared on the basis of fat-free mass and the daily physical activity counts of each subject. Baseline measurement of hepatic fat content was performed afterwards. The overfeeding with a high fat diet for an interval of 4 days was started right after the baseline measurement and hepatic fat content was measured again after the overfeeding interval. All measurements were carried out at the Metabolic Research Unit Maastricht (MRUM), Maastricht University, Maastricht, The Netherlands.

\section{Body composition}

Body composition was determined according to a 3- compartment model based on body weight, body volume and total body water. Body weight and body volume were determined in the morning, in the fasting state. Body volume was determined by hydrodensitometry with simultaneous measurement of residual lung volume using the helium dilution technique. Total body water was determined with deuterium dilution according to the Maastricht protocol (25). Body composition was calculated from body density and total body water using the equation of Siri (26). 


\section{CHAPTER 4}

\section{Anthropometry}

Anthropometric measures were performed at the same time as body composition. Waist circumference was measured using a circumference measuring tape (Seca 201, United Kingdom) at the umbilical, while subject standing in very light clothing. Hip circumference was measured as the largest circumference between waist and thighs (27). Skinfold thickness of the biceps, triceps, subscapular and suprailiac was determined using Harpenden skinfold caliper (Body Care, England). Anthropometry measures were performed using The NHANES body measurement guidelines (28).

\section{Cardio-respiratory fitness}

Physical fitness was assessed with an incremental test on a bicycle ergometer using the protocol of Kuipers et al.(29). During the test, $\mathrm{O}_{2}$-consumption and $\mathrm{CO}_{2}$-production were measured continuously and heart rate was monitored (Polar heart rate monitor, Polar Electro Oy, Kempele, Finland). After a warming up of $5 \mathrm{~min}$ at 100 Watt (W) for men, workload was increased with $50 \mathrm{~W}$ every $2.5 \mathrm{~min}$. When heart rate (HR) reached a value of 35 beats per min (bpm) below the age predicted maximal HR (220 bpm - age) or the respiratory quotient $\left(\mathrm{RQ}=\mathrm{CO}_{2}\right.$-production $/ \mathrm{O}_{2}$-consumption) exceeded 1 , workload was increased with $25 \mathrm{~W}$ every $2.5 \mathrm{~min}$ until exhaustion. $\mathrm{VO}_{2}$ max was determined by averaging the last few points of maximum $\mathrm{O}_{2}$ consumption. Cardio-respiratory fitness was defined as $\mathrm{VO}_{2}$ max divided by FFM.

\section{Daily physical activity level}

The daily physical activity level (PAL) was measured using a Direct Life triaxial accelerometer for movement registration (TracmorD) (Philips New Wellness Solutions; http://www.directlife.philips.com). The device is a small $(3.2 \times 3.2 \times 0.5 \mathrm{~cm})$, light-weight (12.5 g) instrument. The accelerometer was attached to the lower back by means of an elastic belt. It registered accelerations minute by minute, in the mediolateral (x-axis), 
longitudinal (y-axis) and anterioposterior (z-axis) direction of the trunk as described elsewhere (30). Subjects were instructed to wear the accelerometer for 7 consecutive days, during waking hours except during water activities. Subjects were advised to maintain their habitual physical activity level and not to perform any strenuous physical activity during the diet intervention. TracmorD output was expressed as activity counts/minute. The TracmorD activity counts/minute were summed over the entire monitoring period and divided by the number of monitoring days to determine the average TracmorD counts per day (counts/d). Daily PAL was calculated based on the activity counts/d with the formula, PAL $=1.354+256 \times 10^{-9} \times$ counts/d (30). Daily total energy expenditure was calculated with the formula of Bonomi et al., TEE accelerometer $=$ $0.04+0.17 \mathrm{FFM}+1.67 \times 10^{-6} \times$ counts/d (30) by including activity counts/d (from the accelerometer) and fat-free mass (FFM, from the body composition measurement).

\section{Energy intake}

The weight maintenance diet to be consumed at home for 3 days before the baseline measurement was calculated on the basis of TEE. TEE was calculated by the formula of Bonomi et al. (30) as described above. The macronutrients distribution of the diet prior to baseline measurement was $30 \%$ fat, $55 \%$ carbohydrate and $15 \%$ protein.

The overfeeding with a high fat diet was prepared with $50 \%$ excess energy above the requirement (31). The macronutrients composition of the high fat diet was $60 \%$ fat, $25 \%$ carbohydrate and $15 \%$ protein $(24,32)$. Fatty acids composition of the diet was $40 \%$ saturated fatty acids and $60 \%$ unsaturated fatty acids.

A written instruction was given to prepare the diet at home. During the weight maintenance, subjects were provided with the diet in an excess amount than TEE and were allowed to eat more or less from the diet prescribed, according to what they needed (ad libitum). Any additional intake from those prescribed foods was recorded. All unfinished foods were collected and returned to the university, to calculate actual energy 


\section{CHAPTER 4}

intake. During the overfeeding period, subjects were asked to finish all the foods prescribed, but otherwise noted down and returned the unfinished foods. The diet consisted of normal ready-to-eat foods combining a typical Western and Asian diet. Foods were selected by reviewing the ingredients content to ensure there was no/limited effect of certain ingredients on fat oxidation (such as spices). During the high fat diet period, subjects were also provided with decaffeinated coffee and fruit tea, as caffeine was also reported to increase fat oxidation. Alcohol intake was limited during the diet intervention (only one serving per day if needed) and was not allowed within 2 days prior to the liver fat measurement.

\section{Abdominal fat measurement}

Fat in the abdominal compartment was measured using a 3.0 Tesla MRI scanner (Achieva, Philips Healthcare, Best, The Netherlands) with a body coil. A single MRI slice on the umbilical level (33) was acquired using an axial T1 weighted spin-echo sequence in breath hold with following parameters: echo time of $15 \mathrm{~ms}$, repetition time of $500 \mathrm{~ms}$, matrix size of $180 \times 96$ and slice thickness of $8 \mathrm{~mm}$. Analysis of the abdominal MR images was performed using OsiriX DICOM viewer software. A threshold value was chosen for separation of lean and adipose tissue. Manual segmentation by the region-growing tool was used to segment the area of total abdominal fat (TAT) and region of interest (ROI) borderline for subcutaneous abdominal fat (SAT), whereas visceral fat (VAT) was calculated by subtracting SAT from TAT.

\section{Hepatic lipid content}

Lipid accumulation in the liver was measured before and after overfeeding with a high fat diet. All measurements were performed on a 3.0 T Philips Achieva scanner (Philips Healthcare, Best, The Netherlands) using a SENSE-cardiac coil (34). A single voxel of $20 \mathrm{x}$ $20 \times 20 \mathrm{~mm}^{3}$ was positioned in the right liver lobe, avoiding large biliary or vascular 
structures (34). Spectra were acquired using a point-resolved spectroscopy sequence PRESS (34) with repetition time of $4000 \mathrm{~ms}$, echo time of $33 \mathrm{~ms}$, and number of averages of 64 . To minimize the motion artifacts, subjects were asked to breathe in the rhythm of the measurement and to be at end-expiration during acquisition of spectra (35). To determine the intensity of the lipid peak, the water signal was suppressed using frequency-selective prepulses. The unsuppressed water resonance was used as internal reference (number of averages $=16$ ). The spectra were fitted with AMARES (36) in the jMRUI software (37). Values are given as T2-corrected ratios of the $\mathrm{CH}_{2}$ peak, relative to the unsuppressed water resonance (as percentage) according to Hamilton et al. (38)

\section{Statistical analysis}

Data are presented as means and SDs. Data were first tested for normal distribution by using normality test Kolmogorov-Smirnov and Shapiro-Wilk. When normality was met, statistical comparison of the subjects' baseline characteristics and body fat distribution between ethnic groups was performed using independent sample t-test. Non-normally distributed data were compared using the non-parametric Mann-Whitney $U$ test. Repeated-measures ANOVA were performed to compare differences in the changes in liver fat accumulation before and after overfeeding with a high fat diet within and between ethnic groups. ANCOVA analysis and multiple regression analysis were applied to assess the main effect of ethnicity on parameters of interests by including potential covariates (determinants). The SPSS program version 20 (SPSS, Chicago, IL) was used for statistical analysis, and statistical significance was set as $p<0.05$.

\section{RESULTS}

\section{Subject characteristics}

South Asian subjects were Indian $(n=8)$ and Pakistani $(n=2)$. Caucasian subjects were Dutch $(n=3)$, Germans $(n=2)$, French $(n=1)$, British $(n=1)$, Danish $(n=1)$, Polish $(n=1)$ 


\section{CHAPTER 4}

and Icelander $(n=1)$. South Asians were measured within 3 y of their stay in The Netherlands $(n=5)$ and within 1 y $(n=5)$. Subjects' characteristics are presented in Table 4.1. South Asian subjects were slightly older than Caucasians and had a significantly lower BMI $(P=0.04)$, but there was no difference in body fat percentage $(P=0.58)$. As consistently reported by many studies, South Asian men had a lower fat-free mass $(P=$ 0.001) compared to Caucasian men, and a lower fat-free mass per square meter of height $\left(17 \mathrm{~kg} / \mathrm{m}^{2}\right.$ versus $\left.20 \mathrm{~kg} / \mathrm{m}^{2}\right)$.

Waist and hip circumference were higher in Caucasians than South Asians, resulting in no difference in waist to hip ratio between ethnicities $(P=0.32)$. There was no difference in cardio-respiratory fitness corrected for fat-free mass between ethnicities $(P=0.15)$ and nor was physical activity $(P=0.68)$.

\section{Body fat distribution}

Body fat distribution of South Asian and Caucasian men are presented in Table 4.2. Caucasian men had a slightly higher absolute fat mass and fat mass per square meter of height but this was not significantly different $(P=0.85$ and $P=0.65$ respectively). Body composition of our two populations was further characterized, by calculating the fat mass to fat-free mass ratio (39). In our study, the matching procedure in body fat percentage resulted in no difference in the fat mass to fat-free mass ratio $(P=0.63)$.

Abdominal obesity as shown by total abdominal fat area (TAT) and subcutaneous abdominal fat area (SAT) was slightly higher in Caucasians, whereas visceral fat area (VAT) was slightly higher in South Asians but did not reach statistical significance $(P=0.37, P$ $=0.18$ and $\mathrm{P}=0.32$ respectively). This may be due to the larger variation in the Caucasian group. However, as a percentage of the total abdominal fat area, VAT was higher in South Asians $(P=0.003)$ and so was the VAT to SAT ratio $(P=0.003)$.

The abdominal fat scan was performed at the umbilical, except in one subject of the South Asian group, in this subject abdominal fat scan was performed at the sagital lumbar 
spine L3/L4 instead of the umbilical. Excluding this subject did not change the resulting $P$ values for TAT, SAT, VAT, percentage VAT and VAT/SAT ratio $(0.36 ; 0.18 ; 0.36 ; 0.004$ and 0.004 respectively).

Fat in the extremities measured as biceps and triceps skinfold did not differ between ethnicities $(P=0.91$ and $P=0.19$ respectively). Truncal fat measured as subscapular skinfold was not different between groups $(P=0.36)$ nor was the suprailliac skinfold $(P=$ $0.69)$.

Table 4.1. Subjects' characteristics ${ }^{a}$

\begin{tabular}{|c|c|c|c|}
\hline Characteristics & South Asian & Caucasian & $P$ \\
\hline $\mathrm{N}$ & 10 & 10 & - \\
\hline $\operatorname{Age}^{b}(y)$ & $27 \pm 2$ & $24 \pm 2$ & 0.001 \\
\hline Body weight (kg) & $68.9 \pm 7.4$ & $88.3 \pm 18.1$ & 0.009 \\
\hline BMI $\left(\mathrm{kg} / \mathrm{m}^{2}\right)$ & $23.3 \pm 3.0$ & $27.0 \pm 4.2$ & 0.04 \\
\hline Fat mass (\%) & $25.5 \pm 6.4$ & $23.7 \pm 7.5$ & 0.58 \\
\hline Fat-free mass (kg) & $51.0 \pm 3.7$ & $66.5 \pm 8.5$ & 0.001 \\
\hline Waist circumference $(\mathrm{cm})$ & $85.9 \pm 7.7$ & $96.0 \pm 12.0$ & 0.05 \\
\hline Hip circumference (cm) & $97.0 \pm 5.5$ & $105.4 \pm 8.7$ & 0.03 \\
\hline Waist to hip ratio & $0.9 \pm 0.04$ & $0.91 \pm 0.06$ & 0.32 \\
\hline $\mathrm{VO}_{2}$ max corrected for $\mathrm{FFM}^{c}(\mathrm{ml} \mathrm{O} / \mathrm{min})$ & $2780 \pm 265$ & $3249 \pm 152$ & 0.15 \\
\hline Physical activity accelerometer ${ }^{b}\left(10^{3}\right.$ counts/d) & $1123 \pm 239$ & $1304 \pm 442$ & 0.68 \\
\hline
\end{tabular}




\section{CHAPTER 4}

Table 4.2. Body fat distribution ${ }^{a, b}$

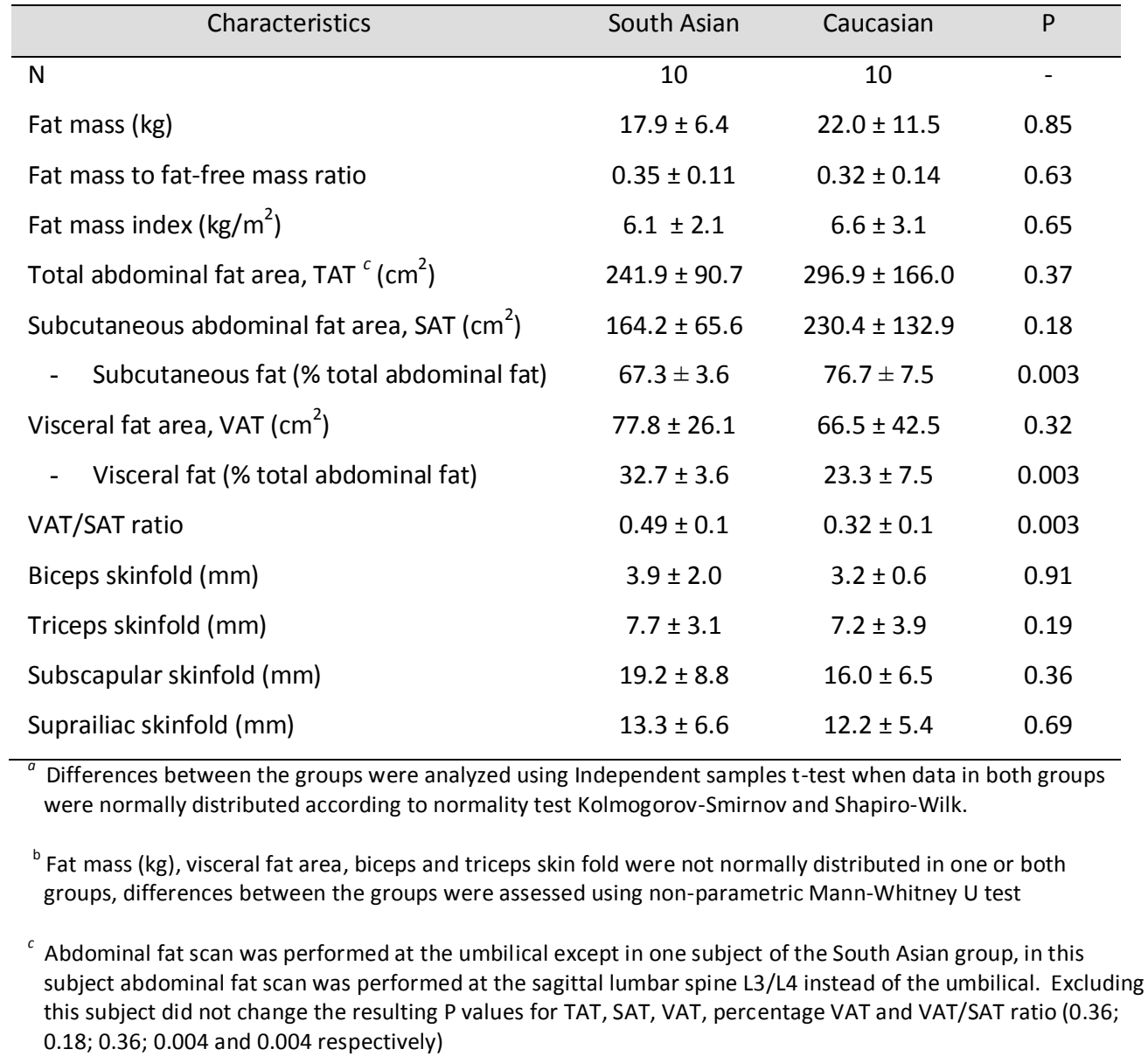

\section{Diet composition and compliance}

There was no difference in the compliance to the diet. Energy intake, as percentage overfeeding achieved, was $43 \%$ and $52 \%$ exceeding the requirement $(P=0.16)$ for South Asians and Caucasians respectively. Macronutrients composition of the actual energy intake during overfeeding was similar; with carbohydrate $(26.2 \%$ versus $26.4 \%, P=0.85)$, 
protein $(14.6 \%$ versus $14.9 \%, P=0.20)$ and fat $(59.3 \%$ versus $58.8 \%, P=0.53)$ for South Asians and Caucasians respectively. There was no difference in the proportion of saturated and unsaturated fatty acids in the $\operatorname{diet}(P=0.49)$.

\section{Hepatic fat content}

Liver fat content before and after short-term overfeeding with a high fat diet is shown in Figure 4.1. Data were available for 8 South Asians and 8 Caucasians matched for body fat percentage $(P=0.53)$. In the South Asian group, one had to be excluded because of poor signal to noise ratio in the spectra. In the Caucasian group, one subject could not undergo the measurement due to a technical problem. Therefore, these subjects were excluded from the analysis along with their body fat matched counterparts in the other group respectively.

Liver fat content at baseline did not differ between ethnicities $(P=0.48)$. Overfeeding with a high fat diet significantly increased liver fat content $(P=0.01)$ but the increase did not differ between ethnicities $(P=0.47)$. The mean increase was $33 \%$ and $34 \%$ for South Asians and Caucasians respectively.

We assessed the association between liver fat at baseline and body fat percentage, it turned out that liver fat at baseline was positively associated with body fat percentage $\left(R^{2}\right.$ $=0.44, P=0.03$, Figure 4.2a). Furthermore, we assessed the effect of ethnicity on the baseline liver fat content with body fat percentage as a covariate (ANCOVA analysis) and found that baseline liver fat content was associated with body fat percentage $(P=0.02)$ but not with ethnicity $(P=0.21)$. We assessed the association between liver fat at baseline with visceral fat area, and found that liver fat at baseline had a stronger association with visceral fat area $\left(R^{2}=0.62, P=0.003\right.$, Figure $\left.4.2 b\right)$.

In a multiple regression analysis by including ethnicity in the model, visceral fat area was found to be the significant predictor of liver fat content at baseline $\left(P=0.002, R^{2}=\right.$ $0.56)$ and not ethnicity $(P=0.13)$. There was an outlier in Figure $4.2 \mathrm{a}$ and Figure $4.2 \mathrm{~b}$. 


\section{CHAPTER 4}

Excluding the outlier did not change the significant association between body fat percentage and liver fat content in Figure 4.2a $\left(R^{2}=0.36, P=0.018\right)$ and the significant association between visceral fat area and liver fat content in Figure 4.2b $\left(R^{2}=0.76, P=\right.$ 0.001).

a.

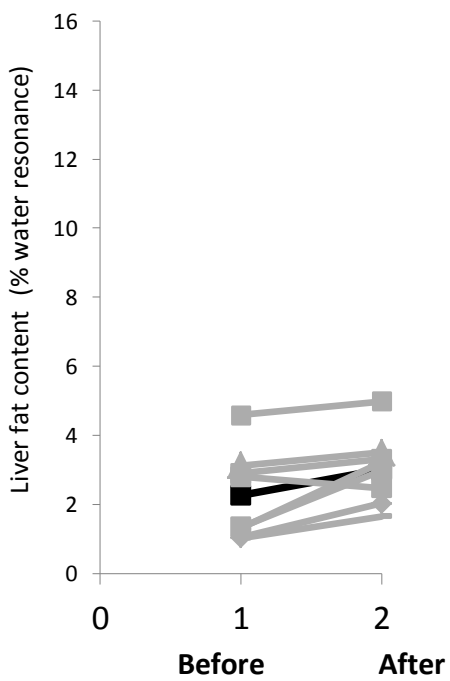

b.

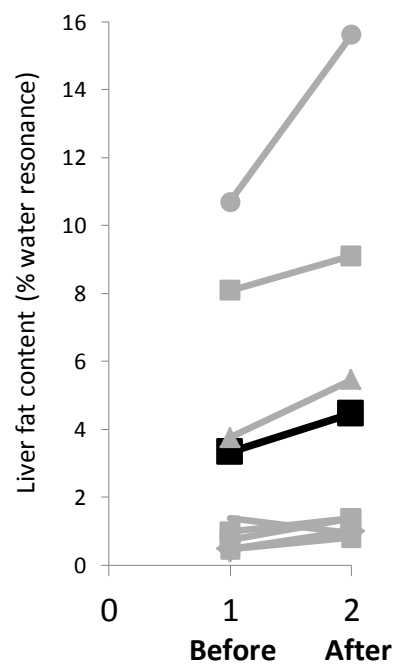

Figure 4.1. Individual (grey line) and the mean (black line) response of liver fat content to overfeeding with a high fat diet in South Asians (a) and Caucasians (b). Liver fat content before and after overfeeding with a high fat diet were assessed using repeated-measures ANOVA. Data were available from eight South Asians and eight Caucasians matched for body fat percentage $(25.0 \pm 5.4 \%$ and $23.2 \pm 6.3 \%$ for South Asian and Caucasian respectively, $P=0.53)$. Overfeeding with a high fat diet increased liver fat content $(P=0.01)$ but the increase did not differ between ethnicities ( $P=0.47)$. SA: South Asian, C: Caucasian. 
a.

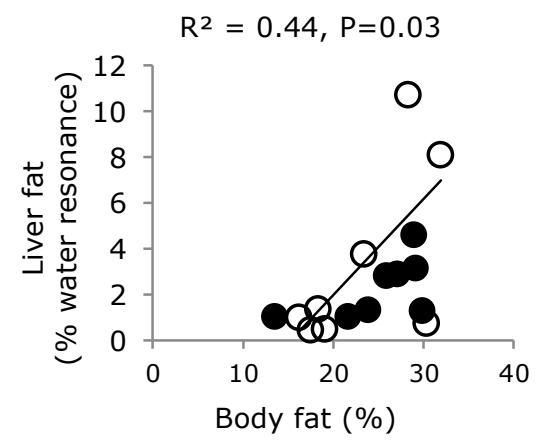

- South Asian o Caucasian b. $R^{2}=0.62, P=0.003$

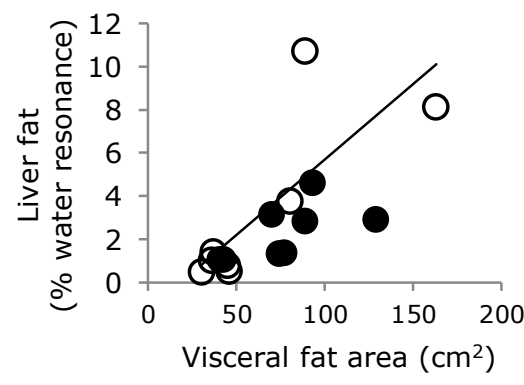

- South Asian o Caucasian

Figure 4.2. The association between liver fat at baseline with body fat percentage (a) and the association between liver fat at baseline with visceral fat area (b). Liver fat at baseline was associated with body fat percentage $\left(R^{2}=0.44, P=0.03\right)$. Liver fat at baseline had a stronger association with visceral fat area $\left(R^{2}=\right.$ $0.62, P=0.003)$. In a multiple regression analysis, visceral fat area was the significant predictor of baseline liver fat $\left(R^{2}=0.56, P=0.002\right)$ and no effect of ethnicity was found $(P=0.13)$. Excluding the outlier did not change the significant association between body fat percentage and baseline liver fat content in Figure 4.2a $\left(R^{2}=0.36, P=0.018\right)$ and did not change the signifiacnt association between visceral fat area and liver fat content in Figure $4.2 b\left(R^{2}=0.76, P=0.001\right)$.

\section{DISCUSSION}

We found that South Asian and Caucasian men with the same body fat percentage (not the same BMI) showed no difference in the baseline liver fat content. Furthermore, visceral fat area was found to be the significant predictor of liver fat content at baseline. Liver fat content increased similarly in both groups in response to short term overfeeding with a high fat diet.

Earlier cross-sectional studies reported higher liver fat content in South Asians when compared to BMI-matched Caucasians (15), suggesting a higher susceptibility to ectopic fat storage in Asians. It is known that, due to differences in body composition, matching 


\section{CHAPTER 4}

for BMI will result in a higher body fat percentage in the Asian group, which may be a confounding factor. Therefore, in the current study, we chose to match subjects with respect to whole body fat percentage, as determined by a three-compartment model. When these groups, with similar body fat percentage, were compared, hepatic lipid content was similar, and in both groups, body fat percentage and the absolute amount of visceral adipose tissue area (which was also similar between groups) are predictive for baseline liver fat content. This is in line with earlier studies, where visceral fat has been reported to be associated with liver fat content in Caucasian populations $(18,40,41)$ as well as a South Asian population (15).

It was also reported that South Asians might be more susceptible to the negative metabolic effects of high-fat high-caloric diets. Also here, the difference in body fat percentage between Asians and Caucasians (when matched for BMI) may have played a role. To investigate whether Asians still have higher susceptibility to a high energy, highfat diet, when controlled for body fat percentage, we investigated hepatic fat storage after overfeeding with a high fat diet for 4 days in groups matched for body fat percentage. We expected to create a massive positive energy balance that favors fat accumulation rather than fat oxidation.

Earlier studies already showed that high fat diets can increase liver fat content in a relatively short period of time. A dietary intervention with an isocaloric high fat diet $(21,23)$ resulted in an increase in liver fat content by $35 \%$ after 2 weeks in obese Caucasian women (23) and by $17 \%$ after 3 weeks in overweight Caucasian men (21). In the latter study, fat accumulation was observed after one week with no further increase in the following weeks, suggesting an adaptation (21). This is also in accordance with a study in healthy male Caucasians by van der Meer et al. (22) showing that a 2-3 fold increase in liver fat content had already occurred after 3 days consumption of supplemental cream (800 ml, $280 \mathrm{~g}$ fat) added to the regular diet. Here, we conducted a short-term intervention with a high fat diet ( 4 days), by overfeeding subjects with $50 \%$ energy above 
the individual requirements and $60 \%$ of energy from fat. The mean increase in liver fat content was $33 \%$ and $34 \%$ in South Asians and Caucasians respectively. Thus in South Asian and Caucasian men with the same body fat percentage, and similar liver fat content at baseline, the increase in liver fat in response to short-term overfeeding with a high fat diet was similar. The inter-individual variability in the baseline liver fat is rather high, especially in the Caucasian group and is partially explained by the range of body fat percentage included (range from $17 \%$ to $31 \%$, see also figure 4.1 ). The increase in liver fat content is modest but very consistent and highly significant. The inter-individual variability in the percentage changes in liver fat content is higher than differences between ethnicities. Therefore, when carefully matched for body fat percentage (rather than BMI) we find no indication of South Asian subjects being more susceptible to overfeeding.

In a study with very similar set-up, we found insulin levels to be increased in both Asians and Caucasians (42), which may be favoring hepatic fat storage and therefore underlie the present findings. During overfeeding, the postprandial state, including high insulin levels, is slightly extended as a result of extended meal consumption (42). Insulin was also reported to suppress hepatic lipid oxidation (43) and to promote the synthesis and storage of triglycerides in the liver (44).

Interestingly, even though absolute amount of visceral adipose tissue was similar between the two groups, it is striking that due to smaller body size in Asians, the visceral adipose tissue depot represents a higher percentage of total abdominal adipose tissue. It was hypothesized that the high prevalence of metabolic diseases in South Asians might be attributed to a smaller subcutaneous adipose tissue compartment and a relatively enlarged VAT. As obesity develops, South Asians could exceed the storage capacity of subcutaneous adipose tissue before Caucasians do and develop metabolic complications (16). Our data confirm that in the abdominal region, South Asians have a relatively enlarged VAT and a relatively smaller subcutaneous adipose tissue compartment. Lear et al. (45) reported that throughout a range of total body fat mass, South Asians had less VAT 


\section{CHAPTER 4}

with total body fat $>37.4 \mathrm{~kg}$, but more VAT when total body fat was below $37.4 \mathrm{~kg}$ than did Europeans, after adjusted for age, sex and household income. In our study, South Asian men had a range of absolute fat mass between 7-29 kg and thus the relatively higher VAT was consistent with a previous study (45). However, our data showed that despite a relatively higher percentage of VAT area in South Asians, liver fat content at baseline did not differ between ethnicities and also the response to overfeeding was very similar in the two groups.

The limitation of our study is that we induced exposure to excess FFA from the diet in a short-term period, thus it cannot elucidate the differences, which may be observed in a longer period. Additionally, the low number of subjects may not represent the general population in South Asian and Caucasian and only young men were investigated. Although we matched the subjects for body fat percentage, we found variation in the baseline liver fat content and the variation was larger in Caucasian group which was not ideal. Taken into account the limitation, this was a well-controlled dietary intervention study using state of the art techniques to investigate liver fat content and body composition in response to overfeeding and no such studies have been performed comparing two ethnicities.

\section{CONCLUSIONS}

In summary, when groups are matched for body fat percentage, no differences in liver fat were found at baseline between South Asians and Caucasians and both groups showed a similar increase in hepatic lipid content in response to a hypercaloric, high-fat diet. This suggests that differences between ethnicities that were reported so far, may (at least partially) be ascribed to differences in body fat percentage.

Future studies to assess the response of different ethnicities to dietary intervention may be approached by matching body fat percentage within a closer range, by including only lean or only overweight subjects, to avoid large inter-individual variation. 


\section{ABBREVIATIONS}

BMI: body mass index; FFA: free-fatty acids; FFM: fat-free mass; FM: fat mass; IMCL: intramyocellular lipid; $1 \mathrm{H}-\mathrm{MRS}$ : proton-magnetic resonance spectroscopy; MRI: magnetic resonance imaging; PAL: physical activity level; SAT: subcutaneous abdominal adipose tissue; TAT: total abdominal adipose tissue; TEE: total energy expenditure; VAT: visceral adipose tissue.

\section{ACKNOWLEDGEMENTS}

The present work was funded by the grant from the scholarship from The Directorate General of Higher Education, The Ministry of Education and Culture (former Ministry of Research, Technology and Higher Education) of The Republic of Indonesia to SNW. In addition, VBS-H was supported by a veni grant (91611136) for innovative research from the Netherlands Organization for Scientific Research.

We gratefully thank Loek Wouters, Paul Schoffelen, for technical assistance and help with the analysis. We thank H. Schoenmakers, R. Kersemakers and the technicians of the MRI Unit, Academic Hospital Maastricht. Also, we deeply appreciate and thank all subjects who participated in the study.

The authors' contributions were as follows-SNW: conducted the research, performed the data analysis, and wrote the manuscript under the supervision of KRW, VBS-H and GP who designed the study, interpreted the data, and reviewed the manuscript. All authors read and approved the final manuscript.

The authors declare that they have no competing interests in relation to the present study. 


\section{CHAPTER 4}

\section{REFERENCES}

1. Popkin BM (2006) Global nutrition dynamics: the world is shifting rapidly toward a diet linked with noncommunicable diseases. Am J Clin Nutr 84, 289-298.

2. Subramanian SV, Perkins JM, Ozaltin E, Davey Smith G (2011) Weight of nations: a socioeconomic analysis of women in low- to middle-income countries. Am J Clin Nutr 93, 413-421.

3. Kelly T, Yang W, Chen CS, Reynolds K, He J (2008) Global burden of obesity in 2005 and projections to 2030. Int J Obes (Lond) 32, 1431-1437.

4. Wulan SN, Westerterp KR, Plasqui G (2012) Dietary and 24-h fat oxidation in Asians and whites who differ in body composition. Am J Clin Nutr 95, 1335-1341.

5. Forouhi NG, Jenkinson G, Thomas EL, Mullick S, Mierisova S, Bhonsle U et al. (1999) Relation of triglyceride stores in skeletal muscle cells to central obesity and insulin sensitivity in European and South Asian men. Diabetologia 42, 932-935.

6. Deurenberg P, Deurenberg-Yap M (2001) Differences in body-composition assumptions across ethnic groups: practical consequences. Curr Opin Clin Nutr Metab Care 4, 377-383.

7. Deurenberg P, Deurenberg-Yap M (2003) Validity of body composition methods across ethnic population groups. Forum Nutr 56, 299-301.

8. Deurenberg P, Deurenberg-Yap M, Guricci S (2002) Asians are different from Caucasians and from each other in their body mass index/body fat per cent relationship. Obes Rev 3, 141-146.

9. Chang CJ, Wu CH, Chang CS, Yao WJ, Yang YC, Wu JS et al. (2003) Low body mass index but high percent body fat in Taiwanese subjects: implications of obesity cutoffs. Int J Obes Relat Metab Disord 27, 253-259.

10. Rush EC, Goedecke JH, Jennings C, Micklesfield L, Dugas L, Lambert EV et al. (2007) BMI, fat and muscle differences in urban women of five ethnicities from two countries. Int J Obes (Lond) 31, 1232-1239.

11. Rush EC, Freitas I, Plank LD (2009) Body size, body composition and fat distribution: comparative analysis of European, Maori, Pacific Island and Asian Indian adults. Br J Nutr 102, 632-641.

12. Sampei MA, Novo NF, Juliano Y, Sigulem DM (2008) Anthropometry and body composition in ethnic Japanese and Caucasian adolescent boys. Pediatr Int 50, 679-686.

13. Hull HR, Thornton J, Wang J, Pierson RN, Jr., Kaleem Z, Pi-Sunyer X et al. (2010) Fat-free mass index: changes and race/ethnic differences in adulthood. Int J Obes (Lond).35,121-127

14. Deurenberg-Yap M, Schmidt G, van Staveren WA, Hautvast JG, Deurenberg P (2001) Body fat measurement among Singaporean Chinese, Malays and Indians: a comparative study using a four-compartment model and different two-compartment models. Br J Nutr 85, 491-498.

15. Anand SS, Tarnopolsky MA, Rashid S, Schulze KM, Desai D, Mente A et al. (2011) Adipocyte hypertrophy, fatty liver and metabolic risk factors in South Asians: the Molecular Study of Health and Risk in Ethnic Groups (mol-SHARE). PLoS One 6, e22112.

16. Sniderman AD, Bhopal R, Prabhakaran D, Sarrafzadegan N, Tchernof A (2007) Why might South Asians be so susceptible to central obesity and its atherogenic consequences? The adipose tissue overflow hypothesis. Int J Epidemiol 36, 220-225.

17. Korenblat KM, Fabbrini E, Mohammed BS, Klein S (2008) Liver, muscle, and adipose tissue insulin action is directly related to intrahepatic triglyceride content in obese subjects. Gastroenterology 134, 1369-1375.

18. Fabbrini E, Magkos F, Mohammed BS, Pietka T, Abumrad NA, Patterson BW et al. (2009) Intrahepatic fat, not visceral fat, is linked with metabolic complications of obesity. Proc Natl Acad Sci U S A 106, 15430-15435.

19. Wulan SN, Westerterp KR, Plasqui G (2010) Ethnic differences in body composition and the associated metabolic profile: a comparative study between Asians and Caucasians. Maturitas 65, 315-319.

20. Popkin BM (2001) The nutrition transition and obesity in the developing world. J Nutr 131, 871S-873S.

21. van Herpen NA, Schrauwen-Hinderling VB, Schaart G, Mensink RP, Schrauwen P (2011) Three weeks on a high-fat diet increases intrahepatic lipid accumulation and decreases metabolic flexibility in healthy overweight men. J Clin Endocrinol Metab 96, E691-695. 
22. van der Meer RW, Hammer S, Lamb HJ, Frolich M, Diamant M, Rijzewijk LJ et al. (2008) Effects of short-term high-fat, high-energy diet on hepatic and myocardial triglyceride content in healthy men. J Clin Endocrinol Metab 93, 2702-2708.

23. Westerbacka J, Lammi K, Hakkinen AM, Rissanen A, Salminen I, Aro A et al. (2005) Dietary fat content modifies liver fat in overweight nondiabetic subjects. J Clin Endocrinol Metab 90, 2804-2809.

24. Schrauwen-Hinderling VB, Kooi ME, Hesselink MK, Moonen-Kornips E, Schaart G, Mustard KJ et al. (2005) Intramyocellular lipid content and molecular adaptations in response to a 1-week high-fat diet. Obes Res 13, 2088-2094.

25. Westerterp KR, Wouters L, van Marken Lichtenbelt WD (1995) The Maastricht protocol for the measurement of body composition and energy expenditure with labeled water. Obes Res 3 Suppl 1, 49-57.

26. Siri WE (1993) Body composition from fluid spaces and density: analysis of methods. 1961. Nutrition 9, 480491; discussion 480, 492.

27. Wang Y, Rimm EB, Stampfer MJ, Willett WC, Hu FB (2005) Comparison of abdominal adiposity and overall obesity in predicting risk of type 2 diabetes among men. Am J Clin Nutr 81, 555-563.

28. Greenberg JA (2001) Biases in the mortality risk versus body mass index relationship in the NHANES-1 Epidemiologic Follow-Up Study. Int J Obes Relat Metab Disord 25, 1071-1078.

29. Kuipers H, Keizer HA, Verstappen FT, Costill DL (1985) Influence of a prostaglandin-inhibiting drug on muscle soreness after eccentric work. Int J Sports Med 6, 336-339.

30. Bonomi AG, Plasqui G, Goris AH, Westerterp KR (2010) Estimation of free-living energy expenditure using a novel activity monitor designed to minimize obtrusiveness. Obesity (Silver Spring) 18, 1845-1851.

31. Joosen AM, Bakker AH, Zorenc AH, Kersten S, Schrauwen P, Westerterp KR (2006) PPARgamma activity in subcutaneous abdominal fat tissue and fat mass gain during short-term overfeeding. Int J Obes (Lond) 30 , 302-307.

32. Schrauwen P, van Marken Lichtenbelt WD, Saris WH, Westerterp KR (1997) Changes in fat oxidation in response to a high-fat diet. Am J Clin Nutr 66, 276-282.

33. Schwenzer NF, Machann J, Schraml C, Springer F, Ludescher B, Stefan N et al. (2010) Quantitative analysis of adipose tissue in single transverse slices for estimation of volumes of relevant fat tissue compartments: a study in a large cohort of subjects at risk for type 2 diabetes by MRI with comparison to anthropometric data. Invest Radiol 45, 788-794.

34. van Werven JR, Hoogduin JM, Nederveen AJ, van Vliet AA, Wajs E, Vandenberk P et al. (2009) Reproducibility of 3.0 Tesla magnetic resonance spectroscopy for measuring hepatic fat content. J Magn Reson Imaging 30, 444-448.

35. Timmers S, Konings E, Bilet L, Houtkooper RH, van de Weijer T, Goossens GH et al. (2011) Calorie restrictionlike effects of 30 days of resveratrol supplementation on energy metabolism and metabolic profile in obese humans. Cell Metab 14, 612-622.

36. Vanhamme L, van den Boogaart A, Van Huffel S (1997) Improved method for accurate and efficient quantification of MRS data with use of prior knowledge. J Magn Reson 129, 35-43.

37. Naressi A, Couturier C, Devos JM, Janssen M, Mangeat C, de Beer R et al. (2001) Java-based graphical user interface for the MRUI quantitation package. MAGMA 12, 141-152.

38. Hamilton G, Yokoo T, Bydder M, Cruite I, Schroeder ME, Sirlin CB et al. (2011) In vivo characterization of the liver fat (1)H MR spectrum. NMR Biomed 24, 784-790.

39. 39. Lear SA, Kohli S, Bondy GP, Tchernof A, Sniderman AD (2009) Ethnic variation in fat and lean body mass and the association with insulin resistance. J Clin Endocrinol Metab 94, 4696-4702.

40. Ducluzeau PH, Manchec-Poilblanc P, Roullier V, Cesbron E, Lebigot J, Bertrais S et al. (2010) Distribution of abdominal adipose tissue as a predictor of hepatic steatosis assessed by MRI. Clin Radiol 65, 695-700.

41. Chan DC, Watts GF, Ng TW, Hua J, Song S, Barrett PH (2006) Measurement of liver fat by magnetic resonance imaging: Relationships with body fat distribution, insulin sensitivity and plasma lipids in healthy men. Diabetes Obes Metab 8, 698-702.

42. Wulan SN, Westerterp KR, Plasqui G (2014) Metabolic profile before and after short-term overfeeding with a high-fat diet: a comparison between South Asian and White men. BrJ Nutr 111: 1853-1861. 


\section{CHAPTER 4}

43. Kotronen A, Seppala-Lindroos A, Vehkavaara S, Bergholm R, Frayn KN, Fielding BA et al. (2009) Liver fat and lipid oxidation in humans. Liver Int 29, 1439-1446.

44. Sparks JD, Sparks CE (1990) Insulin modulation of hepatic synthesis and secretion of apolipoprotein B by rat hepatocytes. J Biol Chem 265, 8854-8862.

45. Lear SA, Humphries KH, Kohli S, Chockalingam A, Frohlich JJ, Birmingham CL (2007) Visceral adipose tissue accumulation differs according to ethnic background: results of the Multicultural Community Health Assessment Trial (M-CHAT). Am J Clin Nutr 86, 353-359. 


\section{CHAPTER 5}

Metabolic profile before and after short-term overfeeding with a high-fat diet: a comparison between South Asian and white men

Siti N. Wulan, Klaas R. Westerterp and Guy Plasqui Br J Nutr (2014), $111: 1853-1861$ 


\section{CHAPTER 5}

\section{ABSTRACT}

Background: For the same BMI, South Asians have a higher body fat percentage and an adverse metabolic profile compared with whites.

Objective: The objective of the present study was to determine the metabolic profiles of South Asian and white men matched for body fat percentage, in response to short-term overfeeding with a high-fat diet.

Methods: A total of ten healthy non-diabetic South Asian men matched for body fat percentage with ten white men were included in the study. A weight-maintenance diet (containing $30 \%$ fat, $55 \%$ carbohydrate and $15 \%$ protein) was provided for $3 \mathrm{~d}$ followed by $4 \mathrm{~d}$ of overfeeding ( $150 \%$ energy requirement) with a high fat diet (60\% fat, $25 \%$ carbohydrate, and $15 \%$ protein). Before and after the overfeeding period, plasma glucose, insulin, TAG, NEFA, total cholesterol and HDL-cholesterol concentrations were determined. Glucose clearance was calculated using a $2 \mathrm{~h}$ oral glucose tolerance test.

Results: In South Asian and white men, respectively, overfeeding with a high fat diet decreased plasma TAG concentrations by $0.4 \pm 0.6$ and $0.4 \pm 0.5 \mathrm{mmol} / \mathrm{l}\left(\mathrm{P}_{\text {diet }}=0.008\right.$; $\left.P_{\text {ethnicity }}=0.24\right)$, increased $\mathrm{HDL}$-cholesterol concentrations by $0.12 \pm 0.1$ and $0.14 \pm 0.2$ $\mathrm{mmol} / \mathrm{I}\left(\mathrm{P}_{\text {diet }}=0.001 ; \mathrm{P}_{\text {ethnicity }}=0.06\right)$ and decreased glucose clearance by $48.8 \pm 53.5$ and $37.2 \pm 34.2 \mathrm{ml} / \mathrm{min}$ per $\mathrm{m}^{2}$ body surface $\left(P_{\text {diet }}=0.004 ; P_{\text {ethnicity }}=0.18\right)$. There was a significant interaction between diet and ethnicity with regard to the changes in total and LDL-cholesterol concentrations ( $P=0.01$ and $P=0.007$, respectively), which trended towards a larger increase in South Asian subjects than white subjects.

Conclusion: Despite a similar body fat percentage, short-term overfeeding with a high fat diet had more adverse effects on the lipid profile of South Asians than that of whites. 


\section{INTRODUCTION}

The prevalence of energy imbalance and related obesity is rapidly increasing worldwide, including in a number of Asian countries (1-3). This is linked to an increase in the prevalence of non-communicable diseases such as diabetes, CVD and hypertension (1). It is estimated that 300 million people will have diabetes by the year 2025 and that among them more than 100 million people live in Asia (4). However, diabetes in Asia has developed in a shorter time (3-5 fold increase within 30 years), in a younger age group (45-64 years old), and in people with a lower BMI compared with that in Western countries (5).

Compared with whites with the same BMI and of the same age and sex, Asians have been found to have a higher body fat percentage and a lower fat-free mass (FFM)/appendicular skeletal muscle mass, as has been reported recently by us (6) and by others (7-13). Among Asians, South Asians (people from the Indian sub-continent) have the most pronounced difference in body fat compared with whites (14). Metabolic consequences, as revealed by the prevalence of the metabolic syndrome, are also greater than those in other Asian countries (4,5). Raji et al. (15) reported that even at normal BMI Asian Indians exhibit clustering of cardiovascular risk factors such as insulin resistance, dyslipidemia and pro-coagulant state.

A strong gene-environmental interaction, which is triggered by lifestyle changes due to modernization, is suggested to be the cause of the rapid increase in the prevalence of diabetes in Asia $(3,16)$. Furthermore, migrant Asian groups have also been reported to have higher susceptibility to adverse environmental influences than co-inhabitants of different races (16). Major dietary changes such as a large increase in the consumption of fats and added sugar in the diet have accelerated in Asia in recent decades(17). Distinct genetic background represented partly by differences in body composition between South Asians and whites may contribute to the differences in metabolic responses when they are exposed to a high-fat diet challenge. It has been shown that a high-fat diet resulted in liver 


\section{CHAPTER 5}

fat accumulation in a short time period (18), leading to metabolic complications (19). In the present study, South Asians and whites were matched for body fat percentage, which is one of the confounding factors affecting metabolic profiles in individuals. The objective was to determine the effect of short-term overfeeding with a high-fat diet on the metabolic profile of South Asian and white men.

\section{SUBJECTS AND METHODS}

\section{Subjects}

A total of ten healthy adult non-diabetic South Asian men and ten white men were included in the study. They were matched for body fat percentage on an individual basis; as a consequence the variation in body fat percentage was comparable between groups. The number of subjects was determined based on a previous study that detected a significant reduction in insulin sensitivity, after an intervention with a high fat diet in ten white subjects (20). Subject characteristics are presented in Table 5.1. Asian subjects had 4 grandparents from South Asia, while white subjects were non-Hispanic Europeans. Subjects were selected based on the following inclusion criteria: healthy; not having metabolic diseases (diabetes or CVD); not using medication; aged between 20 and 40 years with BMI ranging between 18 and $29 \mathrm{~kg} / \mathrm{m}^{2}$ for South Asians and 22 and $33 \mathrm{~kg} / \mathrm{m}^{2}$ for whites; having a stable body weight (as defined by a weight change $<5 \mathrm{~kg}$ ) for the last three months before participating in the study; not being on a diet and not being an athlete. Verbal and written information about the study was given to all subjects before obtaining their consent. Written informed consent was obtained from all subjects. The study was conducted according to the guidelines laid down in the Declaration of Helsinki, and all procedures involving human subjects were approved by the Medical Ethics Committee of Maastricht University Medical Centre, MEC No. 10-3-013, and registered in the public trial registry (www.ccmo.nl No. NL31217.068.10) 


\section{Experimental protocol}

The present study was a dietary intervention study carried out in a free-living condition. Body composition was measured before the start of the dietary intervention to ensure that the body fat percentage of the two ethnic groups matched. Cardiorespiratory fitness (defined as $\mathrm{VO}_{2}$ max corrected for FFM) was measured before the start of the dietary intervention. Daily physical activity levels were measured for seven consecutive days with an accelerometer. Energy requirements of a weight maintenance diet for $3 \mathrm{~d}$ were calculated based on FFM and daily physical activity levels of each subject (see below). The metabolic profiles were determined just before and after overfeeding with a high-fat diet for $4 \mathrm{~d}$. All measurements were carried out at the Metabolic Research Unit Maastricht (MRUM), Maastricht University, Maastricht, The Netherlands.

\section{Determination of body composition}

Body composition was determined according to a three-compartment model based on body weight, body volume and total body water. Body weight and body volume were determined in the morning, in a fasting state. Body volume was determined by hydrodensitometry with simultaneous measurement of residual lung capacity using the helium dilution technique. Total body water was determined using the ${ }^{2} \mathrm{H}$ (deuterium) dilution method according to the Maastricht protocol (21). Body composition was calculated from body density and total body water using the equation of Siri (22).

\section{Assessment of cardiorespiratory fitness}

Physical fitness was assessed with an incremental test on a bicycle ergometer using the protocol of Kuipers et al. (23). During the test, $\mathrm{O}_{2}$-consumption $\left(\mathrm{VO}_{2}\right)$ and $\mathrm{CO}_{2}$-production $\left(\mathrm{VCO}_{2}\right)$ were measured continuously and heart rate was monitored (Polar heart rate monitor; Polar Electro Oy). After 5 min of warm-up at 100 Watt, the workload was increased by $50 \mathrm{~W}$ every $2.5 \mathrm{~min}$. When the heart rate reached a value of $35 \mathrm{beats} / \mathrm{min}$ 


\section{CHAPTER 5}

below the age-predicted maximal heart rate (220 beats/min - age) or the respiratory quotient ( $\mathrm{RQ}=\mathrm{VCO}$ production $/ \mathrm{VO}_{2}$ consumption) exceeded 1 , the workload was increased with $25 \mathrm{~W}$ every 2.5 min until exhaustion. $\mathrm{VO}_{2}$ max was determined by averaging the last few points of maximum $\mathrm{O}_{2}$ consumption. Cardiorespiratory fitness was defined as $\mathrm{VO}_{2}$ max corrected for FFM.

\section{Measurement of daily physical activity levels}

Daily physical activity levels (PAL) was measured using a Direct Life triaxial accelerometer for movement registration (Tracmor-D; Philips NewWellness Solutions; http://www.directlife.philips.com). The device is a small $(3.2 \times 3.2 \times 0.5 \mathrm{~cm})$, lightweight (12.5 g) instrument. The accelerometer was attached to the lower back of the subjects by means of an elastic belt. It registered accelerations minute by minute, in the mediolateral (x-axis), longitudinal (y-axis) and anterioposterior (z-axis) positions of the trunk as described elsewhere(24).

The subjects were instructed to wear the accelerometer for 7 consecutive days during waking hours, except during water activities. The subjects were advised to maintain their habitual physical activity levels during the dietary intervention period. Tracmor-D output was expressed as activity counts/min. To determine the average Tracmor-D counts per day (counts/d), Tracmor-D activity counts/min were summed over the entire monitoring period and divided by the number of monitoring days. Daily PAL were calculated based on the activity counts/d using the following formula (24).

$$
\mathrm{PAL}=1.354+256 \times 10^{-9} \times \text { counts } / \mathrm{d}
$$

Total energy expenditure (TEE) was calculated using the formula of Bonomi et al. (24) by including activity counts/d (from the accelerometer) and fat-free mass (FFM).

$$
\text { TEE accelerometer }=0.04+0.17 \mathrm{FFM}+1.67 \times 10^{-6} \times \text { counts } / \mathrm{d}
$$




\section{Determination of energy intake}

The energy balance (weight maintenance) diet to be consumed at home for $3 \mathrm{~d}$ before the baseline measurement was calculated on the basis of TEE of each subject as calculated above. The macronutrients distribution of the energy balance diet before the baseline measurement was $30 \%$ fat, $55 \%$ carbohydrate and $15 \%$ protein.

The high-fat diet was formulated with $50 \%$ excess energy above the TEE of the balance diet (25). The macronutrients composition of the high-fat diet was $60 \%$ fat, $25 \%$ carbohydrate and $15 \%$ protein $(26,27)$. The fatty acids composition of the diet was $40 \%$ saturated fatty acids and $60 \%$ unsaturated fatty acids.

A written instruction was given to prepare the diet at home. During the balance diet period, subjects were provided with amounts of the diet that exceeded their TEE and were allowed to eat more or less than the amounts prescribed, according to their preference (ad libitum). Any additional intake from the prescribed foods was recorded. All unfinished foods were collected and returned to the university, to calculate actual energy intake. During the overfeeding period, the subjects were asked to completely consume all the foods prescribed, but on failing to do so, to record their intake and return the unfinished foods. The diet consisted of normal ready-to-eat foods combining a typical Western and Asian diet. Foods were selected by reviewing the ingredients content to ensure that there was no (or only a minimal) effect of certain ingredients on fat oxidation (such as spices). During the overfeeding period, the subjects were also provided with decaffeinated coffee and fruit tea, as caffeine has been reported to increase fat oxidation. Alcohol intake was limited during the dietary intervention period (only one serving/d when needed). During the dietary intervention period, the subjects were asked to wear an accelerometer and to maintain their habitual physical activity levels, this allowed us to monitor the energy balance of the subjects during the entire dietary intervention period. 


\section{CHAPTER 5}

\section{Oral glucose tolerance test}

A $2 \mathrm{~h}$ oral glucose tolerance test (OGTT) was carried out before and after overfeeding with a high fat diet. After an overnight fast, the subjects underwent an OGTT test. A fasting blood sample was collected $(t=0)$, after which the subjects drank a glucose solution ( $82.5 \mathrm{~g}$ glucose monohydrate dissolved in $600 \mathrm{ml}$ water) within $5 \mathrm{~min}$ (28). This method is a modification of the American Diabetes Association (ADA) guidelines (29), as it has been reported to improve overall tolerability and have only a minor impact on the intra-subject variation of plasma glucose and insulin responses with no effect on the diagnostically relevant $2 \mathrm{~h}$ endpoint irrespective of the body composition (28). Venous blood samples were collected every $15 \mathrm{~min}$ in the first hour $(\mathrm{t}=15, \mathrm{t}=30, \mathrm{t}=45$ and $\mathrm{t}=$ 60 ) and every $30 \mathrm{~min}$ in the second hour ( $t=90$ and $t=120$ ). Plasma glucose concentrations were measured to determine glucose tolerance according to the ADA criteria (30).

Venous plasma glucose and insulin concentrations determined during the OGTT were used to assess pancreatic $\beta$-cell function and insulin sensitivity. These parameters were assessed using the updated homeostasis model assessment (HOMA) (31) and the oral glucose insulin sensitivity (OGIS) index (32), respectively. The OGIS index is a measure of insulin sensitivity derived from glucose clearance in the OGTT test. It is expressed as glucose clearance $(\mathrm{ml} / \mathrm{min})$ per $\mathrm{m}^{2}$ body surface by taking into account the subject's body weight and height (body surface), the dose of glucose solution, the concentration of plasma glucose at time 0,90 and $120 \mathrm{~min}$, and the concentration of insulin at time 0 and $90 \min (29)$.

\section{Blood analysis}

Blood samples were collected in tubes containing $30 \mu \mathrm{l}$ of $0.2 \mathrm{M}$-EDTA. Plasma samples were immediately centrifuged at $3000 \mathrm{rpm}$ for $10 \mathrm{~min}$, frozen in liquid $\mathrm{N}_{2}$ and stored at $80^{\circ} \mathrm{C}$ until analysis. Glucose (Roche) concentrations were determined enzymatically. 
Insulin concentrations were determined using a RIA (Linco Research). Fasting blood lipid profiles were measured as followed: NEFA using the Wako Nefa C test kit; TAG with correction for free glycerol (Sigma Diagnostics); total cholesterol (Roche), using the oxidase phenol 4-aminoantipyrine peroxidase method. HDL-cholesterol concentrations were measured using the precipitation method, while LDL-cholesterol concentrations were calculated using the Friedewald equation (33).

\section{Statistical analysis}

Data are presented as means and standard deviations. Statistical comparison of the subjects' baseline characteristics, energy intake and macronutrient composition of the diet consumed between the ethnic groups was made using an independent- samples $t$ test. Repeated-measures ANOVA were carried out to assess within-group (effect of diet) and between- groups (effect of ethnicity) differences in parameters before and after overfeeding as well as the interaction between ethnicity and diet. The SPSS program version 16 (SPSS) was used for statistical analysis, and the statistical significance was set at $P<0.05$.

\section{RESULTS}

\section{Subject characteristics}

South Asian subjects were of Indian $(n=8)$ and Pakistani $(n=2)$. White subjects were of Dutch $(n=3)$, German ( $n=2)$, French ( $n 1)$, British $(n=1)$, Danish $(n=1)$, Polish $(n=1)$ and Icelander $(n=1)$. For South Asian subjects, measurement were carried out within 3 years $(n=5)$ and within 1 year $(n=5)$ of their stay in The Netherlands. Subject characteristics are given in Table 5.1. 


\section{CHAPTER 5}

Table 5.1. Subjects' characteristics ${ }^{a}$

\begin{tabular}{lccc}
\hline \multicolumn{1}{c}{ Characteristics } & $\begin{array}{c}\text { South } \\
\text { Asian }\end{array}$ & White & P \\
\hline $\mathrm{N}$ & 10 & 10 & \\
Age (years) & $27 \pm 2$ & $24 \pm 2$ & 0.001 \\
Weight (kg) & $68.9 \pm 7.4$ & $88.3 \pm 18.1$ & 0.006 \\
Height (m) & $1.72 \pm 0.06$ & $1.80 \pm 0.08$ & 0.02 \\
BMI (kg/m ${ }^{2}$ ) & $23.3 \pm 3.0$ & $27.0 \pm 4.2$ & 0.04 \\
Fat mass (\%) & $25.5 \pm 6.4$ & $23.7 \pm 7.5$ & 0.58 \\
Fat-free mass (kg) & $51.0 \pm 3.7$ & $66.5 \pm 8.5$ & 0.001 \\
Waist circumference (cm) & $85.9 \pm 7.7$ & $96.0 \pm 12.0$ & 0.04 \\
Hip circumference (cm) & $97.0 \pm 5.5$ & $105.4 \pm 8.7$ & 0.02 \\
Waist to hip ratio & $0.9 \pm 0.04$ & $0.91 \pm 0.06$ & 0.31 \\
Waist to height ratio & $0.50 \pm 0.05$ & $0.53 \pm 0.06$ & 0.23 \\
VO ${ }_{2}$ max corrected for FFM & $2780 \pm 265$ & $3249 \pm 152$ & 0.15 \\
(ml $\mathrm{O}_{2}$ /min ) & & & \\
Physical activity accelerometer & $1123 \pm 239$ & $1304 \pm 442$ & 0.27 \\
(10 ${ }^{3}$ counts/d) & & & \\
Daily PAL & $1.64 \pm 0.06$ & $1.69 \pm 0.11$ & 0.27 \\
\hline
\end{tabular}

${ }^{a}$ Values are mean and SDs. FFM, fat-free mass; PAL, physical activity level.

Differences between the groups were assessed using an Independent t-test.

South Asian subjects were slightly older than white subjects. South Asian subjects had a significantly lower BMI than white subjects $\left(23.3 \pm 3.0 \vee 27.0 \pm 4.2 \mathrm{~kg} / \mathrm{m}^{2} ; P=0.04\right)$, but there was no difference in body fat percentage $(25.5 \pm 6.4$ and $23.7 \pm 7.5 \%$ for South Asian and white subjects, respectively; $P=0.58$ ). The FFM in South Asian subjects was lower than that of white subjects $(P=0.001)$. White subjects had significantly higher waist circumference and hip circumference than South Asian subjects, resulting in no difference being observed in waist to hip ratio between groups $(P=0.31)$. Cardiorespiratory fitness, defined as $\mathrm{VO}_{2}$ max corrected for FFM, did not differ between the ethnic groups $(P=0.15)$, and there was no difference in daily physical activity counts $(P=0.27)$. Additionally, in the South Asian group, of the ten subjects, a family history of diabetes, dyslipidemia and CVD 
was found in four, five and four subjects, respectively. In the white group, of ten subjects, a family history of diabetes, dyslipidemia and CVD was found in three, five and five subjects, respectively.

\section{Energy intake and macronutrient composition during the dietary intervention period}

Compliance with the dietary intervention is summarized in Table 5.2. White subjects had a significantly higher energy requirement due to a higher FFM and therefore had a significantly higher energy intake. During the overfeeding period, South Asian subjects consumed $143 \pm 12 \%$ of their energy requirement, whereas white subjects consumed 152 $\pm 16 \%$ of their energy requirement $(P=0.16)$. There was no difference in the macronutrient composition of the diet consumed between South Asian and white subjects. The percentage of fat intake (as \% energy intake) on the balance diet period was $29 \pm 1.0 \%$ and $28.8 \pm 0.5 \%(P=0.33)$ for South Asian and white subjects, respectively. The percentage of fat intake during the overfeeding period was $59.3 \pm 1.3 \%$ and $58.8 \pm$ 2.3\% $(P=0.53)$ for South Asian and white subjects, respectively. There was no difference in the fatty acid composition of the diet consumed between South Asian and white subjects $(P=0.49)$.

\section{Plasma parameters}

Plasma parameters are given in Table 5.3. Short-term overfeeding with the high-fat diet decreased fasting TAG $(P=0.008)$, with no difference being observed between the ethnic groups $(P=0.24)$, and increased HDL-cholesterol concentrations $(P=0.001)$, which tended to be higher in white subjects $(P=0.06)$. There was a significant interaction between diet and ethnicity with regard to the changes in total cholesterol $(P=0.01)$ and LDLcholesterol $(P=0.007)$ concentrations, which trended towards a larger increase in South Asian subjects than white subjects, whereas fasting NEFA concentrations remained unaffected. 


\section{CHAPTER 5}

Table 5.2. Energy intake and macronutrients composition during weight maintenance and diet intervention ${ }^{a}$

\begin{tabular}{|c|c|c|c|}
\hline & South Asian & White & $\mathbf{P}$ \\
\hline \multicolumn{4}{|c|}{$\begin{array}{l}\text { Energy balance (weight maintenance) } \\
\text { diet }\end{array}$} \\
\hline Energy intake $(\mathrm{MJ} / \mathrm{d})$ & $10.8 \pm 1.0$ & $12.9 \pm 2.2$ & 0.01 \\
\hline Fat (\% energy intake) & $29.1 \pm 1.0$ & $28.8 \pm 0.5$ & 0.33 \\
\hline Carbohydrate (\% energy intake) & $55.6 \pm 1.3$ & $55.6 \pm 0.6$ & 0.99 \\
\hline Protein (\% energy intake) & $15.3 \pm 0.6$ & $15.6 \pm 0.6$ & 0.19 \\
\hline \multicolumn{4}{|l|}{ Overfeeding a high fat diet } \\
\hline Energy intake (MJ/d) & $15.4 \pm 1.3$ & $19.5 \pm 2.4$ & 0.001 \\
\hline Percentage overfeeding & $143 \pm 12$ & $152 \pm 16$ & 0.16 \\
\hline \multicolumn{4}{|l|}{ (\% from energy balance) } \\
\hline Fat intake (\% energy intake) & $59.3 \pm 1.3$ & $58.8 \pm 2.3$ & 0.53 \\
\hline Carbohydrate (\% energy intake) & $26.2 \pm 1.5$ & $26.4 \pm 2.3$ & 0.85 \\
\hline Protein (\% energy intake) & $14.5 \pm 0.3$ & $14.9 \pm 0.7$ & 0.20 \\
\hline Saturated fatty acids (\% fat intake) & $40.9 \pm 1.1$ & $40.5 \pm 1.2$ & 0.49 \\
\hline $\begin{array}{l}\text { Unsaturated fatty acids } \\
\text { (\% fat intake) }\end{array}$ & $59.1 \pm 1.1$ & $59.5 \pm 1.2$ & 0.49 \\
\hline
\end{tabular}

There was no effect of overfeeding with the high-fat diet on fasting glucose and fasting insulin concentrations and hence there were no differences in the HOMA index before and after overfeeding the high-fat diet $(P=0.94)$ and no differences between the ethnic groups $(P=0.84)$. Overfeeding with the high-fat diet decreased insulin sensitivity $(P=$ $0.004)$ expressed as the OGIS index, which was calculated from glucose clearance in $2 \mathrm{~h}$ OGTT ( $\mathrm{ml} / \mathrm{min})$ per $\mathrm{m}^{2}$ body surface. 


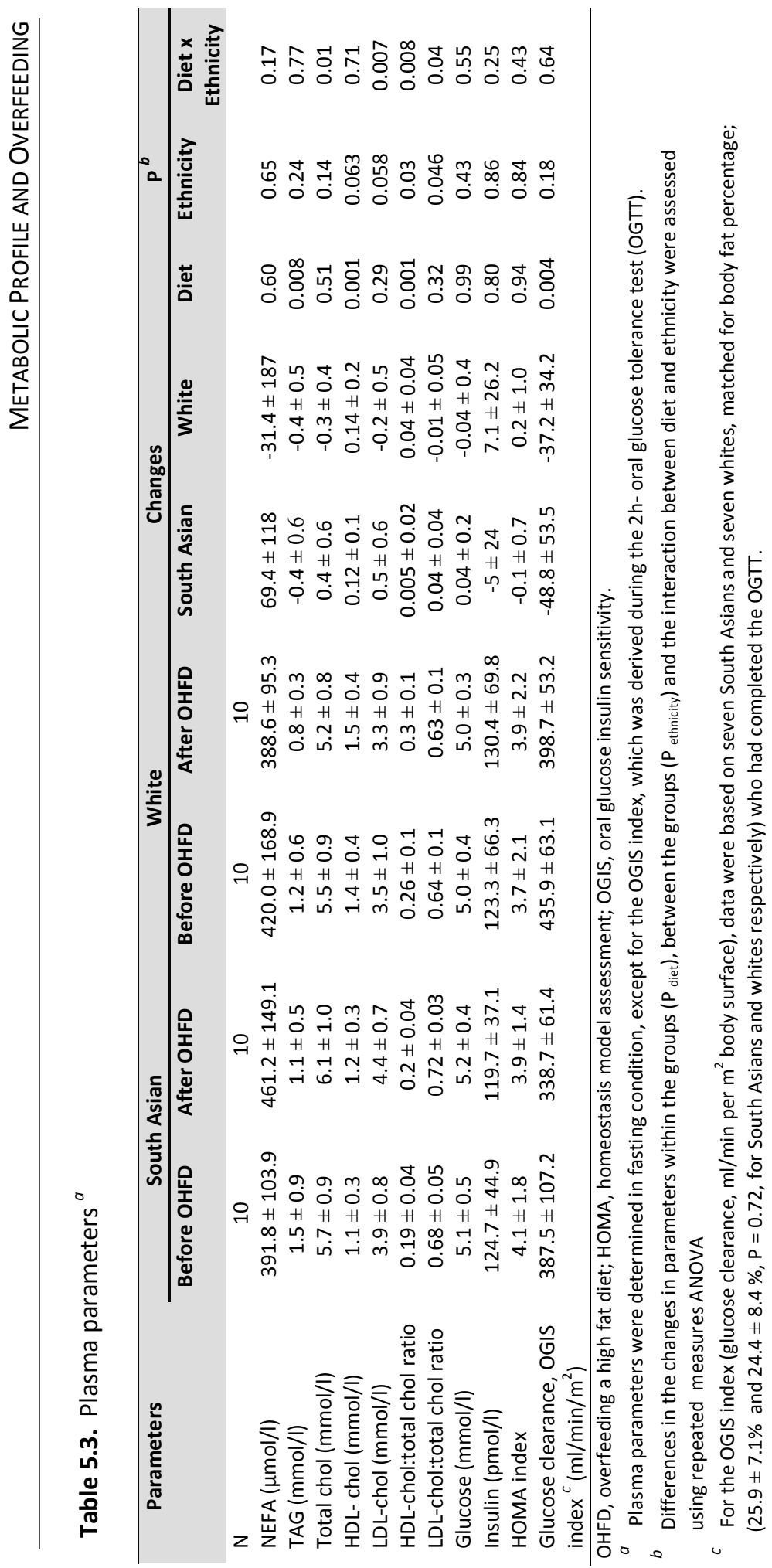




\section{CHAPTER 5}

There was no difference in the changes in glucose clearance between the ethnic groups $(P=0.18)$. Figure $\mathbf{5 . 1}(\mathbf{a})$ and $(\mathrm{b})$ shows that the glucose response during the $2 \mathrm{~h}$ OGTT was not affected by the diet $(P=0.16)$ and did not differ between the ethnic groups $(P=0.6)$, whereas the insulin response (Figure 5.1 (c) and (d)) increased significantly with overfeeding $(P=0.046)$, but no differences was observed between the ethnic groups $(P=$ $0.23)$.

\section{DISCUSSION}

In the present study, two ethnic groups were matched for body fat percentage, confirming the evidence that South Asian men have a lower BMI for the same body fat percentage when compared with white men. Despite a similar body fat percentage, South Asian men had a more adverse lipid profile i.e. a larger increase in total cholesterol and LDL-cholesterol concentrations as a response to overfeeding with the high-fat diet, whereas glucose clearance (insulin sensitivity) decreased similarly in both ethnic groups.

Cross-sectional studies comparing South Asians and whites have consistently reported an unfavorable metabolic profile such as dyslipidemia in South Asians when matched or adjusted for BMI, sex and age (34-36), which is expected, given that the South Asians have a higher body fat percentage at the same BMI than whites. In the present study, subjects were matched for body fat percentage, and the baseline metabolic profile measured before the overfeeding period was comparable between the ethnic groups, except for the HDL-cholesterol:total cholesterol ratio, which tended to be lower in South Asian subjects. Another study has reported comparable fasting TAG, total cholesterol, HDL-cholesterol and LDL-cholesterol concentrations but higher plasma NEFA in South Asian Indians compared with body fat percentage-matched white men (37). 
a.

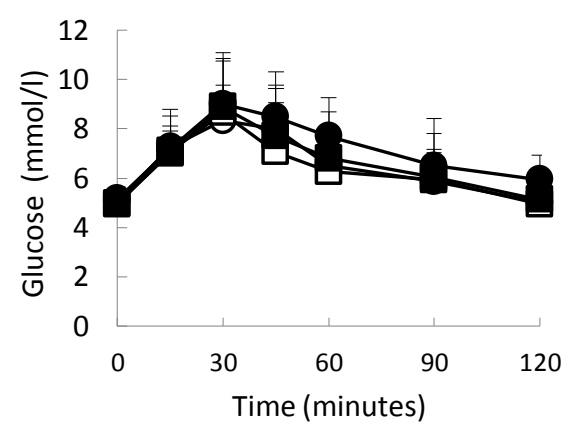

c.

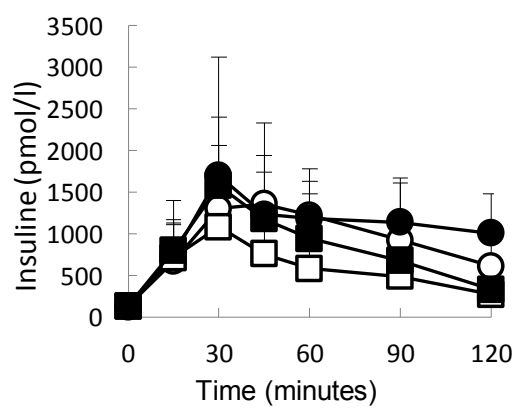

b.

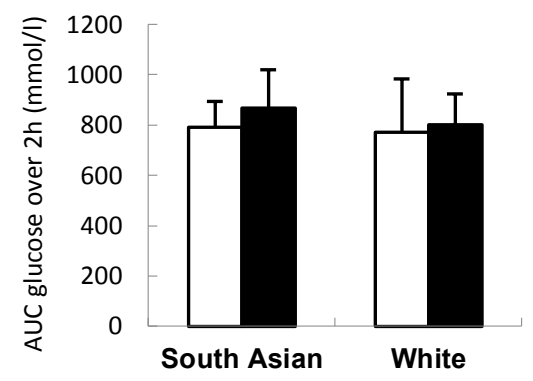

d.

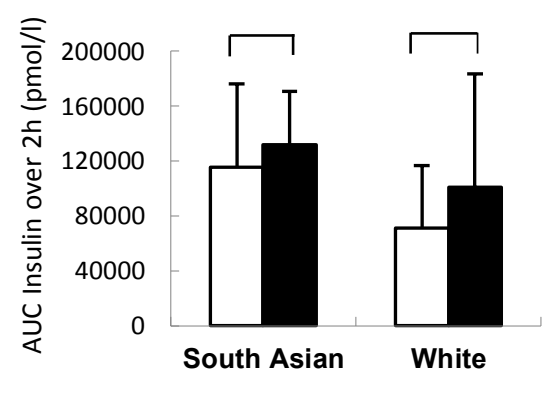

Figure 5.1. Glucose (a) and insulin (c) responses before and after overfeeding with a high- fat diet (OHFD) in South Asians (before, $\mathrm{O}$; after, $\bullet$ ) and whites (before, $\square$; after, $\mathbf{\square}$ ) and the corresponding AUC of glucose (b) and insulin (d) during $2 \mathrm{~h}$ oral glucose tolerance test (OGTT) (before, $\square$; after, $\mathbf{m}$ ) OHFD. Values are means and standard deviations represented by vertical bars. Differences within and between the groups after the dietary intervention were assessed using repeated measures-ANOVA. *Mean values obtained after overfeeding with high-fat diet was significantly different from that obtained before overfeeding in both ethnicities, but the changes did not differ between ethnicities. Data were available from fourteen subjects, seven subjects in each group matched for body fat $(25.9 \pm 7.1 \%$ and $24.4 \pm 8.4 \%$ for South Asians and whites respectively, $\mathrm{P}=0.72)$, who completed the OGTT: AUC glucose $\left(P_{\text {diet }}=0.16 ; P_{\text {ethnicity }}=0.60 ; P_{\text {diet } x}\right.$ ethnicity $=0.53)$, AUC insulin $\left(P_{\text {diet }}=0.046 ; P_{\text {ethnicity }}=0.23 ; P_{\text {diet } x \text { ethnicity }}=0.53\right)$. 


\section{CHAPTER 5}

In the present study, fasting plasma NEFA concentrations were unaffected by overfeeding with the high-fat diet, and there was no difference between the ethnic groups. In the fasting state, lipolysis is activated, fatty acids released by the action of hormone-sensitive lipase (38) are directed primarily into venous plasma (39). In the fed state lipoprotein lipase (LPL) is activated and the fatty acids released from circulating TAG are directed into the tissue for esterification and storage in white adipose tissue (39). In the overfeeding condition, the postprandial (fed) state may be slightly extended as a result of the extended meal ingestion; the release of NEFA from subcutaneous fat presumably declines due to the prolonged presence of high insulin concentrations. However, it is a common observation either during infusion of TAG emulsions or after ingestion of high-fat meals (40) that the plasma NEFA concentration is relatively maintained, despite elevation in insulin concentrations (39). In addition, after the consumption of a high-fat meal, both the inward flux of fatty acids from the plasma into adipose tissue and the release of LPLderived NEFA into the venous plasma are greater than after the consumption of a lowerfat mixed meal (41). LPL appears to operate continuously, generating a pool of fatty acids, of which some are always released into the venous plasma, while a proportion are diverted into the tissue for esterification and storage in the postprandial state (39).

We observed a decrease in fasting TAG after short-term overfeeding with the high- fat diet, but the decrease did not differ between the ethnic groups. Diets that replace fat with carbohydrate isoenergetically have been consistently observed to worsen certain elements of the plasma lipid profile $(42)$, particularly TAG $(43,44)$. In a multiethnic population study in Canada, Merchant et al. (44) reported that South Asian Indians consumed large amounts of carbohydrate followed by Europeans, Aboriginals and Chinese. In that study, higher carbohydrate intake was found to be associated with higher fasting TAG concentrations and those with the highest percentile of carbohydrate intakes were found to have the highest fasting TAG concentrations. In the present study, reduction in fasting plasma TAG may be attributed to a lower proportion of carbohydrate 
in the high-fat diet (25\% energy from carbohydrate in the overfeeding period equals $37.5 \%$ carbohydrate compared with $55 \%$ carbohydrate in the balance diet period), as also reported by others (45-47). High-carbohydrate diets are hypothesised to increase TAG concentrations by inducing fatty acid production in the liver and inhibiting the action of LPL through increased apo CIII production, particularly in the presence of insulin resistance (48). Higher fat intakes may increase circulating chylomicron concentrations, but do not affect LPL and the clearance of circulating TAG and hence do not increase TAG concentrations (49).

A significant interaction between diet and ethnicity was found with regard to the changes in total cholesterol and LDL-cholesterol concentrations, which trended towards a larger increase in South Asian subjects than in white subjects. In addition, overfeeding with the high-fat diet increased HDL-cholesterol concentrations, but the increase tended to be higher in white subjects than in South Asian subjects. Furthermore, the changes in HDL-cholesterol:total cholesterol ratio and LDL-cholesterol:total cholesterol ratio were different between the ethnic groups. Thus, overfeeding with the high-fat diet clearly resulted in a more unfavorable lipoprotein profile in South Asian subjects. The effect of a high-fat diet on lipoproteins varies considerably depending on the type of fat consumed, i.e. fatty acid composition of the diet (50). SFA increase the concentrations of both total cholesterol and LDL-cholesterol, while unsaturated fatty acids lower the concentrations of total cholesterol and LDL-cholesterol (50). Both SFA and unsaturated fatty acids increase HDL-cholesterol concentrations, although this increase is greater with SFA (50). A recent review by Hooper et al. (51) has reported that reduced and modified fat intakes decrease total cholesterol and LDL-cholesterol, with no effect on HDL-cholesterol concentrations.

In the present study, during the overfeeding period, the subjects were given a diet containing $60 \%$ energy from fat, of which $40 \%$ of the fat consumed was from SFA and $60 \%$ was from unsaturated fatty acids. No difference in the adherence to the diet and no difference in the fat intake and fatty acids composition were observed between the ethnic 


\section{CHAPTER 5}

groups. Given that the subjects in the present study had a comparable range of body fat percentage and comparable metabolic profiles at baseline except for HDL-cholesterol:total cholesterol ratio, which tended to be present at lower concentrations in South Asian subjects, the unfavorable lipoproteins profile in South Asian subjects as a response to the high-fat diet needs to be investigated further. This may possibly be due to differences in the rate of LDL-clearance and production (52). Furthermore, data obtained from thirtyone study cohorts of twelve countries revealed that South Asian Indian men and women have the lowest HDL-cholesterol concentrations compared with Central and Northern Europeans, Japanese and Chinese across the glucose level categories (53).

Overfeeding $(54,55)$ and a high-fat diet $(56)$ has been reported to be associated with disturbances in glucose metabolism and insulin sensitivity. As expected, short-term overfeeding with a high-fat diet increased the insulin response (AUC insulin) during the $2 \mathrm{~h}$ OGTT. We also calculated the glucose clearance $(\mathrm{ml} / \mathrm{min})$ per $\mathrm{m}^{2}$ body surface, which allowed us to correct for the differences in body height between South Asian and white subjects (indirectly FFM). The result remains that short-term overfeeding with a high-fat diet decreased glucose clearance per $\mathrm{m}^{2}$ body surface, with no difference being observed between the ethnic groups. In response to a meal, insulin suppresses lipolysis and the release of NEFA concentrations into the circulation and stimulates skeletal muscle glucose uptake (57). In vivo, elevation of NEFA concentrations induced by intra-lipid plus heparin infusion has consistently been shown to reduce glucose oxidation and glucose uptake in the skeletal muscle (58). Others have suggested the importance of CD36 in NEFA transport and ectopic TAG accumulation; incomplete oxidation generates intermediates that can impair insulin signaling (59).

A limitation of the present study is the low number of subjects, which may not reflect the general population of South Asians and whites. Additionally, the short-term dietary intervention may reflect an early response to overfeeding with the high-fat diet. Although an early response may precede the metabolic complications in the long-term, it cannot be 
simply extrapolated to assess the response in a longer term. However, this is a wellcontrolled dietary intervention study and, to our knowledge, no such studies comparing two ethnic groups have been carried out.

In summary, we observed a more adverse lipid profile in South Asian men compared with white men in response to short-term overfeeding with a high fat diet, whereas insulin sensitivity decreased similarly. Although the ethnic groups differed with respect to age in the present study, a regression analysis to assess the predictors of baseline metabolic profiles by including age, fat mass percentage and ethnicity revealed that age did not have a significant effect in the groups studied, presumably because all of them were young and the age difference between the groups was small. The differences in the lipid profile may be associated with differences in body fat distribution towards a more central fat deposition (60) in South Asians. These results may partly explain the high prevalence of the metabolic syndrome in South Asians, which is triggered by life style changes i.e. increased consumption of high-energy-density foods.

\section{ACKNOWLEDGEMENTS}

The authors gratefully thank Jos Stegen, Loek Wouters and Paul Schoffelen, for their technical assistance and help with the analyses. They also deeply appreciate and thank all subjects who participated in the study.

The present study was funded by a scholarship from the Directorate General of Higher Education (DGHE), the Ministry of Education and Culture of The Republic of Indonesia to S.N.W. The Ministry of Education and Culture of the Republic of Indonesia had no role in the design and analysis of the study and in writing of this article.

The authors' contributions are as follows: S.N.W conducted the research, carried out the data analysis, and wrote the manuscript under the supervision of K.R.W and G.P who designed the study, interpreted the data, and reviewed the manuscript.

None of the authors had a conflict of interest in relation to the present study. 


\section{CHAPTER 5}

\section{REFERENCES}

1. Popkin BM (2006) Global nutrition dynamics: the world is shifting rapidly toward a diet linked with noncommunicable diseases. Am J Clin Nutr 84, 289-298.

2. Subramanian SV, Perkins JM, Ozaltin E, Davey Smith G (2011) Weight of nations: a socioeconomic analysis of women in low- to middle-income countries. Am J Clin Nutr 93, 413-421.

3. Misra A, Khurana L (2008) Obesity and the metabolic syndrome in developing countries. J Clin Endocrinol Metab 93, S9-S30.

4. King H, Aubert RE, Herman WH (1998) Global burden of diabetes, 1995-2025: prevalence, numerical estimates, and projections. Diabetes Care 21, 1414-1431.

5. Yoon KH, Lee JH, Kim JW, Cho JH, Choi YH, Ko SH et al. (2006) Epidemic obesity and type 2 diabetes in Asia. Lancet 368, 1681-1688.

6. Wulan SN, Westerterp KR, Plasqui G (2012) Dietary and 24-h fat oxidation in Asians and whites who differ in body composition. Am J Clin Nutr 95, 1335-1341.

7. Deurenberg P, Deurenberg-Yap M (2001) Differences in body-composition assumptions across ethnic groups: practical consequences. Curr Opin Clin Nutr Metab Care 4, 377-383.

8. Deurenberg P, Deurenberg-Yap M (2003) Validity of body composition methods across ethnic population groups. Forum Nutr 56, 299-301.

9. Deurenberg-Yap M, Chew SK, Deurenberg P (2002) Elevated body fat percentage and cardiovascular risks at low body mass index levels among Singaporean Chinese, Malays and Indians. Obes Rev 3, 209-215.

10. Chang CJ, Wu CH, Chang CS, Yao WJ, Yang YC, Wu JS et al. (2003) Low body mass index but high percent body fat in Taiwanese subjects: implications of obesity cutoffs. Int J Obes Relat Metab Disord 27, 253-259.

11. Rush EC, Goedecke JH, Jennings C, Micklesfield L, Dugas L, Lambert EV et al. (2007) BMI, fat and muscle differences in urban women of five ethnicities from two countries. Int J Obes (Lond) 31, 1232-1239.

12. Sampei MA, Novo NF, Juliano Y, Sigulem DM (2008) Anthropometry and body composition in ethnic Japanese and Caucasian adolescent boys. Pediatr Int 50, 679-686.

13. Rush EC, Freitas I, Plank LD (2009) Body size, body composition and fat distribution: comparative analysis of European, Maori, Pacific Island and Asian Indian adults. Br J Nutr 102, 632-641.

14. Deurenberg-Yap M, Schmidt G, van Staveren WA, Hautvast JG, Deurenberg P (2001) Body fat measurement among Singaporean Chinese, Malays and Indians: a comparative study using a four-compartment model and different two-compartment models. Br J Nutr 85, 491-498.

15. Raji A, Seely EW, Arky RA, Simonson DC (2001) Body fat distribution and insulin resistance in healthy Asian Indians and Caucasians. J Clin Endocrinol Metab 86, 5366-5371.

16. Ramachandran A, Ma RC, Snehalatha C (2010) Diabetes in Asia. Lancet 375, 408-418.

17. Popkin BM (2001) The nutrition transition and obesity in the developing world. J Nutr 131, 871S-873S.

18. van der Meer RW, Hammer S, Lamb HJ, Frolich M, Diamant M, Rijzewijk LJ et al. (2008) Effects of short-term high-fat, high-energy diet on hepatic and myocardial triglyceride content in healthy men. J Clin Endocrinol Metab 93, 2702-2708.

19. Brons C, Jacobsen S, Hiscock N, White A, Nilsson E, Dunger D et al. (2012) Effects of high-fat overfeeding on mitochondrial function, glucose and fat metabolism, and adipokine levels in low-birth-weight subjects. Am J Physiol Endocrinol Metab 302, E43-51.

20. Westerbacka J, Lammi K, Hakkinen AM, Rissanen A, Salminen I, Aro A et al. (2005) Dietary fat content modifies liver fat in overweight nondiabetic subjects. J Clin Endocrinol Metab 90, 2804-2809.

21. Westerterp KR, Wouters L, van Marken Lichtenbelt WD (1995) The Maastricht protocol for the measurement of body composition and energy expenditure with labeled water. Obes Res 3 Suppl 1, 49-57.

22. Siri WE (1993) Body composition from fluid spaces and density: analysis of methods. 1961. Nutrition 9, 480491; discussion 480, 492.

23. Kuipers H, Keizer HA, Verstappen FT, Costill DL (1985) Influence of a prostaglandin-inhibiting drug on muscle soreness after eccentric work. Int J Sports Med 6, 336-339. 
24. Bonomi AG, Plasqui G, Goris AH, Westerterp KR (2010) Estimation of free-living energy expenditure using a novel activity monitor designed to minimize obtrusiveness. Obesity (Silver Spring) 18, 1845-1851.

25. Joosen AM, Bakker AH, Zorenc AH, Kersten S, Schrauwen P, Westerterp KR (2006) PPARgamma activity in subcutaneous abdominal fat tissue and fat mass gain during short-term overfeeding. Int $J$ Obes (Lond) 30 , 302-307.

26. Schrauwen-Hinderling VB, Kooi ME, Hesselink MK, Moonen-Kornips E, Schaart G, Mustard KJ et al. (2005) Intramyocellular lipid content and molecular adaptations in response to a 1-week high-fat diet. Obes Res 13, 2088-2094.

27. Schrauwen P, van Marken Lichtenbelt WD, Saris WH, Westerterp KR (1997) Changes in fat oxidation in response to a high-fat diet. Am J Clin Nutr 66, 276-282.

28. Sievenpiper JL, Jenkins DJ, Josse RG, Vuksan V (2001) Dilution of the 75-g oral glucose tolerance test improves overall tolerability but not reproducibility in subjects with different body compositions. Diabetes Res Clin Pract 51, 87-95.

29. Report of the Expert Committee on the Diagnosis and Classification of Diabetes Mellitus (1997). Diabetes Care 20, 1183-1197.

30. American Diabetes Association (2010) Standards of medical care in diabetes--2010. Diabetes Care 33 Suppl 1, S11-61.

31. Levy JC, Matthews DR, Hermans MP (1998) Correct homeostasis model assessment (HOMA) evaluation uses the computer program. Diabetes Care 21, 2191-2192.

32. Mari A, Pacini G, Murphy E, Ludvik B, Nolan JJ (2001) A model-based method for assessing insulin sensitivity from the oral glucose tolerance test. Diabetes Care 24, 539-548.

33. Friedewald WT, Levy RI, Fredrickson DS (1972) Estimation of the concentration of low-density lipoprotein cholesterol in plasma, without use of the preparative ultracentrifuge. Clin Chem 18, 499-502.

34. Forouhi NG, Jenkinson G, Thomas EL, Mullick S, Mierisova S, Bhonsle U et al. (1999) Relation of triglyceride stores in skeletal muscle cells to central obesity and insulin sensitivity in European and South Asian men. Diabetologia 42, 932-935.

35. Anand SS, Tarnopolsky MA, Rashid S, Schulze KM, Desai D, Mente A et al. (2011) Adipocyte hypertrophy, fatty liver and metabolic risk factors in South Asians: the Molecular Study of Health and Risk in Ethnic Groups (mol-SHARE). PLoS One 6, e22112.

36. Chandalia M, Lin P, Seenivasan T, Livingston EH, Snell PG, Grundy SM et al. (2007) Insulin resistance and body fat distribution in South Asian men compared to Caucasian men. PLoS One 2, e812.

37. Abate N, Chandalia M, Snell PG, Grundy SM (2004) Adipose tissue metabolites and insulin resistance in nondiabetic Asian Indian men. J Clin Endocrinol Metab 89, 2750-2755.

38. Nelson TF, Gortmaker SL, Subramanian SV, Cheung L, Wechsler H (2007) Disparities in overweight and obesity among US college students. Am J Health Behav 31, 363-373.

39. Frayn KN, Shadid S, Hamlani R, Humphreys SM, Clark ML, Fielding BA et al. (1994) Regulation of fatty acid movement in human adipose tissue in the postabsorptive-to-postprandial transition. Am J Physiol 266, E308317.

40. Karpe F, Olivecrona T, Walldius G, Hamsten A (1992) Lipoprotein lipase in plasma after an oral fat load: relation to free fatty acids. J Lipid Res 33, 975-984.

41. Frayn KN, Coppack SW, Fielding BA, Humphreys SM (1995) Coordinated regulation of hormone-sensitive lipase and lipoprotein lipase in human adipose tissue in vivo: implications for the control of fat storage and fat mobilization. Adv Enzyme Regul 35, 163-178.

42. Hellerstein MK (2002) Carbohydrate-induced hypertriglyceridemia: modifying factors and implications for cardiovascular risk. Curr Opin Lipidol 13, 33-40.

43. Parks EJ, Hellerstein MK (2000) Carbohydrate-induced hypertriacylglycerolemia: historical perspective and review of biological mechanisms. Am J Clin Nutr 71, 412-433.

44. Merchant AT, Anand SS, Kelemen LE, Vuksan V, Jacobs R, Davis B et al. (2007) Carbohydrate intake and HDL in a multiethnic population. Am J Clin Nutr 85, 225-230. 


\section{CHAPTER 5}

45. Sharman MJ, Gomez AL, Kraemer WJ, Volek JS (2004) Very low-carbohydrate and low-fat diets affect fasting lipids and postprandial lipemia differently in overweight men. J Nutr 134, 880-885.

46. Maki KC (2004) Dietary factors in the prevention of diabetes mellitus and coronary artery disease associated with the metabolic syndrome. Am J Cardiol 93, 12C-17C.

47. Hu T, Mills KT, Yao L, Demanelis K, Eloustaz M, Yancy WS, Jr. et al. (2012) Effects of low-carbohydrate diets versus low-fat diets on metabolic risk factors: a meta-analysis of randomized controlled clinical trials. $\mathrm{Am} \mathrm{J}$ Epidemiol 176 Suppl 7, S44-54.

48. Grundy SM, Abate N, Chandalia M (2002) Diet composition and the metabolic syndrome: what is the optimal fat intake? Am J Med $\mathbf{1 1 3}$ Suppl 9B, 25S-29S.

49. Grundy SM (1998) Hypertriglyceridemia, atherogenic dyslipidemia, and the metabolic syndrome. Am $J$ Cardiol 81, 18B-25B.

50. Samaha FF (2005) Effect of very high-fat diets on body weight, lipoproteins, and glycemic status in the obese. Curr Atheroscler Rep 7, 412-420.

51. Hooper L, Summerbell CD, Thompson R, Sills D, Roberts FG, Moore HJ et al. (2012) Reduced or modified dietary fat for preventing cardiovascular disease. Cochrane Database Syst Rev 5, CD002137.

52. Sniderman AD, De Graaf J, Couture P, Williams K, Kiss RS, Watts GF (2009) Regulation of plasma LDL: the apoB paradigm. Clin Sci (Lond) 118, 333-339.

53. Zhang L, Qiao Q, Tuomilehto J, Janus ED, Lam TH, Ramachandran A et al. (2010) Distinct ethnic differences in lipid profiles across glucose categories. J Clin Endocrinol Metab 95, 1793-1801.

54. Samocha-Bonet D, Campbell LV, Viardot A, Freund J, Tam CS, Greenfield JR et al. (2010) A family history of type 2 diabetes increases risk factors associated with overfeeding. Diabetologia 53, 1700-1708.

55. Samocha-Bonet D, Campbell LV, Mori TA, Croft KD, Greenfield JR, Turner N et al. (2012) Overfeeding reduces insulin sensitivity and increases oxidative stress, without altering markers of mitochondrial content and function in humans. PLoS One 7, e36320.

56. Bachmann OP, Dahl DB, Brechtel K, Machann J, Haap M, Maier T et al. (2001) Effects of intravenous and dietary lipid challenge on intramyocellular lipid content and the relation with insulin sensitivity in humans. Diabetes 50, 2579-2584.

57. Magkos F, Fabbrini E, Conte C, Patterson BW, Klein S (2012) Relationship between adipose tissue lipolytic activity and skeletal muscle insulin resistance in nondiabetic women. J Clin Endocrinol Metab 97, E12191223.

58. Lewis GF, Carpentier A, Adeli K, Giacca A (2002) Disordered fat storage and mobilization in the pathogenesis of insulin resistance and type 2 diabetes. Endocr Rev 23, 201-229.

59. Fabbrini E, Magkos F, Mohammed BS, Pietka T, Abumrad NA, Patterson BW et al. (2009) Intrahepatic fat, not visceral fat, is linked with metabolic complications of obesity. Proc Natl Acad Sci U S A 106, 15430-15435.

60. Misra A, Vikram NK (2003) Clinical and pathophysiological consequences of abdominal adiposity and abdominal adipose tissue depots. Nutrition 19, 457-466. 


\section{BIAPTER 6}

Substrate utilization and metabolic profile in response to overfeeding with a high fat diet in South Asian and white men:

a sedentary life style study

SN Wulan, VB Schrauwen-Hinderling, KR Westerterp and G Plasqui

Submitted for publication 


\section{CHAPTER 6}

\section{ABSTRACT}

Background: For the same BMI, South Asians have a higher body fat percentage, a higher liver fat content and an adverse metabolic profile than whites. South Asians may have a lower fat oxidation than whites, when exposed to increased high fat foods consumption and decreased physical activity as in current modern lifestyle, which could result in an unfavorable metabolic profile

Objective: To determine substrate partitioning, liver fat accumulation and metabolic profile in South Asian and white men in response to overfeeding with high fat diet under sedentary conditions in a respiration chamber.

Design: Ten South Asian men (BMI, $18-29 \mathrm{~kg} / \mathrm{m}^{2}$ ) and 10 white men (BMI, 22-33 kg/m²), matched for body fat percentage, aged $20-40$ y were included. A weight maintenance diet ( $30 \%$ fat, $55 \%$ carbohydrate and $15 \%$ protein) was given for 3 days. Thereafter, a baseline measurement of liver fat content (1H-MRS) and blood parameters was performed. Subsequently, subjects were overfed (150\% energy requirement) with a high fat diet $(60 \%$ fat, $25 \%$ carbohydrate and $15 \%$ protein) over 3 consecutive days while staying in a respiration chamber mimicking a sedentary lifestyle. Energy expenditure and substrate use were measured for $3 \times 24-\mathrm{h}$. Liver fat and blood parameters were measured again after the subjects left the chamber.

Results: The 24-h fat oxidation as a percentage of total energy expenditure did not differ between ethnicities $(P=0.30)$. Overfeeding increased liver fat content $(P=0.02)$ but the increase did not differ between ethnicities $(P=0.64)$. In South Asians, overfeeding tended to increase LDL cholesterol $(P=0.08)$, tended to decrease glucose clearance $(P=0.06)$ and tended to elevate insulin response $(P=0.07)$ slightly more than whites.

Conclusions: Despite a similar substrate partitioning and similar accretion of liver fat, overfeeding with high fat under sedentary conditions tended to have more adverse effects on the lipid profile and insulin sensitivity in South Asians. 


\section{INTRODUCTION}

Globally, the number of overweight and obese people was projected to be 1.35 billion and 573 million respectively in 2030 (1). It is also estimated that by 2020, two-thirds of the global burden of diseases will be attributable to chronic non-communicable diseases; most of them are strongly associated with diet, i.e. an increased consumption of refined foods or fats (2) and decreased physical activity (1).

Interestingly, in South Asian countries the development of diabetes and CVD was observed in people with a younger age and at a lower BMI compared to that in western countries (3) and may be explained by a higher body fat \% in South Asians for the same $\mathrm{BMI}$ as whites (4-7). It is suggested that differences in fat oxidation may be underlying the differences in body fat between ethnicities. However, we previously showed that despite differences in body composition, Asians and BMI-matched whites had a comparable dietary and 24-h fat oxidation when they were fed a normal-fat diet in energy balance (8). Whether South Asians oxidize as much fat as whites when they are exposed to a high-fat diet and reduced physical activity is unknown.

Sedentarism is known to be able to aggravate the effect of obesogenic factors. Low physical activity accentuated the effect of the FTO-gene on body fat accumulation (9), whereas a high level of occupational activity was associated with a decreased likelihood of being obese (10). Moderate intensity (11) or a single bout of exercise (12) and a high intensity exercise that lowered glycogen stores (13) were shown to increase fat oxidation. Training a group of sedentary men increased palmitate and oleate oxidation, whereas detraining a group of trained men by reducing structured and spontaneous activity reduced the oxidation of those fatty acids (14).

In the present study, we introduced a 3-day stay under sedentary conditions in a respiration chamber while overfeeding South Asians and whites with a high-fat diet to mimic the current lifestyle. To avoid potential confounders, South Asians and whites were 


\section{CHAPTER 6}

matched for body fat percentage. Thus, the objectives of the present study were to compare: 1 , substrate partitioning; 2 , the change in liver fat content; and 3 , the changes in metabolic profile between South Asians and whites in response to a massively positive energy balance.

\section{SUBJECTS AND METHODS}

\section{Subjects}

Subjects were 10 healthy adult non-diabetic South Asian men and 10 body fat-matched white men. The number of subjects was determined based on previous studies showing an increase in liver fat content $(15,16)$ and changes in metabolic profile $(17)$ in response to short-term high-fat feeding. Asian subjects had 4 grandparents from South Asia, while white subjects were European Caucasians. Subjects were selected based on the following inclusion criteria: healthy, not having diabetes or CVD, not using medication, aged between 20 and 40 y with BMI (in $\mathrm{kg} / \mathrm{m}^{2}$ ) between 18-29 for South Asians and between 22-33 for whites, having a stable body weight for the last three months, not being on a diet and not being an athlete. Written informed consent was obtained from all subjects. The study was approved by the Medical Ethics Committee of Maastricht University Medical Centre, MEC No.10-3-013 and registered in the public trial registry (www.ccmo.nl No. NL31217.068.10).

\section{Experimental design}

The study was a diet-intervention study under sedentary conditions in a respiration chamber. Body composition was measured before the start of the intervention to match body fat percentage between two ethnicities. Energy requirement of a weight maintenance diet for 3 days preceding the intervention were calculated based on fat-free 
mass (FFM) and daily physical activity level (PAL) of each subject. On the third day of the weight maintenance period, subjects came to the university in the morning to have a baseline measurement of the liver fat content and metabolic profile. On the same day, after having dinner, subjects entered the respiration chamber and stayed for the next 3 days. During this period, subjects were overfed with a high-fat diet while no exercise or strenuous physical activity was allowed. Liver fat content and metabolic profile were measured again after the subjects left the chamber in the morning. All measurements were carried out at the Metabolic Research Unit Maastricht (MRUM) and MRI unit, Maastricht University Medical Center, Maastricht, The Netherlands.

\section{Body composition}

Body composition was determined according to a 3-compartment model based on body weight, body volume and total body water. Body weight and body volume were determined in the morning, in a fasted state. Body volume was determined by hydrodensitometry with simultaneous measurement of residual lung volume using the helium dilution technique. Total body water was determined with deuterium dilution according to the Maastricht protocol (18). Body composition was calculated from body density and total body water using the equation of Siri (19).

\section{Daily physical activity level}

The daily PAL was measured for 7 consecutive days (during waking hours except water activities) using a tri-axial accelerometer for movement registration (Tracmor-D, Philips New Wellness Solutions; http://www.directlife.philips.com). A detail description about the device has been provided elsewhere (20). Accelerometer output was expressed as activity counts/minute and were summed over the entire monitoring period, then divided by the number of monitoring days to determine the average counts per day (counts/d). 


\section{CHAPTER 6}

Daily PAL was calculated based on the activity counts/d with the formula,

$P A L=1.354+256 \times 10^{-9} \times$ counts $/ d(20)$.

Total energy expenditure (TEE) was calculated with the formula of Bonomi et al.,

TEE accelerometer $(\mathrm{MJ} / \mathrm{d})=0.04+0.17 \mathrm{FFM}(\mathrm{kg})+1.67 \times 10^{-6} \times$ counts $/ \mathrm{d}(20)$.

\section{Energy intake}

The weight maintenance diet to be consumed at home for 3 days before the intervention was calculated based on TEE as shown above, containing $30 \%$ energy as fat, $55 \%$ carbohydrate and $15 \%$ protein. The overfeeding with a high-fat diet was given with $50 \%$ excess energy above the TEE of the weight maintenance diet (21), containing $60 \%$ fat, $25 \%$ carbohydrate and $15 \%$ protein $(22,23)$.

A written instruction was given to prepare the weight maintenance diet at home. Subjects were provided with the diet in an excess amount than calculated TEE and were allowed to eat ad libitum. Any additional intake from those prescribed foods was recorded. All unfinished foods were collected and returned to the university, to calculate actual energy intake (17).

During overfeeding, subjects stayed in the respiration chamber. They were asked to eat all the foods prepared, but on failing to do so, the left overs were weighed. The diet consisted of normal ready-to-eat foods combining a typical Western and Asian diet. Foods and drinks were selected by reviewing the ingredients content to ensure there was no (or only a minimal) effect of certain ingredients on fat oxidation (such as spices, caffeine). Alcohol was not allowed to be consumed in the respiration chamber. 


\section{Energy expenditure}

Subjects stayed in the respiration chamber from 20:00 in the evening of the third day of their weight maintenance diet (day 3) until 07:00 in the morning of day 7 ( 83 hours). The respiration chamber is a $14-\mathrm{m}^{3}$ room furnished with a bed, table, chair, freeze toilet, washing bowl, radio, television and computer (24).

During the 83-h stay, oxygen consumption and carbon dioxide production were measured continuously. Subjects were allowed to move freely, sit, lie down, study, use the telephone, watch television, and use the computer from 07:00 to 23:00, but were not allowed to do strenuous physical activity (exercise) or sleeping during the day. Total energy expenditure over $3 \times 24-h$ (TEE) and $3 \times 24-h-R Q$ were calculated from 07:00 on the first morning until 07:00 on the fourth morning in the chamber. TEE was calculated by using the equation of Carpenter, as published by Brouwer (25):

TEE $(\mathrm{kJ} / \mathrm{d})=16 \times \mathrm{O}_{2}(\mathrm{~L} / \mathrm{d})+5 \mathrm{CO}_{2}(\mathrm{~L} / \mathrm{d})-0.95 \times \mathrm{P}$, where $\mathrm{P}$ is oxidized protein in $\mathrm{g} / \mathrm{d}$.

Sleeping metabolic rate (SMR) was calculated by assessing the lowest mean activity of the subjects during 3 consecutive hours between 00:00 and 07:00 of the second, third and fourth night of their stay in the chamber. SMR was the mean energy expenditure in which the activity was the lowest (26). SMR was also corrected for FFM (27). Resting metabolic rate (RMR) was calculated by plotting energy expenditure ( $y$ axis) against radar output ( $x$ axis), both being averaged over $30 \mathrm{~min}$ intervals every $24-\mathrm{h}$ of the stay. RMR was calculated by entering the earlier mentioned lowest mean activity into the formula of the linear regression line of the plot. Diet induced thermogenesis (DIT) was calculated by subtracting SMR from RMR. Activity energy expenditure (AEE) (28) was calculated by subtracting RMR from TEE (26). 


\section{CHAPTER 6}

\section{Substrate oxidation}

Substrate oxidation was calculated from 24-h urinary nitrogen, $\mathrm{O}_{2}$ consumption, and $\mathrm{CO}_{2}$ production. Urine samples $(3 \times 24-h)$ were collected from the second voiding on day 4 until the first voiding on day 7. To prevent nitrogen loss through evaporation, 24-h urine was collected in containers with $10 \mathrm{~mL} \mathrm{HCl}$, whereas total volume was measured afterwards. Nitrogen concentrations were measured with a nitrogen analyzer (CHN-ORapid; Heraeus, Hanau, Germany). Protein oxidation (g/d) was calculated by multiplying 24-h urinary nitrogen $(\mathrm{g} / \mathrm{d})$ by 6.25 . Carbohydrate $(\mathrm{g} / \mathrm{d})$ and fat oxidation $(\mathrm{g} / \mathrm{d})$ were calculated with the following equations of Carpenter, as published by Brouwer (25):

Carbohydrate oxidation $=-2.97 \times \mathrm{O}_{2}(\mathrm{~L} / \mathrm{d})+4.17 \times \mathrm{CO}_{2}(\mathrm{~L} / \mathrm{d})-0.39 \times \mathrm{P}$

Fat oxidation $=1.72 \times \mathrm{O}_{2}(\mathrm{~L} / \mathrm{d})-1.72 \times \mathrm{CO}_{2}(\mathrm{~L} / \mathrm{d})-0.32 \times \mathrm{P}$, where $P$ is protein oxidation $(g / d)$.

\section{Hepatic lipid content}

Liver fat content was measured before and after overfeeding with a high-fat diet, on a 3.0 T scanner (Achieva, Philips Healthcare, Best, The Netherlands) using a SENSE-cardiac coil (29). A single voxel of $20 \times 20 \times 20 \mathrm{~mm}^{3}$ was positioned in the right liver lobe, avoiding large biliary or vascular structures (29). Spectra were acquired using a point-resolved spectroscopy sequence PRESS (29) with repetition time of $4000 \mathrm{~ms}$, echo time of $33 \mathrm{~ms}$, and number of averages of 64 . To minimize the motion artifacts, subjects were asked to breathe in the rhythm of the measurement and to be at end-expiration during acquisition of spectra (30). To determine the intensity of the lipid peak, the water signal was suppressed using frequency-selective prepulses. The unsuppressed water resonance was used as internal reference (number of averages $=16$ ). The spectra were fitted with AMARES (31) in the jMRUI software (32). Values are given as T2-corrected ratios of the 
$\mathrm{CH}_{2}$ peak, relative to the unsuppressed water resonance (as percentage) according to Hamilton et al. (33).

\section{Oral glucose tolerance test (OGTT)}

Subjects underwent an OGTT test before and after overfeeding with a high-fat diet under sedentary conditions. A fasting blood sample was taken $(t=0)$, after which subjects drank a glucose solution ( $82.5 \mathrm{~g}$ glucose monohydrate dissolved in $600 \mathrm{~mL}$ water) within 5 min (34), a modification of the American Diabetes Association (ADA) guidelines (35). Venous blood samples were collected every $15 \mathrm{~min}$ for the first hour $(t=15, t=30, t=45$ and $t=60)$ and every $30 \mathrm{~min}$ for the second hour $(t=90$ and $t=120)$. Plasma glucose and insulin concentrations were measured to determine glucose tolerance according to ADA criteria (36), the HOMA-index (37) and the oral glucose insulin sensitivity (OGIS)-index (38).

\section{Blood analysis}

Blood was collected in tubes containing $30 \mu \mathrm{l}$ of $0.2 \mathrm{~mol} / \mathrm{L}$ EDTA. Plasma was immediately centrifuged at $3000 \mathrm{rpm}$ for $10 \mathrm{~min}$, frozen in liquid nitrogen and stored at $80^{\circ} \mathrm{C}$ until analysis. Glucose (Roche, Basel, Switzerland) concentrations were determined enzymatically. Insulin levels were determined using a RIA (Linco Research, St. Charles, MO). Free-fatty acids (FFA) using the Wako Nefa C test kit (Neuss, Germany), triglyceride (TAG) with correction for free-glycerol (Sigma Diagnostics, St. Louis, MO), total cholesterol (Roche) by using the oxidase phenol 4-aminoantipyrine peroxidase method. High-density lipoprotein (HDL)-cholesterol was measured using the precipitation method, while lowdensity lipoprotein (LDL)-cholesterol was calculated using the Friedewald equation (39). 


\section{CHAPTER 6}

\section{Statistical analysis}

Data were first tested for normal distribution by using normality test KolmogorovSmirnov and Shapiro-Wilk. When normality was met, statistical comparison was performed using independent sample t-test. Non-normally distributed data were compared using the non-parametric Mann-Whitney $U$ test. Repeated-measures ANOVA were performed to compare within-and between-groups difference in changes in liver fat accumulation and metabolic profile before and after overfeeding with a high-fat diet. Regression analysis was applied to assess the main effect of ethnicity on parameters of interest by including potential independent variables. The IBM SPSS Statistic program version 21 (SPSS, Chicago, IL) was used for statistical analysis, and statistical significance was set as $p<0.05$.

\section{RESULTS}

\section{Subject characteristics}

South Asian subjects were Indian $(n=7)$, Pakistani $(n=1)$ and Nepali $(n=2)$. White subjects were Dutch $(n=2)$, German $(n=1)$, Irish $(n=1)$, British $(n=1)$, Polish $(n=2)$, Italian $(n=2)$ and Portuguese $(n=1)$. South Asians were measured within 3 y $(n=2)$ and within 1 y $(n=8)$ of their stay in The Netherlands. Subjects' characteristics are presented in Table 6.1. South Asians had a slightly lower BMI than whites but not statistically significant $(23.5 \pm 2.8$ versus $24.8 \pm 3.3 ; P=0.36)$. Groups were matched for body fat percentage $(22.0 \pm 5.1 \%$ and $22.8 \pm 7.2 \%$ for South Asians and whites respectively; $P=$ 0.78). The FFM was lower in South Asians $(P=0.005)$, after corrected for height, the difference in FFM disappeared $(P=0.29)$. Both ethnicities had similar activity counts $(P=$ 0.91). 
Table 6.1. Subjects' characteristics ${ }^{a}$

\begin{tabular}{lccc}
\hline \multicolumn{1}{c}{ Characteristics } & South Asian & White & P \\
\hline $\mathrm{N}$ & 10 & 10 & - \\
Age $(\mathrm{y})$ & $26 \pm 4$ & $23 \pm 2$ & 0.05 \\
Body weight $(\mathrm{kg})$ & $69.2 \pm 7.3$ & $81.9 \pm 13.6$ & 0.04 \\
Body height $(\mathrm{m})$ & $1.72 \pm 7.9$ & $1.81 \pm 6.2$ & 0.02 \\
$\mathrm{BMI}\left(\mathrm{kg} / \mathrm{m}^{2}\right.$ ) & $23.5 \pm 2.8$ & $24.8 \pm 3.3$ & 0.36 \\
Fat mass $(\%)$ & $22.0 \pm 5.1$ & $22.8 \pm 7.2$ & 0.78 \\
Fat-free mass $(\mathrm{kg})$ & $53.7 \pm 4.3$ & $61.9 \pm 6.4$ & 0.005 \\
Fat mass index $\left(\mathrm{kg} / \mathrm{m}^{2}\right)$ & $5.3 \pm 1.7$ & $5.8 \pm 2.6$ & 0.59 \\
Fat-free mass index $\left(\mathrm{kg} / \mathrm{m}^{2}\right.$ ) & $18.2 \pm 1.5$ & $18.9 \pm 1.6$ & 0.29 \\
Fat mass/fat-free mass ratio & $0.29 \pm 0.1$ & $0.31 \pm 0.1$ & 0.71 \\
Waist circumference (cm) & $85.1 \pm 6.5$ & $88.2 \pm 8.6$ & 0.37 \\
Hip circumference (cm) & $97.7 \pm 5.8$ & $102.0 \pm 9.9$ & 0.25 \\
Waist to hip ratio & $0.87 \pm 0.03$ & $0.87 \pm 0.03$ & 0.68 \\
Physical activity & $1254 \pm 395$ & $1271 \pm 243$ & 0.91 \\
accelerometer $\left(10^{3}\right.$ counts/d) & & & \\
PAL & $1.67 \pm 0.1$ & $1.68 \pm 0.06$ & 0.89 \\
\hline Values are mean \pm SDs; PAL, physical activity level. & & \\
Differences between the groups in normally distributed data were assessed using an Independent \\
t-test, non-normally distributed data were assessed using non-parametric test Mann-Whitney U test.
\end{tabular}

\section{Energy intake and macronutrients composition during the dietary intervention}

Whites had a higher energy need due to a higher FFM. Whites had a slightly higher energy intake during the weight maintenance period, although not statistically significant $(P=0.39)$. The actual energy intake was $11.5 \pm 1.0 \mathrm{MJ} / \mathrm{d}$ and $12.2 \pm 2.1 \mathrm{MJ} / \mathrm{d}$, containing fat, $29.3 \pm 0.8 \%$ and $28.8 \pm 1.1 \%(P=0.13)$; carbohydrate, $55.2 \pm 1.1 \%$ and $56.0 \pm 1.5 \%(P=$ $0.21)$; protein, $15.5 \pm 0.5 \%$ and $15.4 \pm 0.6 \%(P=0.70)$ for South Asians and whites respectively.

During the overfeeding period, South Asians and whites consumed $150 \pm 13 \%$ and 161 $\pm 27 \%(P=0.28)$ of weight maintenance requirements respectively. The macronutrient 


\section{CHAPTER 6}

composition was $59.4 \pm 0.6 \%$ and $59.0 \pm 0.6 \%$ fat $(P=0.21), 26.3 \pm 0.8 \%$ and $26.4 \pm 0.7 \%$ carbohydrate $(P=0.77)$ and $14.3 \pm 0.3 \%$ and $14.5 \pm 0.4 \%$ protein $(P=0.14)$ for South Asians and whites respectively.

\section{Energy expenditure and substrate oxidation}

The compliance to the overfeeding intervention along with the energy and substrate use is presented in Table 6.2. Whites had a higher energy intake $(P=0.03)$ and a higher TEE $(P=0.004)$, but energy balance was similar between groups $(P=0.32)$. Substrate balances (Figure 6.1) were also similar between groups (protein balance, $P=0.25$; carbohydrate balance, $P=0.48$; fat balance, $P=0.99$ ). Whites had a higher SMR due to their higher FFM than South Asians, after corrected for FFM, SMR did not differ between groups $(P=0.12)$. The contribution of SMR, AEE and DIT to TEE did not differ between groups and was on average $75-76 \%(P=0.82), 13-15 \%(P=0.17)$ and $10 \%(P=0.76)$ respectively.

Substrate oxidation as a percentage of TEE was comparable between groups, with a large inter-individual variation in the fat and carbohydrate oxidation in each group. For South Asians and whites respectively, fat oxidation was $30.9 \pm 19.4 \%$ and $38.6 \pm 12.0 \%$ of TEE $(P=0.30)$, carbohydrate oxidation was $53.6 \pm 18.3 \%$ and $46.6 \pm 9.6 \%$ of TEE $(P=0.30)$ and protein oxidation was $15.5 \pm 3.1 \%$ and $14.8 \pm 4.0 \%$ of TEE $(P=0.68)$. 
Table 6.2. Energy expenditure and substrate oxidation during short-term overfeeding ${ }^{a}$

\begin{tabular}{lccc}
\hline & South Asian & White & P \\
\hline Energy Intake (MJ/d) & $17.4 \pm 1.4$ & $19.3 \pm 1.7$ & 0.03 \\
Total Energy Expenditure, TEE (MJ/d) & $9.4 \pm 0.8$ & $10.8 \pm 0.9$ & 0.004 \\
Sleeping Metabolic Rate, SMR corrected for FFM (MJ/d) & $7.4 \pm 0.3$ & $8.2 \pm 0.3$ & 0.12 \\
- SMR contribution (\% of TEE) & $76.6 \pm 4.3$ & $75.1 \pm 6.4$ & 0.82 \\
Resting Energy Expenditure (MJ/d) & $8.2 \pm 0.7$ & $9.2 \pm 0.7$ & 0.009 \\
Diet Induce Thermogenesis, DIT (MJ/d) & $1.0 \pm 0.3$ & $1.1 \pm 0.3$ & 0.52 \\
- DIT contribution (\%TEE) & $10.6 \pm 2.8$ & $10.2 \pm 2.8$ & 0.76 \\
Activity Energy Expenditure, AEE (MJ/d) & $1.2 \pm 0.3$ & $1.6 \pm 0.6$ & 0.04 \\
- AEE contribution (\%TEE) & $12.8 \pm 3.0$ & $14.7 \pm 3.9$ & 0.17 \\
Energy Balance (MJ/d) & $8.0 \pm 1.2$ & $8.5 \pm 1.7$ & 0.32 \\
RQ & $0.88 \pm 0.05$ & $0.86 \pm 0.03$ & 0.29 \\
24 h Fat oxidation (MJ/d) & $2.8 \pm 2.0$ & $3.9 \pm 1.3$ & 0.16 \\
- Fat oxidation (\%TEE) & $30.9 \pm 19.4$ & $38.6 \pm 12.0$ & 0.30 \\
24 h Carbohydrate oxidation (MJ/d) & $4.6 \pm 1.5$ & $4.7 \pm 1.0$ & 0.91 \\
- Carbohydrate oxidation (\%TEE) & $53.6 \pm 18.3$ & $46.6 \pm 9.6$ & 0.30 \\
24 h Protein oxidation (MJ/d) & $1.4 \pm 0.3$ & $1.5 \pm 0.4$ & 0.44 \\
- Protein oxidation (\%TEE) & $15.5 \pm 3.1$ & $14.8 \pm 4.0$ & 0.68 \\
\hline Vales are means SDs. & & & \\
\hline
\end{tabular}

\footnotetext{
${ }^{a}$ Values are means \pm SDs.

Differences between the groups in normally distributed data were assessed using an Independent t-test, non-normally distributed data were assessed using non-parametric test Mann-Whitney $U$ test.
} 


\section{CHAPTER 6}

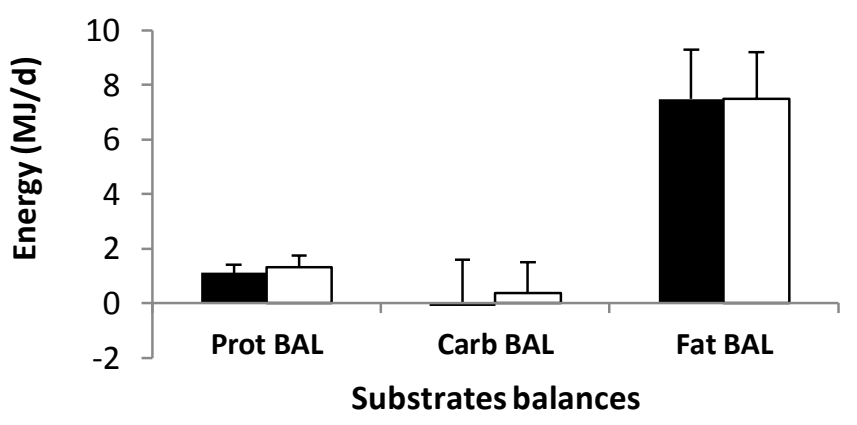

- South Asian $\quad \square$ White

Figure 6.1. Substrate balances during overfeeding period. South Asians (black bars), whites (white bars). Values are means and SDs represented by vertical bars. Differences between the groups were assessed using an independent t-test, protein balances $(P=0.25)$, carbohydrate balances $(P=0.48)$ and fat balances $(P=0.99)$.

\section{Liver fat content}

Liver fat content at baseline did not differ between ethnicities $(1.7 \pm 1.4 \%$ and $2.6 \pm 3.5 \%$, $P=0.45)$ in South Asians and whites respectively. In Figure 6.2, high-fat overfeeding increased liver fat $(P=0.02)$, being $2.7 \pm 1.9 \%$ and $3.1 \pm 4.9 \%$ in South Asians and whites respectively, but the increase was similar between ethnicities $(P=0.64)$. There was no association between the change in liver fat content and 24-h fat oxidation $(r=-0.17, P=$ $0.47)$ and fat balance $(r=-0.03, P=0.90)$.

\section{Fasting plasma parameters}

Plasma parameters are presented in Table 6.3. High-fat overfeeding under sedentary conditions decreased fasting NEFA $(P=0.03)$ and TAG $(P=0.001)$ similarly $(P=0.44$ and $P=$ 0.83 respectively) in both ethnicities. LDL-cholesterol tended to increase more in South 
Asians than in whites $(P=0.08)$. Overfeeding increased fasting insulin $(P=0.04)$ and the HOMA-index $(P=0.04)$ similarly in both ethnicities $(P=0.56$ and $P=0.55$ respectively).

a.

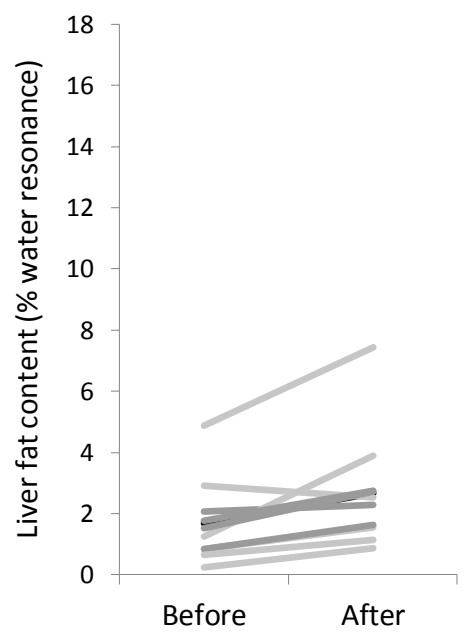

b.

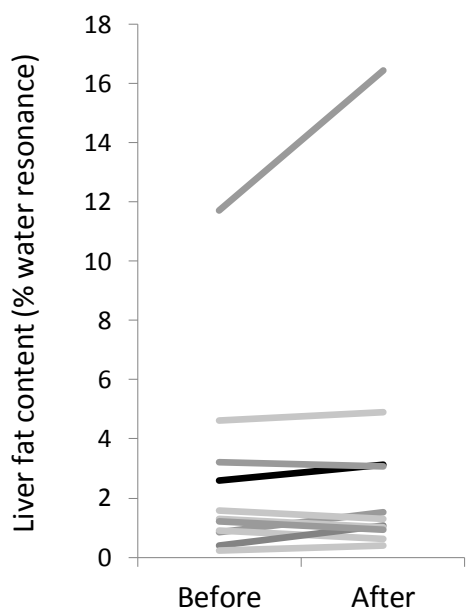

Figure 6.2. Individual (grey line) and the mean (black line) response of liver fat content to overfeeding with a high-fat diet under sedentary conditions in South Asians (a) and whites (b). Liver fat content before and after overfeeding with a high-fat diet were assessed using repeated-measure ANOVA. Overfeeding with a high-fat diet increased liver fat content $(P=0.02)$ but the increase did not differ between ethnicities $(P=0.64)$.

\section{Glucose clearance (insulin sensitivity)}

High-fat overfeeding under sedentary conditions decreased glucose clearance $(P=$ 0.001) expressed as the OGIS-index (Table 6.3) and the decrease tended to be larger in South Asians than whites $(P=0.06)$. Figure 6.3 shows that overfeeding increased glucose response $(P=0.002)$ and insulin response $(P=0.002)$ during the 2-h OGTT, with a 


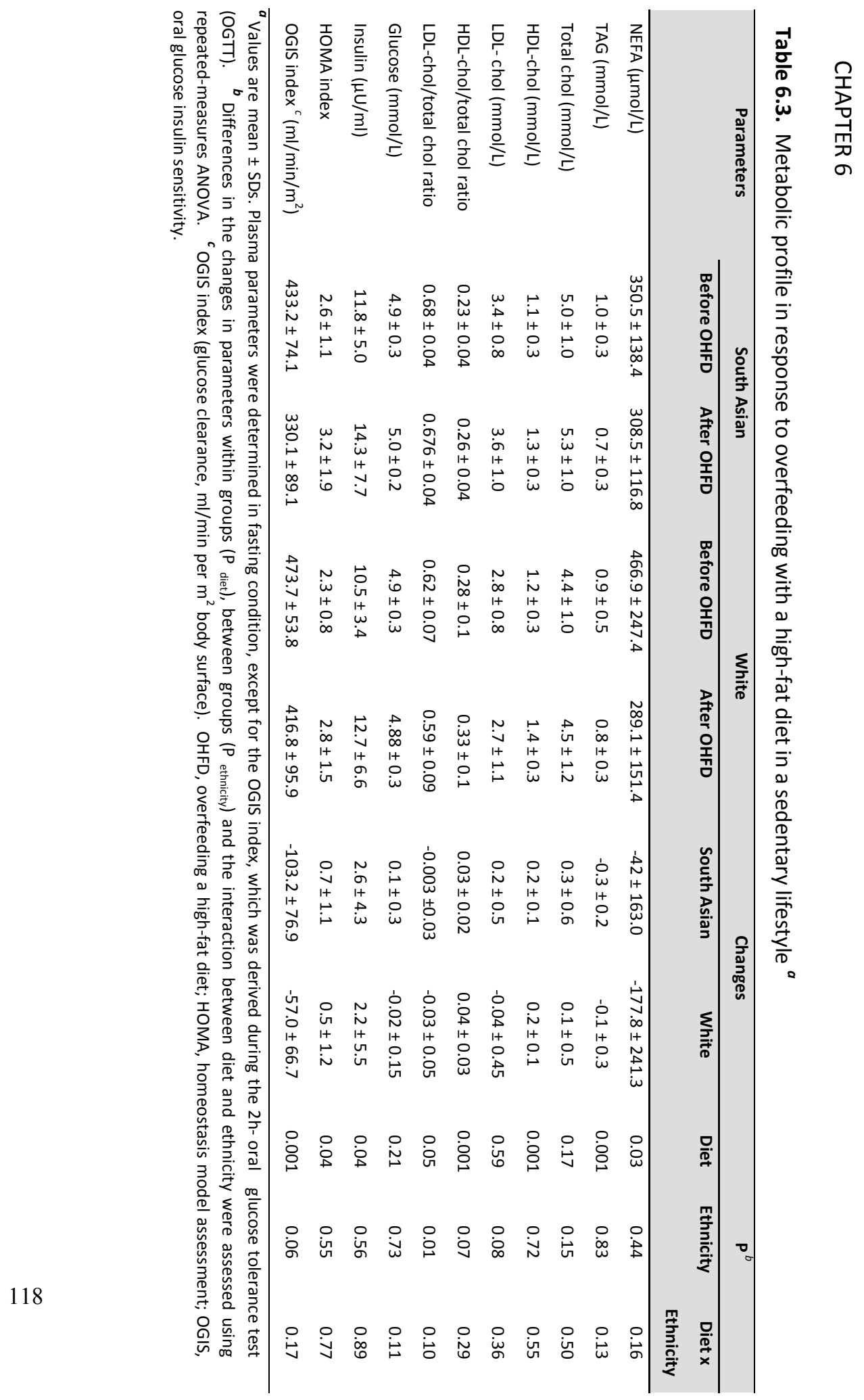


tendency towards a higher increase in South Asians than whites $(P=0.06$ and $P=0.07)$ for glucose and insulin response respectively.

The change in liver fat content was positively correlated with the change in fasting insulin $(r=0.55, P=0.01)$, HOMA- index $(r=0.57, P<0.01)$, glucose response over 2 -h $(r=$ $0.48, P=0.03)$, insulin response over 2-h OGTT $(r=0.39, P=0.09)$ and was negatively correlated with glucose clearance/ the change in OGIS-index $(r=-0.40, P=0.09)$.

In a multiple regression analysis, the increase in liver fat content predicted $(P=0.04)$ and a higher body fat tended to predict $(P=0.08)$ the increased fasting insulin, together explained $42 \%$ of the variation. The increased liver fat content predicted $(P=0.03)$ and a higher body fat tended to predict $(P=0.08$ ) the increased HOMA-index, explained $44 \%$ of the variation. Ethnicity was not a significant predictor for those parameters. The increased glucose response over 2-h OGTT was predicted by ethnicity $(P=0.05)$, South Asians more than whites and by a higher body fat $(P=0.04)$ which explained $35 \%$ of the variation.

\section{DISCUSSION}

Our study demonstrated that South Asian and white men matched for body fat percentage, oxidized fat (as percentage of TEE), similarly in response to overfeeding with a high-fat diet under sedentary conditions. However, there was a large inter-individual variation in the contribution of fat oxidation to TEE in each ethnic group. Liver fat content increased similarly in both groups. Despite an equal contribution of fat oxidation to TEE and a comparable increase in liver fat content, South Asians tended to have an adverse lipoprotein profile and a larger decrease in glucose clearance and insulin sensitivity. 


\section{CHAPTER 6}

a.

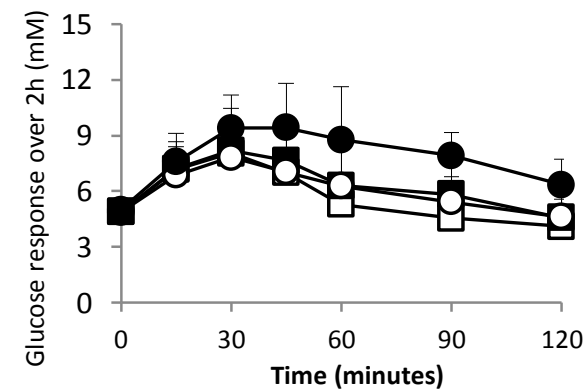

$\longrightarrow$ White_Before OHFD White_After OHFD

$\longrightarrow$ South Asian_Before OHFD $\longrightarrow$ South Asian_After OHFD

c.

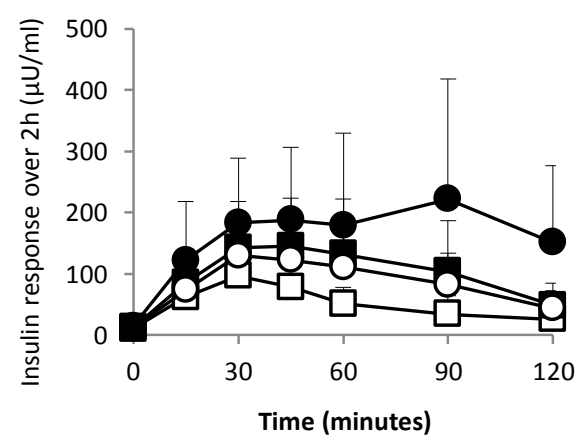

- White_Before OHFD

$\longrightarrow$ White_After OHFD

$\longrightarrow$ South Asian_Before OHFD

$\longrightarrow$ South Asian_After OHFD b.

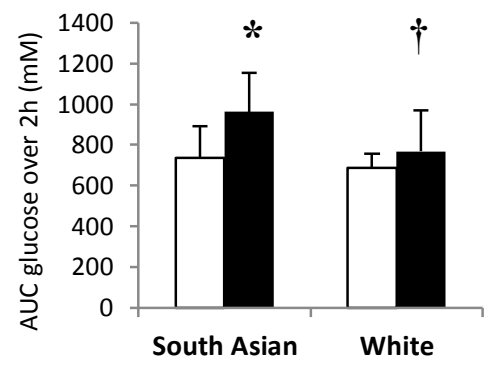

$\square$ Before OHFD $\mathbf{A f t e r}$ OHFD d.

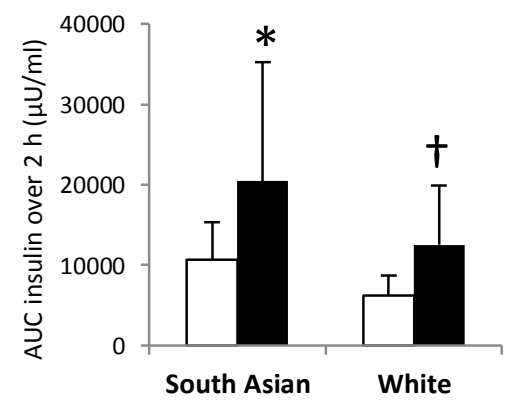

$\square$ Before OHFD $\square$ After OHFD

Figure 6.3. Glucose (a) and insulin (c) responses to overfeeding with a high fat diet (OHFD) under

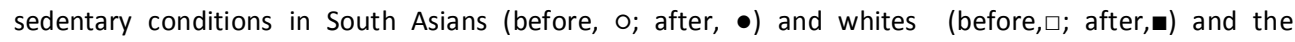
corresponding AUC of glucose (b) and insulin (d) during 2-h OGTT (before, $\square$; after, $\mathbf{a})$. Values are means and standard deviations represented by vertical bars. Differences within and between groups after dietary intervention were assessed using repeated-measures ANOVA. AUC glucose $\left(P\right.$ diet $=0.002 ; P_{\text {ethnicity }}=0.06$; $\left.P_{\text {diet } x \text { ethnicity }}=0.09\right)$, AUC insulin $\left(P_{\text {diet }}=0.002 ; P_{\text {ethnicity }}=0.07 ; P_{\text {diet } x \text { ethnicity }}=0.42\right)$. 
The sedentary conditions were confirmed by the large contribution of SMR to TEE, reaching on average $75-76 \%$ of TEE in both groups, resulting in a mean PAL of 1.32. AEE was only $13-15 \%$ of TEE, whereas at the same time overfeeding resulted in a similar DIT of around $10 \%$ for both ethnicities. Physical activity energy expenditure is a major determinant of dietary fat oxidation (14), it lowers glycogen storage (13) and stimulates fat oxidation (40).

Although the diet was high in dietary fat $(60 \%)$, substrate partitioning showed a greater reliance on carbohydrate oxidation in both groups (on average $47-53 \%$ of TEE). Under sedentary conditions, glycogen stores were maintained (not depleted) therefore the degree of replenishment of the body's glycogen stores was low. This condition influences the contribution made by glucose and fatty acids to the fuel mix oxidized (41). Most of the glucose was oxidized to match carbohydrate intake, as the body glycogen stores are small ${ }^{(40)}$. Therefore, the contribution of carbohydrate oxidation to TEE was higher and fat was oxidized to a lesser extent to meet total energy requirement. Thus, most of the dietary fat was stored, resulting in a positive fat balance of 7-7.5 MJ/d. In addition, overfeeding prolonged the postprandial period and high insulin levels, thus promoting fat storage rather than oxidation. To meet energy requirements, the body oxidized more carbohydrate during the prolonged postprandial period. Consequently, the contribution of fat oxidation was lower during the post-absorptive period.

Indeed, we observed a large inter-individual variation in the contribution of carbohydrate and fat oxidation to TEE, whereas protein oxidation was comparable and did not vary between ethnicities. Most individuals maintain relatively stable body weights and body composition during long periods of their lives $(42,43)$. This steady state of approximate weight maintenance, implies that their average energy intake matches their average energy expenditure and also the composition of the fuel mix that the body oxidizes is equivalent to the nutrient mix consumed (43). We assumed that before 


\section{CHAPTER 6}

overfeeding, our subjects were in a steady state condition, in which glycogen level was maintained at the habitual level. Overfeeding disturbed this steady state. It has been suggested that fat oxidation is restrained until the expansion of the body fat mass is sufficient to promote fat oxidation to a rate proportional to dietary fat intake (43). For many individuals, the new steady state is reached only after an excessive amount of body fat has been accumulated, which may explain the observed large variation in the contribution of fat and carbohydrate oxidation.

There was lack of association between the changes in liver fat content and 24-h fat oxidation, suggesting that liver fat accumulation may be affected by hepatic fat oxidation (44) rather than whole-body fat oxidation. A significant fraction of fatty acids are taken up by the liver during the postprandial period $(15,45,46)$. Depending on the amount of fat given, liver fat increased within 3 days $(44)$ up to 2-3 weeks $(15,16)$. South Asians were reported to have a higher liver fat content as compared to BMI-matched whites (47), which may be expected as Asians have a higher body fat for the same BMI than whites $(4,8,48)$. In the present study, matching the two ethnicities for body fat percentage instead of BMI showed that baseline liver fat content and the increase in response to overfeeding did not differ between ethnicities, as we observed previously under free-living conditions.

Under sedentary conditions, LDL-cholesterol tended to increase more in South Asians in response to overfeeding, thus consistent with the study performed in free-living condition (17). This may indicate differences in the rate of LDL clearance and production between ethnicities (49). Fasting NEFA decreased similarly in both ethnicities and may be due to the suppression of lipolysis by relatively higher insulin levels (50). TAG decreased after high-fat overfeeding but similar between ethnicities, and may be attributed to a lower proportion of carbohydrate in the high-fat diet (51-53). High-carbohydrate intakes are hypothesized to increase TAG by inhibiting LPL action through increased apo CIII 
production (54), high-fat intakes do not affect LPL and TAG clearance from the circulation (55).

Recently, we observed a similar decrease in insulin sensitivity in South Asians and whites in response to overfeeding with a high-fat diet under free-living conditions (17). In the present study, subjects were sedentary and South Asians tended to have a larger decrease in insulin sensitivity than whites. This suggests that South Asians may be more susceptible to the negative effect of being sedentary. The increase in fasting insulin and HOMA-index was strongly associated with the increase in liver fat content. Insulin is wellknown to hamper fat oxidation and to stimulate triglyceride storage in the liver, thereby favoring accretion of liver fat (44). On the other hand, increased liver fat may be underlying insulin resistance, which in turn leads to elevated plasma insulin levels (50).

The low number of subjects was a limitation of our study, which is a direct consequence of the use of these state-of-the-art and labor-intensive techniques. However, the experimental set-up used is highly relevant, creating sedentary conditions for $3 \mathrm{~d}$ and simultaneously overfeeding with a high-fat diet, is a more physiological approach than lipid infusions and/or a very high-fat drink, as we are commonly exposed to short-term overfeeding with a high-fat during feast period.

In conclusions, in South Asians and whites with similar body fat percentage, substrate partitioning was similar in response to overfeeding with a high-fat diet. Despite similar response of the two ethnicities in terms of substrate oxidation and liver fat accumulation, insulin sensitivity seems to be affected more severely in the Asian population.

\section{ACKNOWLEDGEMENT}

We gratefully thank Paul Schoffelen, Loek Wouters, Jos Stegen, Wendy Sluijsmans and Hasibe Aydeniz for technical assistance and help with the analysis. We thank Henk Schoenmakers, Roland Kersemakers and the technicians of the MRI Unit, Academic 


\section{CHAPTER 6}

Hospital Maastricht for technical assistance. Also, we deeply appreciate and thank all subjects who participated in the study.

The study was funded by a scholarship from The Directorate General of Higher Education, The Ministry of Education and Culture (former Ministry of Research, Technology and Higher Education) of The Republic of Indonesia, to SNW. The Ministry of Education and Culture of The Republic of Indonesia had no role in the design and analysis of the study and in the writing of this article. In addition, VBS-H was supported by a veni grant (91611136) for innovative research from the Netherlands Organization for Scientific Research.

The authors' responsibilities were as follows-SNW: conducted the research, performed the data analysis, and wrote the manuscript; KRW, VBS-H and GP: designed the study, interpreted the data, and reviewed the manuscript.

None of the authors had a conflict of interest.

\section{REFERENCES}

1. Kelly T, Yang W, Chen CS, Reynolds K, He J: Global burden of obesity in 2005 and projections to 2030. Int J Obes (Lond) 2008; 32: 1431-1437.

2. Chopra M, Galbraith S, Darnton-Hill I: A global response to a global problem: the epidemic of overnutrition. Bull World Health Organ 2002; 80: 952-958.

3. Yoon KH, Lee JH, Kim JW, Cho JH, Choi YH, Ko SH et al.: Epidemic obesity and type 2 diabetes in Asia. Lancet 2006; 368: 1681-1688.

4. Forouhi NG, Jenkinson G, Thomas EL, Mullick S, Mierisova S, Bhonsle U et al.: Relation of triglyceride stores in skeletal muscle cells to central obesity and insulin sensitivity in European and South Asian men. Diabetologia 1999; 42: 932-935.

5. Chandalia M, Lin P, Seenivasan T, Livingston EH, Snell PG, Grundy SM et al.: Insulin resistance and body fat distribution in South Asian men compared to Caucasian men. PLoS One 2007; 2: e812.

6. Nair KS, Bigelow ML, Asmann YW, Chow LS, Coenen-Schimke JM, Klaus KA et al.: Asian Indians have enhanced skeletal muscle mitochondrial capacity to produce ATP in association with severe insulin resistance. Diabetes 2008; 57: 1166-1175.

7. Rush EC, Freitas I, Plank LD: Body size, body composition and fat distribution: comparative analysis of European, Maori, Pacific Island and Asian Indian adults. Br J Nutr 2009; 102: 632-641.

8. Wulan SN, Westerterp KR, Plasqui G: Dietary and 24-h fat oxidation in Asians and whites who differ in body composition. Am J Clin Nutr 95: 1335-1341.

9. Andreasen $\mathrm{CH}$, Stender-Petersen KL, Mogensen MS, Torekov SS, Wegner L, Andersen G et al:: Low physical activity accentuates the effect of the FTO rs9939609 polymorphism on body fat accumulation. Diabetes 2008; 57: 95-101. 
10. King GA, Fitzhugh EC, Bassett DR, Jr., McLaughlin JE, Strath SJ, Swartz AM et al.: Relationship of leisure-time physical activity and occupational activity to the prevalence of obesity. Int J Obes Relat Metab Disord 2001; 25: 606-612.

11. Kim IY, Park S, Trombold JR, Coyle EF: Effects of Moderate- and Intermittent Low-Intensity Exercise on Postprandial Lipemia. Med Sci Sports Exerc 2014.

12. Bergouignan A, Kealey EH, Schmidt SL, Jackman MR, Bessesen DH: Twenty-four hour total and dietary fat oxidation in lean, obese and reduced-obese adults with and without a bout of exercise. PLoS One 2014; 9: e94181.

13. Schrauwen $P$, van Marken Lichtenbelt WD, Saris WH, Westerterp KR: Role of glycogen-lowering exercise in the change of fat oxidation in response to a high-fat diet. Am J Physiol 1997; 273: E623-629.

14. Bergouignan A, Momken I, Lefai E, Antoun E, Schoeller DA, Platat C et al.: Activity energy expenditure is a major determinant of dietary fat oxidation and trafficking, but the deleterious effect of detraining is more marked than the beneficial effect of training at current recommendations. Am J Clin Nutr 2013; 98: 648-658.

15. Westerbacka J, Lammi K, Hakkinen AM, Rissanen A, Salminen I, Aro A et al.: Dietary fat content modifies liver fat in overweight nondiabetic subjects. J Clin Endocrinol Metab 2005; 90: 2804-2809.

16. van Herpen NA, Schrauwen-Hinderling VB, Schaart G, Mensink RP, Schrauwen P: Three weeks on a high-fat diet increases intrahepatic lipid accumulation and decreases metabolic flexibility in healthy overweight men. J Clin Endocrinol Metab 2011; 96: E691-695.

17. Wulan SN, Westerterp KR, Plasqui G: Metabolic profile before and after short-term overfeeding with a highfat diet: a comparison between South Asian and White men. Br J Nutr 2014; 111: 1853-1861.

18. Westerterp KR, Wouters L, van Marken Lichtenbelt WD: The Maastricht protocol for the measurement of body composition and energy expenditure with labeled water. Obes Res 1995; 3 Suppl 1: 49-57.

19. Siri WE: The gross composition of the body. Adv Biol Med Phys 1956; 4: 239-280.

20. Bonomi AG, Plasqui G, Goris AH, Westerterp KR: Estimation of free-living energy expenditure using a novel activity monitor designed to minimize obtrusiveness. Obesity (Silver Spring) 18: 1845-1851.

21. Joosen AM, Bakker AH, Zorenc AH, Kersten S, Schrauwen P, Westerterp KR: PPARgamma activity in subcutaneous abdominal fat tissue and fat mass gain during short-term overfeeding. Int J Obes (Lond) 2006; 30: 302-307.

22. Schrauwen-Hinderling VB, Kooi ME, Hesselink MK, Moonen-Kornips E, Schaart G, Mustard KJ et al.: Intramyocellular lipid content and molecular adaptations in response to a 1-week high-fat diet. Obes Res 2005; 13: 2088-2094.

23. Schrauwen $P$, van Marken Lichtenbelt WD, Saris WH, Westerterp KR: Changes in fat oxidation in response to a high-fat diet. Am J Clin Nutr 1997; 66: 276-282.

24. Schoffelen PF, Westerterp KR, Saris WH, Ten Hoor F: A dual-respiration chamber system with automated calibration. J Appl Physiol 1997; 83: 2064-2072.

25. Brouwer E: On simple formulae for calculating the heat expenditure and the quantities of carbohydrate and fat oxidized in metabolism of men and animals, from gaseous exchange (Oxygen intake and carbonic acid output) and urine-N. Acta Physiol Pharmacol Neerl 1957; 6: 795-802.

26. Hochstenbach-Waelen A, Veldhorst MA, Nieuwenhuizen AG, Westerterp-Plantenga MS, Westerterp KR: Comparison of 2 diets with either $25 \%$ or $10 \%$ of energy as casein on energy expenditure, substrate balance, and appetite profile. Am J Clin Nutr 2009; 89: 831-838.

27. Wouters-Adriaens MP, Westerterp KR: Low resting energy expenditure in Asians can be attributed to body composition. Obesity (Silver Spring) 2008; 16: 2212-2216.

28. Westerterp KR, Plasqui G: Physical activity and human energy expenditure. Curr Opin Clin Nutr Metab Care 2004; 7: 607-613.

29. van Werven JR, Hoogduin JM, Nederveen AJ, van Vliet AA, Wajs E, Vandenberk P et al.: Reproducibility of 3.0 Tesla magnetic resonance spectroscopy for measuring hepatic fat content. J Magn Reson Imaging 2009; 30: 444-448. 


\section{CHAPTER 6}

30. Timmers S, Konings E, Bilet L, Houtkooper RH, van de Weijer T, Goossens GH et al.: Calorie restriction-like effects of 30 days of resveratrol supplementation on energy metabolism and metabolic profile in obese humans. Cell Metab 14: 612-622.

31. Vanhamme L, van den Boogaart A, Van Huffel S: Improved method for accurate and efficient quantification of MRS data with use of prior knowledge. J Magn Reson 1997; 129: 35-43.

32. Naressi A, Couturier C, Devos JM, Janssen M, Mangeat C, de Beer R et al.: Java-based graphical user interface for the MRUI quantitation package. MAGMA 2001; 12: 141-152.

33. Hamilton G, Yokoo T, Bydder M, Cruite I, Schroeder ME, Sirlin CB et al.: In vivo characterization of the liver fat (1)H MR spectrum. NMR Biomed 24: 784-790.

34. Sievenpiper JL, Jenkins DJ, Josse RG, Vuksan V: Dilution of the 75-g oral glucose tolerance test improves overall tolerability but not reproducibility in subjects with different body compositions. Diabetes Res Clin Pract 2001; 51: 87-95.

35. Report of the Expert Committee on the Diagnosis and Classification of Diabetes Mellitus. Diabetes Care 1997; 20: 1183-1197.

36. Standards of medical care in diabetes--2010. Diabetes Care 33 Suppl 1: S11-61.

37. Levy JC, Matthews DR, Hermans MP: Correct homeostasis model assessment (HOMA) evaluation uses the computer program. Diabetes Care 1998; 21: 2191-2192.

38. Mari A, Pacini G, Murphy E, Ludvik B, Nolan JJ: A model-based method for assessing insulin sensitivity from the oral glucose tolerance test. Diabetes Care 2001; 24: 539-548.

39. Friedewald WT, Levy RI, Fredrickson DS: Estimation of the concentration of low-density lipoprotein cholesterol in plasma, without use of the preparative ultracentrifuge. Clin Chem 1972; 18: 499-502.

40. Flatt JP: Use and storage of carbohydrate and fat. Am J Clin Nutr 1995; 61: 952S-959S.

41. Flatt JP: Glycogen levels and obesity. Int J Obes Relat Metab Disord 1996; 20 Suppl 2: S1-11.

42. Westerterp KR: Metabolic adaptations to over--and underfeeding--still a matter of debate? Eur J Clin Nutr 2013; 67: 443-445.

43. Flatt JP: Carbohydrate-fat interactions and obesity examined by a two-compartment computer model. Obes Res 2004; 12: 2013-2022.

44. van der Meer RW, Hammer S, Lamb HJ, Frolich M, Diamant M, Rijzewijk LJ et al.: Effects of short-term highfat, high-energy diet on hepatic and myocardial triglyceride content in healthy men. $J$ Clin Endocrinol Metab 2008; 93: 2702-2708.

45. Heath RB, Karpe F, Milne RW, Burdge GC, Wootton SA, Frayn KN: Selective partitioning of dietary fatty acids into the VLDL TG pool in the early postprandial period. J Lipid Res 2003; 44: 2065-2072.

46. Lindeboom L, Nabuurs Cl, Hesselink MK, Wildberger JE, Schrauwen P, Schrauwen-Hinderling VB: Proton magnetic resonance spectroscopy reveals increased hepatic lipid content after a single high-fat meal with no additional modulation by added protein. Am J Clin Nutr 2015; 101: 65-71.

47. Anand SS, Tarnopolsky MA, Rashid S, Schulze KM, Desai D, Mente A et al.: Adipocyte hypertrophy, fatty liver and metabolic risk factors in South Asians: the Molecular Study of Health and Risk in Ethnic Groups (molSHARE). PLoS One 6: e22112.

48. Deurenberg $P$, Deurenberg-Yap M, Guricci S: Asians are different from Caucasians and from each other in their body mass index/body fat per cent relationship. Obes Rev 2002; 3: 141-146.

49. Sniderman AD, De Graaf J, Couture P, Williams K, Kiss RS, Watts GF: Regulation of plasma LDL: the apoB paradigm. Clin Sci (Lond) 118: 333-339.

50. Brons C, Jensen CB, Storgaard H, Hiscock NJ, White A, Appel JS et al.: Impact of short-term high-fat feeding on glucose and insulin metabolism in young healthy men. J Physiol 2009; 587: 2387-2397.

51. Sharman MJ, Gomez AL, Kraemer WJ, Volek JS: Very low-carbohydrate and low-fat diets affect fasting lipids and postprandial lipemia differently in overweight men. J Nutr 2004; 134: 880-885.

52. Hu T, Mills KT, Yao L, Demanelis K, Eloustaz M, Yancy WS, Jr. et al.: Effects of low-carbohydrate diets versus low-fat diets on metabolic risk factors: a meta-analysis of randomized controlled clinical trials. Am J Epidemiol 176 Suppl 7: S44-54. 
53. Merchant AT, Anand SS, Kelemen LE, Vuksan V, Jacobs R, Davis B et al:: Carbohydrate intake and HDL in a multiethnic population. Am J Clin Nutr 2007; 85: 225-230.

54. Grundy SM, Abate N, Chandalia M: Diet composition and the metabolic syndrome: what is the optimal fat intake? Am J Med 2002; 113 Suppl 9B: 25S-29S.

55. Grundy SM: Hypertriglyceridemia, atherogenic dyslipidemia, and the metabolic syndrome. Am J Cardiol 1998; 81: 18B-25B. 


\section{CHAPTER 7}

Molecular adaptation in response to overfeeding with a high-fat diet under sedentary conditions in South Asian and Caucasian men

SN Wulan, FG Bouwman, KR Westerterp, ECM Mariman and G Plasqui Submitted for publication 


\section{CHAPTER 7}

\section{ABSTRACT}

Background: For the same BMI, South Asians have a higher body fat percentage than Caucasians. There might be differences in the fatty acid handling in adipose tissue when both ethnicities are exposed to high fat overfeeding.

Objective: The objective of the present study was to investigate the molecular adaptation in relation to fatty acid metabolism in response to overfeeding with a high fat diet in South Asian and Caucasian men.

Methods: Ten South Asian men (BMI, $18-29 \mathrm{~kg} / \mathrm{m}^{2}$ ) and 10 Caucasian men (BMI, 22-33 $\mathrm{kg} / \mathrm{m}^{2}$ ), matched for body fat percentage, aged 20-40 y were included. A weight maintenance diet (30\% fat, $55 \%$ carbohydrate and $15 \%$ protein) was given for 3 days followed by 3 days of overfeeding ( $150 \%$ energy requirement) with a high fat diet $(60 \%$ fat, $25 \%$ carbohydrate and $15 \%$ protein) while staying in a respiration chamber mimicking a sedentary life style. Before and after overfeeding, abdominal subcutaneous fat biopsies were taken. Proteins were isolated, analyzed and quantified for HADH, CPT1a, ATGL, PLINA, PLINB, LPL and FABP4 using Western blotting.

Results: There was a large inter-individual variation in the protein levels as a response to overfeeding with a high fat diet in both ethnic groups. Overfeeding with high fat diet decreased the HADH level $(P<0.05)$ in Caucasians more than in Asians $(P<0.05)$, but the baseline and after intervention HADH level was relatively higher in Caucasians. The level of CPT1a decreased in South Asians and increased in Caucasians $(P<0.05)$. PLINA did not change with diet but differed between ethnicities $(P<0.05)$. Other proteins were unaffected by the intervention and did not differ between ethnicities.

Conclusion: The observed differences in HADH and PLINA levels and as well as in CPT1a response may be important for differences in the long-term regulation of energy (fat) metabolism in these populations. 


\section{INTRODUCTION}

In contrast to people in Western countries, people from South Asian countries (Indian sub continents) were reported to develop metabolic diseases such as diabetes at a younger age and at a lower BMI (1). The prevalence of type 2 diabetes is extremely high and continues to rise in both native and migrant South Asians (2). South Asian Indians also have earlier onset, more severe and more prevalent CVD than many other ethnic groups (3).

Recent epidemiological studies $(3,4)$ reported a direct correlation between a western dietary pattern, but not with eastern (vegetarian) and mixed dietary pattern, and overall risk of metabolic syndrome in migrant South Asians in the UK (4) and in the US (3). It has been suggested that gene-environment interaction may be the cause of the rapid increase of the prevalence of diabetes and cardiovascular diseases in South Asians (5). A number of comparative studies supported this hypothesis, as South Asians were found to have a higher body fat \% for the same BMI as compared to Caucasians (6-9). The unfavorable body composition may contribute to the susceptibility of South Asians to the negative effect of the current lifestyle in Asia and western countries, where consumption of high fat foods increases and physical activity decreases. Alternatively, the inability of South Asians to cope with an obesogenic environment may initiate the development of an unfavorable body composition and obesity-associated metabolic diseases.

In Caucasian populations, a large inter-individual variation was reported in the susceptibility to weight gain under similar external influences such as decreased physical activity or excessive caloric intake $(10,11)$ suggesting genetic predisposition (12). In response to changes in caloric intake, either caloric restriction or overfeeding (13), alteration in body weight were found to be preceded by changes in adipocyte gene expression involved in lipogenesis, protein synthesis, beta oxidation and insulin resistance. In South Asians, reduced oxidative capacity and capacity for fatty acids utilization at the whole body level (measured as $\mathrm{VO}_{2}$ max and fat oxidation during sub-maximal exercise) 


\section{CHAPTER 7}

were reported to be associated with insulin resistance, but were not the consequences of reduced skeletal muscle expression of oxidative and lipid metabolism genes (14). In that study, South Asians exhibited significantly higher skeletal muscle gene expression of CPT1a and FASN and significantly lower skeletal muscle protein expression of PI3K and PKB Ser473 phosphorylation compared to Caucasians (14). Little is known about the molecular adaptation in the adipose tissue when South Asians are exposed to an obesogenic environment that favors fat storage rather than oxidation.

In the present study, we introduced a 3-day stay under sedentary conditions in a respiration chamber while overfeeding young South Asian and Caucasian men with a high fat diet. To avoid potential confounders, South Asians and Caucasians were matched for body fat percentage. The objectives of the present study were 1) to investigate the molecular adaptation focusing on proteins involved in fatty acids metabolism in the adipose tissue in response to overfeeding with a high fat diet, and 2) to test whether the molecular adaptations differ between South Asians and Caucasians.

For that purpose, seven proteins involved in fatty acids metabolism were selected and measured in adipose tissue by Western blotting. Those proteins represent different processes of fatty acids metabolism (15): lipoprotein lipase (LPL) and fatty acid binding protein (FABP4) are responsible for fatty acids uptake and transport inside the adipocyte, respectively; adipose triglyceride lipase (ATGL) and perilipin1 (PLINA and PLINB) are responsible for fatty acid release (lipolysis) and fat droplet turnover, respectively; short chain 3-hydroxyacil-CoA dehydrogenase (HADH) and carnitine palmitoyl-transferase 1alpha (CPT1a) are crucial enzymes for mitochondrial $\beta$-oxidation.

\section{SUBJECTS AND METHODS}

\section{Subjects}

Subjects were 10 healthy adult non-diabetic South Asian and 10 Caucasian men. They were matched for body fat percentage. Subject characteristics are presented in Table 7.1. 
Asian subjects had 4 grandparents from South Asia, while Caucasian subjects were European Caucasians. Subjects were selected based on the following inclusion criteria: healthy, not having metabolic diseases (diabetes or cardiovascular diseases), not using medication, aged between 20 and 40 years old with BMI (in $\mathrm{kg} / \mathrm{m}^{2}$ ) between 18-29 for South Asians and 22-33 for Caucasians, having a stable body weight for the last three months, not being on a diet and not being an athlete. All subjects received verbal and written information before giving their consent. The study was approved by The Medical Ethics Committee of Maastricht University, MEC No. 10-3-013 and registered in the public trial registry www.ccmo.nl No. NL31217.068.10

\section{Experimental design}

The study was a diet-intervention study under sedentary conditions in a respiration chamber. Body composition was measured before the start of the intervention to match body fat percentage between the 2 ethnic groups. Energy requirements for a weight maintenance diet for 3 days preceding the intervention were calculated based on fat-free mass and the daily physical activity level of each subject as measured for 7 consecutive days with an accelerometer. On the third day of the weight maintenance diet, subjects came to the university in the morning in the fasting state; abdominal subcutaneous fat biopsies were taken for baseline measurement. On the same day, after having dinner, subjects entered the respiration chamber and stayed for the next 3 days (and 4 nights). During this period, subjects were overfed with a high fat diet while no exercise or strenuous physical activity was allowed in the respiration chamber. The second fat biopsies were taken after the subjects left the chamber in the morning.

\section{Body composition}

Body composition was determined according to a 3-compartment model based on body weight, body volume and total body water. Body weight and body volume were 


\section{CHAPTER 7}

determined in the morning, in a fasted state. Body volume was determined by hydrodensitometry with simultaneous measurement of residual lung volume using the helium dilution technique. Total body water was determined with deuterium dilution according to the Maastricht protocol (16). Body composition was calculated from body density and total body water using the equation of Siri (17).

\section{Daily physical activity level}

The daily physical activity level (PAL) was measured using a Direct Life triaxial accelerometer for movement registration (Tracmor-D, Philips NewWellness Solutions; http://www.directlife.philips.com). The device is a small $(3.2 \times 3.2 \times 0.5 \mathrm{~cm})$, light-weight $(12.5 \mathrm{~g})$ instrument. The accelerometer was attached to the lower back by means of an elastic belt. It registered accelerations minute by minute, in the mediolateral (x-axis), longitudinal (y-axis) and anterioposterior (z-axis) direction of the trunk as described elsewhere (18).

Subjects were instructed to wear the accelerometer for 7 consecutive days, during waking hours except during water activities. Subjects were advised to maintain their habitual physical activity level during the diet intervention. Accelerometer output was expressed as activity counts/minute. The activity counts/minute were summed over the entire monitoring period and divided by the number of monitoring days to determine the average counts per day (counts/d).

Daily PAL was calculated based on the activity counts/d with the formula, PAL $=1.354$ $+256 \times 10^{-9} \times$ counts/d (18). Total energy expenditure (TEE) was calculated with the formula of Bonomi et al., TEE accelerometer $(\mathrm{MJ} / \mathrm{d})=0.04+0.17 \mathrm{FFM}(\mathrm{kg})+1.67 \times 10^{-6} \mathrm{x}$ counts/d (18), where FFM is fat-free mass and counts/d are activity counts from the accelerometer. 


\section{Energy intake}

The weight maintenance diet to be consumed at home for 3 days before the intervention was calculated on the basis of TEE as shown above. The energy contribution of macronutrients of the weight maintenance diet prior to the baseline measurement was $30 \%$ fat, $55 \%$ carbohydrate and $15 \%$ protein.

A written instruction was given to prepare the weight maintenance diet at home. During the weight maintenance diet, subjects were provided with the diet in an excess amount than TEE and were allowed to eat more or less from the diet according to what they needed (ad libitum). Any additional intake from those prescribed foods was recorded. All unfinished foods were collected and returned to the university, to calculate actual energy intake as described previously $(19,20)$.

The overfeeding with a high fat diet was given with $50 \%$ excess energy above the TEE of the weight maintenance diet (21). The energy contribution of macronutrients of the high fat diet was $60 \%$ from fat, $25 \%$ from carbohydrate and $15 \%$ from protein $(22,23)$. Fatty acid composition of the diet was $40 \%$ saturated fatty acids and $60 \%$ unsaturated fatty acids.

During overfeeding, subjects stayed in the respiration chamber. They were asked to eat all the foods prepared, but on failing to do so, the left overs were weighed. The diet consisted of normal ready-to-eat foods combining a typical Western and Asian diet. Foods were selected by reviewing the ingredients content to ensure there was no (or only a minimal) effect of certain ingredients on fat oxidation (such as spices). During overfeeding, the subjects were also provided with decaffeinated coffee and fruit tea, as caffeinecontaining coffee and tea have also been reported to increase fat oxidation. Alcohol intake was not allowed to be consumed in the respiration chamber. 


\section{CHAPTER 7}

\section{Fat biopsies and Western blot analysis}

Abdominal subcutaneous adipose tissue biopsies (approximately $1.5 \mathrm{~g}$ ) were obtained by needle liposuction under local anesthesia (2\% lidocaine, Fresenius Kabi BV, The Netherlands) after an overnight fast, in the morning before and after overfeeding with a high fat diet. The fat tissues were rinsed in a sterile cold saline, frozen in liquid nitrogen and stored in $-80^{\circ} \mathrm{C}$ until protein isolation.

About $200 \mathrm{mg}$ frozen fat tissue was grinded in a mortar. The powder was dissolved in $200 \mu \mathrm{l} 8 \mathrm{M}$ urea, 2\% w/v CHAPS, 65 mM DTT per 100 mg biopsy. The homogenate was vortexed for 5 minutes and centrifuged at $14000 \mathrm{rpm}$ and at $10^{\circ} \mathrm{C}$ for 30 minutes. The supernatant containing the adipose tissue proteome was carefully collected and aliquots were stored at $-80^{\circ} \mathrm{C}$. Protein concentrations were determined by a Biorad Bradfordbased protein assay (24).

Samples with an equal amount of protein were run on a $12 \%$ denaturing polyacrylamide gel (180 V, Criterion Cell; Bio-Rad, Hercules, CA). After electrophoresis, proteins were transferred (90 min, $100 \mathrm{~V}$, Criterion blotter; Bio-Rad) to 0.45-mm nitrocellulose membranes. After Ponceau S staining and destaining, membranes were blocked for $1 \mathrm{~h}$ in 5\% non-fat dry milk powder (NFDM; Bio-Rad) in Tris-buffered saline containing $0.1 \%$ Tween 20 (TBST) or 5\% BSA-TBST depending on the primary antibody. Thereafter, the blots were incubated respectively with antibodies against LPL (1:1000 dilution, Santa Cruz sc-58780), FABP4 (1:1000 dilution, Cayman 10004944), ATGL (1:1000 dilution, Cell Signaling 2138), PLIN 1 A/B (1:5000 dilution, ProGen GP33), HADH (1:500 dilution, Santa Cruz sc-74650) in 5\% NFDM-TBST overnight at $4^{\circ} \mathrm{C}$ on a shaker. For CPT1a (1:500 dilution, Abgent AP2524b) blots were incubated with the primary antibody in 5\% BSA-TBST overnight at $4^{\circ} \mathrm{C}$ on a shaker. Thereafter, the blots were washed three times for $10 \mathrm{~min}$ in TBST, and then incubated with 1:10000 dilution of horseradish peroxidaseconjugated secondary antibody (DAKO) in 5\% BSA-TBST or 5\% NFDM-TBST for $1 \mathrm{~h}$. The blots were washed three times for $10 \mathrm{~min}$ in TBST. A CCD camera (XRS-system, Bio-Rad) 
was used to detect immunoreactive bands using chemiluminescent substrate (SuperSignal $\mathrm{CL}$; Pierce). The quantification was performed with the program Quantity One version 4.6.5 (Bio-Rad). Blots were normalized to $\beta$-actin (1:1000 dilution, Santa Cruz sc-47778) to correct for differences in protein loading.

\section{Statistical analysis}

Data of subject characteristics and macronutrient intake were first tested for normal distribution by using Kolmogorov-Smirnov and Shapiro-Wilk normality test. When normality was met, statistical comparison was assessed using independent sample t-test. Non-normally distributed data were compared using the non-parametric Mann-Whitney $U$ test. Repeated-measure ANOVA was used to assess differences in protein relative abundance before and after overfeeding with a high fat diet within groups (the effect of diet), between the groups (the effect of ethnicity) and the interaction between diet and ethnicity by including body fat percentage as a covariate. Spearman's Rho correlation was applied to assess the correlation between changes in proteins. Spearman's Rho correlation was also used to assess the correlation between baseline protein levels and adiposity measures. The SPSS statistic program version 16 (SPSS, Chicago, IL) was used for statistical analysis, and statistical significance was set as $p \leq 0.05$.

\section{RESULTS}

\section{Subject characteristics}

South Asian subjects were Indian $(n=7)$, Pakistani $(n=1)$ and Nepali $(n=2)$. Caucasian subjects were Dutch $(n=2)$, German $(n=1)$, Irish $(n=1)$, Italians $(n=2)$, British $(n=1)$, Portuguese $(n=1)$ and Polish $(n=2)$. South Asians were measured within 3 y $(n=2)$ and within 1 y $(n=8)$ of their stay in The Netherlands. Subjects' characteristics are presented in Table 7.1. Subjects were matched for body fat percentage individually, thus there was a wide range of body fat percentage of the subjects in each group ranging from $16-29 \%$ in 


\section{CHAPTER 7}

South Asian and $10-38 \%$ in Caucasian group. As a group, average body fat percentage did not differ between ethnicities $(P=0.78)$. Although absolute fat-free mass was significantly higher in Caucasians $(P=0.005)$, the ratio of fat mass to fat-free mass did not differ between groups $(P=0.71)$.

Waist circumference as a proxy of subcutaneous abdominal fat volume did not differ between ethnicities $(P=0.37)$ with the range in South Asians being 77-98 cm and 77-108 $\mathrm{cm}$ in Caucasians.

\section{Energy intake and macronutrient composition during the dietary intervention}

Caucasians had a higher energy need due to a higher fat-free mass, hence the energy intake was higher than South Asians. During the weight maintenance period, the actual energy intake was $11.5 \pm 1.0 \mathrm{MJ} / \mathrm{d}$ for South Asians and $12.2 \pm 2.1 \mathrm{MJ} / \mathrm{d}$ for Caucasians (P $=0.39$ ), where the energy contribution of the macronutrients was: fat, $29.3 \pm 0.8 \%$ and $28.8 \pm 1.1 \%(P=0.13)$; carbohydrate, $55.2 \pm 1.1 \%$ and $56.0 \pm 1.5 \%(P=0.21)$; protein, 15.5 $\pm 0.5 \%$ and $15.4 \pm 0.6 \%(P=0.70)$ for South Asians and Caucasians respectively.

During the period of overfeeding with a high fat diet under sedentary conditions, South Asians and Caucasians consumed $150 \pm 13 \%$ and $161 \pm 27 \%(P=0.28)$ of weight maintenance requirements, respectively, resulting in a positive energy balance of $8.0 \pm 1.2$ $\mathrm{MJ} / \mathrm{d}$ in South Asians and $8.5 \pm 1.7 \mathrm{MJ} / \mathrm{d}$ in Caucasians $(P=0.32)$. The macronutrient composition was $59.4 \pm 0.6 \%$ and $59.0 \pm 0.6 \%$ fat $(P=0.21), 26.3 \pm 0.8 \%$ and $26.4 \pm 0.7 \%$ carbohydrate $(P=0.77)$ and $14.3 \pm 0.3 \%$ and $14.5 \pm 0.4 \%$ protein $(P=0.14)$ for South Asians and Caucasians respectively. 
Table 7.1. Subjects' characteristics ${ }^{a}$

\begin{tabular}{llll}
\hline Characteristics & South Asian & Caucasian & P \\
\hline $\mathrm{N}$ & 10 & 10 & - \\
Age $(\mathrm{y})$ & $26 \pm 4(21-34)$ & $23 \pm 2(20-27)$ & 0.048 \\
Body weight $(\mathrm{kg})$ & $69.2 \pm 7.3(62-82)$ & $81.9 \pm 13.6(70-112)$ & 0.035 \\
Body height $(\mathrm{m})$ & $1.72 \pm 7.9(1.53-1.8)$ & $1.81 \pm 6.2(1.7-1.9)$ & 0.015 \\
BMI $\left(\mathrm{kg} / \mathrm{m}^{2}\right)$ & $23.5 \pm 2.8(20-28)$ & $24.8 \pm 3.3(20-32)$ & 0.36 \\
Fat mass (\%) & $22.0 \pm 5.1(16-29)$ & $22.8 \pm 7.2(10-38)$ & 0.78 \\
Fat-free mass (kg) & $53.7 \pm 4.3(47-60)$ & $61.9 \pm 6.4(52-72)$ & 0.005 \\
Fat mass/fat-free mass ratio & $0.29 \pm 0.1(0.19-0.42)$ & $0.31 \pm 0.1(0.11-0.62)$ & 0.71 \\
Waist circumference (cm) & $85.1 \pm 6.5(77-98)$ & $88.2 \pm 8.6(77-108)$ & 0.37 \\
Hip circumference (cm) & $97.7 \pm 5.8(90-108)$ & $102.0 \pm 9.9(92-126)$ & 0.25 \\
Waist to hip ratio & $0.87 \pm 0.03(0.82-0.9)$ & $0.87 \pm 0.03(0.82-0.92)$ & 0.68 \\
$\begin{array}{l}\text { Physical activity accelerometer } \\
\text { (10 }{ }^{3} \text { counts/d) }\end{array}$ & $1254 \pm 395$ & $1271 \pm 243$ & 0.91 \\
\hline $\begin{array}{l}\text { Values are mean } \pm \text { SDs. Values within brackets are their respected ranges. } \\
\text { Differences between the groups in normally distributed data were assessed using an Independent t-test, non- } \\
\text { normally distributed data were assessed using non-parametric test Mann-Whitney U test. }\end{array}$
\end{tabular}

\section{The relative abundance and the change of the proteins responsible in fat metabolism}

The change in relative abundance of proteins before and after overfeeding with a high fat diet was analyzed by correcting for body fat percentage (Table 7.2). This was done because of a wide range in body fat percentage in each group i.e. from lean - obese. In line with Table 7.2, a schematic figure to describe the different processes regulated by the proteins involved in fat metabolism is shown in Figure 7.1. 


\section{CHAPTER 7}

\section{Mitochondrial B-oxidation}

The relative abundance of HADH was significantly decreased $(P<0.05)$ in both South Asians and Caucasians as a response to overfeeding with a high fat diet. The decrease was greater $(P<0.05)$ in Caucasians than in South Asians, however HADH level at baseline and after overfeeding was relatively higher in Caucasians than in South Asians.

The protein CPT1a located in the mitochondrial membrane decreased significantly with diet in South Asians $(P<0.05)$, whereas in Caucasians, CPT1a increased with diet $(P<$ 0.05). There was an interaction between diet and body fat percentage $(P<0.05)$.

\section{Fatty acids release and storage}

Protein involved in lipolysis, ATGL, did not change significantly with overfeeding, although there was an indication to be upregulated in South Asians and down-regulated in Caucasians. Proteins responsible for lipid droplet turnover, PLINA and PLINB, did not change with diet, although there was an indication for PLINA to be down-regulated and PLINB to be upregulated in both ethnic groups (not statistically significant). The decrease in PLINA differed between ethnicities; it was greater in Caucasians $(P<0.05)$. However, PLINA level at baseline and after the intervention was relatively higher in South Asians.

\section{Fatty acids uptake and handling}

Fatty acid binding protein (FABP4) and LPL did not change with diet and did not differ between ethnicities. There was a trend for FABP4, involved in fatty acid handling within adipocytes, to be upregulated in both groups (not significant). LPL, involved in fatty acid uptake appeared to be upregulated in South Asians and down-regulated in Caucasians but did not reach statistical significance. 


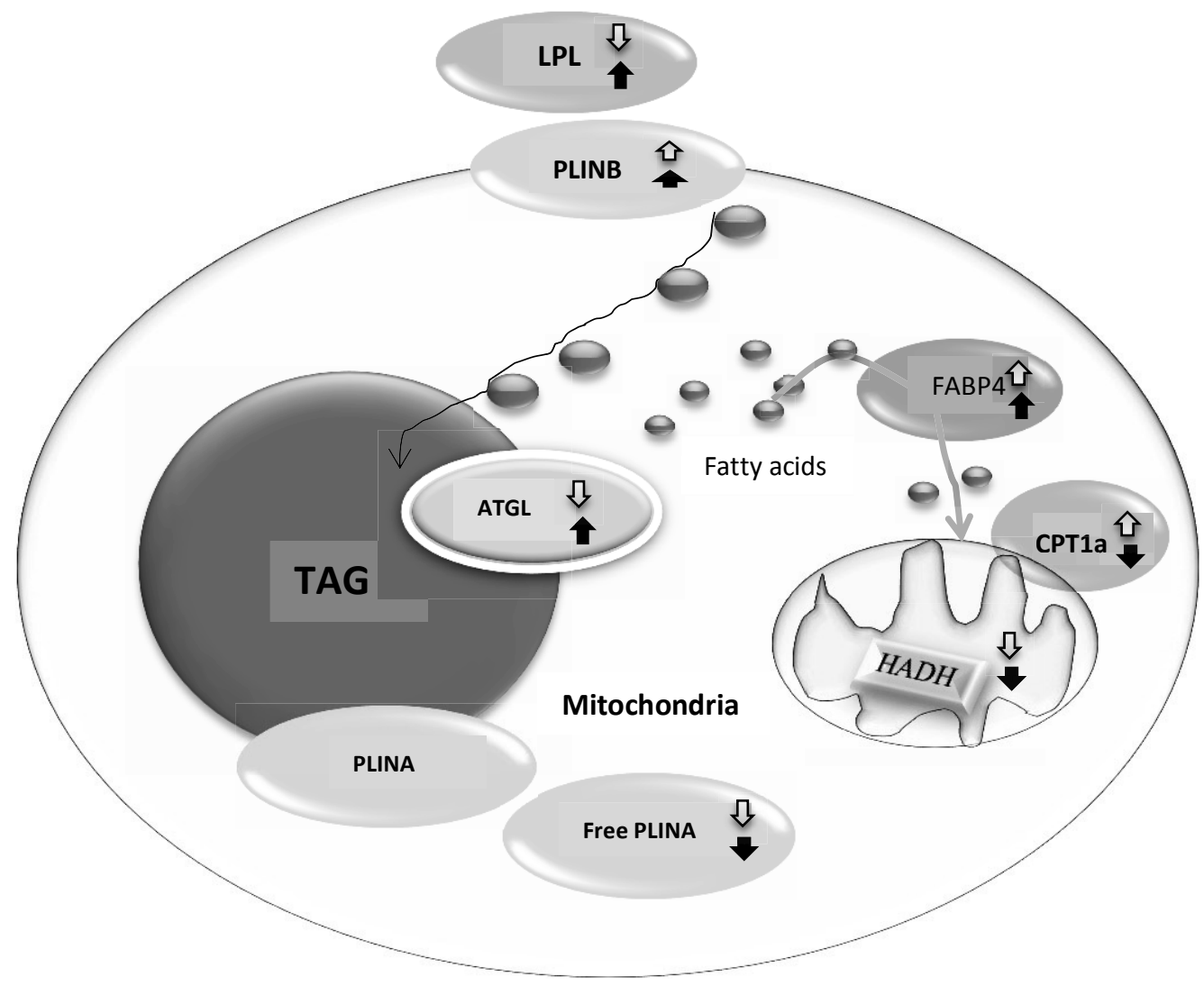

Figure 7.1. Fat cell with different processes regulated by different proteins involved in fat metabolism in response to overfeeding with a high fat diet under sedentary conditions (black arrow, South Asians; white arrow, Caucasians; up-arrow, upregulated; down-arrow, down-regulated). 


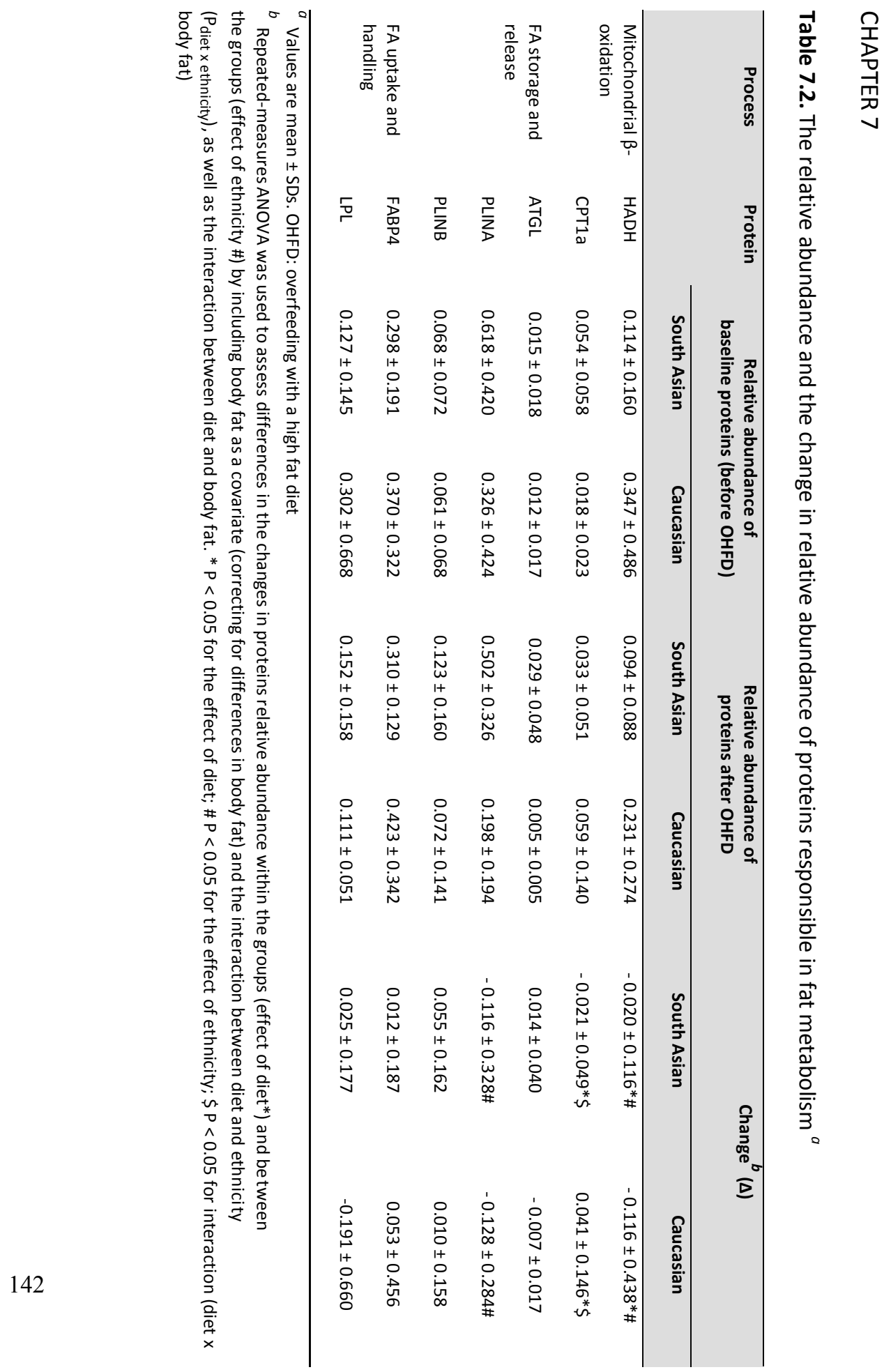




\section{Correlation between protein changes}

The correlation between protein changes indicates a coordinated regulation of the proteins in fat metabolism as shown in Table 7.3. Changes in CPT1a were negatively correlated with changes in PLINB $(P<0.05)$ in South Asians and in the combined group, whereas changes in HADH were positively correlated with changes in PLINA in South Asians $(P<0.05)$, Caucasians $(P<0.05)$ and the combined group $(P<0.01)$. Changes in HADH were positively correlated with changes in $\mathrm{LPL}$, in the combined group $(P<0.05)$ and with changes in marker of fatty acids handling FABP4 in South Asians $(P<0.05)$.

In Caucasians, changes in PLINA were positively correlated with changes in PLINB $(P<0.05)$. In addition, changes in PLINA were positively correlated with changes in LPL in South Asians $(P<0.05)$, Caucasians $(P<0.05)$ and in the combined group $(P<0.01)$. Changes in PLINB were also shown to be positively correlated with changes in LPL in Caucasians $(P<0.05)$, whereas in South Asians, PLINB was positively correlated with changes in FABP4 $(P<0.05)$.

\section{Correlation between baseline proteins and adiposity measures}

Correlations between proteins at baseline with adiposity measures were only found in Caucasians (Table 7.4). In this regard, baseline HADH was negatively correlated $(P<0.05)$ with BMI, body fat percentage, absolute fat mass, fat mass index, FM/FFM ratio, waist circumference and hip circumference. Baseline ATGL was negatively correlated $(P<0.05)$ with all adiposity measures mentioned above except with hip circumference, whereas baseline FABP4 was negatively correlated $(P<0.05)$ with absolute fat mass. 


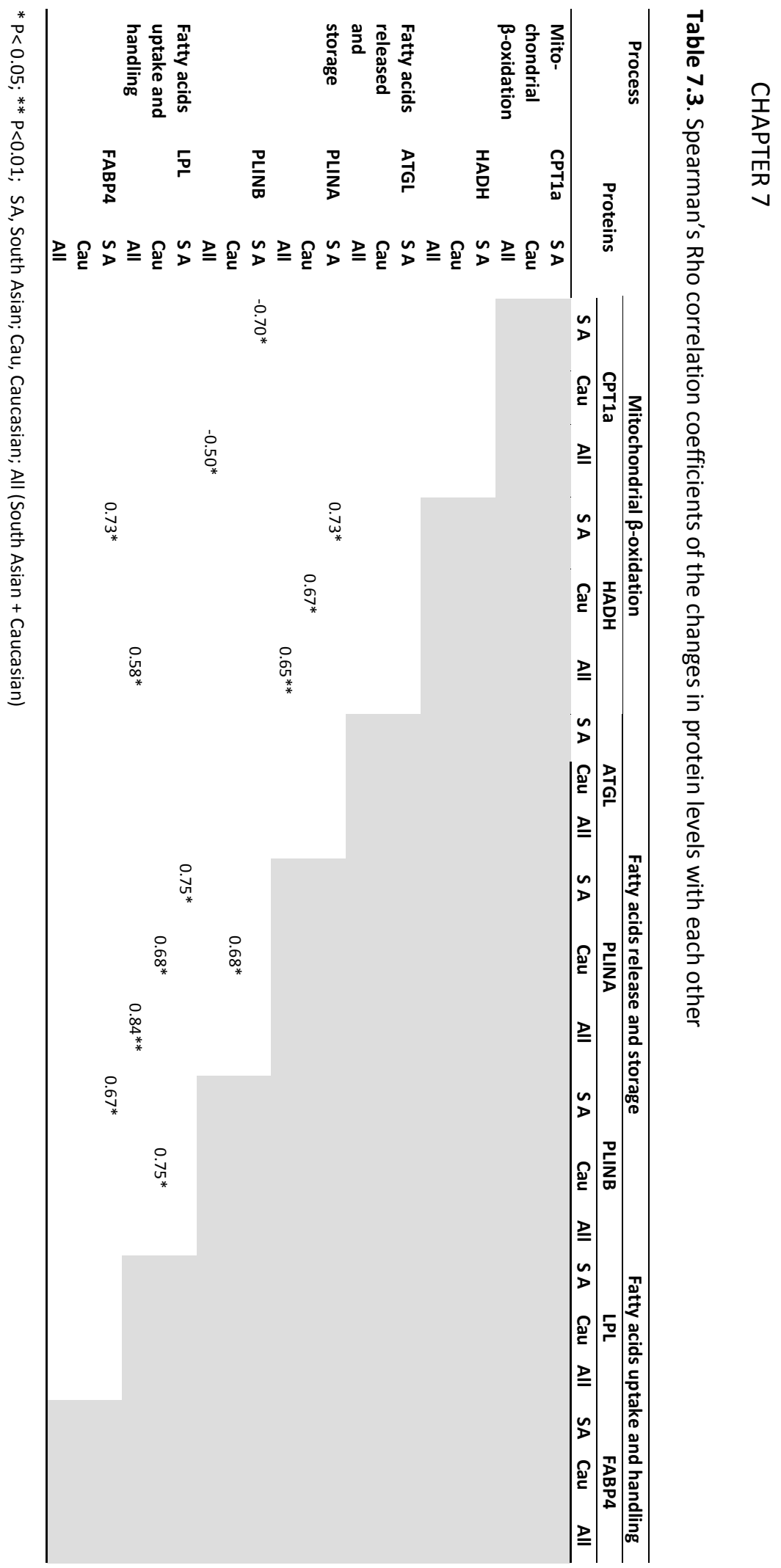




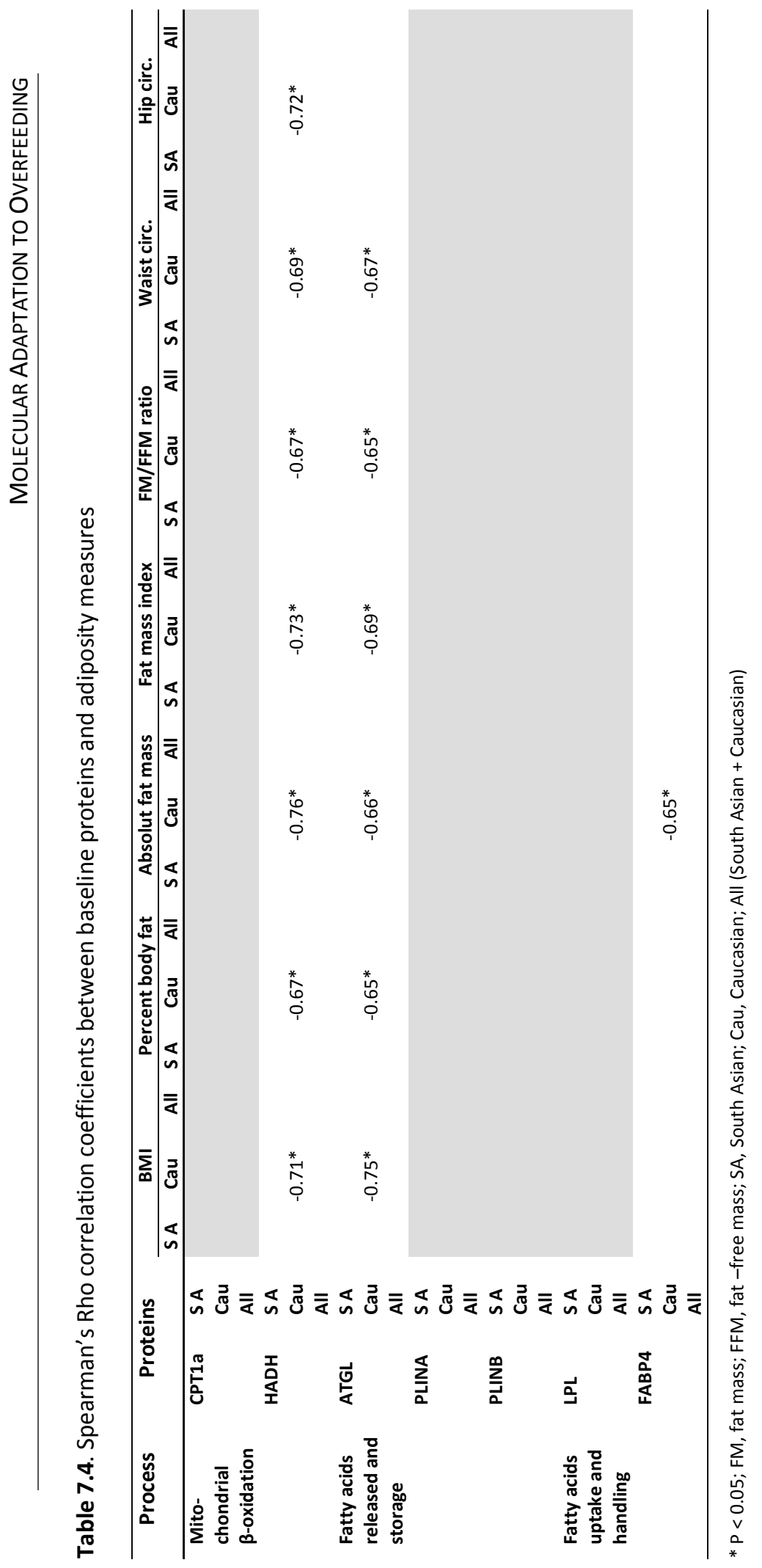




\section{DISCUSSION}

Our study demonstrated that the response to overfeeding with a high fat diet varied largely between individuals among both South Asian men and Caucasian men. In addition, proteins involved in mitochondrial $\beta$-oxidation changed significantly with diet. HADH level was decreased in both ethnicities whereas CPT1a was decreased in South Asians and increased in Caucasians. The decrease in HADH was greater in Caucasians; however, the HADH level at baseline and after intervention was relatively higher in Caucasians. PLINA did not change with diet, although there was an indication towards a decrease and the decrease differed between ethnicities. The level of PLINA at baseline and after intervention was relatively higher in South Asians. Other proteins were unaffected by diet, and no ethnic difference was found.

The large variation in protein abundance at baseline as well as in the response to overfeeding may be a consequence of the large variation of subject's body fat percentage in each group. Therefore, to assess the changes in protein abundance, we corrected for body fat percentage.

A crucial enzyme for mitochondrial $\beta$-oxidation involved in the rate-limiting acyl-CoA dehydrogenase step (25), HADH, significantly decreased in both groups. Overfeeding with a high fat diet for 3 days under sedentary condition in a respiration chamber led to a massively positive energy balance in both groups. In this state, glycogen stores in the body are maintained (26) and glucose is oxidized to match carbohydrate intake (27). On the other hand, fat is oxidized to a lesser extent to meet energy requirement. This was supported by our data from the same study as presented here, that an extended meal consumption due to overfeeding, prolonged the postprandial state and prolonged high insulin levels, which in turn favors fat storage rather than oxidation (Wulan et al. 2015, Substrate utilization and metabolic profiles in response to overfeeding with a high fat diet in South Asian and white men: a sedentary life style study, submitted for publication). Previous studies by us $(20)$ and others $(28,29)$ have shown higher insulin levels as a 
response to overfeeding. Moreover, Schmidt et al. (30) reported a decrease in postabsorptive $24 \mathrm{~h}$-fat oxidation following 3-days of overfeeding in obesity resistant subjects but not changed in obesity prone subjects (presumably due to a higher FFA level from the enlarged fat mass). Therefore, a decrease in HADH level as a crucial enzyme in mitochondrial $\beta$-oxidation was as expected. Studies on caloric restriction showed the opposite effect in $\mathrm{HADH}$ response, where there was an increase after the intervention $(15,31)$. Interestingly, although the decrease in HADH level was greater in Caucasians, this ethnic group had a relatively higher HADH at baseline and while decreasing, the HADH level remained relatively higher after the intervention as compared to that in South Asians. This may have implication in the long-term fat metabolism and energy balance maintenance in these ethnicities.

CPT1a, a protein in the mitochondrial membrane, catalyzes the conversion of cytoplasmic long-chain fatty acyl-CoA to acylcarnitine, which then enters the mitochondria (15). It changed significantly with diet, decreasing in South Asians, but increasing in Caucasians. This enzyme is a rate-limiting enzyme for mitochondrial fatty acid uptake, suggesting that Caucasians may have a higher ability for mitochondrial fatty acid uptake.

The ATGL abundance was unaffected by overfeeding. Although there was an indication towards a two fold increase of ATGL in South Asians, whereas about $50 \%$ decrease in Caucasians, it did not reach statistical significance. ATGL performs the initial step of TAG hydrolysis, releasing fatty acids (FA) and producing diacyl glycerol (DAG); DAG is hydrolyzed by HSL (hormone sensitive lipase) resulting a second FA and MAG (monoacyl glycerol), which is subsequently hydrolyzed by MAG lipase generating glycerol and a final FA. The FA promotes utilization within the adipocytes or release into the circulation (32). It has been suggested that HSL is the major rate-limiting enzyme in human lipolysis that regulates both basal (fed state) and stimulated lipolysis, whereas ATGL plays a role in the regulation of basal lipolysis (33). The anti-lipolytic effect of insulin during the postprandial (fed) state is mediated primarily through phosphorylation or activation of 
phosphodiesterase $3 B$ which decreases CAMP; subsequently, protein kinase $A$ (PKA) activity is inhibited, causing reduced HSL phosphorylation; accordingly, the HSL translocation from cytosol to the lipid droplet is inhibited and lipolysis is decreased (32). Thus, high insulin levels during overfeeding may have a direct impact on HSL activity as a major rate-limiting enzyme rather than on ATGL.

Perilipin A (PLINA) is the most abundant protein associated with lipid droplets and in the mouse is able to maintain numerous and tightly clustered lipid droplets (35). Perilipin A increases TAG storage by decreasing the rate of basal and stimulated lipolysis $(34,35)$. The action of PLINA, like the action of HSL, is maintained under tight hormonal regulation. Catecholamines initiate the activation of cAMP-dependent protein kinase (PKA) causing increased PLINA phosphorylation translocating PLINA away from the lipid droplets to the cytosol. This facilitates accessibility of the degrading enzyme HSL to the lipid droplets (34). Under high insulin levels, where cAMP-dependent PKA is inhibited, PLINA is not phosphorylated and remains bound to lipid droplets. In the present study we observed a decrease in PLINA in both groups although not significant. Of note, the technique that we used (extracting protein from fat tissue) may limit the observation to unbound PLINA only. Thus, a decrease in unbound PLINA (less phosphorylated PLINA) may indirectly reflect more bound PLINA protecting lipid droplets from lipolysis during overfeeding. The positive correlation between PLINA and HADH seemed to support this observation. Alternatively, overfeeding that favors fat storage may trigger numerous and tightly clustered lipid droplets to fuse into slightly enlarged lipid droplets thus reducing the total lipid droplet surface area requiring less PLINA to cover it. The fusion of droplets is likely and there is a sequential progression of coat proteins during droplet formation and maturation. As droplets enlarge further, perilipin replaces other droplet coating proteins and eventually the largest lipid droplets are coated only with perilipin (36). An opposite effect is shown in the caloric-restriction study, where PLINA increases (15). In the present study, the decrease of PLINA was greater in Caucasians; in addition, PLINA at baseline and 
after intervention was relatively higher in South Asians. Just as the relatively higher level of $\mathrm{HADH}$ in Caucasians, a relatively higher PLIN A level in South Asians that plays an important role in the turn-over of stored TAG, may influence the long-term energy utilization in this population as well.

Another perilipin isoform, PLINB did not change with diet. There was an increase in both ethnicities but not statistically significant. Insulin was reported to stimulate the accumulation of PLINB at the plasma membrane to protect newly synthesized TAG as a product of reesterification of exogenous fatty acids (37). Others suggested increased PLINB was associated with the formation of small lipid droplets (15). In Caucasians, PLINB showed a positive correlation with PLINA and LPL, suggesting coordinated regulation between fatty acid uptake, the formation of small lipid droplets, and of the larger lipid droplets. In South Asians and the combined group, PLINB showed a negative correlation with CPT1a.

The process of fatty acid uptake by adipocytes occurs in two stages, hydrolysis of circulating TAG by lipoprotein lipase (LPL) bound to the capillary endothelium, followed by tissue uptake of the resultant fatty acids (38). Surprisingly, LPL did not change with overfeeding. Although there was an indication towards an increase in South Asians and a decrease in Caucasians, it did not reach statistical significance. Our explanation is that as previously reported in a tracer study (38), entrapment of fatty acids in adipose tissue during the postprandial period varies markedly with time. After the meal, TAG extraction increases reflecting an increased LPL activity. Entrapment of fatty acids (tracers) is $100 \%$ at 60 min and falls during the 6 -h postprandial period to $~ 10-30 \%$ at 360 min suggesting a highly regulated process. The up-regulation of fatty acid entrapment in adipose tissue follows a time course similar to that of the increase in insulin concentration (38). Thus, it seems that time course of observation for LPL activity (or content) may be important (while fat biopsy to collect tissue sample was done at the end of postprandial period/entering post-absorptive period). In our study, a higher amount of fatty acids may 
have been entrapped by adipose tissue after each meal and after snack consumptions in between meals during the overfeeding period, as compared to that during the weight maintenance period. However, the entrapment of fatty acids by adipose tissue that decreases over the time during the postprandial period may indicate that LPL activity (or content) have decreased as well by the end of the postprandial period due to a decrease in substrate (TAG) load. Hence, a small difference in LPL level before and after overfeeding might not be detected.

Despite unaffected LPL level by the diet, LPL consistently showed a significant positive correlation with PLINA in South Asians and Caucasians, and the correlation became stronger in the combined groups. This suggests a coordinated regulation between fatty acid uptake and storage. In Caucasians, LPL also showed a significant positive correlation with PLINB, indicating an increased protection of newly synthesized TAG or small fat droplets made from exogenous fatty acids (reesterification) (15).

We did correlation analysis between baseline protein expression and adiposity measures. Interestingly, significant correlations between some proteins and indexes of adiposity were found in Caucasians but not in South Asians. HADH showed a significant negative correlation with adiposity measures such as: BMI, body fat percentage, absolute fat mass, fat mass index, fat mass/fat-free mass ratio, waist circumference and hip circumference. This is in line with a study by Marrades et al. (12) showing that several transcripts encoding key enzymes in the $\beta$ oxidation cycle including sc-HADH were downregulated in obese subjects as compared to lean subjects when consuming high fat-diet. In addition, a protein responsible for lipolysis (ATGL) showed a negative correlation with all adiposity indexes mentioned above, except with hip circumference. Bouwman et al. (15) reported an upregulated ATGL protein upon weight loss (after caloric restriction) and reduced body fat mass, thus supporting this finding. In contrast, Mairal and Langin (39) found that ATGL mRNA levels were unaffected by obesity and weight reduction. 
A limitation of the study was the small sample size and perhaps the wide range in body fat percentage. Thus, future comparative proteomic studies between South Asians and Caucasians have to involve subjects with matched body fat percentage, but preferably with a more homogenous (within a narrow range) body fat percentage; i.e. a study on lean South Asians and Caucasians or a study on overweight South Asians and Caucasians.

In summary, we observed a significant decrease in $\mathrm{HADH}$ as a crucial enzyme in mitochondrial $\beta$-oxidation in South Asians and Caucasians as a response to overfeeding with a high fat diet. Although the decrease was larger in Caucasians, this group had a relatively higher HADH level at baseline and remained higher after decreasing as compared to South Asians. СРT1a was decreased in South Asians but increased in Caucasians in response to a high fat overfeeding. On the other hand, South Asians had a relatively higher PLINA level. The differences in HADH and PLINA levels as well as in the response of CPT1a between ethnicities may be important for the long-term regulation of energy (fat) metabolism in these populations.

\section{ACKNOWLEDGEMENTS}

The authors gratefully thank Gabby Hul, Sanne Verhoef and Stefan Camps for the help during fat biopsy. Also, we deeply appreciate and thank all subjects who participated in the study.

The study was funded by a scholarship from The Directorate General of Higher Education, The Ministry of Education and Culture (former Ministry of Research, Technology and Higher Education) of The Republic of Indonesia, to SNW. The Ministry of Education and Culture of The Republic of Indonesia had no role in the design and analysis of the study and in the writing of this article.

The authors' contributions are as follows-SNW: conducted the research, performed the data analysis, and wrote the manuscript; FGB: together with SNW did the proteomic analysis and quantification; ECMM: interpreted the proteomic data and reviewed the 
manuscript; KRW and GP: designed the study and reviewed the manuscript.

None of the authors had any conflict of interest to declare.

\section{REFERENCES}

1. Yoon KH, Lee JH, Kim JW, Cho JH, Choi YH, Ko SH et al. (2006) Epidemic obesity and type 2 diabetes in Asia. Lancet 368, 1681-1688.

2. Gujral UP, Pradeepa R, Weber MB, Narayan KM, Mohan V (2013) Type 2 diabetes in South Asians: similarities and differences with white Caucasian and other populations. Ann N Y Acad Sci 1281, 51-63.

3. Gadgil MD, Anderson CA, Kandula NR, Kanaya AM (2014) Dietary patterns in Asian Indians in the United States: an analysis of the metabolic syndrome and atherosclerosis in South Asians Living in America study. Journal of the Academy of Nutrition and Dietetics 114, 238-243.

4. Garduno-Diaz SD, Khokhar S (2013) South Asian dietary patterns and their association with risk factors for the metabolic syndrome. J Hum Nutr Diet 26, 145-155.

5. Ramachandran A, Ma RC, Snehalatha C (2010) Diabetes in Asia. Lancet 375, 408-418.

6. Forouhi NG, Jenkinson G, Thomas EL, Mullick S, Mierisova S, Bhonsle U et al. (1999) Relation of triglyceride stores in skeletal muscle cells to central obesity and insulin sensitivity in European and South Asian men. Diabetologia 42, 932-935.

7. Chandalia M, Lin P, Seenivasan T, Livingston EH, Snell PG, Grundy SM et al. (2007) Insulin resistance and body fat distribution in South Asian men compared to Caucasian men. PLoS One 2, e812.

8. Nair KS, Bigelow ML, Asmann YW, Chow LS, Coenen-Schimke JM, Klaus KA et al. (2008) Asian Indians have enhanced skeletal muscle mitochondrial capacity to produce ATP in association with severe insulin resistance. Diabetes 57, 1166-1175.

9. Rush EC, Freitas I, Plank LD (2009) Body size, body composition and fat distribution: comparative analysis of European, Maori, Pacific Island and Asian Indian adults. Br J Nutr 102, 632-641.

10. Tappy L (2004) Metabolic consequences of overfeeding in humans. Curr Opin Clin Nutr Metab Care 7, 623628.

11. Joosen AM, Westerterp KR (2006) Energy expenditure during overfeeding. Nutr Metab (Lond) 3, 25.

12. Marrades MP, Gonzalez-Muniesa P, Arteta D, Martinez JA, Moreno-Aliaga MJ (2011) Orchestrated downregulation of genes involved in oxidative metabolic pathways in obese vs. lean high-fat young male consumers. J Physiol Biochem 67, 15-26.

13. Franck N, Gummesson A, Jernas M, Glad C, Svensson PA, Guillot G et al. (2011) Identification of adipocyte genes regulated by caloric intake. J Clin Endocrinol Metab 96, E413-418.

14. Hall LM, Moran CN, Milne GR, Wilson J, MacFarlane NG, Forouhi NG et al. (2010) Fat oxidation, fitness and skeletal muscle expression of oxidative/lipid metabolism genes in South Asians: implications for insulin resistance? PLoS One 5, e14197.

15. Bouwman FG, Wang P, van Baak M, Saris WH, Mariman EC (2014) Increased beta-oxidation with improved glucose uptake capacity in adipose tissue from obese after weight loss and maintenance. Obesity (Silver Spring) 22, 819-827.

16. Westerterp KR, Wouters L, van Marken Lichtenbelt WD (1995) The Maastricht protocol for the measurement of body composition and energy expenditure with labeled water. Obes Res 3 Suppl 1, 49-57.

17. Siri WE (1956) The gross composition of the body. Adv Biol Med Phys 4, 239-280.

18. Bonomi AG, Plasqui G, Goris AH, Westerterp KR (2010) Estimation of free-living energy expenditure using a novel activity monitor designed to minimize obtrusiveness. Obesity (Silver Spring) 18, 1845-1851.

19. Wulan SN, Westerterp KR, Plasqui G (2012) Dietary and 24-h fat oxidation in Asians and whites who differ in body composition. Am J Clin Nutr 95, 1335-1341. 
20. Wulan SN, Westerterp KR, Plasqui G (2014) Metabolic profile before and after short-term overfeeding with a high-fat diet: a comparison between South Asian and White men. BrJ Nutr 111, 1853-1861.

21. Joosen AM, Bakker AH, Zorenc AH, Kersten S, Schrauwen P, Westerterp KR (2006) PPARgamma activity in subcutaneous abdominal fat tissue and fat mass gain during short-term overfeeding. Int $J$ Obes (Lond) $\mathbf{3 0}$, 302-307.

22. Schrauwen-Hinderling VB, Kooi ME, Hesselink MK, Moonen-Kornips E, Schaart G, Mustard KJ et al. (2005) Intramyocellular lipid content and molecular adaptations in response to a 1-week high-fat diet. Obes Res 13, 2088-2094.

23. Schrauwen P, van Marken Lichtenbelt WD, Saris WH, Westerterp KR (1997) Changes in fat oxidation in response to a high-fat diet. Am J Clin Nutr 66, 276-282.

24. Bradford MM (1976) A rapid and sensitive method for the quantitation of microgram quantities of protein utilizing the principle of protein-dye binding. Analytical biochemistry 72, 248-254.

25. Kler RS, Jackson S, Bartlett K, Bindoff LA, Eaton S, Pourfarzam M et al. (1991) Quantitation of acyl-CoA and acylcarnitine esters accumulated during abnormal mitochondrial fatty acid oxidation. J Biol Chem 266, 22932-22938.

26. Flatt JP (1996) Glycogen levels and obesity. Int J Obes Relat Metab Disord 20 Suppl 2, S1-11.

27. Flatt JP (1995) Use and storage of carbohydrate and fat. Am J Clin Nutr 61, 952S-959S.

28. Brons C, Jensen CB, Storgaard H, Hiscock NJ, White A, Appel JS et al. (2009) Impact of short-term high-fat feeding on glucose and insulin metabolism in young healthy men. $J$ Physiol 587, 2387-2397.

29. Samocha-Bonet D, Campbell LV, Mori TA, Croft KD, Greenfield JR, Turner N et al. (2012) Overfeeding reduces insulin sensitivity and increases oxidative stress, without altering markers of mitochondrial content and function in humans. PLoS One 7, e36320.

30. Schmidt SL, Kealey EH, Horton TJ, VonKaenel S, Bessesen DH (2013) The effects of short-term overfeeding on energy expenditure and nutrient oxidation in obesity-prone and obesity-resistant individuals. Int $J$ Obes (Lond) 37, 1192-1197.

31. Verhoef SP, Camps SG, Bouwman FG, Mariman EC, Westerterp KR (2013) Physiological response of adipocytes to weight loss and maintenance. PLoS One 8, e58011.

32. Ahmadian M, Duncan RE, Sul HS (2009) The skinny on fat: lipolysis and fatty acid utilization in adipocytes. Trends in endocrinology and metabolism: TEM 20, 424-428.

33. Ryden M, Jocken J, van Harmelen V, Dicker A, Hoffstedt J, Wiren M et al. (2007) Comparative studies of the role of hormone-sensitive lipase and adipose triglyceride lipase in human fat cell lipolysis. Am J Physiol Endocrinol Metab 292, E1847-1855.

34. Brasaemle DL, Subramanian V, Garcia A, Marcinkiewicz A, Rothenberg A (2009) Perilipin A and the control of triacylglycerol metabolism. Molecular and cellular biochemistry 326, 15-21.

35. Brasaemle DL, Rubin B, Harten IA, Gruia-Gray J, Kimmel AR, Londos C (2000) Perilipin A increases triacylglycerol storage by decreasing the rate of triacylglycerol hydrolysis. J Biol Chem 275, 38486-38493.

36. Brasaemle DL (2007) Thematic review series: adipocyte biology. The perilipin family of structural lipid droplet proteins: stabilization of lipid droplets and control of lipolysis. J Lipid Res 48, 2547-2559.

37. Aboulaich N, Vener AV, Stralfors P (2006) Hormonal control of reversible translocation of perilipin B to the plasma membrane in primary human adipocytes. J Biol Chem 281, 11446-11449.

38. Evans K, Burdge GC, Wootton SA, Clark ML, Frayn KN (2002) Regulation of dietary fatty acid entrapment in subcutaneous adipose tissue and skeletal muscle. Diabetes 51, 2684-2690.

39. Mairal A, Langin D, Arner P, Hoffstedt J (2006) Human adipose triglyceride lipase (PNPLA2) is not regulated by obesity and exhibits low in vitro triglyceride hydrolase activity. Diabetologia 49, 1629-1636. 


\section{CHAPTER 8}

General discussion 


\section{CHAPTER 8}

\section{GENERAL DISCUSSION}

Asians have a higher body fat percentage compared to Caucasians when matched for BMI. Despite these differences in body composition, dietary and $24 \mathrm{~h}$ fat-oxidation were similar in both ethnicities. When South Asian and Caucasian men were matched for body fat percentage, fat distribution in the abdominal area was different between ethnicities. The amount of visceral fat as a percentage of the total abdominal fat area was higher in South Asians, whereas subcutaneous abdominal fat was higher in Caucasians. In both ethnicities, liver fat content increased to the same extent in response to overfeeding with a high fat diet, both under free living and sedentary conditions. Insulin sensitivity decreased similarly between ethnicities under free-living conditions, but tended to decrease more in South Asians under sedentary conditions. In addition, overfeeding with a high fat diet had a more adverse effect on the lipid profile in South Asians. Substrate partitioning did not differ between ethnicities, both showing a greater contribution of carbohydrate oxidation rather than fat oxidation in response to overfeeding with a high fat diet under sedentary conditions and this was supported by a significant decrease in $\mathrm{HADH}$ a crucial enzyme involved in mitochondrial $\beta$-oxidation.

\section{BODY COMPOSITION AND ENERGY EXPENDITURE}

Comparative studies have shown that Asians differ from Caucasians in their body composition when matched for BMI. Asians have a higher body fat percentage whereas Caucasians have a higher fat-free mass (FFM) as reported by us (1) and others (2-13). Among three major ethnic groups in Asia, South Asian Indians had the most pronounced difference in body fat percentage compared with those of Caucasians, followed by Malay and Chinese subjects (14). As there is an ethnic-specific BMI-body fat relationship (15), differences in body fat percentage can be a confounding factor when Asians and 
Caucasians matched for BMI are compared in an intervention study. Therefore, by matching the two ethnicities for body fat percentage instead of BMI (16) one could avoid misinterpretation of the response to a diet or physical activity intervention.

The relationship between body composition and energy expenditure has been studied in health and diseases. Studies have established FFM as the major determinant of resting energy expenditure (REE) or resting metabolic rate (RMR) (17), which is the largest component (60-70\% in moderately active adults) of total energy expenditure (TEE). Although RMR and also sleeping metabolic rate (SMR) correlate best with FFM, RMR is also independently influenced by fat mass; the greater the FM, the higher the RMR (18). Asians were reported to have a lower RMR (19) and a lower SMR in the present study (1) than Caucasians because of having a lower FFM. The difference in RMR and SMR disappeared when adjusted for body composition $(1,19)$.

\section{BODY COMPOSITION AND FAT OXIDATION}

A low RMR, after adjustment for fat-free mass, fat mass, age and gender have been associated with an increased risk of body weight gain in a follow-up study of 3-4 y $(20,21)$. An unfavorable body composition, shown by a higher body fat accumulation, may be a consequence of a lower rate of energy expenditure and a higher respiratory quotient (RQ), indicating a lower proportion of fat to carbohydrate oxidation. Alternatively, a low rate of energy expenditure may be due to an unfavorable body composition. In a longitudinal study, a higher RQ was associated with susceptibility to weight gain in Pima Indians (22). However, Weyer et al. (23) reported no evidence for a lower metabolic rate or impairment in 24-h fat oxidation in obesity prone-Pima Indians as compared to whites. Similarly, Bergouignan et al. (24) showed no difference in 24-h fat oxidation in obese, reduced obese and lean subjects under similar eucaloric and negative energy balance. Despite 


\section{CHAPTER 8}

differences in body composition, 24-h fat oxidation was similar between Asians and Caucasians, when they were fed in energy balance with the same diet (1).

The 24-h fat oxidation reflected both endogenous fat oxidation, mostly during the post absorptive period, and exogenous fat oxidation from dietary fat during the postprandial period. Most exogenous fat is stored during the postprandial period, whereas a limited fraction ( 10\%) is directly oxidized (25). In the present study, despite differences in body composition, dietary fat oxidation was similar in Asians and Caucasians being on average $11.7 \%$ and $10.4 \%$ from dietary fat consumed respectively (1). Previous tracer studies showed that dietary fat oxidation was negatively correlated with body fat percentage in men and women (26), whereas others found increased dietary fat oxidation with increasing body fat percentage in men (27). Interestingly, a recent study showed no difference in dietary fat oxidation between obese, reduced-obese and lean subjects (men and women) (24). The discrepancy of the results may be due to the differences in the metabolic fate of dietary fatty acid tracers (palmitic acid or oleic acid) used in different studies, the labelling $\left({ }^{2} \mathrm{H}\right.$ or $\left.{ }^{14} \mathrm{C}\right)$ and the duration of the observation (24).

When comparing lean subjects and post-obese subjects (predisposed to obesity) instead of obese subjects and providing them with both isocaloric low- and high fat diets, Astrup et al. (28) and Buemann et al. (29) found that formerly obese women failed to increase fat oxidation in response to increased dietary fat compared to lean women. This was expressed as the ratio of fat to carbohydrate oxidation (28) and measured as postprandial fat oxidation after supper (29) and was independent of energy balance.

In the subsequent intervention study, South Asian and Caucasian men with matched body fat percentage were compared in their ability to adapt to an increased dietary fat content as described below. 


\section{SUBSTRATE PARTITIONING: THE ROLE OF ENERGY BALANCE, SUBSTRATE BALANCE AND MACRONUTRIENT COMPOSITION}

Energy balance in the respiration chamber predicted $24 \mathrm{~h}$ fat oxidation in Asians and Caucasians in the present study (1) and predicted $24 \mathrm{~h} \mathrm{RQ}$ in other studies (22). The more negative energy balance the higher the fat oxidation (the lower the $\mathrm{RQ}$ ), the more positive energy balance the lower the fat oxidation (the higher the RQ). In the subsequent study, when subjects were overfed with a high fat diet under sedentary conditions, the association between $24 \mathrm{~h}$ fat oxidation and energy balance was weak because all subjects were in a massively positive energy balance of $8-8.5 \mathrm{MJ} / \mathrm{d}$ as a result of the combination of overfeeding and the sedentary conditions.

Energy balance status indicates whether there is a gap between energy intake and energy expenditure. Total substrate oxidation in the body is determined by the need to regenerate ATP (30) thus equals TEE. In this regard, nitrogen (protein) balance is readily maintained on high or low (but adequate) protein intakes (30). Similarly, the capacity of the body to store glycogen is limited to a few hundred grams and is usually maintained within a relatively stable range (30). Therefore, protein and carbohydrate oxidation are adjusted to protein and carbohydrate intakes respectively; consequently protein and carbohydrate balance are achieved.

In contrast to the other two macronutrients, numerous studies on dietary fat supplementation or isoenergetic diets with high-or low- fat content have shown that fat intake does not stimulate its own oxidation; on the other hand, body fat stores are large (31). Adaptation of fat oxidation to increased fat intake in lean subjects consuming an isocaloric diet occurred within 7 days (32) and the adjustment of fat oxidation to match fat intake can be accelerated when glycogen stores are lowered through exhausting exercise in both lean (33) and obese subjects (34). This suggests that fat oxidation is regulated primarily by events pertaining to the use and storage of carbohydrate in the body, or in 


\section{CHAPTER 8}

other occasions, is determined by the gap between total energy expenditure and the energy ingested in the form of carbohydrate and protein, rather than by the amount of fat consumed in a given day (31).

Isocaloric diets differing in macronutrient composition (protein/carbohydrate/fat, in a mixed diet: $15 / 55 / 30$, a high fat diet: $15 / 25 / 60$ and a high carbohydrate diet: $15 / 70 / 15$ ) showed a relative contribution of each macronutrient oxidation to TEE (substrate partitioning) that was close to the macronutrient composition (35). Likewise, reduced oxidation of dietary fat was also observed after a high carbohydrate diet (36).

In the present study, by overfeeding with a high fat diet under sedentary conditions, a massively positive energy balance of $8-8.5 \mathrm{MJ} / \mathrm{d}$ was created and glycogen stores were relatively maintained (not depleted) since physical activity was low. Therefore, although the diet was high in dietary fat (60\% energy intake), substrate partitioning showed a greater reliance on carbohydrate oxidation in both South Asians and Caucasians being on average $53 \%$ and $47 \%$ of TEE respectively; whereas average fat oxidation was $31 \%$ and $39 \%$ of TEE in South Asians and Caucasians respectively. As the need for replenishment of the body's glycogen stores was low, most of the glucose was oxidized to match carbohydrate intake; whereas fat was oxidized to a lesser extent to meet energy requirements, resulting in a positive fat balance of 7-7.5 MJ/d. Thus, most of the dietary fat was stored.

\section{ABDOMINAL FAT DISTRIBUTION AND LIVER FAT ACCUMULATION}

Although excess body fat is a significant health hazard, body fat percentage may not reflect the amount of atherogenic lipids such as fat in the abdominal compartment (37). Metabolic complications are much more common in those with an upper body/visceral fat distribution compared to those with a lower body fat distribution (38). 
When matched for body fat percentage, South Asian men distribute a higher percentage of the total abdominal fat area as visceral fat (33\%) compared to Caucasians (23\%), whereas the percentage of subcutaneous fat was higher in Caucasians (77\%) than that in South Asians (67\%). The smaller body size of South Asians may shape this population to have a smaller subcutaneous adipose tissue compartment; therefore it was hypothesized that as obesity develops, South Asians could exceed the storage capacity of subcutaneous adipose tissue before Caucasians do, inducing lipid overflow to the visceral area (39) or ectopic fat deposition in the liver (40). A recent study in a Caucasian population (41) did show that the accumulation of fat in the visceral depot was due to defective regulation of lipid-storage related genes (DGAT 2, SREBP1 and CIDEA) in the subcutaneous adipose tissue.

In the current study, South Asian and Caucasian men with the same body fat percentage showed no difference in the baseline liver fat content. In response to overfeeding with a high fat diet, either under free-living or sedentary conditions, liver fat content increased similarly in South Asian and Caucasian men. Thus, the hypothesis that South Asians may be more susceptible to a negative effect of a high-fat high-calorie diet with respect to an increased liver fat content was not the case.

Liver fat content was reported to increase in response to a high fat diet within a relatively short-period of time. Depending on the amount of dietary fat given, it occurred within 3 days $(42)$ or $2-3$ weeks $(43,44)$. A very recent study $(45)$ revealed that liver fat increased $3 \mathrm{~h}$ after a single high-fat meal and did not further increase after $5 \mathrm{~h}$, suggesting that a significant fraction of fatty acids are taken up by the liver during the postprandial period (43). During that period, LPL-mediated fatty acid uptake in adipose tissue is stimulated. However, local accumulation of fatty acids at the site of LPL action can lead to premature detachment of the LPL together with remnant particle (46), which will then deliver an increased fatty acid load in the form of TAG-rich remnants to the liver and other 


\section{CHAPTER 8}

tissues (47). No association was found between the change in liver fat content and $24 \mathrm{~h}$ fat oxidation, suggesting that liver fat accumulation may be affected by the balance between fatty acid delivery to the liver and hepatic fat oxidation $(42,48)$ rather than whole body fat oxidation.

\section{GLUCOSE CLEARANCE (INSULIN SENSITIVITY) IN RESPONSE TO OVERFEEDING WITH A HIGH FAT DIET}

In the present study, fasting insulin and $2 \mathrm{~h}$ insulin response significantly increased after overfeeding with a high fat diet in both South Asians and Caucasians, suggesting a decrease in insulin sensitivity, as also reported by others $(49,50)$. The increase in fasting insulin and the HOMA index was strongly associated with the increase in liver fat content; whereas the association between the increase in insulin response during a $2 \mathrm{~h}$ OGTT and the increase in liver fat content was more modest. Presumably the increase of glucose and insulin response during the $2 \mathrm{~h}$ OGTT was mostly associated with peripheral insulin resistance that develops later than hepatic insulin resistance (50). Others reported both hepatic and peripheral insulin actions were inversely correlated with intra hepatic lipid content (51).

The change in insulin sensitivity in response to overfeeding with a high fat diet was observed in two independent conditions (free-living and sedentary). Under free-living conditions, insulin sensitivity decreased similarly in the two ethnic groups after high-fat overfeeding. By contrast, under sedentary conditions, insulin sensitivity tended to decrease more in South Asians than that in Caucasians. This finding suggests that South Asians may be more susceptible to a negative effect of being sedentary. 


\section{LIPID PROFILE AFTER HIGH-FAT OVERFEEDING}

When matched for body fat percentage, lipid profile at baseline (before the intervention) was relatively comparable between ethnicities. Lipid profile after the intervention is described below:

\section{An unfavorable lipoprotein profile in South Asians}

In response to overfeeding with a high fat diet, under free-living conditions, South Asians showed a slightly lower HDL, a higher LDL, a lower ratio of HDL/total cholesterol and a higher ratio of $\mathrm{LDL} /$ total cholesterol as compared to Caucasians. When exposed to sedentary conditions, South Asians also showed a slightly higher LDL, a lower ratio of $\mathrm{HDL} /$ total cholesterol and a higher ratio of LDL/total cholesterol.

Clearly from two independent studies, South Asians showed a more unfavorable lipoprotein profile; suggesting there might be differences in cholesterol metabolism i.e. differences in the rate of LDL clearance and production (52) between ethnicities. The result of the present study was in agreement with a large population cohort study showing that South Asian Indians have the lowest HDL cholesterol compared to Central and Northern Europeans, Japanese and Chinese across glucose level categories (53).

\section{Decreased fasting TAG concentration in response to a high fat-overfeeding independent of ethnicities}

Both in South Asians and Caucasians either under free-living or sedentary conditions, TAG significantly decreased in response to overfeeding with a high fat diet but did not differ between ethnicities. The reduction of fasting TAG was likely due to a lower proportion of carbohydrate in the high fat diet. In a large population study, it was shown that those with the highest percentile carbohydrate intake had the highest fasting TAG (54). Higher carbohydrate intake may increase fatty acid production in the liver and inhibit 


\section{CHAPTER 8}

LPL action through an increased apo- CIII production (55). Higher fat intakes may increase circulating chylomicrons, but do not affect LPL action and the clearance of circulating TAG (56) hence, TAG concentration decreased.

\section{Decreased fasting plasma NEFA (a greater suppression of lipolysis) under sedentary conditions independent of ethnicities}

Fasting plasma NEFA did not change with overfeeding in both ethnicities under freeliving conditions and there was no ethnic difference observed. Interestingly, under sedentary conditions, fasting plasma NEFA decreased with diet but did not differ between ethnicities. Regulation of the plasma NEFA concentrations during the post absorptive and postprandial period are coordinated by HSL and LPL respectively (57-59). HSL catalyzes lipolysis, in keeping with adipose tissue's major role as supplier of fuel for other tissues $(58,59)$ or activities $(60)$; whereas LPL stimulates fatty acid esterification in the adipocytes $(58,59)$.

Overfeeding with a high-fat diet extended the postprandial state due to extended meal consumptions, therefore prolonged high insulin concentrations and suppressed lipolysis. Under free-living conditions, it seems that the need to mobilize NEFA for fuel substrate in typical day to day activities may counter the suppression of lipolysis, therefore fasting plasma NEFA did not change with the intervention. By contrast, under sedentary conditions when activities were limited to a lower level in a respiration chamber, the suppression of lipolysis may be more sustained resulting in decreased fasting plasma NEFA. 


\section{MOLECULAR ADAPTATION IN RESPONSE TO OVERFEEDING WITH A HIGH-FAT DIET}

The most striking finding in the molecular adaptation to overfeeding with a high fat diet (under sedentary conditions) was the significant decrease in the HADH level, a crucial enzyme for mitochondrial $\beta$-oxidation involved in the rate-limiting acyl CoA dehydrogenase step (61) in both South Asians and Caucasians. The decrease of HADH was as expected, along with some metabolic alterations described previously such as elevated insulin concentrations, decreased fasting plasma NEFA indicating a suppression of lipolysis, and decreased fasting TAG concentration indicating fatty acid uptake in adipose tissue, all together pointing towards fatty acids storage rather than oxidation. In addition, a 3-day overfeeding with a high fat diet under sedentary conditions led to a massively positive energy balance of 8-8.5 MJ/d, of which around 7-7.5 MJ/d came from a positive fat balance, thus most of the fat was stored. Opposite results have been reported in caloric restriction studies, where HADH level increased $(62,63)$. Caucasians had a relatively higher HADH level at baseline and while decreasing, the HADH level after overfeeding remained higher as compared to South Asians. This characteristic may be important in the long term energy (fat) metabolism in this population.

The entry of the acyl group into the matrix space of the mitochondria is catalyzed by the Carnitine palmitoiltransferases (CPT1a), converting cytoplasmic long-chain fatty acylCoA to acylcarnitine $(61,62)$. Here, the study showed CPT1a significantly changed with diet; decreasing in South Asians, but increasing in Caucasians. This may suggest a higher capacity of mitochondrial fatty acids uptake in Caucasians.

Perilipin (PLINA) that plays a role in the turn-over of stored TAG and localized in the lipid droplets (64) did not significantly change with diet, but the changes differed between ethnicities. PLINA decreased more in Caucasians, whereas, the baseline and after intervention PLINA levels were relatively higher in South Asians, which may influence the long-term energy utilization in this population as well. 


\section{CHAPTER 8}

\section{CONCLUSIONS}

There are several conclusions that can be drawn as a result from these studies,

- Despite differences in body composition, fat oxidation and other substrate partitioning did not differ between Asians and Caucasians in response to a normal fat diet in energy balance or overfeeding with a high-fat diet.

- When matched for body fat percentage, South Asians displayed a higher percentage of visceral fat while Caucasians displayed a higher percentage of subcutaneous fat.

- Liver fat content did not differ at baseline and increased similarly in South Asian and Caucasian men in response to a overfeeding with a high-fat diet.

- Glucose clearance and insulin sensitivity decreased similarly in response to overfeeding with a high-fat diet in both ethnicities under free-living conditions but tended to decrease more in South Asians under sedentary conditions.

- South Asians consistently displayed an adverse lipoproteins profile (HDL, LDL and total cholesterol) in response to overfeeding with a high-fat diet either under freeliving or sedentary conditions.

- A crucial enzyme in mitochondrial $\beta$-oxidation, $\mathrm{HADH}$, significantly decreased in response to overfeeding with a high fat diet in both South Asians and Caucasians.

- The differences in HADH and PLINA levels as well as in the response of CPT1a between ethnicities may be important for the long-term regulation of energy (fat) metabolism in these populations. 


\section{DIRECTION FOR FUTURE RESEARCH}

This study raised several new interesting questions to investigate in future research

- Is the unfavorable body composition the cause or the consequence of a lower rate of energy metabolism or a lower expression of oxidative genes/proteins? The causal relationship may be observed in a longitudinal setting, but this requires a cohort.

- It is interesting to compare the response between ethnicities to various dietary manipulations other than a high fat diet; at the end it may help to select an appropriate dietary composition for certain ethnicities. A high protein diet could be of importance as this manipulation may help in improving Asian's body composition.

- While it has consistently been reported that South Asians display an unfavorable lipoprotein profile, investigating cholesterol metabolism in this population is important to understand the underlying mechanism.

- Setting up a lifestyle intervention study such as exercise in overweight South Asians or lean but metabolically obese South Asians may be interesting to address physical activity guidelines for this population to improve body composition and the associated metabolic profiles.

- In addition to setting up an exercise or dietary intervention study, it will be interesting to characterize further for instance, the differences in the type of muscle fiber, e.g. whether there are more oxidative type in Caucasians as compared to South Asians. Together with observing what happens in the molecular adaptation in the skeletal muscle, to have a complete picture of the cross-talk between muscle and adipose tissue in metabolic regulation in different ethnicities. 


\section{CHAPTER 8}

\section{REFERENCES}

1. Wulan SN, Westerterp KR, Plasqui G. Dietary and 24-h fat oxidation in Asians and whites who differ in body composition. Am J Clin Nutr 2012;95:1335-1341.

2. Deurenberg $P$, Deurenberg Yap M, Wang J, Lin FP, Schmidt G. The impact of body build on the relationship between body mass index and percent body fat. Int J Obes Relat Metab Disord 1999;23:537-542.

3. Deurenberg $P$, Deurenberg-Yap $M$. Differences in body-composition assumptions across ethnic groups: practical consequences. Curr Opin Clin Nutr Metab Care 2001;4:377-383.

4. Deurenberg P, Deurenberg-Yap M, Guricci S. Asians are different from Caucasians and from each other in their body mass index/body fat per cent relationship. Obes Rev 2002;3:141-146.

5. Forouhi NG, Jenkinson G, Thomas EL, Mullick S, Mierisova S, Bhonsle U et al. Relation of triglyceride stores in skeletal muscle cells to central obesity and insulin sensitivity in European and South Asian men. Diabetologia 1999;42:932-935.

6. Chandalia M, Lin P, Seenivasan T, Livingston EH, Snell PG, Grundy SM et al. Insulin resistance and body fat distribution in South Asian men compared to Caucasian men. PLoS One 2007;2:e812.

7. Nair KS, Bigelow ML, Asmann YW, Chow LS, Coenen-Schimke JM, Klaus KA et al. Asian Indians have enhanced skeletal muscle mitochondrial capacity to produce ATP in association with severe insulin resistance. Diabetes 2008;57:1166-1175.

8. Rush EC, Goedecke JH, Jennings C, Micklesfield L, Dugas L, Lambert EV et al. BMI, fat and muscle differences in urban women of five ethnicities from two countries. Int J Obes (Lond) 2007;31:1232-1239.

9. Rush EC, Freitas I, Plank LD. Body size, body composition and fat distribution: comparative analysis of European, Maori, Pacific Island and Asian Indian adults. Br J Nutr 2009;102:632-641.

10. Kamath SK, Hussain EA, Amin D, Mortillaro E, West B, Peterson CT et al. Cardiovascular disease risk factors in 2 distinct ethnic groups: Indian and Pakistani compared with American premenopausal women. Am J Clin Nutr 1999;69:621-631.

11. Chang CJ, Wu CH, Chang CS, Yao WJ, Yang YC, Wu JS et al. Low body mass index but high percent body fat in Taiwanese subjects: implications of obesity cutoffs. Int J Obes Relat Metab Disord 2003;27:253-259.

12. Gurrici S, Hartriyanti Y, Hautvast JG, Deurenberg P. Relationship between body fat and body mass index: differences between Indonesians and Dutch Caucasians. Eur J Clin Nutr 1998;52:779-783.

13. Kagawa M, Kerr D, Binns C. Ethnic differences in the BMI-\%BF relationships between young Japanese and Australian-Caucasian males living in Australia using dual-energy X-ray absorptiometry. Asia Pac J Public Health 2003;15 Suppl:S27-32.

14. Deurenberg-Yap M, Schmidt G, van Staveren WA, Hautvast JG, Deurenberg P. Body fat measurement among Singaporean Chinese, Malays and Indians: a comparative study using a four-compartment model and different two-compartment models. Br J Nutr 2001;85:491-498.

15. Pan WH, Yeh WT, Weng LC. Epidemiology of metabolic syndrome in Asia. Asia Pac J Clin Nutr 2008;17 Suppl 1:37-42.

16. Wulan SN, Westerterp KR, Plasqui G. Metabolic profile before and after short-term overfeeding with a highfat diet: a comparison between South Asian and White men. Br J Nutr 2014;111:1853-1861.

17. Muller MJ, Bosy-Westphal A, Later W, Haas V, Heller M. Functional body composition: insights into the regulation of energy metabolism and some clinical applications. Eur J Clin Nutr 2009;63:1045-1056.

18. Swinburn BA, Ravussin E. Energy and macronutrient metabolism. Baillieres Clin Endocrinol Metab 1994;8:527-548.

19. Wouters-Adriaens MP, Westerterp KR. Low resting energy expenditure in Asians can be attributed to body composition. Obesity (Silver Spring) 2008;16:2212-2216.

20. Ravussin E, Lillioja S, Knowler WC, Christin L, Freymond D, Abbott WG et al. Reduced rate of energy expenditure as a risk factor for body-weight gain. N Engl J Med 1988;318:467-472.

21. Tataranni PA, Harper IT, Snitker S, Del Parigi A, Vozarova B, Bunt J et al. Body weight gain in free-living Pima Indians: effect of energy intake vs expenditure. Int J Obes Relat Metab Disord 2003;27:1578-1583. 
22. Zurlo F, Lillioja S, Esposito-Del Puente A, Nyomba BL, Raz I, Saad MF et al. Low ratio of fat to carbohydrate oxidation as predictor of weight gain: study of 24-h RQ. Am J Physiol 1990;259:E650-657.

23. Weyer C, Snitker S, Rising R, Bogardus C, Ravussin E. Determinants of energy expenditure and fuel utilization in man: effects of body composition, age, sex, ethnicity and glucose tolerance in 916 subjects. Int J Obes Relat Metab Disord 1999;23:715-722.

24. Bergouignan A, Kealey EH, Schmidt SL, Jackman MR, Bessesen DH. Twenty-four hour total and dietary fat oxidation in lean, obese and reduced-obese adults with and without a bout of exercise. PLoS One 2014;9:e94181.

25. Maffeis C, Armellini F, Tato L, Schutz Y. Fat oxidation and adiposity in prepubertal children: exogenous versus endogenous fat utilization. J Clin Endocrinol Metab 1999;84:654-658.

26. Westerterp KR, Smeets A, Lejeune MP, Wouters-Adriaens MP, Westerterp-Plantenga MS. Dietary fat oxidation as a function of body fat. Am J Clin Nutr 2008;87:132-135.

27. Hodson L, McQuaid SE, Humphreys SM, Milne R, Fielding BA, Frayn KN et al. Greater dietary fat oxidation in obese compared with lean men: an adaptive mechanism to prevent liver fat accumulation? Am J Physiol Endocrinol Metab 2010;299:E584-592.

28. Astrup A, Buemann B, Christensen NJ, Toubro S. Failure to increase lipid oxidation in response to increasing dietary fat content in formerly obese women. Am J Physiol 1994;266:E592-599.

29. Buemann B, Toubro S, Astrup A. Substrate oxidation and thyroid hormone response to the introduction of a high fat diet in formerly obese women. Int J Obes Relat Metab Disord 1998;22:869-877.

30. Flatt JP. Dietary fat, carbohydrate balance, and weight maintenance: effects of exercise. Am J Clin Nutr 1987;45:296-306.

31. Flatt JP. Use and storage of carbohydrate and fat. Am J Clin Nutr 1995;61:952S-959S.

32. Schrauwen $P$, van Marken Lichtenbelt WD, Saris WH, Westerterp KR. Changes in fat oxidation in response to a high-fat diet. Am J Clin Nutr 1997;66:276-282.

33. Schrauwen $P$, van Marken Lichtenbelt WD, Saris WH, Westerterp KR. Role of glycogen-lowering exercise in the change of fat oxidation in response to a high-fat diet. Am J Physiol 1997;273:E623-629.

34. Schrauwen $P$, Lichtenbelt WD, Saris $W H$, Westerterp KR. Fat balance in obese subjects: role of glycogen stores. Am J Physiol 1998;274:E1027-1033.

35. Davy KP, Horton T, Davy BM, Bessessen D, Hill JO. Regulation of macronutrient balance in healthy young and older men. Int J Obes Relat Metab Disord 2001;25:1497-1502.

36. Roberts R, Bickerton AS, Fielding BA, Blaak EE, Wagenmakers AJ, Chong MF et al. Reduced oxidation of dietary fat after a short term high-carbohydrate diet. Am J Clin Nutr 2008;87:824-831.

37. Arsenault BJ, Beaumont EP, Despres JP, Larose E. Mapping body fat distribution: a key step towards the identification of the vulnerable patient? Ann Med44:758-772.

38. Santosa S, Jensen MD. Why are we shaped differently, and why does it matter? Am J Physiol Endocrinol Metab 2008;295:E531-535.

39. Sniderman AD, Bhopal R, Prabhakaran D, Sarrafzadegan N, Tchernof A. Why might South Asians be so susceptible to central obesity and its atherogenic consequences? The adipose tissue overflow hypothesis. Int J Epidemiol 2007;36:220-225.

40. Anand SS, Tarnopolsky MA, Rashid S, Schulze KM, Desai D, Mente A et al. Adipocyte hypertrophy, fatty liver and metabolic risk factors in South Asians: the Molecular Study of Health and Risk in Ethnic Groups (molSHARE). PLoS One6:e22112.

41. Alligier M, Gabert L, Meugnier E, Lambert-Porcheron S, Chanseaume E, Pilleul F et al. Visceral fat accumulation during lipid overfeeding is related to subcutaneous adipose tissue characteristics in healthy men. J Clin Endocrinol Metab 2013;98:802-810.

42. van der Meer RW, Hammer S, Lamb HJ, Frolich M, Diamant M, Rijzewijk LJ et al. Effects of short-term highfat, high-energy diet on hepatic and myocardial triglyceride content in healthy men. J Clin Endocrinol Metab 2008;93:2702-2708.

43. Westerbacka J, Lammi K, Hakkinen AM, Rissanen A, Salminen I, Aro A et al. Dietary fat content modifies liver fat in overweight nondiabetic subjects. J Clin Endocrinol Metab 2005;90:2804-2809. 


\section{CHAPTER 8}

44. van Herpen NA, Schrauwen-Hinderling VB, Schaart G, Mensink RP, Schrauwen P. Three weeks on a high-fat diet increases intrahepatic lipid accumulation and decreases metabolic flexibility in healthy overweight men. J Clin Endocrinol Metab 2011;96:E691-695.

45. Lindeboom L, Nabuurs Cl, Hesselink MK, Wildberger JE, Schrauwen P, Schrauwen-Hinderling VB. Proton magnetic resonance spectroscopy reveals increased hepatic lipid content after a single high-fat meal with no additional modulation by added protein. Am J Clin Nutr 2015;101:65-71.

46. Saxena U, Witte LD, Goldberg IJ. Release of endothelial cell lipoprotein lipase by plasma lipoproteins and free fatty acids. J Biol Chem 1989;264:4349-4355.

47. Frayn KN. Adipose tissue as a buffer for daily lipid flux. Diabetologia 2002;45:1201-1210

48. Hodson L, Frayn KN. Hepatic fatty acid partitioning. Curr Opin Lipidol 2011;22:216-224.

49. Samocha-Bonet D, Campbell LV, Mori TA, Croft KD, Greenfield JR, Turner N et al. Overfeeding reduces insulin sensitivity and increases oxidative stress, without altering markers of mitochondrial content and function in humans. PLoS One7:e36320.

50. Brons C, Jensen CB, Storgaard H, Hiscock NJ, White A, Appel JS et al. Impact of short-term high-fat feeding on glucose and insulin metabolism in young healthy men. J Physiol 2009;587:2387-2397.

51. Koska J, Stefan N, Permana PA, Weyer C, Sonoda M, Bogardus C et al. Increased fat accumulation in liver may link insulin resistance with subcutaneous abdominal adipocyte enlargement, visceral adiposity, and hypoadiponectinemia in obese individuals. Am J Clin Nutr 2008;87:295-302.

52. Sniderman AD, De Graaf J, Couture P, Williams K, Kiss RS, Watts GF. Regulation of plasma LDL: the apoB paradigm. Clin Sci (Lond)118:333-339.

53. Zhang L, Qiao Q, Tuomilehto J, Janus ED, Lam TH, Ramachandran A et al. Distinct ethnic differences in lipid profiles across glucose categories. J Clin Endocrinol Metab95:1793-1801.

54. Merchant AT, Anand SS, Kelemen LE, Vuksan V, Jacobs R, Davis B et al. Carbohydrate intake and HDL in a multiethnic population. Am J Clin Nutr 2007;85:225-230.

55. Grundy SM, Abate N, Chandalia M. Diet composition and the metabolic syndrome: what is the optimal fat intake? Am J Med 2002;113 Suppl 9B:25S-29S.

56. Grundy SM. Hypertriglyceridemia, atherogenic dyslipidemia, and the metabolic syndrome. Am J Cardiol 1998;81:18B-25B.

57. Frayn KN, Shadid S, Hamlani R, Humphreys SM, Clark ML, Fielding BA et al. Regulation of fatty acid movement in human adipose tissue in the postabsorptive-to-postprandial transition. Am J Physiol 1994;266:E308-317.

58. Frayn KN, Coppack SW, Fielding BA, Humphreys SM. Coordinated regulation of hormone-sensitive lipase and lipoprotein lipase in human adipose tissue in vivo: implications for the control of fat storage and fat mobilization. Adv Enzyme Regul 1995;35:163-178.

59. Frayn KN, Summers LK, Fielding BA. Regulation of the plasma non-esterified fatty acid concentration in the postprandial state. Proc Nutr Soc 1997;56:713-721.

60. Koutsari C, Mundi MS, Ali AH, Jensen MD. Storage rates of circulating free fatty acid into adipose tissue during eating or walking in humans. Diabetes 2012;61:329-338.

61. Kler RS, Jackson S, Bartlett K, Bindoff LA, Eaton S, Pourfarzam M et al. Quantitation of acyl-CoA and acylcarnitine esters accumulated during abnormal mitochondrial fatty acid oxidation. J Biol Chem 1991;266:22932-22938.

62. Bouwman FG, Wang P, van Baak M, Saris WH, Mariman EC. Increased beta-oxidation with improved glucose uptake capacity in adipose tissue from obese after weight loss and maintenance. Obesity (Silver Spring) 2014;22:819-827.

63. Verhoef SP, Camps SG, Bouwman FG, Mariman EC, Westerterp KR. Physiological response of adipocytes to weight loss and maintenance. PLoS One 2013;8:e58011.

64. Brasaemle DL, Subramanian V, Garcia A, Marcinkiewicz A, Rothenberg A. Perilipin A and the control of triacylglycerol metabolism. Molecular and cellular biochemistry 2009;326:15-21. 


\section{Summary Samenvatting Ringkasan}




\section{SUMMARY}

Obesity and metabolic complications such as insulin resistance and dyslipidemia are becoming major health problems, especially in Asia. In Asia, there was a three to five fold increase over the last 30 years. Metabolic complications occur at a younger age and at a lower body mass index (BMI) in Asian than in Caucasian subjects. Here, comparative studies were performed between Asians and Caucasians focusing on body composition, energy metabolism and the associated metabolic profile in relation to diet and physical activity. Comparing Asians with Caucasians, matched for BMI, Asians have an unfavorable body composition with a higher body fat percentage, a lower fat-free mass and a lower fat-free mass index. This population also shows a feature of body fat distribution towards a more centrally fat depot and an increased ectopic fat deposition (such as in the liver and muscle) leading to an adverse metabolic profile. Interestingly, the unfavorable body composition already presents at young age, suggesting that although environmental factor is important, genetic may also play a role.

Three independent studies were performed: a cross-sectional study and two intervention studies. The cross-sectional study compared whether Asians and Caucasians matched for BMI, and thus different for body composition, oxidize fat similarly when given a similar diet in energy balance. The intervention studies addressed changes in lifestyle including overfeeding with a high-fat diet and a decrease in physical activity. The first intervention compared the response between South Asian and Caucasian men when overfed with a high-fat diet under free-living conditions. The second intervention included a similar intervention under sedentary conditions. Response parameters were substrate oxidation, liver fat accumulation, metabolic profile, insulin sensitivity and molecular responses in the adipose tissue. Body composition was determined using a threecompartment model based on body weight, body volume and total body water. Physical activity level was measured using a tri-axial accelerometer. Energy expenditure and substrate oxidation were measured in a respiration chamber. Body fat distribution was 
determined using anthropometry and MRI scan of the abdomen, whereas liver fat content was measured using $1 \mathrm{H}-\mathrm{MRS}$.

Dietary and 24-h fat oxidation were similar in Asians and Caucasians when fed in energy balance, despite differences in body composition. In response to overfeeding with a high-fat diet, substrate partitioning did not differ between South Asian and Caucasian men. Both ethnicities showed a similar and significant decrease in the level of HADH, crucial enzyme for mitochondrial $\beta$-oxidation. Overfeeding with a high-fat diet significantly increased liver fat content either under free-living or sedentary conditions, with no difference between ethnicities. Independent of the conditions, South Asian men showed a different lipoprotein profile with HDL concentration and ratio HDL to total cholesterol being lower, whereas LDL concentration and ratio LDL to total cholesterol being higher than in Caucasian men. Glucose clearance and insulin sensitivity decreased similarly in both ethnicities in response to high-fat overfeeding under free-living conditions, but tended to decrease more in South Asian men under sedentary conditions. In addition, abdominal fat distribution showed that visceral fat represented a higher percentage in South Asians, whereas subcutaneous fat was higher in Caucasians.

In response to overfeeding under sedentary conditions, glycogen levels were maintained and carbohydrate was oxidized to match carbohydrate intake, whereas fat was oxidized to a lesser extent to meet energy requirement. The greater reliance on carbohydrate oxidation was in line with the decrease in the HADH level, a crucial enzyme involved in the rate-limiting acyl-CoA dehydrogenase step responsible for mitochondrial $\beta$ oxidation of fatty acids.

There was no evidence for South Asians being more susceptible to high-fat overfeeding than Caucasians as shown by a similar increase in liver fat content. High-fat overfeeding induced an increased insulin response and a decreased glucose clearance, indicating a decrease in insulin sensitivity. The larger decrease in insulin sensitivity in South Asians under sedentary condition suggests that this population may be more susceptible to the 


\section{SUMMARY}

negative effect of being sedentary. An adverse lipoprotein profile in South Asians may indicate differences in cholesterol metabolism between ethnicities i.e. differences in the rate of LDL clearance and production.

In conclusion, (South) Asians and Caucasians oxidize fat similarly when fed a similar diet in energy balance. In response to high-fat overfeeding, both ethnicities showed similar substrate partitioning, a similar decrease in $\mathrm{HADH}$, a similar increase in liver fat content and a similar decrease in insulin sensitivity under free-living conditions. South Asians had a greater decrease in insulin sensitivity under sedentary conditions and consistently showed an adverse lipoprotein profile. 
Obesitas en verstoringen van het metabolisme zoals insulineresistentie en dyslipidemie zijn tegenwoordig veel voorkomende gezondheidsproblemen, vooral in Azië. De afgelopen 30 jaar was er in Azië een drie- to vijf-voudige toename. Daarnaast beginnen metabole verstoringen bij Aziaten op jongere leeftijd en bij een lagere gewichts index (BMI) dan bij Kaukasiërs. Hier werden vergelijkende studies tussen Aziaten en Kaukasiërs uitgevoerd wat betreft lichaamssamenstelling, energiemetabolisme en het metabole profiel, in verband met voeding en lichamelijke activiteit. Aziaten hebben in vergelijking met Kaukasiërs met dezelfde BMI een andere lichaamssamenstelling met een hoger vetpercentage, een lagere vetvrije massa en een lagere vetvrije massa index. Aziaten hebben ook een vetverdeling met meer centraal opgeslagen vet zoals in de lever en spieren, met navenant risico voor gezondheidsproblemen. De verschillen in lichaamssamenstelling met Kaukasiërs bestaan al op jonge leeftijd wat suggereert dat naast omgevingsfactoren mogelijk ook aanleg een rol speelt.

Drie onafhankelijke studies werden uitgevoerd: een cross-sectionele studie en twee interventiestudies. In de cross-sectionele studie werd de vetverbranding vergeleken tussen Aziaten en Kaukasiërs met dezelde BMI, dus verschillend voor lichaamssamenstelling, gevoed in energiebalans met hetzelde dieet. De interventie studies waren gericht op veranderingen in leefstijl wat betreft voeding en lichamelijke activiteit. De eerste interventie vergeleek bij Zuid-Aziatische en Kaukasische mannen het effect van overvoeding met een vetrijk dieet onder vrijlevende condities. De tweede interventie was een soortgelijke vergelijking onder sedentaire leefomstandigheden. Effect maten waren substraat oxidatie, vetopslag in de lever, metabool profiel, insulinegevoeligheid en moleculaire veranderingen in het vetweefsel. Lichaamssamenstelling werd bepaald met een drie compartimenten model op basis van lichaamsgewicht, lichaamsvolume en lichaamswater. Lichamelijke activiteit werd gemeten met een drie-assige versnellingsopnemer voor bewegingsregistratie. Energiegebruik en substraat oxidatie 


\section{SAMENVATTING}

werden gemeten in een respiratiekamer. Lichaamsvetverdeling werd bepaald met anthropometrie en een MRI-scan van de buik, terwijl vetgehalte van de lever werd gemeten met $1 \mathrm{H}-\mathrm{MRS}$.

Dieet- en totaal-vetverbranding waren vergelijkbaar bij Aziaten en Kaukasiërs gevoed in energiebalans, ondanks verschillen in lichaamssamenstelling. Overvoeding met een vetrijk dieet veroorzaakte geen verschillen in substraat gebruik tussen de Zuid-Aziatische en Kaukasische mannen. Beide groepen vertoonden een vergelijkbare en significante daling van de $\mathrm{HADH}$ concentratie, een sleutel enzym voor mitochondriale $\beta$-oxidatie. Overvoeding met een vetrijk dieet veroorzaakte een significant verhoogd lever vetgehalte, zowel onder dagelijkse als onder sedentaire leefomstandigheden, en vergelijkbaar tussen de etnische groepen. Onafhankelijk van de leefomstandigheden hadden Zuid-Aziatische mannen een ander lipoproteïne profiel met een lagere HDL-concentratie en lagere verhouding tussen HDL en totaal cholesterol, terwijl de LDL-concentratie en de verhouding tussen LDL en totaal cholesterol hoger was dan bij Kaukasische mannen. Glucoseklaring en insulinegevoeligheid daalden vergellijkbaar bij de twee etnische groepen in reactie op vetrijke overvoeding onder vrijlevende omstandigheden. De daling leek wel sterker bij Zuid-Aziatische mannen onder sedentaire leefomstandigheden, een sterker negatief effect suggererend van een sedentaire leefstijl voor deze groep.

Concluderend, Zuid-Aziaten en Kaukasiërs hebben een vergelijkbare vetverbranding bij eenzelfde dieet en gevoed in energiebalans. Overvoeding met een vetrijk dieet veroorzaakt geen verschillen in substraat gebruik en de afname in $\mathrm{HADH}$, de toename in levervet en de afname in insulinegevoeligheids is ook vergelijkbaar tussen beide groepen onder vrijlevende omstandigheden. Zuid-Aziaten hebben wel een grotere afname in insulinegevoeligheid onder sedentaire leefomstandigheden. Onafhankelijk van de leefomstandigheden hebben Zuid-Aziaten een ongunstiger lipoproteïne profiel dan Kaukasiërs. 
Obesitas dan komplikasi metabolic seperti resistensi terhadap insulin dan dyslipidemia menjadi masalah kesehatan yang serius terutama di Asia. Di Asia, peningkatan prevalensinya mencapai 3-5 kali dalam 30 tahun. Komplikasi metabolic terjadi pada usia muda dan indeks massa tubuh (BMI) yang rendah dibandingkan orang Caucasia (Eropa). Di sini, dilakukan studi perbandingan antara orang Asia dan Eropa dengan titik berat pada komposisi tubuh, metabolism energi dan hubungannya terhadap profil metabolic akibat pengaruh komposisi diet dan tingkat aktivitas. Membandingkan orang Asia dan Eropa dengan BMI yang sama, orang Asia memiliki komposisi tubuh dengan lemak tubuh yang tinggi dan jaringan non-lemak yang rendah. Populasi ini juga menunjukkan karakteristik distribusi lemak tubuh dengan lemak yang di simpan di perut dan dalam jaringan nonlemak (ectopic, seperti liver dan otot) yang menyebabkan profil metabolik yang buruk. Yang menarik, karakteristik ini sudah ada sejak usia muda, sehingga dapat dikatakan bahwa meskipun faktor lingkungan penting, faktor genetic juga berperan.

Tiga studi yang independen dilakukan: satu studi bersifat cross-sectional dan dua studi bersifat intervensi. Pada studi yang bersifat cross-sectional, bertujuan membandingkan apakah orang Asia dan Eropa dengan BMI yang sama (komposisi tubuh berbeda), mempunyai kemampuan mengoksidasi lemak yang sama bila diberikan diet yang sama dalam kondisi energy balance (energy yang masuk = energy yang digunakan). Studi yang bersifat intervensi, mengakomodasi perubahan gaya hidup, yaitu konsumsi diet tinggilemak yang berlebih dan penurunan aktivitas fisik (malas/santai). Studi intervensi yang pertama membandingkan respon orang Asia selatan dan Eropa (laki-laki) bila diberikan diet tinggi-lemak yang berlebihan dalam aktivitas normal sehari-hari. Studi intervensi yang kedua, diet yang diberikan sama tetapi dalam kondisi aktivitas rendah (malas dan sangat sedikit beraktivitas dalam ruangan saja). Parameter respon yang diamati adalah oksidasi makronutrien sumber energi tubuh (karbohidrat-lemak-protein), akumulasi lemak dalam liver, profil metabolik dalam darah, sensitivitas terhadap insulin dan respon molekuler dalam jaringan lemak (adipose). Komposisi tubuh ditentukan menggunakan model tiga- 


\section{RINGKASAN}

kompartemen berdasarkan berat badan, volume badan dan kandungan total air dalam tubuh. Tingkat aktivitas fisik diukur dengan akselerometer. Energy expenditure (penggunaan energy oleh tubuh) dan oksidasi makronutrient sumber energi diukur dalam kamar respirasi. Distribusi lemak tubuh diukur dengan antropometri dan magnetic resonance imaging (MRI) scan pada bagian abdomen (perut), sementara akumulasi lemak dalam liver (hati) diukur dengan proton- magnetic resonance spectroscopy (1H-MRS).

Kemampuan mengoksidasi lemak dari makanan maupun kemampuan mengoksidasi lemak selama 24 jam tidak berbeda antara orang Asia dan Eropa jika diberi makan dalam kondisi energy balance, walaupun komposisi tubuhnya berbeda. Melihat respon keduanya terhadap diet tinggi lemak, kemampuan mengoksidasi makronurient sumber energi juga tidak berbeda antara laki-laki Asia Selatan dan laki-laki Eropa. Kedua etnik ini menunjukkan penurunan level $\mathrm{HADH}$, enzim yang berperan sangat penting dalam $\beta$ oxidasi dalam mitokondria. Konsumsi diet tinggi lemak yang berlebihan meningkatkan akumulasi lemak di dalam liver, baik dalam kondisi aktivitas normal sehari-hari maupun aktivitas rendah (bermalas-malasan dalam ruangan), dan peningkatan akumulasinya tidak berbeda antara kedua etnis. Dalam kondisi aktivitas normal maupun rendah, laki-laki Asia Selatan mempunyai respon profil lipoprotein yang berbeda dengan laki-laki Eropa, dimana konsentrasi $\mathrm{HDL}$ dan rasio $\mathrm{HDL} /$ total-cholesterolnya rendah, sementara konsentrasi $\mathrm{LDL}$ dan rasio LDL/total-cholesterolnya tinggi. Masuknya glukosa darah dalam otot dan sensitivitas terhadap insulin menurun akibat konsumsi diet tinggi lemak, dan penurunannya sama pada kedua etnis bila aktivitasnya normal, namun dalam kondisi aktivitas yang rendah, penurunannya lebih tajam pada laki-laki Asia selatan. Sebagai tambahan, distribusi lemak dalam tubuh menunjukkan persentase lemak yang disimpan di visceral (rongga perut antara usus) lebih tinggi pada orang Asia selatan, sedangkan pada orang Eropa sebagian besar lemak dalam perut disimpan di jaringan lemak di bawah kulit (subkutan). 
Mengamati respon terhadap over konsumsi diet tinggi-lemak dalam kondisi aktivitas rendah, level glikogen dalam otot terjaga (tidak/sedikit berkurang). Oleh karena itu, sebagian besar karbohidrat yang dikonsumsi akan dioksidasi (tidak digunakan untuk mengisi cadangan glikogen). Sementara itu lemak dioksidasi dalam kadar yang lebih sedikit untuk memenuhi kekurangan energi yang diperlukan tubuh. Karena oksidasi karbohidratnya tinggi (sementara oksidasi lemak rendah), pada level molekuler dalam sel lemak (jaringan lemak) terjadi penurunan protein enzim $\mathrm{HADH}$, sebagai marker dalam tahap konversi Acyl-CoA dehydrogenase yang bertanggung jawab dalam $\beta$-oksidasi asam lemak dalam mitokondria.

Bukti menunjukkan bahwa laki-laki Asia selatan tidak memiliki kecenderungan respon yang lebih buruk akibat konsumsi diet tinggi lemak dibandingkan laki-laki Eropa, seperti terlihat pada peningkatan lemak dalam liver yang sama. Konsumsi diet tinggi lemak meningkatkan sekresi insulin selama 2 jam OGTT dan menurunkan penyerapan glukosa darah oleh jaringan otot, hal ini mengindikasikan penurunan sensitivitas terhadap insulin. Penurunan sensitivitas terhadap insulin yang lebih tajam pada laki-laki Asia selatan, menandakan populasi ini mungkin lebih rentan terhadap efek buruk dari aktivitas fisik yang rendah. Profil cholesterol yang buruk pada laki-laki Asia selatan, mungkin disebabkan oleh perbedaan dalam metabolism kolesterol, khususnya laju pembersihan kolesterol dari dalam darah dan laj uproduksi kolesterol dalam tubuh.

Sebagai kesimpulan, orang Asia dan Eropa kemampuan mengoksidasi lemak sama bila diberikan diet yang sama dalam kondisi energy balance. Respon kedua etnis terhadap diet tinggi lemak, menunjukkan kesamaan dalam: oksidasi makronutrien, penurunan enzim $\mathrm{HADH}$, peningkatan lemak dalam liver dan penurunan sensitivitas terhadap insulin pada aktivitas normal. Pada aktivitas rendah, orang Asia selatan mengalami penurunan sensitivitas insulin yang lebih tajam dan secara konsisten menunjukkan profil kolesterol yang buruk akibat konsumsi diet tinggi lemak dalam kondisi aktivitas normal maupun sedentary. 
Valorization 


\section{VALORIZATION}

Gene-environment interaction has been suggested to be the cause of the rapid increase in obesity prevalence and obesity-related metabolic diseases. In this regard, Asians and Caucasians that differ in genetic background represented partly by differences in body composition and differences in metabolic responses to dietary interventions and physical (in)activity may need different approaches in terms of lifestyle intervention to achieve a more favorable body composition and a low risk of developing metabolic diseases.

The results described in this thesis are written in original articles that have been published in or submitted to scientific journals in the field of nutrition, metabolism, health and obesity. The articles are accessible online for scientists, physicians, nutritionists, health-workers and others who are interested in this topic. The results of the studies have also been presented in the international conferences to colleagues of the same field of interests or of other related sciences. The present studies explore possible differences in energy metabolism of different ethnicities when exposed to similar diet and lifestyle changes by assessing both physiological response and molecular adaptation and by controlling for possible confounders.

Valorization aims to make value out of knowledge. Results from nutrition research are in general highly relevant to be translated to daily life and the results described in this thesis are no exception. There are several aspects of today's lifestyle in relation to the findings of this study that deserve attention.

\section{IMPROVING THE DIETARY PATTERN}

In general, current dietary patterns of the Asians (especially in South Asians: Indian, Pakistani, etc.; and in Southeast Asians: Indonesian, Malaysian, etc.) are characterized by a large amount of carbohydrate intake ( $>55 \%$ of the calorie intake), a low protein intake (< $10 \%$ of the calorie intake) and a high saturated fat intake. This typical dietary pattern may 
have to be improved to achieve healthier metabolic profiles. High carbohydrate intake has been associated with high plasma TAG concentrations and low HDL-cholesterol concentrations in a population study. Thus over time, high carbohydrate (and/or sugar) intake may contribute to the development of dyslipidemia. We confirmed in our study, when the proportion of carbohydrate was reduced, TAG concentration decreased. On the other hand, we have shown that high-fat diet have an adverse effect on total and LDLcholesterol in this population. Although differences in cholesterol metabolism between ethnicities need to be further investigated, defining a suitable macronutrient composition for Asian dietary patterns deserves further study.

Body mass index, age, gender and physical activity are important factors in determining energy requirements of different individuals in the population. However, physical activity may have to be emphasized as an important factor when advising macronutrient composition of the diet for different individuals, as there is a coordinated regulation between carbohydrate and fat oxidation to fulfill energy requirements, where glycogen depletion plays an important role as discussed in this thesis.

\section{REGULATION ON COMMERCIAL FOOD PRODUCTS}

Urbanization and modernization are responsible for several changes in people's lifestyle such as the increasing demand for a fast (ready-to-eat) and convenience food that optimizes ease of consumption or a more frequent dining-out due to having no time for preparing a meal at home. Although these convenience foods indicate improvement in food technology, some of them have received criticism due to imbalanced nutrient content such as high-fat content, high-salt content, low-fiber content or high-sugar content as well as the misuse of food preservatives and food additives.

Excessive intake of these typical foods over a long period of time will contribute to the development of obesity and other health problems, as we have shown for a high-fat diet. 


\section{VALORIZATION}

Thus, the challenge remains how to use food technology to produce healthy convenience foods in this modern world. Whereas at the same time, government should take responsibility on law enforcement and regulation, such as pushing the industries to cut back on sugars, fat, trans-fat and salts found in food products, introducing low-calorie products and reducing portion-size, as well as targeting taxes and levies onto the unhealthy products.

\section{PROMOTING AN ACTIVE LIFESTYLE}

We showed that Asians have a lower fat-free mass/appendicular skeletal muscle mass than other ethnicities. This characteristic may cause this population more susceptible to the negative effect of being sedentary, as it may affect glucose disposal. The results of this thesis indicated that South Asians have an adverse glucose and insulin metabolism as compared to Caucasians when consuming a high-fat diet under sedentary condition. Whereas, no difference being observed between ethnicities in the glucose and insulin response to overfeeding under free living condition. This suggests that an active lifestyle may help to improve glucose metabolism in obesity-prone individuals like Asians. In addition, physical activity guidelines may be important to be addressed that differ from those in Caucasians.

The period of the present study may not be long enough to show apparent differences between ethnicities, however based on the early response of glucose, insulin and cholesterol metabolism when adopting unhealthy lifestyle, there is a potential that the metabolic disturbance will develop more severely in the long-term in Asians.

\section{EARLY PREVENTION}

The development of obesity (increased fat mass) is genetically determined but also there is a significant influence from the environment during the life course; whereas fat- 
free mass is consistently reported to be influenced by birthweight. Thus, to obtain a favorable amount of fat-free mass in the future adult-life, the effort must be started from the period of pregnancy to supply with good nutrition and other elements of a healthy lifestyle.

Healthy lifestyle must also be introduced as early as possible to children. Home and school should share responsibility in educating children, to help them understand how importance to have a healthy diet and an active daily life by moving and playing outside. This should go beyond increasing knowledge but more active involvement. Children are not too young to be taught about nutrition through kitchen and food gardens for instance. Teachers could also ask children to bring fruits and other healthy snacks for their morning and afternoon break. By doing this, they will be well-equipped with healthy living behavior. When they are approaching puberty and adult life and facing choices about their behavior that, if they choose inappropriate lifestyle could impair their health, they will choose otherwise.

\section{TARGET GROUPS}

\section{Health professionals}

Health professionals are knowledgeable people with sufficient skill to handle health problem in the society. In the case of promoting a healthy diet and an active lifestyle, physicians, nutritionists, dieticians, nurses are capable of doing that and must work together through advising the patients during visit, educating people both institutionally or colloquially, campaigning through media or focus group discussion. The aim is to make ordinary people aware of and well-informed about healthy living behavior. However, encouraging people in the society will not be effective without active involvement. People need example and perhaps role model, thus they should be approached in a more creative 


\section{VALORIZATION}

way to be willing to change their habit towards a more positive attitude with respect to lifestyle.

\section{Government}

Government has full authority to issue some regulations and policies that assure the well-being of the citizens. Policies targeting food and nutrition are needed across several sectors like agriculture, (food) industries, trades, health, social welfare and education. A tight regulation towards global market of fast-foods that have been shown to be one of several aspects that trigger obesity epidemic is a must. In addition, regulation on food safety, food production, food processing, food packaging, food-labelling and food distribution must be accompanied by law enforcement. Economic incentives such as subsidies must be given to growers/farmers to sell healthy and fresh products and to food industries to produce healthy and safe food products. On the other hand, disincentives such as cutting subsidies and targeting tax must be taken to slow or reverse the production and distribution of unhealthy food products.

When it comes to promoting active lifestyle, government should take responsibility in providing more safe and friendly public spaces as well as facilities at school, in the neighborhood or other areas in the city, for children to play outside and people to move more in a nice and convenient environment. Safe pedestrian path and bicycle path should be provided to encourage people to be more physically active. On the other hand, increasing park fees, vehicle tax and cutting subsidies on fuel for private transportation may help to discourage people to use vehicle unless necessary.

\section{Mass Media}

The mass media play an important role in spreading information in this modern world. Broadcast media (TV, radio, film) and digital media (internet and mobile) are able to reach 
a larger audience than print media or outdoor media (billboards) these days. Thus it is a useful tool for educating, promoting, advertising and campaigning a healthy lifestyle. Although advertisement revenue provides a significant portion of the funding for most privately owned television networks, it is important to be selective and apply tight regulation on commercials/advertisement that promote unhealthy products especially those targeting children. Instead, providing more slot to advertise healthy (food) products. 


\section{Dankwoord \\ (Acknowledgement)}




\section{DANKWOORD}

First, let me thank God for giving me this wonderful journey of my life. Being involved in the area of research that reveals His great creation, in the precise control and beautiful regulation of physiology and metabolism in humans, yet its uniqueness in different individuals, that science comes up with its excellent explanation. Every single thing in the human body is designed for a function, its regularity and pattern cannot happen randomly or by chance. Science explains the mechanism, but does not explain the creation. The more I learn about it, the more I found how extremely intelligent The Designer is. The regularity (or pattern) of the creation I believe has a purpose. Once this pattern is discovered by human mind (namely science), any irregularities caused by unfavorable environment or inheritance can be traced, which develops science even more to the discovery of diseases or other abnormalities, leading to the discovery of the cures, drugs, establishing the treatments and so on for a better (quality of) life. Therefore, admiration of the creation should leave no room for a lazy mind, because what we know is very little, yet there is still so much to discover.

Human metabolism is a fascinating subject, but it would never been discovered without continuous works and efforts of dedicated scientists all over the world and the invention of modern-advanced technologies to reveal it. Here, I came to the right place to learn and nurture this fascinating subject with other fellow researchers under the guidance and supervision of the experienced and knowledgeable researchers and professors. Therefore, I would like to thank all the people who made all these things possible.

I would like to begin with giving my deepest gratitude to Prof. Margriet Westerterp, as because of you it was all started. After a year of searching of a place in universities in Asia, Europe and Australia and almost giving up hope, there was only 1 answer from you to give me the opportunity in Maastricht University. Thank you, for opening my way and arranging my early year MSc. Program for the PhD preparation, above all, for your trust. Thank you, for making sure that I was enjoying the Dutch hospitality and delicacies $(\dot{)}$. 
Many thanks for the lovely dinner and summer's picnic in the beautiful landscape and nature in the province of Limburg (Netherland), Belgium or Germany.

My deepest gratitude to my promoter, Prof. Klaas Westerterp, thank you for always replied my e-mail directly (considering time difference between Indonesia and The Netherlands) and spent time for long-distance discussion before I started the PhD program. You did not even know me seven years ago, but you give me the opportunity, thank you. After I came here, I learned from you how to work efficiently, on schedule and right on target. Sometimes, it was hard to follow your speed as I am a slow person, but at least I tried $(;$. Thank you for all your guidance, invaluable discussions, and stimulating ideas nevertheless your sincerity, trust and never-ending enthusiasm (:).

My wonderful supervisor, the one and only Dr. Guy Plasqui, what can I say $\odot$. Saying thank you may not be enough, but thank you so much for everything (too much and too many to mention). Well, amongst them, carefully reviewing my terrible writing and continuously boosting my confidence, although the latter did not always work out $\odot$. You are my very best friend, my "partner in crime" who always made sure that our subjects going home safe and sound after all those experiments (Siti, is your subject still alive?:)). My simple unprejudiced hypothesis when we started the project was "nothing is wrong with the Asians";) and you keep teasing me about that (and Mr. Westerterp was sometimes too, both of you together, that's unfair (:)), making the end of each study always exciting to find out whether it was true $(-)$. And now, someone who was continuously popping up into your office with problem is no more...eindelijk! :)

Dr. Vera Shcrauwen-Hinderling, it is a privilege to know you and learn from you about this versatile technique. Thank you very much for your unconditional patience $;$ spending hours and hours to train me using MRI/MRS technique in the hospital (sometimes even after putting your kids in bed) and to re-analyse together the result spectra and images which was a bit excessive. Your expertise and research experience in this particular 


\section{DANKWOORD}

subject, both the technique and its interpretation is such a great value to gain more insight in the observation of our study.

Prof. Edwin Mariman, thank you for your thoroughness and careful interpretation of our protein data, and for the invaluable knowledge that you have given me on this subject. I always remember, with your remarkable experience in the molecular life science, you said humbly (though we could expect the effect of a treatment) we don't know what to expect from molecular point of view $(-)$.

The board of the examination committee: Prof. Patrick Schrauwen, Prof. Jeyakumar Henry, Prof. Jaap Keijer, Prof Joachim Wildberger and Prof. Margriet Westerterp, thank you for finding the time to review my thesis, for your suggestions and for being present in the academic ceremony.

De proef personen, to all my subjects (volunteers) of the entire study, without you I am nothing. I would like to thank you for being cooperative and patient in following all those demanding protocols.

My paranimfen, Pilou and Gabby, thank you so much for everything you have done to help me with the preparations of my defense. I am very happy to have you both by my sides on my big day.

I gratefully acknowledge The Directorate General of Higher Education, The Ministry of Education and Culture of The Republic of Indonesia (former Ministry of Research, Technology and Higher Education) and NUTRIM- School of Nutrition and Translational Research in Metabolism, for supporting the study. I do hope that there will be possibilities (opportunities) to have research collaboration in the future.

I would like to thank people from my home institution, Brawijaya University in MalangEast Java, Indonesia for the continuous support. Prof. Ifar Subagyo, Prof. Yogi Sugito, Prof. Harijono, Prof. Bambang Suharto, Bp. Markum Soemitro, SH.MS., Bp. Imam Safei (alm), Dr. Bambang Soesilo, Dr. Yunianta, Dr. Sudarminto S Yuwono, Dr. Elok Zubaidah, Dr. Agustin 
Wardani, Mba Triesni Andriani, Pak Kotok Gurito, Mba Santi, dik Vrita and other university members for taking care of me (-) in many ways during my study.

De mensen van Humane Biologie (en Bewegingwetenschappen), hartelijk dank voor alles. Thank you for allowing me to be part of this big family. Starting from mijn naaste (oud) kolegas: Alberto (coming to work only once a week, but making my day with his Italian greetings...ciao ciao(:)), Sanne $V$ (my presentation partner and fat biopsy tutor, go Siti you can! with raising and fisting your hand, typical Sanne, surprisingly it worked well(:), Stefan (the funniest literature club chairman ever $:$ thanks for helping and encouraging me in the lab!), Giulio (always on time and precise on everything, I will always remember the way you describe Maastricht of The Netherlands on the map, off the record!); , Gil (just as cool as his supervisor $(-)$ ), Rick (with your great sense of humour, it is always a pleasure to talk about many things with you(:), Juriaan (I admire your thoughtfulness, thoroughness and independence $(;)$ ), Sofie (cool and calm spirit $(;)$, somehow you remind me of Juliette Binoche in a younger version $\odot$, forgive me if you object), Mieke (I can recognize that the ladies talking on TV are Belgian, just by remembering the way you speak $(;$, but you are so unique $(\dot{)})$, Eveline (never running out of energy, though she eats only protein (:)), Hanne (I believe you could sleep well, after the sleep study is over $(\dot{)})$, Pilou (my paranimf with sweet and youthful spirit $\odot$ ), Blandine (my early morning scanning-friend, coming all the way from France, with whom I sometimes shared my croissant (-)), Mandy (I wish you had a British accent that I love $)$ but you don't, in fact you speak Dutch that is a pity (-)), Givan (my holiday's lab mate, who still worked at Christmas eve(:)), Tanja, Femke, Stijn, Ananda, Margriet and Anneke (all of you are so knowledgeable people, thank you for sharing your thoughts in our literature clubs, most importantly for your friendship(:)). Mathijs and Catalina, hartelijk welkom! En veel success met je AIO! To Simon and Susan of my little cluster, thanks for your friendship and let's reunite! $:$. Nuria, thanks for making my days here even more colourful with your 


\section{DANKWOORD}

presence-(-). Bedankt allemaal, voor de samenwerken, dag uitjes, gezieleg etentjes, de humor, en lekker wandelen in de natuur (-) ik zal jullie missen!

What can I do without Mr. Schoffelen, Mr. Wouters, Mr. Jos, Laurens R, Wendy, Hasibe and Gabby? Thank you so much for the technical assistance, the excellent analysis and for organizing the MRUM. Mr. Schoffelen, "terima kasih banjak-banjak" for being so patient (with my calls, which means problem calls $\odot$ ), listening to my questions and explaining to me some principals of your "fancy" chamber installation and "sparkling yet illuminating" gas analyser $\odot$, even though you knew it was difficult to understand for my little brain. By the way, I still remember what the blue and red cables analogue to $(-)$. It is always a great pleasure talking about many things with you, because you always find a way to make sensible jokes-: Mr. Wouters, thank you for always asking how my family is doing (one day you came and said, I heard about the volcano eruption, where was it? Where do you and your family live, could you show me on the map? Is that far enough from the mountain? Are they safe? $\odot$, you even still concerned about that a few months later). I really appreciated that you are such a caring and loving person $(-)$. Thank you also for the deuterium analysis and all the computer, devices, soft wares and IT problem solving (after so many attempts to help me out, my supervisor's last and best advice was "Ask Loek" $($ )). Mr. Jos, thank you for the weekend lab works and the TV football matches, I was so happy for not working alone (-) but you should also take a rest, a.u.b! I am sorry, I never joined the BORRELTIJD!!!!! $\odot$, I am a shy person for such occasion $\odot$. Wendy and Hasibe, thank you for the Nitrogen analysis!-) Substrates oxidation will never be accurate without your dedication, and I love substrates oxidation $(-)$. Gabby, I know exactly you give your best to manage and organize things in the MRUM. Good luck with everything!-;.

De dames van het secretariaat, Desiree, Claudia, Yolanda (thank you so much for helping me with the administration of my promotion), Ilona and Sherly, all, thank you for taking care of us in so many ways-(-) I will miss the "vlaai om half elv" announcements and the lovely greetings in every Dutch national holiday $(\cdot)$. Ladies, you obviously have the most 
beautiful room in the department, but the room is nice enough simply with your presence. Thank you so much for being so kind and helpful all these years $(-)$.

I would also like to thank my other colleagues for their friendship, the neighbours' chat, lab's chat and the kind help during the preparation of the studies, practical works, experiments and data analysis. I know it is dangerous to mention names (as there is a risk to forget someone's name, but I could not help), I would like to thank Gabby (for your friendship and everything, mijn kamergenoot, mijn paranimf and my excellent fat biopsy tutor (:)), Prof. Marleen (thank you for the caliper skinfold that I borrow for my entire study and the nice chat $(-)$ ), Sabine \& Sanne van der Made (my saviours for IV cannulation in some special subjects $(-)$ ), Tineke, Lucas and Eline (my MRI/MRS experts, thanks for your help/advice $(-)$ ), Peter, Rudi and Olaf (for the fitness test with the cyclists $\odot$ ), Dr. Freek (my proteomics hero $(-)$, thank you so much for your great help! training me in "fingers-sport" pipetting, teaching me how to crush human (tissue) into powder(:)), Nadia and Yvonne (for helping me so much with fat cell size analysis $(-)$ ) and Jan-Willem (for the "A tot $Z$ " of an OGTT (:)).

I would like to thank my "upstairs and downstairs" colleagues for making me feel at home with your every day's smile, greets and chats $(-):$ Silvie (you are the scientist!) $)$, Rudi (soft spoken 'buurman'(-)), Florence (very open-minded, as my number one friend on $\mathrm{FB}(\dot{-}, \mathrm{I}$ always admire your enthusiasm and mountain climbing adventures $(-))$, Martine (thanks for the nice chat), Bianca, Nina, Chris, Dorien P, Els, Nadine, Sophie, Bram (I should say Brouwers(-)), Lena, Lauren, Emanuel, Jasper, Dorien R, Boris, Mark, Roel, Laura, Adeela, Ping (you are the scientist! thank you for your company and enthusiasm in almost everyone's onderzoek bespreking $(\dot{)})$, Kariana \& Erik (for your friendship since we were a master student), Cyril, Gijs, Johan J, Ellen K, Annemieke, Judith, Chantal, Maartje, Marjet, Madelene, Sabina, Johan S, Maurice, Nicole, Antoine, Prof. Wouter, Prof Ronald, Dr. Johan R, Dr. Jonathan, Prof. Ellen, Prof. Wim, Prof. Fred, Dr. Jogchum and other colleagues, thank you for the wonderful work environment. 


\section{DANKWOORD}

I would like to thank the former and current MRI leader of the MRI unit, Academic Hospital Maastricht (AZM), Mr. Henk Schoonmakers and Roland Kersmakers for their great and kind help. I would like to thank all technicians in the MRI unit for teaching and training me during my internship and for the technical problem-solving. Thank you Lisbeth, Dagmar, Iren, Etiene, Kak Sonja, Eslina, Eveline, Chloe, Tea, Anita, Sala, Mr. Mark Geerlings and other technicians as well as Mvr. Sylvia Gijzen (:)

UM Employee; the technicians, the receptionists, the librarians, the securities (who greet me late at night, when I stayed for chamber experiment), the cleaning ladies and men (who found me early in the morning), for all the help, although I could not remember your name one by one, you will always be part of my beautiful memories in Holland.

Indonesische Studenten Vereniging-Maastricht (Persatuan Pelajar Indonesia-PPIMaastricht). Although most of you already left Maastricht and could not be here for my big day, let's have a reunion when all of us in Indonesia. Adik-adikku, terutama Ayu, Budi, Fithri (makasih udah nemenin aku 6 tahun ini dik, dalam suka dan duka $)$, banyak kurepotkan, semoga Allah membalas dengan kebaikan yang lebih banyak), Rio, Frida, Wilma, Maruf (makasih udah dikasih kamar mungilnya), Unang, Harry, Nuni, Rini, Yolan, Bang Herman, Rizqi, Jappy, Fedri, Indar, Sasi, Emmi, Billy, Fava, Yanti, Brian, Bram, Mone, Keke, Emma, Mega, Dina, Nuri, Bono, Enjang, Wisnu, Ardian, Yogi, Intan, Arina, Wardah, Astrid and Ifa thanks for the great time guys! (-). I would like to thank Tante Jane \& Oom Donny Roumen (my parents in Maastricht $(-)$ ), Oom Richard (alm), Tante Erina \& Oom, Oom Ben, Eli \& Rabourt Muurmans, Mbak Sycilia \& familie, hartelijk dank for always welcome me in your house $(;)$, many thanks for the gatherings, talking non-sense and makanmakan $:$. Teman seperjuangan en soulmateku Mbak Erry di Wageningen terima kasih banyak semuanya, nasehatnya, bantuannya, curhatnya, guyonannya, ngerumpi, makanmakan, jalan-jalan...setelah perjuangan melawan belanda akhirnya kita pulang (;) MERDEKA!!! 
Avant Garde, Vijverdalseweg 2, Maastricht, a paradise for student $(;)$, where I spent my first 4 years in Holland. Thank you Niels, Kani, Iman, Ahmed, Joubi, Navid, Pourya, Diana, Mila, Puyan, Lucy, Eun-Sung, Collette, Henry, Joany and Borut for the wonderful times, the international dinner and party. Dorpsstraat 66, Maastricht, thank you Ma'ruf, Fithri, Binod, and Lenny (for playing the piano every weekend). Also thanks to Qaisar, Mohsin, Rubin, Mitrajit, Subhashis, Narendra, Nadia, Raj, Ram, Manlio, Rajkumar, Yasin, Olif Surachet, Kate, Duangjun "big F", Saychon and Sumalai for your friendship.

Many thanks to all my colleagues and the big family of the Dept. of Agricultural Product Technology (both Food Science and Technology study program and Biotechnology study program) and the Faculty of Agricultural Technology, Brawijaya University for supporting me, cheering me up and updating news back home $;$; Terima kasih teman-teman, kalian semua selalu di hati tanpa terkecuali! I am glad to be back (-). Wabil khusus Dik Kamim, Dik Dian and Mas Yudo, Mbak Ifa sekeluarga dan Asmaul sekeluarga terima kasih atas bantuan yang tak terkira.

I would like to thank all my teachers who have shaped me the way I am now especially Prof Marry Astuti, Prof Zuheid Noor (alm), Prof. Y. Marsono for the basic understanding in nutrition that became my interest and will be a field to contribute for the rest of my life.

My family, Ibu dan Bapak, matur sembah nuwun ingkang kathah, untuk kasih sayang, semangat, nasehat dan doa yang senantiasa kau panjatkan. When I was far away from home, it's amazing how talking to you on the phone could change my mood and feelings more positively $180^{\circ}$ !!! $\odot$. Adik-adikku Anjar, Dian (juga Moko dan Iwan) terima kasih supportnya, curhatnya, repot-repotnya, doanya selama ini. My sunshine, Nasywa, Naiya, Jundi, Aziz dan Auzi...terimakasih udah bikin hidup bude ceria penuh tawa dengan senyum dan kepolosan kalian $(:)$. 


\section{CURRICULUM VITAE}

Siti Wulan was born in Magelang, Central Java, Indonesia on $25^{\text {th }}$ December 1973 . She studied Food Science and Technology in Gadjah Mada University, Jogjakarta, Indonesia and graduated in 1997. She received a University Research for Graduate Education (URGE) scholarship from the World Bank between 1998-2000 to undertake a Master program in Food Science and Technology also in Gadjah Mada University, she took a specialization in Experimental Nutrition. During this period, she worked in a project "Developing soybean based-functional foods for diabetic" resulting in her Master thesis. Since 1999 to present, she joined the Dept. of Agricultural Product Technology (Study Program Food Science \& Technology), Brawijaya University, Malang, East-Java, Indonesia as a lecturer. In 2008, she received a scholarship from The Netherlands Fellowship Program to attend a 3 month short-course in Food Security and Nutrition in Wageningen University. She also used the short period of stay in The Netherlands to have a brief interview for Master Program, European-Master Metabolism and Nutrition in Maastricht University, following her longtime correspondence with Prof. Klaas Westerterp about doing a PhD in Maastricht University. She pursued a 1 year MSc. Program Metabolism and Nutrition from 2008-2009 to prepare herself with sufficient skill and knowledge before doing a PhD research and graduated in September 2009. She was awarded with a PhD scholarship from The Directorate General of Higher Education, The Ministry of Education and Culture of The Republic of Indonesia in August 2008, but only after finishing her Master, she started her PhD project on "Energy metabolism in relation to diet and physical activity: a comparison between Asians and Caucasians" in November 2009. She worked under the supervision of Dr. Guy Plasqui and Prof. Klaas Westerterp from November 2009-November 2015. Additionally, for part of the research she was also supervised by Dr. Vera SchrauwenHinderling and Prof. Edwin Mariman in the Department of Human Biology, NUTRIM School of Nutrition and Translational Research in Metabolism, Maastricht University Medical Centre. The works during her PhD period are presented in this thesis. 


\section{LIST OF PUBLICATIONS}

\section{FULL PAPERS}

Wulan, S.N., Westerterp, K.R. and Plasqui, G. Ethnic differences in body composition and the associated metabolic profile: A comparative study between Asians and Caucasians. Maturitas (2010), 65: 315-319.

Wulan, S.N., Westerterp, K.R. and Plasqui, G. Dietary and 24-h fat oxidation in Asians and whites who differ in body composition. Am J Clin Nutr (2012), 95: 1335-1341.

Wulan, S.N., Westerterp, K.R. and Plasqui, G. Metabolic profile before and after shortterm overfeeding with a high-fat diet: a comparison between South Asian and white men. Br J Nutr (2014), 111 : 1853-1861.

Wulan, S.N., Schrauwen-Hinderling, V.B., Westerterp, K.R. and Plasqui, G. Liver fat accumulation in response to overfeeding with a high fat diet: a comparison between South Asian and Caucasian men. Nutrition \& Metabolism (2015), 12:18.

Wulan, S.N., Schrauwen-Hinderling, V.B. Westerterp, K.R. and Plasqui, G. Substrate utilization and metabolic profile in response to overfeeding with a high fat diet in South Asian and white men: a sedentary life style study. Submitted for publication.

Wulan, S.N., Bouwman, F.G., Westerterp, K.R., Mariman, E.C.M. and Plasqui, G. Molecular adaptation in response to overfeeding with a high-fat diet under sedentary conditions in South Asian and Caucasian men. Submitted for publication.

\section{ABSTRACTS \& PRESENTATIONS}

Wulan, S.N., Westerterp, K.R. and Plasqui, G. Ethnic differences in body composition and energy expenditure: A comparison between Asians and Caucasians. NWO werkgemeenschap voeding; 14-15 October 2010. Deurne, The Netherlands. Oral presentation.

Wulan, S.N., Westerterp, K.R. and Plasqui, G. Ethnic differences in body composition and energy metabolism: a comparative study between Asians and Caucasians. The $9^{\text {th }}$ International Symposium on In Vivo Body Composition Studies; 21-24 May 2011. HangZhou, China. Oral presentation.

Wulan, S.N., Westerterp, K.R. and Plasqui, G. Dietary and 24-h fat oxidation in Asians and whites who differ in body composition. $2^{\text {nd }}$ International Conference on Recent Advances 


\section{LIST OF PUBLICATIONS}

and Controversies in Measuring Energy Metabolism. 2-4 November 2011. Maastricht, The Netherlands. Poster presentation.

Wulan, S.N., Westerterp, K.R. and Plasqui, G. Metabolic profile before and after shortterm overfeeding with a high fat diet: a comparison between South Asians and Whites. European Congress on Obesity. 12-15 May 2013. Liverpool, UK. Oral presentation.

Wulan, S.N., Schrauwen-Hinderling, V.B., Westerterp, K.R. and Plasqui, G. Liver fat accumulation and metabolic profile before and after overfeeding with a high fat diet: a comparison between South Asian and white men. Advance in Human Metabolism Research: Metabolism, Mitochondria and Fatty Acids. 16-17 May 2013. Warwick, UK. Poster presentation (Poster prize winner).

Wulan, S.N., Schrauwen-Hinderling, V.B., Westerterp, K.R. and Plasqui, G. Liver fat accumulation in response to overfeeding with a high fat diet: a comparison between South Asian and Caucasian men. The $12^{\text {th }}$ International Conggress on Obesity. 17-20 March 2014. Kuala Lumpur, Malaysia. Oral presentation (Nominator of New Investigator Award).

Wulan, S.N., Schrauwen-Hinderling, V.B., Westerterp, K.R. and Plasqui, G. Substrate utilization and metabolic profile in response to overfeeding with a high fat diet in South Asian and Caucasian men under sedentary condition. The 3rd International Conference on Recent Advances and Controversies in The Measurement of Energy Metabolism. 11-12 October 2014. Tokyo, Japan. Poster presentation. 